\title{
SCIENCE IN ALASKA
}

\author{
SELECTED PAPERS OF THE \\ ALASKAN SCIENCE CONFERENCE \\ OF THE
}

\section{NATIONAL ACADEMY OF SCIENCES NATIONAL RESEARCH COUNCIL}

\author{
WASHINGTON, NOVEMBER 9-11, 1950
}

\author{
EDITED BY \\ HENRY B. COLLINS
}

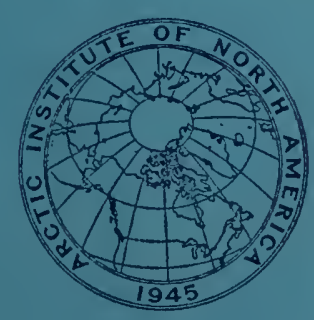

PUBLISHED BY

THE ARCTIC INSTITUTE OF NORTH AMERICA

$$
\text { JUNE } 1952
$$




\section{ARCTIC INSTITUTE OF NORTH AMERICA}

\section{Special. Publication No. 1}

Copies of this volume may be obtained from the Washington Office of the Arctic Institute, 1530 P Street, N.W., Washington 5 , D.C. Price $\$ 2.25$ postpaid. 


\title{
SCIENCE IN ALASKA
}

\author{
SELECTED PAPERS OF THE
}

ALASKAN SCIENCE CONFERENCE

OF THE

NATIONAL ACADEMY OF SCIENCES

NATIONAL RESEARCH COUNCIL

Washington, November 9-11, 1950

EDITED BY

HENRY B. COLLINS
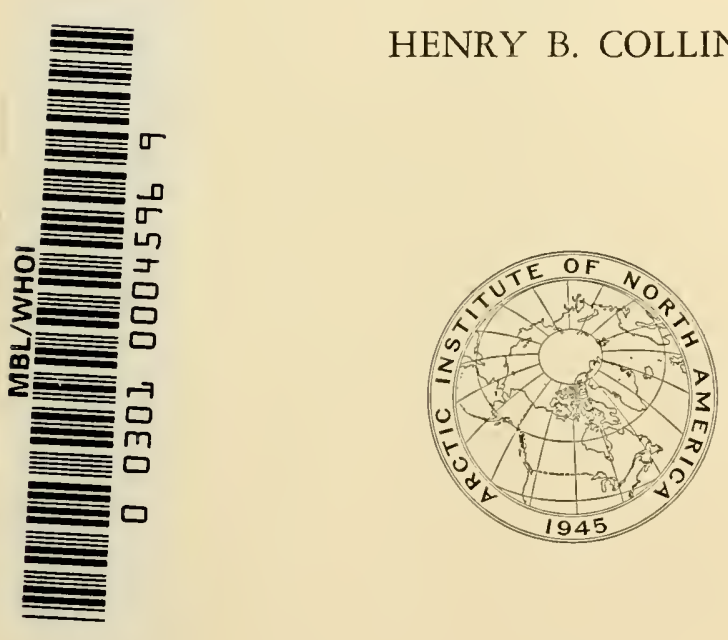

PUBLISHED BY

THE ARCTIC INSTITUTE OF NORTH AMERICA

JUNE 1952 



\section{PREFACE}

The Alaskan Science Conference, held in Washington, D. C., in November $195^{\circ}$ under the auspices of the National Academy of Sciences-National Research Council, had as its objectives (1) to review the status of scientific research in Alaska, (2) to appraise the major requirements for future research, and (3) to explore ways and means of developing new facilities and coordinating existing ones.

The Proceedings of the Conference, published by the Academy-Council in April 1951, carried in full the addresses given at the opening session, the general meeting, and the closing session. The Proceedings also included abstracts of the papers presented at the section meetings and symposia, papers that for the most part followed the general pattern of an appraisal of the past accomplishments and future needs of Alaskan research in the various fields of science. As these papers represented the first broad survey of Alaskan science it was felt that a useful purpose would be served if some of them could be published in full, as a companion volume to the Proceedings of the Conference. Accordingly, the Arctic Institute of North America, which had participated in the work of the Conference, undertook the preparation of the present volume of selected papers, representative of those presented at the Conference.

Grateful acknowledgments are due to the Chairmen of the various sections who recommended papers for publication: C. Earl Albrecht, Territorial Commissioner of Health, Chairman, Section of Public Health and Medicine; P. V. Cardon, U. S. Department of Agriculture, Chairman, Section of Agriculture and Forestry; Albert M. Day, U. S. Fish and Wildlife Service, Chairman, Section of Zoology; James L. Giddings, Jr., University of Pennsylvania, Chairman, Section of Anthropology; Henry R. Joesting, U. S. Geological Survey, Chairman, Section of Geophysics; John C. Reed, U. S. Geological Survey, 
Chairman, Steering Committee and Section of Geology and Geography; Athelstan F. Spilhaus, University of Minnesota, Chairman, Section of Meteorology; William C. Steere, Stanford University, Chairman, Section of Botany; and particularly, A. L. Washburn, Chairman of the General Meeting of the Conference and Executive Director of the Arctic Institute of North America, who conceived the idea of the present volume and made possible its publication.

Henry B. Collins 
PREFACE

AGRICULTURE AND FORESTRY

Status and Accomplishments of Agricultural Research in Alaska. Don L. Irwin . . . . . . . . . 1

Alaska Forest Research Problems and Program. R. F. Taylor

\section{ANTHROPOLOGY}

Survey of Southeastern Alaskan Indian Research.

Viola E. Garfield . . . . . . . . . . 20

Present Status of the Alaskan Eskimos. Margaret

Lantis . . . . . . . . . . . . . $3^{8}$

Preservation of Archaeological and Ethnological Mate-

rial in Alaska. Frederica de Laguna . . . . . 52

Preservation of Archaeological Remains in Canada.

Diamond Jenness . . . . . . . . . . . 6o

Contemporary Problems in the Anthropology of

Southeastern Alaska. IV. S. Laughlin . . . . 66

Ancient Bering Strait and Population Spread. J. L.

Giddings, Jr. .

BOTANY

Botanical Research in Alaska. William C. Steere. . 103 The Future of Botanical Research in Alaska. Ira L.

Wiggins . . . . . . . . . . . . . . 111

GEOLOGY AND GEOGRAPHY

Glaciological Research in Alaska. William $O$.

Field, Jr. . . . . . . . . . . . . . 133

Some Geographical Bases for Planning New Alaskan

Settlement. Kirk H. Stone . . . . . . . . 136

The Hydrology of Alaska. Arvi O. Waananen . . . 151 
GEOPHYSICS

Geomagnetism-Cosmic and Prosaic. David G. Knapp and Elliot B. Roberts . . . . . . . . . . 163

The Geophysical Institute at the University of Alaska.

Wm. S. Wilson . . . . . . . . . . . . 170

METEOROLOGY

Agro-Climatological Investigations in the Permafrost Region of the Tanana Valley, Alaska. Basil $M$. Bensin . . . . . . . . . . . . . 197

PUBLIC HEALTH AND MEDICINE

Water Supply Problems in Low Temperature Areas. Amos J. Alter . . . . . . . . . . . . 219

Relationships of Permafrost to Environmental Sanitation. Amos J. Alter . . . . . . . . . . 240

The Psychological Aspects of Arctic and Sub-Arctic Living. Ernest L. McCollum . . . . . . . 254

\section{ZOOLOGY}

Planning for Alaska's Big Game. Olaus J. Murie . $\quad 25^{8}$ Pressing Problems in Administration of Wildlife Resources in Alaska. W. A. Elkins . . . . . 268

Management of the Marine Resources of Alaska, Seton H. Thompson . . . . . . . . . . 282 Alaskan Waterfowl and their Management. Ira $N$. Gabrielson . . . . . . . . . . • • . 292 


\title{
STATUS AND ACCOMPLISHMENTS OF AGRICULTURAL RESEARCH IN ALASKA
}

\author{
Don L. Irwin, Director
}

Alaska Experiment Station

University of Alaska

It is the object of this paper to assess and report the present status and accomplishments of agricultural research work in Alaska. In doing so it is necessary to keep in mind that the enlarged, more technical research program is comparatively new in Alaska. Little more than three years have elapsed since this enlarged research program in agriculture was made possible by increased direct appropriations through both the United States Congress and the Alaska Legislature.

To coordinate the work the University of Alaska and the United States Department of Agriculture agreed on a joint program for the study of the agricultural problems of the Territory. In initiating this joint program the University of Alaska and the Federal Department of Agriculture have signified their willingness, and their intention to cooperate fully and share equally the responsibility for advancing agricultural research in Alaska as rapidly as funds, personnel and facilities permit.

To immediately activate this joint program the University of Alaska made available the physical plant and facilities of its experiment station at Fairbanks and of its sub-stations at Matanuska and Petersburg. To augment this program and implement the more technical and analytical phases of the research work the Federal Department lias undertaken a substantial building program at their station located at Palmer in the Matanuska Valley. A large research laboratory is already completed and in use. Construction companies are now engaged, under contract, in the erection of a large greenhouse, an experimental vegetable storage building, and seven residences for housing the staff. The Department lias also purchased an addi- 
tional staff house adjacent to the laboratory building. At the Matanuska Station a contractor is erecting a building providing garage space, threshing shed for agronomic work, area for work with horticultural crops and fire proof grain storage.

From Territorial building appropriations the University has just completed a large dormitory-mess hall at the Fairbanks Station, in the basement of which is a low pressure steam boiler to be used in technical work and as a central heating plant. Part of the basement floor will be used for laboratory work. In addition they have extended the steam lines to several buildings and are now completing a garage-threshing shed with fire proof grain storage facilities, similar to those under construction by the Federal Department at the Matanuska Station. All of these facilities are part of the coordinated long term planning with which both parties to the joint agreement are in full accord.

Research work of the Alaska Station has been departmentalized. Seven departments are operating on a full time basis. They are: Soils science, horticulture, animal industry, agronomy, agricultural economics, agricultural engineering and entomology. Departments of human nutrition and plant pathology have not yet been organized. All projects in each of the departments are conducted on standard work and line project basis.

There are eleven line projects under the soils science department, nine under horticultural crops, eight under animal industry, five in agricultural engineering, two in agricultural economics, ten in agronomic field crops and three in entomology.

Three departments are new, having operated for approximately one year each. It seems better research policy to at first confine the efforts of the technicians to a few major projects adequately financed, than to dissipate the energies of the personnel over a larger number of projects inadequately staffed and under financed.

The staff for this joint research program is composed of highly trained, carefully selected specialists in their respective fields. Both the employee, his wife and family must be willing to forego certain refinements of living standards. Each must 
have a pioneering spirit and be able to adapt the routine of their lives and their thinking to environmental conditions considerably at variance with those to which they were accustomed.

Offsetting these conditions is the exciting anticipation of being able to accomplish technical research work in a new country, unhampered by precedent and tradition. Even fortified by thorough training and experience the research worker soon learns that the varied environmental conditions of soils and climate encountered over so vast an area of sub-Arctic and Arctic reaches require that he amend his thinking and even his approach to the research problems confronting him.

Because of this situation and in order that each research worker may become thoroughly familiar with problems in the various agricultural areas it is necessary that staff members travel more than would be required in the majority of the States. Staff conferences are held regularly at which various phases of the work are discussed. This gives opportunity for pooling the ideas, observations and opinions of the staff members, and assists in coordinating their thinking. By this means too, the project work of each department becomes more real and vital to each of the other departments in relation to their own particular projects. The effort of the staff members thus becomes cooperative rather than individualistic.

To further bring the agricultural research needs of the Territory into focus, various organizations in Alaska connected with agriculture have been furnished with a list of projects on which station research work is now being accomplished. They have been requested and urged to submit to the station additional subjects on which research information would be of immediate assistance to the growing farm population. Excellent suggestions have been received by this procedure. As rapidly as practicable these suggestions will be incorporated into our research program. By this means the farmers themselves feel that they are assisting in the work, as indeed they are.

Knowledge of soils is basic to any agricultural production. On their productivity rests the foundation of our agricultural economy. Accordingly a soil survey has been established by the 
soils science department of the experiment station. In 1948 there were 49,920 acres mapped and classified in the Matanuska Valley, 29,440 acres in 1949 and 27,520 acres in 1950. In the Tanana Valley 7,860 acres were classified in 1949 and 21,120 acres in 1950. The information obtained is of use both to old and new settlers alike.

A cooperative arrangement has been worked out between the soils science department of the experiment station and the U.S. Soil Conservation Service for an exchange of soils information on the various areas in which their respective field parties are working. By this means preliminary information on soil erosion problems, soil classification, soil horizons and soil fertility levels is more quickly made available to the technicians of both organizations.

Late in September of this year installation of cabinets, benches and other fixed equipment was completed in the various rooms in the new research laboratory building at Palmer. Soil science technicians have only recently begun analytical work in their new laboratory quarters on a tremendous backlog of soil samples collected from the three seasons of field operations.

Rapid soil tests by the soils science department have shown varying deficiencies of nitrates, phosphoric acid and potash in soils of all of the agricultural areas in Alaska. Commercial fertilizers, both singly and in complete form have been applied experimentally on cereals, forage crops and on vegetable crops. These tests are in cooperation with technicians working in the departments of agronomy, horticulture, and animal industry. Striking increased yield responses on crops have been obtained. Circular Number 10, General Recommendations, Fertilizers for Alaska, 1950, was prepared for distribution by the soils science department last February.

Apparently there is a deficiency of manganese in some Alaska soils. This is particularly true of soils in the Matanuska Valley having high calcium or magnesium content. The deficiency is more apparent on growing oat plants. Leaf Speck, or spot on the growing plant frequently defoliates the plants and in some 
instances blights as high as $30 \%$ of the florets. Research on this problem is being accomplished in various areas where this deficiency is evident.

Since potatoes are possibly the foremost cash crop of the Alaska farmer, potato breeding, culture and storage investigations have been given intensive study by the horticultural department. In 1949, 7225 new seedling varieties were planted in individual hills. Twelve hundred of the most promising seedling hills were retained and planted in rod row nurseries this year. The highest yield of any variety of potatoes was obtained from one of these seedlings. A number of standard varieties of potatoes were given fertilizer application tests, during the past three years, at both the Matanuska and Fairbanks Stations. Tests of the dry matter content of tubers of each variety were conducted by the specific gravity salt bath method.

Introductions of many vegetable varieties are being tested for quality, yield and adaptation to market requirements. Vegetable breeding work is now in its initial stage. Preparation of information on recommended vegetable varieties is now in progress.

Tree and bush fruit tests are in progress on an extensive scale. Location and method of planting, fertilizer applications, windbreaks and soil type planting are among the techniques being used. The chief characteristics being sought are winter hardiness, disease resistance, quality and yielding ability. Annual and perennial flowers and ornamentals are being tested extensively. Greenhouse work on an extensive scale will begin as soon as the research greenhouse at the Palmer station is completed.

Research work in animal industry is confined principally to dairy breeding and production, to projects on poultry and on feeding and management of fur bearing animals. Dairying is one of the most stable and economically sound farm enterprises in Alaska. The price of Grade A raw milk, $\$ 10$ to $\$ 11$ per hundred pounds, at $4 \%$ butterfat, is attractive. Therefore, the number of Grade A dairies is increasing steadily in the Mata- 
nuska Valley. The same will be true in the other farm areas when more land is cleared and in cultivation.

For many years replacement cows on dairy farms were imported from the Continental United States. In 1948, the Bureau of Dairy Industry loaded to the Alaska Experiment Station two Holstein bulls and two Red Dane bulls, all were pure bred animals of the highest germ plasm obtainable. They were shipped to Alaska and housed at the Matanuska Experiment Station. In the dairy breeding project the pure bred Guernsey herd of cows at the Matanuska station were divided as nearly as possible into two lots of equal age, weight and milk production. One lot was bred to a pure bred Guernsey bull of high germ plasm. The other lot were cross bred to a Red Dane bull. The object of this project is to secure data on milk production and vigor of the progeny for comparative purposes. All heifer calves are retained through their first lactation period so that experimental error will be reduced to a minimum. The first heifer calves from this experiment have been bred but are not yet in production.

The second phase of the dairy breeding program is an artificial insemination project which is cooperative between the Alaska Experiment Station and the dairy farmers of the Matanuska Valley.

Semen from the two Holstein and two Red Dane bulls is used in inseminating the cows on the farms. To date more than 600 calves have been born since this program was initiated. All of the heifers are being kept for replacements in the farm dairy herds. Semen is also being shipped to dairymen in the Tanana Valley and on the Kenai Peninsula. Calf breeding, using substitute feeds composed mostly of locally grown grain has been in progress for a number of years. The information obtained is finding practical application by the farmers in feeding the replacement heifer calves. Circular No. 12, Better Forage for Alaska, has been published cooperatively by the soils, agronomy and animal industry departments.

Research on the value of artificial light in milk production, regularity of heat periods, sterility and conception rate during 
the winter period is also receiving attention. No marked increase in milk production was registered when artificial light was used. However, heifers exposed to added light had more than twice as many heat periods and the conception rate was markedly higher than for heifers receiving normal light. An increase of approximately $10 \%$ in winter egg production was recorded by extending the light period two hours per day in the laying house.

Investigation is being conducted at the Experimental Fur Station at Petersburg on fur bearing animals, by use of various fish by-products used in feeding mixtures, on fur quality and physical condition. Considerable quantities of fish offal are available at a very low cost at the canneries in southeast Alaska. Feeding salmon waste to young mink at the weaning stage has caused severe losses. Biologists at the station have identified the condition as "Yellow Fat Disease," locally known among Alaska mink farmers as "Watery Hide." Plans are now in progress to secure the services of a qualified pathologist to conduct research on this and other disease problems of fur and farm animals, and of poultry.

The agronomy department is concerned at present principally with research on introduced varieties of cereals and forage crops. Thousands of strains of crop plants are now being grown at the station in plots and evaluated for germ plasm adapted to our relatively young and cold soils and our cool climatic environment. Crops receiving major attention are bromegrass, alfalfa, alsike clover, sweet clover, barley, oats and wheat. Other promising crops are also receiving attention. Winter hardiness, quality, disease resistance, lodging resistance and early maturity are characteristics sought in varieties to be used in plant breeding. Superior crop varieties based on research work are annually recommended to Alaska farmers by the agronomy department. The $195^{\circ}$ recommendations are included in Station Circular No. 11, Recommended Varieties of Field Crops for Alaska.

Two recently recommended varieties of cereals are Edda barley and Siberian 3 oats. Approximately ten tons of each of 
these varieties have been increased under contract in Idaho and Montana this year and will be released to Alaska farmers for growing in 1951 .

Intensive studies are being conducted on methods of crop culture, including rates, dates, and methods of seeding, fertility requirements, weed control and the processing, handling and storage of crops. As soon as more data are available it is anticipated that a project on crop rotation will be initiated.

During the past seventeen months the Department of Agricultural Economics has confined its attention to two major projects. Using the basic information reported in 1948 by a field party from the Bureau of Agricultural Economics, U. S. Department of Agriculture, entitled Some Economic Aspects of Farming in Alaska, station economists are continuing their studies in farm management. These studies are difficult because few of the farms have sufficient acreage developed to operate economically. The soils are new, most of them having been cleared and cultivated in the past fifteen years. Wide variations in soil fertility, methods of crop culture and soil management practices exist among the individual farms. Information on these sketchy farm management factors is being tabulated from on-the-farm-interviews. Data are being obtained on crop yields, livestock numbers, equipment and building inventory, labor distribution and use, and other considerations incident to cost of operation and net farm income of various farm enterprises.

The second phase of economic studies is concerned with markets and the marketing of farm produce. This problem was studied intensively in 1949 by station economists in collaboration with economists from the Bureau of Agricultural Economics. Their preliminary report, Markets for the Products of Cropland in Alaska, has now been released to the public and nay be obtained through either the Bureau of Agricultural Economics of the Department of Agriculture, or by applying to the Agricultural Extension Service of the University of Alaska, College, Alaska. At present this study is being con- 
tinued intensively and has been extended to the smallei outlying villages and mining camps of the Territory.

Agricultural engineering is a new department established approximately one year ago. Its major concern is the use of native lumber in the construction, insulation, and ventilation of farm buildings under sub-Arctic conditions. This becomes of primary importance in the agricultural areas of Alaska where timber is available and where the cost of imported building material is almost prohibitive. Fourteen small buildings, each six feet wide by eight feet long, have been constructed of native materials to test the efficiency of various materials and types of construction. Some are constructed of green logs, others of dry logs and still others of rough sawed material. All buildings are insulated with sawdust. Thermostatically controlled electrical heating elements set at $70^{\circ} \mathrm{F}$. and connected to electric meters have been installed in each unit. Measurements of material shrinkage by means of internal air pressure gauges will be taken at regular intervals throughout the year.

Another project of vital importance to Alaskan agriculture is the drying of threshed grain. Because of rains at harvest time it is not unusual for grain to have a high moisture content when threshed and to heat in the bin. Drying equipment has been constructed on an experimental basis to study this problem. Cost of operation and efficiency of several methods and designs of drying equipment will be studied.

One project on the ventilation of farm buildings and another on methods and equipment for land clearing are each in the initial stage.

The ravages of insects detrimental to crops and livestock annually cause severe economic losses in Alaska. The department of entomology was organized in the spring of $195^{\circ}$. Work has been initiated in projects for the control of root maggots, cut worms and other injurious insects using a number of insecticides at various concentrations. To date results are not conclusive. This may be due to the cold damp soils and cool air temperatures. A study of residues in soils from the various insecticide applications is also receiving attention. 
The efforts of the Alaska Experiment Station personnel are devoted entirely to research activities. Manuscripts for publication, whether press releases, informative circulars, reports or bulletins are all carefully reviewed and checked for accuracy, clarity and form, by an editorial committee composed of three staff members and the station editor. It is the definite policy of the station to release only information based on actual research findings.

Education, except indirectly, is not the function of the Experiment Station. That is the function of the Agricultural Extension Service of the University of Alaska. As rapidly as station publications are received from the printers they are forwarded to the Extension Service for distribution to farm people and other interested parties. 


\title{
ALASKA FOREST RESEARGH PROBLEMS AND PROGRAM
}

\author{
R. F. TAYLOR
}

Forester in Charge, Alaska Forest Research Center

The forests are one of Alaska's renewable resources. If wisely used they can be forever a source of supply for many forest products, and of great value to the future State of Alaska. No one knows exactly how much forest land there is in the Territory. The nationwide forest survey has not been extended to Alaska, but it is estimated that a third of the land area is covered by forests of some kind (10). Figure 1 shows the approximate location and extent of the forest land.

The forests of Southeast Alaska contain dense stands of spruce and hemlock savtimber and pulpivood, very little of which has yet been utilized. The advent of pulpmills will make full use of those forests. The interior of Alaska, too, contains valuable forests and forest land although their value is not yet generally realized.

As most of you know, forestry is the preservation of forests by wise use. This wise use concerns itself not only with timber production, but with the related needs of safeguarding watershed, range, scenic, recreation, wildlife and other values. Wise use requires an intimate knowledge of the forest resource to be managed. Forest research attempts to gain this intimate knowledge and to develop best methods of forest management.

In 1928 a forest experiment station for Alaska was authorized by Congress. Twenty years later the money was appropriated for a small research station, called a research center. Our center, with headquarters in Juneau, was two years old last July 1. It is not yet a regional station with divisions set up to tackle the various lines of research mentioned a moment ago. WVe cannot attempt to work on more than a few of the most pressing problems, and most of these are in Southeast Alaska. They are 


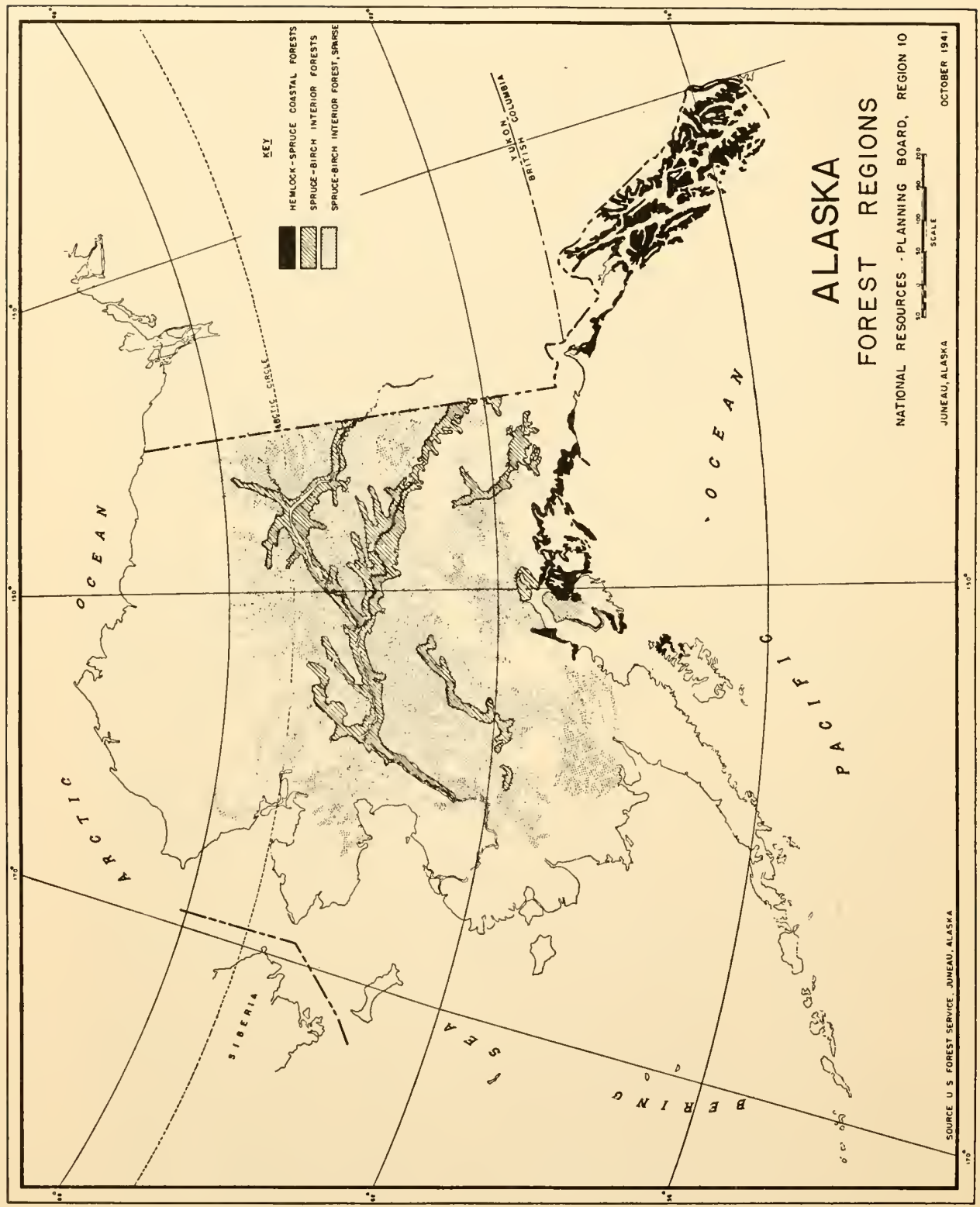


primarily concerned with the development of the pulp and paper industry on the Tongass National Forest.

\section{Interior Research}

The Forest Research Center can use only a small fraction of its funds for research on interior forests, but one study has been undertaken in an effort to determine the effect of forest fires on the timber and other vegetation. This will be described by Dr. H. J. Lutz of the Yale Forest School in another section of this conference. As one result of this study which is being carried on with the cooperation of the Bureau of Land Management's Forestry Division, it was found that volumes of 10 thousand board feet or 20 cords of pulp-sized timber per acre were common in the denser stands of the interior. ${ }^{1}$ It has been estimated that there are 25 million acres still unburned of the dense forests that occupy the lower slopes of river valleys. This area is as large as the Douglas-fir region of Oregon and Washington, or the commercial forest land area of New England (12). The red spruce-balsam fir stands of northern Maine and Ontario seldom contain more than 20 cords per acre yet they support large industries (2).

I am convinced we can grow good timber on the better sites in the Interior, if fire can be controlled. If only the estimated 25 million acres of heavily forested land could be saved it would certainly be of tremendous value to the future State of Alaska.

\section{Southeastern Alaska Research}

The forests of Southeast Alaska are a northward extension of the Pacific Coast western hemlock-Sitka spruce type. It is a climax virgin forest scarcely touched by axe or saw. From 80 to 160 inches of annual rainfall keeps it fire-proof and the foresters dripping wet. The Tongass National Forest of 16 million acres practically blankets this area.

Others will mention the need of the pulp industry to furnish

$18 \mathrm{M}$ per acre in trees $8^{\prime \prime}$ and larger in diameter. Twenty cords per acre in trees $4^{\prime \prime}$ and larger in diameter. 
permanent year-round employment. Our work is in connection with its development. Forest research started in a small way in Southeast Alaska twenty-five years ago with the pulp industry in mind, but there were no funds to continue it through the depression. The results of the work done at that time have been very useful.

The Research Center started operations in July 1948. In August the first preliminary contract for the sale of pulptimber in the Ketchikan region was made. Twenty years previously I had completed a study of the yields of even-aged second-growth and as a result the Forest Service had set up a management plan for pulptimber cutting which envisioned an 8o-year rotation. With an estimated 78 billion board feet of timber on the Tongass National Forest and second growth that resulted from clearcutting maturing in from 75 to 80 years, it was planned that the annual cut could not exceed one billion feet (1). There was little concern over the correctness of the yield figures as no pulpmills were planning immediate operations. Now, however, it seemed advisable to check the growth estimations.

The yield tables had been made from 288 sample plots scattered over the Tongass National Forest. In 1948 twentyfive of these plots having stands somewhere near rotation age were relocated and remeasured. Actual growth was compared with predicted growth. Actual growth of the aggregate of 25 plots was 6 percent less than predicted and the standard error of any one plot was 12 percent. Predictions of growth would be based on many plots in a small range of age classes which would tend to reduce the error. The accuracy of the yield tables is of less consequence when we consider that:

1. Areas cut over for pulptimber will be examined periodically and corrections in predicted yield made as a result.

2. The young stands that follow cutting for pulptimber may differ from the stands on which the yield tables were based. The yield table plots were in old blow-downs and abandoned Indian village sites, and a few old Russian cuttings where the area had been pretty well cleared of the previous growth. Sawtimber logging also clears the area of all but a few culls and 
these soon fall. Pulp cutting, however, will be in the ciimax forest with its many live culls which may be left standing. Regeneration may be sparse as the result of shade and competition and the new stands may contain more hemlock and be somewhat understocked. This is a major silvicultural problem.

\section{The Climax Forest}

This climax forest should be explained, perhaps. The rough picture is this:

When a stand of timber is blown down or clear-cut, an evenaged young stand regenerates. When it becomes mature on the better sites we may have a sawtimber stand. If uncut, the trees become over-mature and gradually, one by one, they fall. The

TABLE 1.-An acre of climax forest and an acre of so-year-old second-growth compared.2 Trees $S$ inches in diameter, breast high and larger

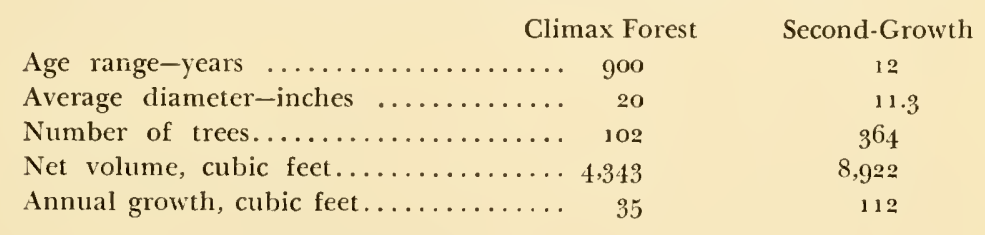

stand gradually gives way to a mixture of ages as new trees, mostly hemlock, come into the small openings. As there is little light or space at any one time, growth is very slow. When the original even-aged stand has vanished, we have the so-called climax composed of trees ranging in age from a few years to over 8 oo years, often on the same acre. The 8 oo year-old tree may be only 18 inches in diameter.

Nature works towards this climax (5). The forester prefers the pre-climax of healthy young even-aged stands. They have little disease or defect and produce on the average twice as much volume in 80 years as the climax forest maintains (7). See Table 1. Theoretically, the second crop, after pulp mills cut the climax, would have so much more volume that the

\footnotetext{
2 Site 3 of climax forest compared to site index 110 of second growth. Climax has 5 sites $(6 \mathrm{logs}$ to less than $1 \mathrm{log})$. Second-growth sites range from 70 feet to 150 feet at 100 years (7).
} 
forest could support a heavier cut on a sustained yield basis. That's for the far distant future. We are concerned now as to how the climax should be logged to get the best stand of reproduction and how to predict, even in rough terms, what kind of a stand will come back. Also, logging for pulp over large areas must not damage other present values, the most important of which are the salmon spawning streams.

\section{Forest Management Problems and Preliminary Results}

Cutting the climax stands. Probably most of you have seen the older logged-off areas in the western states where miles of timber were clear-cut and burned-sometimes reburned several times. Many of these areas had to be replanted at great expense. It has been commonly accepted by many people that pulptimber cutting in Alaska will result in similar blackened areas unless special precautions are taken. IVe cannot say that such a thing could not happen in Southeast Alaska. We can say that it would be very unlikely because:

1. Rainfall is so heavy and so well distributed over the year that forest fires are extremely rare. 2. Logged areas are covered at once by dense vegetation and in 10 years are dense forests of tree reproduction $(4,8)$. 3. If large continuous areas are to be clear-cut they will be broken up by using staggered settings. That is, areas probably no larger than 80 acres will be aiternately logged leaving green forest as a protection from fire spread and as a source of seed.

Large pulptimber areas have been examined by research men during the past two years. It is obvious that few extensive clearcuttings can be made unless pulpmills can economically log the many interspersed areas of scrub. Bands and islands of uncut submerchantable forest will be left, and all through the merchantable tracts live cull trees will be scattered. This may present a problem in getting full stands of reproduction. The Station is now experimenting with costs of girdling or poisoning these culls.

Predicting future growth. This problem is mainly one of trying to tie our present even-aged yield tables to the all-aged 
climax. We want to be able to say that if the climax to he cut for pulp is site 3 the new stand will be of a certain site-index. Small areas of second-growth bordered by climax forest are compared. The site index of the second-growth, its soil depth and horizon characteristics are compared with the site class of the climax adjoining it or interspersed in it. So far correlations are not high, but we need only an approximation. The tests so far are mostly near our Kasaan Bay work area on the Ketchikan pulptimber unit. If results are obtained they will be tested over larger areas. The ability to relate site class of the climax with site index of second-growth will allow more than merely predicting future growth. The climax site classification is partly based on number of 16 -foot logs and other data (6) that a timber cruiser normally gets. From his data we may be able to say whether an unmerchantable stand would regenerate to a merchantable stand. How to get an unmerchantable stand logged is another matter.

\section{The Impact of Logging on Salmon Streams}

The Forest Service must know whether pulptimber logging is likely to damage salmon streams and if so how to prevent it. There is no doubt about the importance of the salmon to Southeast Alaska. Fishing is the main industry and there is much concern even though protective measures are already included in Forest Service timber sales contracts (11). These protective clauses specify that logging is not to be allowed to interfere with the passage of salmon to spawning grounds and there must be no injury to spawning areas in any way. This deals mostly with physical obstructions or damage to the water course and these can be prevented. However, it is thought that logging on the watershed might affect the stream in other ways. Siltation, turbidity, water temperature, flash floods and other factors must be considered. Hence the Research Center is engaged in studies of certain test streams selected on the east coast of Prince of Wales Island. Cooperation of the U. S. Fish and Wildlife Service and the Fisheries Research Institute takes care of fish 
biology work, totally out of a forester's line, and advice of water resource experts of the U.S. Geological Survey aids in the water flow, water stage measurements. A fairly good picture of normal stream changes has been obtained during the past three years. After logging starts on certain of these watersheds any changes in the stream regimen will be observed.

Measurements on 4 test streams taken in the study of the effect of logging on salmon streams indicate that in this region of heavy rainfall watersheds remain almost constantly saturated. Because of this the watersheds have little extra storage capacity during the seasons of heaviest rainfall, hence fall floods are normal. Total rainfall on the watersheds of streams without sizeable lakes drains out within a few hours after it falls.

Basic studies. The silvics and silviculture of the tree species of Alaska-familiar species, but growing under Alaska conditions-must be the subject of long and intensive study. The effect of the various site factors on growth is complicated by such conditions as permafrost in the Interior and deep acid humus layers in Southeast Alaska. Along with studies of immediate importance we must carry on this long range work in silvics dealing with seed production, dissemination, germination, seedling survival and tree growth. Only a good basic knowledge of silvics will insure proper forest management practices.

The small staff of the Alaska Forest Research Center has plenty of problems but we can tackle only a few at a time. Perhaps we will have a small but effective basis for expansion of research when the time comes to broaden the scope of our program. Wise use of Alaska's forest resource must depend on research.

\section{REFERENCES}

1. Heintzleman, B. F. Pulptimber resources of Southeastern Alaska. May 1937.

2. McLintock, T. F. Mapping vulnerability of spruce-fir stands in the Northeast to spruce budworm attack. Northeastern Forest Expt. Station Paper No. 21. Jan. 1949.

3. Sundborg, George. Opportunity in Alaska. New York. 1946. 
4. - The role of Sitka spruce in the development of secondgrowth in Southeastern Alaska. Jour. For. 27: 532-34. 1929.

5. TAYLOR, R. F. The successional trend and its relation to secondgrowth forests in Southeastern Alaska. Ecology 12: 381-391.

6. Indicator vegetation on cutover land of Southeast Alaska. Univ. Wash. Forest Club Quarterly. July 1931.

7. - Yield of second-growth western hemlock-Sitka spruce stands in Southeast Alaska. U. S. Dept. Agr. Tech. Bull. 412. March 1934.

8. - . Available nitrogen as a factor influencing the occurrence of Sitka spruce and western hemlock seedlings in the forests of Southeast Alaska. Ecology, I6 (4). 1935.

9. Alaska Resources Committee of the National Resources Committee. Regional planning. Part VII, Alaska. Dec. 1937.

10. Forest Service, Alaska Region. The forests of Alaska. U. S. Dept. Agr. July 1, 1944.

11. Forest Service, Alaska Region. Sale Prospectus. June 14, 1948.

12. Forest Service. Forests and national prosperity. U. S. Dept. of Agr. Misc. Pub. No. 668.

13. Pacific Pulp \& Paper Industry, North American Review Number. May 1944. 


\title{
SURVEY OF SOUTHEASTERN ALASKAN INDIAN RESEARCH
}

\author{
Viola E. Garfield \\ Department of Anthropology \\ University of Washington
}

Approximately eight thousand Indians now live on the coastal mainland and islands of Alaska from Copper River east to the Canadian border. In the early eighteenth century when Europeans sailed into north Pacific waters the native population was probably much larger. Figures are difficult to compare because of different bases of classification and areas included. The Russians applied the term Kolosh specifically to the Tlingit, but also included all Indians from Prince William Sound to the coast of Washington, as well as those on the Copper River under the same term. ${ }^{1}$ Indians now in southeastern Alaska belong to three distinct language groups although the larger number of them speak Tlingit. Tlingit territory includes coastal mainland and islands from Yakutat Bay to Dixon's Entrance, or most of southeastern Alaska. Haida have occupied the southern half of Prince of Wales and adjacent islands for the last two hundred and fifty to three hundred years. Their ancestors crossed Dixon's Entrance northward from the Queen Charlotte Islands and established themselves in Tlingit territory shortly before European explorers appeared. The third group, the Tsimshian, are very recent migrants. Their one settlement is on Annette Island to which over nine hundred of their ancestors migrated from the vicinity of Prince Rupert, British Columbia, in 1887 .

1 Petroff, 1900. Tikhmenef reported the population of Russian America as 14,019 in 1819. This included an estimated 5,000 Kolosh. Veniaminov estimated the number of Kolosh in sixteen villages (Haida and Tlingit) as 5,850 in 1835 . In 1839 the Hudson's Bay Company enumerated 7,190 Tlingit and Haida, exclusive of those at Sitka. The 1 oth U. S. Census reports 6,763 Tlingit and 788 Haida (1880). 
At the dawn of the eighteenth century the North Pacific ocean and continental northwest America were only vaguely known to Europeans whose ancestors had discovered the western hemisphere over two hundred years earlier. Early in the century Russian explorations prove America to be separate from Asia and led to further discoveries. In 1741 Bering and Chirikov set sail from Petropavlovsk and between them gained some knowledge of the Aleutian Islands and the coast as far south as Sitka Sound. They saw and described Indian campsites, some of which were undoubtedly Thingit, but saw few Indians. Two boatloads of Chirikov's men mysteriously disappeared in or near Sitka harbor. Painted Indians came out of the bay into which the men disappeared and smoke was seen but nothing further was learned of the fate of the men or the identity of the Indians.

When survivors of Chirikov's and Bering's crews reached Petropavlovsk in 1741 and 1742 respectively they touched off a flood of fur seekers and initiated the maritime fur trade that flourished into the nineteenth century. The first well organized Russian fur company under the leadership of Shelikov began systematic exploitation of both the fur bearers and the native peoples with establishment of the settlement on Kodiak Island in 1783 . Rival companies were soon eliminated or merged with the Russian American Company that enjoyed a trade and administrative monopoly of the territory until the transfer of Alaska to the United States in 1867 .

Russian activities until the 1790's centered around the Aleutians, Kodiak Island and Cook Inlet with exploratory trips along the coast to the southeast. Therefore, early Russian annals deal principally with the Aleuts, Kodiak Islanders and Kenai Peninsula Athapascan tribes. There is very little about the Tlingit before the settling of Yakutat Bay in 1796 and of Sitka in 1799 .

Most of the information about natives was supplied by explorers or parties sent to investigate and report on the affairs of the company and their treatment of the natives. Though Russian traders lived intimately with Aleuts, Kodiaks and 
Kenai Peninsula natives, marrying the women and working daily with the men, their records are generally meagre, superficial and untrustworthy. Native men were treated as subordinates and virtual serfs and were accepted on equal social status only if they were thoroughly Russianized. Russian husbands sought to deny so far as possible the cultural backgrounds of their native wives and to raise their children in the Russian tradition. Hence, they did not make an effort to understand native culture and were not interested in recording it. Whatever appears in letters, diaries, official reports and other papers of the Russian traders is generally oriented toward some problem of native-Russian relationship and is not the result of interest in native cultures.

Russian relationships with the Tlingit were never friendly. After the destruction of Sitka in 1802 and of the Yakutat Bay settlement in $180_{5}$ the relationship was one of armed truce marked by attacks and retaliation on both sides. Tlingit were not allowed to settle near the rebuilt Sitka stockade until after 1821 and even then Russian armed guards kept constant vigilance. The Indians apparently did likewise. In such an atmosphere there was little inclination or opportunity for recording language, literature, music, social organization or other esoteric aspects of Tlingit culture. Information is much more detailed on warfare, clothing, canoes, trading practices and treachery. The notable exception is the treatise written by Father Veniaminov who came to Sitka in 1834 and who had previously written an account of Aleut culture. ${ }^{2}$ Almost nothing appears in Russian annals concerning the Haida as a separate tribe, as they were included with the Kolosh. The Haida disposed of pelts to the traders who came to the anchorages in Cordova Bay and Graham Island during the height of the maritime fur trade.

Between 1774 and 1791 the Spanish, fearful for their Pacific domain, sent explorers up the coast where they briefly held Nootka Sound. They left accounts of tribes met with from California northward. Though Perez was off the Queen Char-

\footnotetext{
2 Translated excerpts appear in Petrof, 1900 and Bancroft, 1875 .
} 
lotte Islands in 1774 he did not land or encounter Indians. Maurelle's journal of explorations in Bucareli Bay in 1775 is probably the earliest description of the Haida on record (9). Hezeta's expedition also met Indians at Sitka Sound, presumably Tlingit. Journals of the expedition of 1779 include some accounts of Indians from Bucareli Bay to Kenai Peninsula.

Between about 1785 and 1800 many ships of Spanish, English, French, Russian and American registry plied the coast from California to Cape Prince of Wales $\left(6_{3}\right)$. Some of these men, like Cook (1776) and Vancouver (1792-94) headed expeditions that were primarily exploratory, but the greater number came to garner pelts of the sea otter. In the 1790's as many as twenty to thirty ships came to the anchorages of Nootka Sound, Parry Passage at the north end of Graham Island and Cordova Bay across Dixon's Entrance. As competition became keener vessels cruised among the islands seeking anchorages and unexploited areas where Indians would come out in canoes to trade. There is a wealth of material to be gleaned from the journals, maps and drawings left by these men, fur traders and explorers alike.

Most of the visitors came in the early summer and left before the autumn storms for Hawaii, Macao, Canton, California or the south Pacific. They saw Indian families at the fur rendezvous or summer camps, when they were busy hunting as well as gathering and storing food for their winter supply. The visitors saw little of the rich pageantry or ceremonial life of the Indians, though the wood sculpture piqued their curiosity and caused them to enquire into its meaning. A few traders who returned year after year came to know individual Indians well and to learn something of their social life, beliefs and traditions. The short season gave both traders and Indians a sense of urgency and offered little leisure time for enquiry into cultural backgrounds. Nevertheless, a few men did find time to collect vocabularies, learn something of clans and of inheritance of social position and names. Though Indians accompanied ships to winter quarters, very little advantage seems to have been taken of their presence to learn more of their culture. Con- 
sidering the language difficulties it is perhaps remarkable that so much accurate information was obtained. Certainly abstract ideas and subtle nuances of belief and custom would be impossible to impart by such means.

Almost without exception exploring expeditions included specially trained men such as naturalists, geographers, cartographers, artists and sketchers, in addition to officers and crew primarily concerned with operating the ships. Most Spanish expeditions included priests. Each kept a journal or diary of discoveries and observations in his field. One or more men were also charged with noting everything that did not fall within the domain of a specialist, but that might be of value or interest in establishing trading and possessory rights of the sponsors. Until the beginning of the twentieth century there were no specialists trained in the science of studying people. Therefore, descriptions of native tribes, their customs and manufactures were made by men trained in other fields. Many of them applied the same objective criteria to descriptions of people as they did to recording mountains or plants. Others distorted the cultures and misinterpreted the peoples they encountered in terms of personal attitudes, prejudices and preconceived ideas, and their accounts must be read critically.

In addition to commerce in furs, the search for the Northwest Passage attracted explorers to the area. After 1800 whalers, particularly American, invaded the north Pacific and Bering sea to the Arctic. Exploration was also stimulated by the developing struggle for overseas possessions.

Piecing together many accounts from the eighteenth and early nineteenth centuries it is possible to get a fairly adequate idea of material culture but only a superficial knowledge of non-material aspects of northwest coast Indian life.

By 1820 the herds of otter and seal had been seriously depleted and fewer ships visited the coast each year. The Hudson's Bay Company, pushing westward to share in the take of furs, reached the coast in the early 1830 's and built Fort Simpson in 1834 , the first permanent fort on the coast. To protect their interests the Russian American Company constructed 
Fort St. Dionysius on Wrangell Island in the same year. Competition between the two companies was keen and controversy resulted in agreements to lease the coast from Portland Canal to Cape Spencer to the Hudson's Bay Company for ten years, including Fort St. Dionysius which was renamed Fort Wrangell. The lease was renewed until the cession of Alaska to the United States. Building of the two forts brought Stikine River Tlingit, Kaigani Haida and Tsimshian tribes into the center of trading activities and into the annals of factors and visitors. The Stikines moved into the vicinity of Fort Wrangell and the Tsimshian to Fort Simpson where Haida traders came in large numbers each fall. Hudson's Bay factors' journals add to the picture of native life, though the accounts are primarily confined to matters pertinent to trade and daily events. Changes that were taking place in dress, homes and house furnishings, food habits and trade demands in Indian communities are revealed in these reports (17).

American traders, with more desirable goods than either the English or Russians were able to offer, successfully competed for pelts. Americans are also accused of trading guns, ammunition and liquor to the Indians, providing them with generally more efficient means of hunting and also with both the weapons and stimulus for feuding and aggressive warfare among themselves.

As Russian strength on the coast waned England and the United States emerged as competitors for sovereignty over Northwest America. The year 1867 opened a new era for Alaska and its aboriginal inhabitants when the territory was sold to the United States. Sitka remained the capital of the new possession. A port of entry with a customs officer and a company of soldiers was established at Tongass. Military troops were also stationed at Sitka with a general in command. In 1877 the army was recalled and the customs officer was left in sole charge of Alaska. Jurisdiction was transferred to the navy in 1879 and the Jamestown with Captain Beardslee in charge was sent to Sitka. Seventeen years after the purchase a civil government was set up and a governor appointed to administer the affairs of the District of Alaska (2). 
Following the purchase, the principal sources of information about the Indians are the annual and special reports of army, navy and customs officers and of the men sent to gather data about the new country. Between 1867 and 1884 , when civil government was established, was a period of tension and confusion for Indians and non-Indians alike. Alaska was visited by professional writers, scientists, reporters, adventurers, government officials and church representatives who published their impressions, opinions and observations in books, newspapers, magazines and official reports. Discovery of gold in the Cassiar in 1869 started the influx of prospectors and miners who contributed to unsettled economic and social conditions. Indians far outnumbered white residents, especially at Sitka and Wrangell, and the latter were certain that they would be attacked. Petitions and pleas for protection poured into Washington official circles and were taken up by the press. Though Indians did not undertake, or even plan, any mass attacks so far as can be determined, they did attempt to protect their lives and property according to their orn concepts of justice. A report to Congress in 1879 includes letters from whites living in the territory, personal observations and opinions of travelers and special investigators, and official letters of government personnel concerning the Indians living at Sitka and Wrangell, of whom there were about five thousand in the winter. The report also includes accounts of the Kake and Hootznahoo incidents in which the two towns were shelled and burned for refusal to hand over purported murderers of white men. In each case the Indians contended that whites had first killed men of their villages and that they were entitled to compensation, or lacking that, to revenge. The documents reveal the conflict of ideas of justice between Indians and whites. Characteristically, the report includes very little information based on interviervs with Indians or statements by them (42). Another report was written by an army lieutenant, Frederick Schwatka, sent to determine the kind of military campaign that would be necessary to wipe out Indian communities in the event that it was deemed advisable to do so. He comments that the Indians were generally 
friendly to the whites and that he could find no warlike tendencies among them.

From the date of purchase scientific expeditions were sent to investigate resources, survey coastlines and harbors and collect data that would serve in the economic development of Alaska. Nearly all of these reports contain some data on the native people however brief. One of the best reports is that of Ensign A. P. Niblack who gathered information in the summers of 1885,1886 and 1887 in the course of a survey of the coast. He also took excellent photographs of Haida towns, but did not reach northern Tlingit settlements. Niblack urged that a detailed ethnographic study be made during the winter when Indians were at home and could be interviewed. His book includes illustrations and descriptions of Northwest Coast Indian manufactures in the United States National Museum. This was the earliest systematic attempt on the part of an American to describe the cultures of the Tlingit and Haida Indians. However, other men sent by the government on scientific missions in the latter part of the nineteenth century added measurably to existing knowledge of coastal tribes. Notable contributions were made by Dall (1870), Schwatka (1885), Abercrombie (1884) and Petrof (1881 to 1890). These and other papers were collected and published in Washington in $1900 .^{3}$ They form a valuable source of data, including census reports for Alaska for the years 1880 and 1890 . Publications of the Harriman scientific expedition in the summer of $\mathbf{1} 899$, privately sponsored, include a chapter on the Tlingit and drawings and photographs of towns and sculpture (28).

Missionization of Canadian coastal Indians by the English began with the arrival of a missionary at Fort Simpson in 1856 . He trained Indian lay workers and sent them and white missionaries up and down the coast and into Alaska territory. The first American mission and school in southeastern Alaska was established at Wrangell in 1877 , followed by one at Sitka to take the place of the Russian school for native children. The

3 Under the title Compilation of Narratives of Explorations in Alaska. Washington, 1900 . 
Greek Orthodox church continues to function in Sitka and has many Tlingit among its members. Haines mission was begun in 1880 and in 1885 mission schools were started at Hoonah and Howkan, the latter a Haida town $\left(34,5^{6}\right)$.

Federal funds were appropriated for schools in Alaska in 1869 but were not used until 1885. Sheldon Jackson, a Presbyterian missionary, was appointed General Agent of Education. He made a report for the year $1885^{-6}$. Since then reports of administrators and teachers have been issued annually. They are excellent sources of information on economic and health conditions in native villages. Teachers have not been encouraged to acquaint themselves with the social and religious backgrounds of the people whose economic activities they often supervise and whose children they teach, hence include very little of these aspects of culture.

On the other hand, missionaries and mission teachers are frequently more aware of social, religious and ceremonial practices of the natives though they misinterpret them. Customs, ideas and attitudes that contrast sharply with those of the missionaries' own culture are emphasized and held up for unfavorable comparison.

The first anthropologist to record stories, linguistic texts and notes on the social organization of the Haida and Tlingit was Dr. Franz Boas. The first trained field worker to make a detailed study of the two groups was J. R. Swanton, who spent the vinter of 1900-o1 in the Queen Charlotte Islands and four months in 1904 in Sitka and Wrangell. His analysis of Haida family legendary histories and kinship organization includes the Alaska Haida (Kaigani). He also obtained accounts of the migrations of Haida families to Prince of Wales Island and collected myths, folktales and songs. His reports on Tlingit social organization and mythology are the most comprehensive that have been done to date. Almost twenty-five years passed before anthropologists again visited the Tlingit and Kaigani Haida.

The monumental analysis of Tsimshian culture by Dr. Boas includes comparative data on the mythology of all Northwest 
Coast tribes and is essential to an understanding of the Alaska Tsimshian (14). Two books, written to publicize the missionary work of William Duncan, contain much of ethnographic interest and describe the circumstances that motivated the Alaska migration $(3,65)$. The Annette Island community was the subject of a congressional investigation in 1935 but the report is so burdened with charges, counter-charges and subjective evaluations as to be almost useless for any social science study (68).

Other sources of information on southeast Alaska include four histories of Alaska and one of Sitka. Two of the histories treat the Indians in a very summary manner, dismissing them as obstacles to be overcome in the development of the territory. They do not contribute to our knowledge of the Indians or the part they played in Alaska's history, but do reflect the attitudes of the writers and many of their readers. Other historians describe outstanding Indian leaders and the influence they and their tribesmen had in the shaping of events $(1,2)$. No account, either historical or novelistic, has been written on the theme of Indian personalities and participation, though there is rich material for such a treatise.

Few anthropologists have undertaken studies of broad scope since Dr. Swanton's pioneer survey. Dr. Ronald Olson has yet to publish his data on Tlingit history as preserved in folktales and clan legends. The first field rork to combine the knowledge and techniques of personnel trained in several fields of anthropology was directed by Dr. Frederica de Laguna in northern Tlingit territory in the summer of 1949 and in the vicinity of Angoon during the summer of 1950. Ethnographic, archaeological and linguistic approaches were applied to the complex problems of Tlingit cultural history and prehistory. Such surveys, if carried out systematically to cover a large area, will go a long way toward providing answers to perplexing questions concerning the origins of Northwest Coast cultural elements and their indigenous development.

A large number of studies have been made, limited as to subject and area or both. The techniques of blanket weaving, basketry $\left(20,5^{2}\right)$ and woodworking have been described and 
there are short papers on stone, bone and copper work. Very little has been added to the description of stylistic elements and variety of designs developed by Northwest Coast Indians that Dr. Boas included in Primitive Art. A number of studies of wood sculpture have been published. These include histories of totem poles and the legends and historic events illustrated on them $(5,24,36)$, brief analyses of stylistic differences in illustration and theories concerning the origin of Northwest Coast art style and of totem poles in particular $(6,46,51)$. Almost nothing has been done on mask, rattle and box decoration or on painting beyond publishing illustrations with brief notes identifying designs or owners. Some work has been done on architecture and canoe building $\left(5^{\circ}, 64\right)$. Descriptions of hunting and fishing equipment and techniques are inadequate. Though Indians and Aleuts hunted sea otter and seal and probably accounted for the larger number of pelts taken away by traders, the writer knows of no detailed description of the techniques and weapons employed.

Publications on social organization are both descriptive and theoretical. Theoretical papers are concerned primarily with the probable origin of traits of the matrilineal clan organization and the direction and dates of their diffusion $(4,11)$. Some material has been collected on the growth, spread and disappearance of lineages and clans, noting some of the social, economic and political influences involved (22, 58, 59). Rank, status and slavery have received some attention and several writers have discussed the potlatch and its function in the prestige system $(8,18,44)$.

Economic organization and production for one village has been documented (49), but most of the economic studies have been concerned with distribution of wealth at potlatches and not with the manner in which subsistence needs were satisfied and surplus commodities acquired.

Very little has been done on music, dancing or drama, and nothing on the survival and adaptation of these arts to present modes of life.

Language studies are limited to brief sketches, vocabularies 
and a few myths in text from the Tlingit and Haida, but nothing from the Alaska Tsimshian. Tlingit is known to differ dialectically but the extent of these differences and their geographic boundaries are not known. Nothing is being done on the influence of Russian and English on the native languages.

Myth and folktale collections are adequate, but by no means exhaustive. The comparative analysis of Northwest Coast oral literature, done by Dr. Boas, is now over thirty-five years old and many collections have been made in the meantime. Other comparative studies have been of single stories or of a small collection of plots, themes or motives. These reveal relationships between Northwest Coast oral literature and that of their neighbors or with Asia. The close relationship between pride in lineage ancestors and the process of myth making has been barely touched.

Excepting the pioneer effort of Rev. Jones, no work has been done on culture change. The theory of other-area, particularly Asiatic, origin of Northwest Coast cultures has perhaps impeded work on cultural growth within the area. Since archaeological work is both difficult and unrewarding in an area of high rainfall and extensive use of wood, students have turned to other methods of accounting for cultural traits and complexes. Comparisons between elements of Northwest Coast cultures and those of other areas reveal similarities that are interpreted as evidences of diffusion into Northwest Coast and culture history then becomes a problem of determining dates and sources of introduction. Culture change occurs when new elements are introduced. No attention has been directed to the cultural dynamisms existing in the area, nor to the economic, social, political and religious factors that influence cultural stability, change and direction of change.

The field of personality types and personality development has been entirely neglected. Dr. Benedict's characterization of the Kwakiutl (Patterns of Gulture, Boston, 1934) has been widely used and frequently quoted as a description of Northwest Coast Indians. However, her interpretation has not been checked in the field. We lack documentation on adult per- 
sonalities and on the training and development of children. Some material on adults can be gleaned from ethnographies and myth collections, but there is a dearth of information on the training of small children.

Practically nothing has been done in the field of physical anthropology. An inventory of publications reveals a few skull measurements, general descriptions of physical type and blood types of about a hundred and twenty-five Tlingit.

Investigation of the relationship of Alaska Indians to their resource areas, undertaken in 1944 and continued into 1946 , stemmed from different sources than any of the research cited above.

At the time of the Alaska purchase no reservations were set aside for the natives and no treaties were made with them. The whole question of rights to land and other resource areas was held in abeyance. From time to time the question of whether natives have any rights at all has arisen and has been both denied and affirmed. In 1935 Tlingit and Haida tribes were authorized to bring suit in the U. S. Court of Claims for compensation for "lands and other tribal or community rights" (53). Claims were filed by a few Thingit communities or tribes, but were not allowed by the court. The question again arose as a result of a section of the Alaskan Fisheries Regulations, first promulgated by the Secretary of the Interior in 1942. The regulation provided that "no trap should be established in any site in which any Alaska natives have any rights of fishery by virtue of any grant or of aboriginal occupancy." The Department of the Interior held hearings in Tlingit and Haida villages in 1944 "to determine fishing and other occupancy rights of these communities," in response to petitions from communities dated April 1942 and July 1944. Individuals testified concerning the kinship groups to which they belonged and the areas they were traditionally privileged to use by reason of kinship affiliations. Witnesses were closely questioned to determine locations of camps, smokehouses and other sites in use. Much information was gathered on traditional utilization of resource areas, inheritance of rights and the degree to which the Indians 
continue to exercise aboriginal rights to provide themselves with food. Indian claims were vigorously refuted by cannery and other industrial and business interests. Both sides employed expert researchers and a vast amount of material from published sources was collected. Translators, sociologists, lawyers and anthropologists compiled extensive records dating from eighteenth century explorers and traders to contemporary sources. For the first time a systematic compilation was made of Tlingit and Haida customs of utilization and inheritance of land, streams, beach and salt water resource areas. Changes in food economy and in the extent to which areas were used from the date of the Alaska purchase to the present were documented from published sources, augmented by testimony of elderly Indians of customary usage as related to them by parents and grandparents.

A further point at issue was the legal one of the status of Tlingit and Haida tribes under Russian rule, hence the status they occupied when the territory was ceded to the United States. Russian documents were translated and pertinent sections extracted to support the argument that no territorial rights of the Indians were recognized by the Russians. Whaterer the outcome so far as Indian claims are concerned, much valuable material was compiled relating to the economy, resource utilization, kinship affiliations and functions of the Haida and Tlingit.

A coordinated plan of research for southeastern Alaska is now needed to make use of material already accumulated. Such a plan should include consideration of theoretic problems bearing on the relationship between this and other native areas, the dynamics of culture growth that made this an area of complex cultures, and the processes of acculturation operating at the present time. This goal can best be attained, in the opinion of the writer, by a coordinating committee serving as a clearing house and source of information, not in the role of directing or supervising research. The committee would lay out a tentative plan, with first consideration to traits that are fast disappearing. A report on current and contemplated field work and a list of 
library, museum and other sources of material that might otherwise be overlooked should be compiled. The committee would also assist in the coordination of studies for the rest of Alaska and the Northwest Coast. Though this paper has been primarily concerned with the Indians of southeastern Alaska, the area from Cook Inlet to northern California should be included in the plan.

An integrated plan of research would reveal many concrete problems for students to investigate, either individually or in cooperating teams. The Northwest Coast is quite as rewarding an area as others in the United States and deserves the same careful consideration and coordinated attack from social scientists as it has received from scientists in other fields.

\section{REFERENCES}

1. Andrews, C. L. The story of Sitka. Seattle. 1922.

2. - The story of Alaska. Caldwell, Idaho. 1938.

3. Arctander, J. W. The Apostle of Alaska. New York. 1909.

4. Barbeau, C. Marius. Growth and federation in the Tsimshian phratries. Proceedings: 19th International Congress of Americanists. Washington. 1917 .

5. - Totem poles of the Gitksan, Upper Skeena River, British Columbia. Bull. 1, Anthropology series, no. 12, Canada Dept. of Mines, Ottawa. 1929.

6 . - The modern growth of the totem pole. Jour. of Washington Academy of Sciences, 2S. Washington. 1938.

7. Bancroft, H. H. Native races of the Pacific states, Vol. 1. New York. 1875 .

8. Barnett, H. G. The nature of the potlatch. American Anthropologist, 40 (3). $193^{8}$.

9. Barrington, Daines (translator). Francisco Antonio Maurelle, Voyage of the Sonora in the second Bucareli Expedition1775. San Francisco. 1920.

10. Beynon, William. The Tsimshians of Metlakatla, Alaska. American Anthropologist, 42. 1941.

11. Birket-Smith, K. and Frederica de Laguna. The Eyak Indians of the Copper River Delta, Alaska. Copenhagen. $193^{8}$.

12. BoAs, Franz. First general report on the Indians of British Columbia. British Association for the Advancement of Science, 59. 1889 . 
13. - Indianische Sagen von der Nord-pacifischen Küste Amerkas. Berlin. 1895 .

14. - Tsimshian mythology. 31st Annual Report, Bureau of American Ethnology. Washington. 1916.

15. - Primitive art. Oslo. 1927.

16. Dall, W. H. Alaska and Its Resources. Boston. 1870.

17. DEe, H. D. (editor). The journal of John Work, 1835. British Columbia Historical Quarterly, 8 and 9. Victoria. 1944-45.

18. Drucker, Philip. Rank, wealth, and kinship in Northwest Coast society. American Anthropologist, 4I. 1939.

19. - The antiquity of the Northwest totem pole. Jour. Washington Academy of Sciences, 39. Washington. 1948.

20. Emmons, G. T. The Chilkat blanket. Memoirs, American Museum of Natural History, III. New York. 1903.

21. Garfield, V. E. Research problems in Northwest Indian Economics. American Anthropologist, 47. 1945.

22. - Historical aspects of Tlingit clans of Angoon, Alaska. American Anthropologist. 49. 1947.

23. - Meet the totem. Sitka. 1951.

24. Garfield, V. E. and L. A. Forrest. The Wolf and the Raven. University of Washington Press, Seattle. 1948.

25. Golder, F. A. Russian expansion on the Pacific, 1641-185o. Cleveland. 1914.

26. - Guide to materials for American history in Russian archives. 2 vols. Washington. $1917-37$.

27. Goldschmidt, W. R. and T. H. HaAs. Possessory rights of natives of Southeastern Alaska. Report to Commissioner of Indian Affairs, Oct. 1946. Chicago (mimeo). 1946.

28. Grinnell, G. B. Natives of the Alaska coast region. Harriman Alaska Expedition, vol. 1. New York. 1902.

29. Gsovski, Vladimir. Russian materials available in the Library of Congress on the Tlingit and Haida Indians of Alaska. Washington (mimeo). 1940.

30. - Russian administration of Alaska and the status of the Alaskan natives. Senate document no. 152. Washington. $195^{\circ}$.

31. Hanna, R. H. Aboriginal rights in Alaska. Opinion of Richard H. Hanna, Examiner for the Department of the Interior. 1945 .

32. Hatt, Gudmund. Asiatic influences in American folklore. Copenhagen. 1949.

33. InGRAHAM, JoSEPH. Journal of the voyage of the Brigantine Hope from Boston to the Northwest Coast of America, 17901792. Provincial Archives, Victoria (unpublished) 
34. Jackson, Sheldon. Alaska, and the missions on the North Pacific Coast. New York. 1880.

35. Jones, L. F. A study of the Thlingets of Alaska. New York. 1914 .

36. Keithahn, E. L. Monuments in cedar. Ketchikan. 1945.

37. Krause, Aurel. Die Tlinkit-Indianer. Jena. $\mathbf{1 8 8 5}$.

38. Kroeber, A. L. American Culture and the Northwest Coast. American Anthropologist, 25. 1923.

39. Laguna, Frederica DE. An Archaeological survey in northern Tlingit territory, Alaska. Report of Field Work. Bryn Mawr (mimeo). 1949a.

4o. An anthropological survey of the northern Tlingit. Bryn Mawr (mimeo). 1949b.

41. An anthropological survey of Tlingit of Chatham Strait. Bryn Mawr (mimeo). $195^{\circ}$.

42. Morris, W. G. Public service and resources of Alaska. 45th Congress, gd sess., Ex. Doc. no. 59. Washington. 1879 .

43. Murdock, G. P. Kinship and social behavior among the Haida. American Anthropologist, 36. 1934.

44. - Rank and potlatch among the Haida. Yale University Publications in Anthropology, 13. 1936.

45. - Social structure. New York. 1949.

46. Newcombe, W. A. British Columbia totem poles. Report of the Provincial Museum of Natural History for the year $193^{\circ}$. Victoria. 1931.

47. Niblack, A. P. The Coast Indians of Southern Alaska and Northern British Columbia. Smithsonian Report, 1888, Part 2, Washingtor. 1889 .

48. Oberg, Kalervo. Crime and punishment in Tlingit society. American Anthropologist, 37. 1934.

49. The social economy of the Tlingit Indians. University of Chicago (mimeo). 1937.

5. Olson, R. L. Adze, canoe and house types of the northwest Coast. U. of Wash. Publications in Anthropology, II. Seattle. 1927 .

51. Panlen, Wolfgang. Totem art. Dyn, 4-5. Mexico. 1943.

52. Paul, Frances. Spruce root basketry of the Alaska Tlingit. Haskell Institute. Lawrence, Kansas. 1944.

53. Paul, W. L. Jr. Historical and legal materials relative to the Tlingit and Haida Claims Act of 1935. U. of W. Law School. Seattle. 1939 .

54. Petrof, Ivan. The population and resources of Alaska. Compilation of Narratives of Explorations in Alaska. Washington. 1900. 
55. Rickard, T. A. The use of native copper by the Indigenes of North America. Jour. of the Anthropological Institute of Great Britain and Ireland, 47. London, 1934.

56. Scidmore, E. R. Alaska. Its southern coast and the Sitkan Archipelago. Boston. 1885 .

57. Sivanton, J. R. Haida texts and myths. Bull. 29, Bureau of American Ethnology. Washington. 1905.

58. Social condition, beliefs and linguistic relationship of the Tlingit Indians. 26th Annual Report of the Bureau of American Ethnology. Washington. 1908.

59. Contributions to the ethnology of the Haida. Memoirs of the American Museum of Natural History, VIII. New York. 19oga.

6o. - Tlingit myths and texts. Bull. 39, Bureau of American Ethnology. Washington. 19ogb.

61. Sivanton, J. R. and Franz Boas. Haida songs. Tsimshian texts. American Ethnological Society, 3. 1912.

62. Wagner, H. R. (editor and translator). Journal of Tomas de Suria of his voyage with Malaspina to the Northwest Coast of America in 1791. Glendale. $193^{6}$.

63. Wagner, H. R. The cartography of the Northwest Coast of America to the year 1800. 2 vols. U. of Cal. Press, Berkeley. 1937 .

64. Waterman, T. T. Native houses of western North America. Indian Notes and Monographs, Museum of the American Indian, Heye Foundation, series 2, vol. 11. New York. 1923.

65. Wellcome, H. S. The story of Metlakatla. New York. 1887.

66. Wickersham, James. A bibliography of Alaskan literature, 1724-1924. Cordova. 1927.

67. Hearings on Claims of natives of the Towns of Hydaburg, Klawock, and Kake, Alaska, pursuant to the provisions of Section 201.21b of the Regulations for Protection of Commercial Fisheries of Alaska (mimeo). 1944.

68. Survey of conditions of the Indians in the United States. Hearings before a sub-committee of the Committee on Indian Affairs, U. S. Senate. Part 35. Metlakatla Indians, Alaska. Washington. 1939 . 


\section{PRESENT STATUS OF THE ALASKAN ESKIMOS}

MARGARET LANTIS

Study of Adult Development

Harvard University

In 1940, 15,700 Eskimos were counted in Alaska. Figures for $195^{\circ}$ are not yet available, but it seems likely that the population has increased slightly. Until World War II, Alaskan Eskimos were scattered in 200 or more small settlements. Even the "big

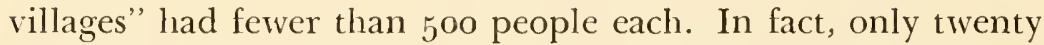
villages had more than 200 inhabitants apiece, according to the 1940 Census. During the war, Eskimos tended to concentrate in Fairbanks, Nome, and other centers of military construction that offered jobs. Since the war, Pt. Barrow has drawn people from all northwest Alaska, also because of work opportunities, finally attaining a population close to 1000 . Hence, during the past ten years the number of villages probably has decreased.

Including Alaska Native Service (Federal) and Territorial systems, there were 55 schools in Eskimo communities in 1948. Although schools gradually are being transferred from A.N.S. to Territorial system, the total number at this moment probably is the same or only slightly decreased. A few Eskimo youngsters go to the boarding school at Mt. Edgecumbe (Sitka) for secondary-level vocational instruction, though not such a high proportion as from the Southeast Alaskan Indians. The White Mountain Boarding School for Eskimo children has had fires and other difficulties, but the policy of the A.N.S. is to keep it open. Not so many Eskimo children (proportionally) attend any school, even the local village school, as among Aleuts and Indians. Eskimos are as intelligent as the others and most of the children enjoy school, but their families' hunting and fishing require migration.

Understandably, teachers and missionaries strive to keep Eskimo families close to their facilities, in some ways an unrealistic 
policy from the standpoint of both Eskimos and the larger 'White community. If people hang around a large village which cannot offer work to very many and where the surrounding area may have been hunted out or over-grazed by the reindeer, they inevitably will become dependent on relief or will be undernourished and tubercular. Because of employment offered by the Navy oil-drilling project, Barrow has grown without the usual effects. However, as this project is not a permanent development of the local economy, it does not change the generalization that, as now constituted, the economy of the west coast of Alaska cannot support many villages of even $5^{\text {oo }}$ population.

Tuberculosis has been in the past two generations the scourge of Alaskan Eskimos, not only in the individual tragedies of its victims but in its effects on community life. When mothers of young families, men 30 to 40 years old who are or can become the experienced leaders, and the better-schooled adolescents are killed indiscriminately, community planning probably will be ineffectual. There are three A.N.S. hospitals, three isolation field-stations for terminal TB cases, and about ten field nurses in Eskimo territory, and the area is served in summer by two of the floating health units of the Territorial Department of Health. For special treatment, Eskimos are sent to hospitals outside their area, also. School lunch program, Aid to Dependent Children (Social Security), and other welfare programs help combat disease by combating poverty and under-nutrition. The indigenous people are of course eligible for all those Federal Security Agency programs that function in Alaska.

The Federal Government does not have treaties with the native peoples of Alaska, just as it does not have treaties with separate groups in Puerto Rico. This is quite unlike the situation in the States. Native peoples of Alaska are protected by a Territorial non-discrimination law. They are citizens, eligible to vote, and expected to pay personal property taxes although only a small proportion of Eskimos do vote or pay taxes. Collecting the taxes would cost more than the return in many remote localities. The principal reason for Eskimos not voting is that their villages are too small, have too few of voting age who 
are literate, to satisfy the requirements for setting up a voting district. Although participating little in Territorial Government, they do participate actively in their own communities. By 1949, 32 Eskimo villages had organized under the Indian Reorganization Act, had their constitutions and officers, and in most cases were really functioning as civil bodies.

In $195^{\circ}$, there were 33 community stores, native owned and operated, in the Eskimo area, in a total of 45 community stores for all Alaska. In the little Eskimo villages, often with difficulties of transportation and other commercial disabilities, such stores have been needed more than in the large Indian towns of Southeast Alaska that can attract competitive privately-owned stores. To keep them reasonably economical, in 1947 twenty Eskimo and seven Aleut and Indian stores were organized by the Alaska Native Service in a purchasing and merchandising cooperative, with headquarters in Seattle. To get these stores and a few other activities started, a Federal revolving credit fund was started in 1939 .

Although the stores have done fairly well, other cooperative economic enterprises, such as reindeer herds and sawmill, have not done so well. Members of an umiak crew will stay together well for whale or walrus hunting, but other productive activities seem to be too individualistic for a quick shift to a modern cooperative enterprise, especially when it is attempted with a technology that also is new. The most successful enterprise (not strictly a cooperative?) has been the Nome Skin Sewers, started during the war to supply fur clothing to the Air Force and other Services. In 1945 , it sold $\$ 35,504$ worth of clothing; in 1946 , $\$ 32,081$ worth. By individual sale to traders and tourists and by sale through the Arts and Crafts Clearing House, run by the A.N.S. as a merchandising organization, Eskimos sell their ivory carvings, baskets, dolls, and a few other craft products. Although it is difficult to judge the volume or value of this trade, it probably is worth at least $\$ 100,000$. This amount seems large, but even $\$ 200,000$ a year would provide only $\$ 50-\$ 60$ per family per year. And craft work never is well distributed, as only a 
few people are really skilled and also have access to the necessary materials.

Not every village that has a school has a resident missionary. Such missionaries as the Moravians along the Kuskokwim River and the Roman Catholics at Hooper Bay and on the lower Yukon travel to visit outlying settlements as few secular teachers do. A.N.S. teachers generally have undertaken more community functions than the Territorial teachers, who until recently have been in the towns and not in the relatively isolated, wholly Eskimo villages. Even so, the typical teacher or missionary does not travel to the Eskimos' outyling settlements, except perhaps for one quick trip a year. Field nurses travel much more.

Although widely scattered Eskimos are subject to the same influences by Whites from the United States and although they themselves travel widely in west Alaska and thus influence each other, still one cannot give a generalized description of an Eskimo village much more easily now than one could a hundred years ago. Regarding the houses, for example, one cannot say much more than that they generally are makeshift wooden structures incorporating any other handy materials: sods, corrugated iron, whale bones, or walrus hide. Most homes are heated by stoves-often home-made-burning coal, fuel oil or wood. On the trail, Primus stoves are used. Even poor homes have an alarm clock, a modern oil lamp, enamel-ware kitchen utensils, crockery, hand-turned sewing machine, flashlight and similar utilitarian articles. Many homes in a village like Unalakleet are well furnished at the level of a comfortable village or farm home on the Northern Plains. (For greater detail, see "Acculturation of Alaskan Eskimos," which will be published in the Encyclopedia Arctica, V. Stefansson, editor.)

In the post-war years, housing has been a serious problem not only for Whites in the rapidly-growing Railbelt but also for Eskimos. In 1949, the Alaska Housing Authority, as a trial, granted loans to rebuild 42 houses at Hooper Bay. The householder was loaned not more than $\$ 500$, to be repaid within six years. In 1950, six Eskimo villages on the Bering Sea coast benefited by 91 completely new homes and improvements 
for 79. In 1949, the Navy and Alaska Native Service housing program at Barrow was completed. Total cost: $\$ 170,000$. It comprised 75 new houses, 49 repaired houses, and 31 additions to houses.

With the vigorous health program under way for Eskimos and others (orthopedic hospital, new 4oo-bed TB hospital, widespread immunization, chest X-rays, etc.) and the Housing Authority's housing program, many sections of the rest coast of Alaska do not have the neglected, slowly deteriorating look that they had ten years ago. The basic problem that has not been approached in similarly comprehensive fashion is the future of the economy of west Alaska.

Most Alaskan Eskimos still do much hunting and fishing for home-consumed food and clothing. The most nearly universal source of cash income is trapping. Income varies greatly from time to time and place to place as the animal populations vary and as fur styles change. In the lower Kuskokwim area, more than $\$ 100,000$ worth of muskrat skins may be taken in one trapping season now that muskrat is in demand. Not far away, Nunivak Islanders, who have fox and a few mink but no muskrat, have none of this prosperity. On the other hand, they have reindeer. Another widely distributed, although not so remunerative, type of income is the Territorial bounty on eagles, hair seals, wolves, and coyotes. Total appropriation for bounties for the biennium beginning 1951: about \$200,000. Much of the hair-seal bounty will be collected by other races than Eskimo, around the south coasts of Alaska where seals are considered foes of the commercial fishing industry.

Other income sources are more localized. There is, for example, a good deal of seasonal lighterage employment at Nome, Kotzebue, Barrow; coal mining on Meade River; gold mining on Seward Peninsula and elsewhere; ivory carving by not only the famous King Islanders but other Bering Strait groups; jade mining in the Shungnak area; reindeer herding by a few families from ten or twelve villages (elsewhere deer are herded only for roundup); and cannery work for men from many villages of southwest Alaska, many of whom are transported by air to 
Prince William Sound and other localities. Around Bristol Bay, men of Eskimo or mixed-Eskimo ancestry but not now living an Eskimo way of life are commercial fishermen. On the whole, the economy is haphazard and poorly balanced. At present, Alaskan Eskimos can get real stability and security only from their hunting and fishing and, in many places, trapping.

For this reason, some people in the States say Eskimos must have land reservations, However, 1) much of their food comes from the sea, which cannot be reserved, 2) the large sustaining caribou herds cannot be held on reservations, 3) it does no good to have a piece of territory if the food or revenue-producing animals are dying out, as they are in some localities. The longrange probabilities of Alaskan development should be considered, and these do not seem to include reservations. Although there are a few small reservations in the Eskimo country (Unalakleet, Wales, Little Diomede Island, Noorvik, Elim, White Mountain, and Mountain Village) and a few reindeer and fishing reserves, the whole U.S. system of treaties, reservations, and allotments was not introduced to Alaska. Eskimos must be considered part of the general population. Where they are treated as a curiosity for tourists, for example at Nome and Kotzebue, they are not helped but are hindered in adjustment to the present condition of Alaska.

If we understand the principal changes occurring in Eskimo culture and the needs that these changes engender, we can see which aspects of Eskimo life need to be studied and in what ways Cultural Anthropology can be useful.

Now that the Eskimos have entered a money economy, they need what all Alaska needs: a stable year-round livelihood. Agriculture, especially the growing of field crops, is not the future hope of the west and north coasts of Alaska. Garden produce grows well in some localities, and range livestock, especially reindeer, might be developed, but these show no prospect of becoming the basis of a whole economy. Reindeer, for example, can be, under present conditions, the chief support of only a few families in each of twenty to twenty-five villages. At one time or another, sheep have been important in Greenland 
and cattle and sheep in Scandinavia, but the mines, manufactures and fisheries of Sweden and Norway can support a growing population far better than their agriculture, and the same is true of Alaska.

A non-agricultural region can be economically useful in three ways: production of raw materials, which, exclusive of agriculture and fishing, are minerals, oil, and timber; processing and manufacturing; and provision of services, including trade. (Military use requires locally principally the service trades, especially when materials and construction labor are imported.) To now, northern and western Alaska has drawn workers from outside only when the first of these, production of such raw materials as whale-oil and gold, has boomed. These activities offered employment to the indigenous people chiefly in the services, for example as dog-team drivers and guides, and in semi-skilled labor in a combination of service and small-scale manufacture, for example as ship's carpenters and deckhands in the great days of steam-boating on the Yukon and, earlier, on the whaling ships. Production in northwest Alaska-which, aside from the reindeer industry, has been entirely a natural-resource use-has been periodic and undependable, poorly organized, and scarcely planned at all. The only type of production in which the Eskimos have operated largely and fairly steadily has been trapping. In a more restricted area, Eskimos have produced ivory for ornaments and knick-knacks. (Since Bristol Bay Eskimos for two generations or more have been so mixed with Indians and others that they can be scarcely recognized as an Eskimo population, their commercial fishing is not included in the above generalization.)

The type of industry that can stabilize Alaskan economy is a varied manufacturing and processing. Along the Railbelt (Anchorage to Fairbanks and environs) this is getting its first small but solid start, although it has been the basis of Southeast Alaskan economy for sixty years, viz. in the seafood-canning industry. If wood pulp processing can be extended beyond its present beginning at Ketchikan, it can provide a new basic industry for the whole Southeast area. So far, these developments have af- 
fected the Eskimo economy relatively little. The $195^{\circ}$ Census shows the following percentage increase in population in the preceding ten years:

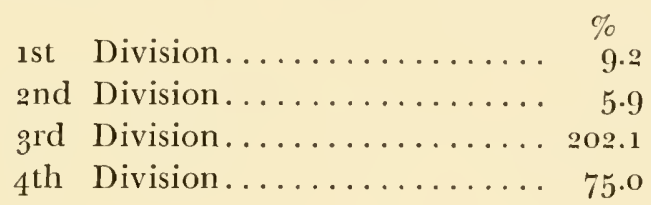

These figures do not include military personnel assigned to Alaska. In the 3 rd Division is the Anchorage-Matanuska-Kenai development. In the $4^{\text {th }}$ Division is the Fairbanks metropolitan development. The and Dirision, which has the highest proportion of natives $-86 \%$ of the total population according to the 1940 Census-has shown the smallest increase. Most of the Eskimos live in this 2nd Division. The 3 rd and 4 th have boomed largely on military construction and the servicing of military establishments, it is true, but not solely on these, fortunately. With their agriculture, tourist business, and other developments, a genuine beginning of a broad and balanced economy has been made. Otherwise, such an influx of people would look like just another stampede, with an impending collapse.

The economy of Alaska has been based until recently almost exclusively on exploitation of natural resources: fur-bearing and oil-bearing animals, fish, minerals, and, to a very small extent, timber. With the exception of fish, virtually all products were shipped out unprocessed. Furs, for example, were not tanned, dyed, glazed, and mounted in Alaska. After the end of the whaling industry, there was not even the rendering of whale oil. Since Alaskan economy is getting its new start by means of a construction boom and will have many construction needs for a long time, as any rapidly developing area does, the first requirement is for 1) local processing plants to provide construction materials, 2) power to run the plants and run the transportation, and 3) development of local skilled labor. In 1949, for example, the first plant in Alaska to produce oxygen and acetylene started operating, similarly the first plant to produce bulk cement, both in the Railbelt. These do the Eskimos no direct 
good, but indirectly these and similar developments provide jobs. It is in the opportunity to supply skilled and semi-skilled labor that Eskimos have the best chance to be integrated into a growing and changing culture.

The Eskimos have been threatened with the fate of other ethnic minorities from unindustrialized areas who were quickly absorbed into a modern economy, for example Negro domestic servants and field labor in the United States, Negro mine labor in South Africa, plantation labor in New Guinea, Mexican field labor in the U.S., and Hindu servants for the British in India. Some of these have moved on into trade and skilled labor. Others have been held static, except that their dissatisfaction has increased. To keep from becoming handy-men, dishwashers, and unskilled laborers around the airfields and on the construction projects, Eskimos need technical training. The apprenticetraining program of the U. S. Department of Labor is being extended to Alaska now for the first time. Eskimos should be fully incorporated into this program, as they have a good background for technical work and constitute a very valuable labor resource, already adapted to the country.

In south and southeast Alaska, power can come from hydroelectric plants. In the summer of $195^{\circ}$, a \$20,000,ooo hydroelectric plant was authorized for the Anchorage area, to have a capacity of 30,000 kilowatts. This will increase Alaska's total non-military generating capacity by $40 \%$ or more. The Federal Power Commission has estimated that Alaska will use in 1960 nearly seven times as much electric power as in 1947 when a survey was made. Expansion of power production and of transportation indirectly creates many jobs. The local people should not be ignored and submerged by a wave of immigrants from the States, immigrants who settle down and become year-round competitors for jobs, unlike the men who work gold dredges in the summer and live in Seattle in the winter. (Some men from the dredges do become trappers or move to Fairbanks in the winter.)

For northwest Alaska, the most promising source of heat and power is coal. Among minerals, coal production was second 
only to gold in 1949 in value of product. Coal production reached a new peak that year: 440,000 tons. Coal has been produced in three new locations in $195^{\circ}$ although total production has decreased slightly. Cost of transportation from the Meade River mine in the Barrow area, the principal mine in northwest Alaska, makes the coal expensive. The Eskimos now need encouragement in locating and mining coal in more accessible places. In $195^{1}$, a coal analysis laboratory will be opened at the University of Alaska, to help the growing industry. If Eskimos can develop this industry themselves on a seasonal basis, they can avoid becoming the Arctic equivalent of South African mine labor.

Oil-drilling by the Navy near Pt. Barrow has produced the only boom in Eskimo territory since the gold rush, but even though this project is extended beyond $195^{1}$, it is not a reliable basis for a regional economy. Several base metals are currently needed and priced high (copper, lead, zinc, tin, antimony, mercury, tungsten, and especially uranium minerals which are found in the Haycock area in Seward Peninsula) but until recently did not receive a high enough price to justify mining, apparently. Although the defense production demand may encourage more mining-Seward Peninsula Eskimos are most likely to be affected since some of them already are miners-still nothing looks so promising for a long-term development as the mining and transportation of coal. Even better is the development of a range of skills so that the people can change and adapt if future technological changes or depletion of natural resources end some of the local industries.

Talk of development of such industries does not presuppose that Eskimos will entirely abandon hunting and fishing. As pointed out in "Wildlife in the Economy of Alaska Natives," a paper given at the 16 th North American Wildlife Conference, March 1951, native families may continue to depend on wildlife resources for much of their food and clothing, using cash income for such things as boats and fuel oil, ammunition and hardware. Most Alaskan Eskimos are in a far better situation than the Aleuts or the Athabascan Indians of the Interior, nei- 
ther of whom have sufficient natural resources of the types needed for modern industry. For example, when the sea-otter disappeared and later the longhaired furs went out of style, the Aleut economy collapsed. Furthermore, the Aleuts could not return to enough of the old hunting and fishing complex to provide even an adequate diet, because they had lost both knowledge of the old techniques and satisfaction in using what skills they did have. Tuberculosis and undernourishment have nearly completed the destruction of a formerly numerous and capable people.

If people understand the Eskimos' experience and interests, which stress mechanical ingenuity, they can help them adapt to the new occupations and can aclapt the occupations to local manpower. Besides raw-material resources and local transportation, we must take account of and use well the local human resources: aptitudes, skills, social organization, and morale. The alternative is a dependent people, whom all of us will have to support. Already, chiefly because north Alaska "just grew," the largest native case-loads of Social Security (Old Age Assistance, Aid to Dependent Children, etc.) are in the 2nd Division (Eskimos) and the $4^{\text {th }}$ Division (Athabascans).

Eskimos, more than most Indians, were mechanically-oriented before the Whites came. They are a friendly, observant, adaptable people who imitate new ways freely, admire ingenuity and self-reliance, and are moderately competitive. Present difficulties appear most seriously in personal relations and socioeconomic organization. There has been in many areas a loss of individual morale and integrity, a break-up of families, and community disorganization. We already understand some of the causes of the growing dependency of Eskimos, but they need more intensive study immediately to see just what has gone wrong in many Eskimo villages. The explanation cannot be merely economic exploitation and lack of subsistence (although that has occurred at times), since there still are enough game animals and fish in most Eskimo territory, if the people are interested in hunting them. It is not merely liquor. Something went wrong in the individual before he took to drinking 
heavily and became an habitué of the Nome jail. It is not only tuberculosis and other diseases, although these are important.

We must consider the more subtle factors of prestige, leadership, opportunity for social advance, and economic self-direction. If Eskimos were sufficiently advanced to take advantage of new techniques when given reasonable opportunity-which they have done-then they probably were too advanced to be treated as child-like dependents. We must try to see realistically how Eskimos and Whites have reacted to each other, and how they can work together in a society that, despite its remote location and scattered population, is becoming surprisingly urban and industrial in its standards, attitudes, and outlook for the future, no matter what are the present physical conditions of living.

Now let us see what ethnological and social anthropological information is available on Alaskan Eskimos.

Alaska's west coast seems to have had a longer history of Eskimo culture, a much higher development of this culture (in social organization, art, ceremonial, and probably other aspects), a denser Eskimo population, and a greater amount of local variation than any other region in the whole Eskimo domain. It should have attracted many students, but did not. After, let us say, 1880 it was not nearly so difficult to reach as the Victoria Island region north of Canada. In fact a large fleet of whaling ships was going there regularly 25 years before 1880 . It was not an alien country. Bering Sea and even much of the Arctic coast north of Seward Peninsula were not so cold and barren as the Canadian Arctic archipelago. Yet scientific monographs on Alaskan Eskimo culture, including language, published between 1880 and $193^{\circ}$ can be counted on fewer than ten fingers. Perhaps someone like Sir John Franklin should have got lost. People going to Alaska to find him might incidentally have found-scientifically-the Eskimos. Or, better still, they might have undertaken a scientific program such as the Danes visualized and supported for Greenland, and as we are doing here at last.

In the next twenty years, Frederica deLaguna, Henry Collins, 
Froelich Rainey, Helge Larsen, Louis Giddings, and a very few others began to present not only masses of personally gathered field data but also organization and analysis of scattered material from earlier observers, and finally basic interpretation. As of $195^{\circ}$, the record is spotty. Only one full modern linguistic study has been undertaken, by Prof. L. L. Hammerich on Nunivak Island, but not yet published. Thorough and extensive archaeology has been done at Pt. Hope, on St. Lawrence Island, in caves on Seward Peninsula, at Cape Denbigh and in a more limited way at Bristol Bay and Cook Inlet. Archaeological reconnaissance has been done more widely, especially along rivers and where gold-dredging has revealed ancient artifacts. Although archaeology lias been started elsewhere, there still are great areas, along the Kuskokwim River and between the Kuskokwim and Yukon deltas for example, that are rich in sites but entirely uninvestigated. In any case, although archaeology gives important culture history, it does not tell much about the present situation of the Eskimos.

The most massive ethnography to date is E. W. Nelson's description of his journeys, collections, and observations in the years around 1880 . He covered the lower Yukon and the coast northward around Norton Sound toward but not so far as Bering Strait. By piecing together missionaries' accounts, some good but never comprehensive modern ethnographic papers, government reports, and miscellaneous notes, one can get the principal elements of the culture of the larger Eskimo groups 1) from Barrow to Kotzebue and the Kobuk Valley, 2) Cape Prince of Wales and the Bering Strait islands. 3) the Yukon Delta, and 4) Nunivak Island. For other localities, we have only bits and pieces. Even in most of the larger works, material culture and graphic arts are stressed to the virtual exclusion of social organization. Religion and folklore have received some attention but not the more individual psychological aspects of culture, especially outside mythology and belief. The explanation for anthropologists' almost complete disregard of social structure and their concentration on technology may be due to their own needs. They needed and appreciated Eskimo technics in order 
to travel and work in the Arctic. Also, Eskimo material culture was so beautifully adapted to the environment, so functional and artistic that it became an ethnographic showpiece. On Eskimo social relationships, the anthropologist did not have so much to show off to his colleagues. Now we are perhaps more sophisticated and ready to look at the remainder of Eskimo culture.

One full study of acculturation has been undertaken, by Dorothy Thompson at Nome; and M. Lantis has started studies in government administration for Eskimo welfare and in relations of Eskimo culture and personality. Yet again, in these fields little has been published. Two non-anthropologists, Anderson and Eells, in the 1930's published a large socio-economic survey of west Alaska; and teachers, physicians, and missionaries have described their villages.

On the whole, the fullest and best work has been done in prehistory. The product of this work is so rich and exciting that anthropologists should be stimulated to see what they can learn about modern Eskimos as well as their ancestors. Certainly the need is immediate and serious. 


\title{
PRESERVATION OF ARCHAEOLOGICAL AND ETHNOLOGICAL MATERIAL IN ALASKA
}

FrEDERICA DE LAGUNA

\author{
Associate Professor of Anthropology \\ Bryn Mawr College \\ Bryn Mawr, Pa.
}

In discussing the problems of preserving archaeological sites in Alaska and of recording native folklore, songs, ceremonies and other ethnographic material, we must keep in mind that the archaeological or ethnological situation varies enormously as we go from region to region in the vast Territory, so that no single formula can be applied, and we must take into account differences in natural environment, in the character of the aboriginal populations, and in the ways in which the white man has affected them. We must also recognize a diversity, even a conflict of interests between groups who might be affected by any plans for anthropological conservation.

"An Act for the Preservation of American Antiquities," approved by Congress June 8, 1906, prohibits, under penalties ranging up to fines of $\$ 500$ and 90 days imprisonment, the excavation, injury, or destruction of historic or prehistoric sites and objects, on lands owned or controlled by the Federal Government. It permits the President of the United States to establish by proclamation as national monuments tracts of land on which such objects or sites are located. It provides also for the granting of permits for excavation to scientific and educational institutions. The Secretaries of the Interior, of Agriculture, and of War are charged with the responsibilities of issuing such permits and of establishing uniform rules and regulations for carrying out the provisions of the act on lands subject to their jurisdiction. These uniform rules were approved on December 28, 19o6, and still apply to the Territory of Alaska, although the Interior Department has recently added a few special rules, which we shall mention presently. With the re- 
organization of the armed forces it may be desirable to have responsibility transferred from the Secretary of War to the Secretary of Defence, since this would provide for legal protection of sites within Army, Navy, and Air Force reservations. However, the legal picture will again be changed if Alaska becomes a state. Presumably the National Forests of southeastern and southwestern Alaska would still remain under the control of the Forest Service (Agriculture), and the few National Monuments be under the care of the Park Service (Interior). As we know, the few native reservations are threatened by the present statehood bills, but even were they preserved, the bulk of the Territory, and precisely those areas where archaeological sites are in most serious jeopardy, would pass from Federal jurisdiction to that of the new State. In that event, state legislation would liave to be devised to care for what had been public lands.

However, we know that the Antiquities Act has not been enforced, and may be unenforceable. It is even unknorn to the bulk of residents in and visitors to the Territory. Paradoxically, it is only professional archaeologists who are likely to fall afoul of the law, through some inadvertent failure to conform to the detailed regulations, since it is only those who apply for permits who come to the attention of the agents of the government. To patrol and protect Alaska's sites against the depredations of unauthorized diggers, would require a far larger personnel than the Federal agencies now responsible can supply, and might demand a greater indifference to popular local feeling than we can expect of law enforcement officers who need public support for the effective performance of more urgent duties.

Actually it is only the site which is still unknown that is completely safe. The dense forests of southeastern and parts of central and southwestern Alaska, inaccessibility, or poverty of spectacular material are still the best protection for archacological remains. On the whole we need not be too concerned with the destruction of sites in the panhandle and interior of Alaska, except possibly in the vicinity of the larger towns. But it would certainly do no harm if all members of the Forest, and Fish and Wildlife Services and the Geological Survey were reminded to 
be alert for possible vandalism. Field personnel might be furnished with light weight signs, to post at known sites within their territories, to warn against vandalism. The public could be made aware of the provisions of the Antiquities Act and its importance through notices in all territorial Post Offices.

It is the large rich sites near military establishments on the one hand, and those on the Eskimo coast on the other which are in the gravest danger, and many of these have already been gutted or destroyed. These are sites on Kodiak, the Aleutian Islands, and on the shores of Bering Sea and the Arctic Ocean. During the war, a number of important shell heaps were wholly or partially destroyed in the course of military construction, and their loss we can mourn as one of the minor sacrifices demanded by the war. However, further damage was and is still being done by the men stationed at military bases, and by the civilian employees of construction companies at these bases. These men regard digging for curios as something to do in their leisure time. It is not only permitted by the commanding officers, but in some instances has even been encouraged as an antidote to boredom and lomesickness. Surely other solutions to the problem of morale might be found, even though commanding officers might be loath to prohibit what to them may seem a harmless Sunday afternoon amusement! It might, we must admit, sometimes be difficult to make such a prohibition effective, for the demand for curios would create a lucrative black market for objects dug up by the natives.

The second serious source of damage is from the Eskimos, for whom the great archaeological sites in their country are literally mines of fossil ivory, and this they indiscriminately dig up for its commercial value. In the past, certainly, archaeological collections have even been purchased from the natives by museums and this has also encouraged their activities. In some villages and for some Eskimos the sale of ivory carvings represents the only or the major source of cash income, and the dark colored fossil ivory fetches a higher price than does the white ivory of newly slain walruses. Before the Russians closed the borders of Siberia, East Cape was one of the main sources of 
fossil ivory, but at present the sites on the American side, for example, on St. Lawrence and the Diomede Islands, are the only places where it can be obtained, and the destruction of some of these sites is virtually complete. An attempt to prohibit all digging by the Eskimos would be useless, and would result simply in inflated prices and poaching.

Even though the preservation of scientific data is desirable, we must recognize that the Eskimos feel that they have a claim to exploit the garbage heaps of their ancestors. The sale of carvings, including those of fossil ivory, has been encouraged by the Indian Arts and Crafts Board, and the Eskimos' interests in fossil ivory protected by the special regulations attached to permits granted by the Interior Department to archacologists. Thus: "All materials found shall be deposited in the - - - Museum, with the exception of unworked ivory, fossil or more recent, together with such complete, partially worked, damaged and broken artifacts of fossil or more recently worked ivory which the Museum does not require for scientific study or display. The material that is not to be retained by the Museum shall be disposed of under agreement with the village concerned, such agreement to be subject to review by the Superintendent of the Alaskan Native Service." Unfortunately there is not enough authorized archaeological work being conducted in Alaska to supply the native carvers with such ivory, and because ivory is traded from hand to hand among the Eskimos it is impossible to know the source of any piece, so that it would in any case be impossible for the Indian Arts and Crafts Board or others to purchase only the carvings made from ivory obtained from archaeologists.

What then can we suggest that might be effective and fair? First, all Federal and Territorial officials should be made acquainted with the Antiquities Act and should be asked to report violators. This might lessen depredations, some of which are unfortunately committed by these officials, but we must not expect that school teachers in isolated villages will always place law enforcement above their need for maintaining friendly relations with local residents, fellow workers, or visiting superi- 
ors. Dr. Laughlin, whose knowledge of the Aleutians is extensive, has suggested that the assistance of the Coast Guard be enlisted. Since their vessels visit many of the isolated settlements on the Aleutians and along the shores of Bering Sea, they could keep an eye on some of the important sites without too much difficulty, and the knowledge of their vigilance would act as a salutary deterrent. Certainly the commanding officers at military establishments should be made arvare of the Antiquities Act and of their responsibilities in preventing its violation by their men and by the civilian employees at their bases. It is possible, however, that an amendment of the Act might be necessary to secure effective action by officers of the Coast Guard, the Air Force and the Navy. The interests of the Eskimos might advantageously be recognized by adopting a procedure followed in Denmark, that is, of exempting from the provisions of the law some sites, already so damaged that they possess little or no scientific value, and officially opening these for native exploitation of fossil ivory. In addition, a new source of income should be encouraged to take the place of work in ivory, such as the making of wooden toys or artistic carving of slate. Where actual construction work threatens to destroy archaeological remains it is surely the duty of the government agencies responsible for the construction to make every effort to salvage as much data as possible, although we realize that military urgency even in peacetime may not give sufficient time and there may be no funds to secure the services of an archaeologist. Still, the principle ought to be recognized.

Lastly, we should not suppose that all damage has been due to violation of the law. There have been a number of unfortunate cases in which permits to excavate have been granted to institutions which sponsored the activities of men who posed as archaeologists but who lacked the training and sense of responsibility of the profession, or to institutions that sent out expeditions that did some archaeological collecting on the side without having even a nominal archaeologist in the party, though the members might be qualified scientists in other fields. 
The accelerated rate with which the aboriginal native cultures are being transformed before our eyes makes the preservation of ethnographic and linguistic material a problem to be solved within the next ten-no, five-years, or to many tribes and communities the ethnographer will come too late, for the knowledge of ceremonial ways no longer practiced, of songs and stories no longer repeated, of beliefs and attitudes no longer honored, will die with a few old men and women, now in their seventies and eighties. The need for salvaging this information is most acute in those communities where the old socio-economic order has been disrupted by the introduction of the white man's money economy (by commercial fishing or by construction projects), where demoralization has resulted from the presence of military establishments, or where school and church have been successful in educating and reorienting the natives towards the new world.

These critical areas embrace all of southeastern Alaska, which includes the northern outposts of Haida and Tsimshian, all of the Tlingit peoples, and the few surviving Eyak. Dr. Garfield has outlined the situation here and has stressed the need for coordinated and integrated studies. On the basis of my own more limited experience in this area, I can only urge the importance of research which will take account of local differences among the heterogeneous Tlingit, and rould place a high priority on studies of Eyak linguistics and social organization.

The second area includes the Eskimos of Prince William Sound and Kenai Peninsula, the Athabaskans of Cook Inlet, the Eskimos of Kodiak Island and the Aleut. The informants among the first-mentioned mainland groups who contributed to the pioneer ethnographic studies made fifteen to twenty years ago are dead and we do not know what opportunities are still left for research, although many important questions remain unanswered. Dr. Laughlin reports a still fertile field in Kodiak. He has for some time been conducting coordinated researches in Aleut ethnology, linguistics, physical anthropology and archaeology. Here the most critical community is Atka, where deculteration is affecting not only the local natives but the Attu 
people transplanted among them. Valuable material can still be gathered also at Belkovski and on the Pribiloffs.

Dr. Lantis has given a vivid picture of the situation among the more northern Eskimo, and this has also been discussed with Drs. Rainey and Giddings. Aside from Point Barrow, where present Naval construction cannot but produce profound changes, the most acculurated communities are those which have grown up as artificial aggregations of formerly separate, more mobile groups about some mission, school or trading center. Here, the lack of an integrated community organization and of cultural patterns adjusted to year-round settled life have contributed to a breakdown of the old culture. As examples, we can name Deering, Teller, Nome, Golofnin, Shaktolik, Elim, Unalakleet, Hooper Bay and Nunivak. Most of these lie within the relatively little studied Bering Sea area.

I cannot report on the situation in the interior, except to mention that already fifteen years ago deculturation and demoralization of the Athabaskans was progressing rapidly. Despite valuable pioneer studies in some areas, chiefly on the $\mathrm{Yu}$ kon, how little we know about the cultural and linguistic differences upon which tribal classifications have been sketched, or about the language, folklore, social organization of the peoples of the Copper River, Tanana, Middle Yukon, or Kuskokwim!

Each of these four major areas presents its own peculiar problems for fieldwork, not simply theoretical but practical problems, and furthermore each settlement poses its own version of these problems. Effective salvaging of records of native life involves the formulation of at least four areal programs, and for some of these areas such plans cannot be drawn up now without preliminary surveys. These should consider for each area what are the possibilities in the various villages; who are the best informants and what they can offer; what cooperation or opposition can be expected from native leaders, native or white missionaries, teachers, and other personalities; what are the attitudes towards the ethnologist or linguist; what time of year is best for fieldwork; is electric power available for wire- 
recorders or photo-flood lights and would these be tolerated; how does one travel, where can one live, what equipment is necessary; and lastly, how much money is needed for the job. Can such fieldwork be entrusted to relatively inexperienced students, or is the situation such that it demands the veteran? For we must emphasize that the acculurated communities generally require the most patient and tactful approach and often long or repeated visits before confidence is established. The question of small teams representing both sexes and different professional specialities versus the less disruptive visits of single workers can only be decided upon the basis of local knowledge. We should also consider the value of intensive studies at richer and less acculturated settlements as a balance to rapid and more superficial salvaging of data at other localities within the same tribal area.

In short we need one or two central clearing houses where information can be pooled, plans drawn, and work coordinated. The Arctic Institute of North America and the Burean of American Ethnology are obviously such centers and could render invaluable service in coordinating the research programs of private institutions and individuals. Time cannot be bought, but were the Congress to realize the urgency and importance of preserving the records of our native Alaskan heritage and make available Federal funds with which to establish firmly the new Arctic Institute and to strengthen and envigorate our worldhonored Bureau, they could help us to make full use of the little time that is left. 


\title{
PRESERVATION OF ARCHAEOLOGICAL REMAINS IN CANADA
}

\author{
Diamond Jenness
}

\author{
Former Chief, Division of Anthropology \\ National Museum of Canada
}

I have been asked to supplement Dr. de Laguna's paper by outlining the efforts that Canada has made to protect her Eskimo remains, and the success that has attended those efforts.

First of all, it is very important to remember that Canada's Arctic and sub-Arctic regions are not organized into self-governing provinces similar to Ontario and British Columbia, but are administered directly from Ottawa by the federal government itself. The head of the administration is a federal cabinet minister whose Deputy bears for this purpose the title "Commissioner of the North West Territories and Yukon." The Commissioner is assisted by a government-appointed Council, all of whose members were, until recently, senior civil servants, one a high-ranking officer of the Royal Canadian Mounted Police. Acting on the advice of this Council, the Commissioner issues ordinances for the regulation of trade, mining and other activities within the region, ordinances which the Royal Canadian Mounted Police then enforces through its numerous outposts. These ordinances have no validity outside the Arctic and sub-Arctic, because farther south the provinces control their own natural resources. They do not apply even to the Labrador Peninsula, because that region also is divided between two of the provinces, Quebec and Newfoundland. Although there are many Eskimo (and Indian) remains in the peninsula, neither of those provinces pays any attention to them. The federal government, however, has instituted a strict watch over the remains in the North West Territories, which fortunately contains by far the largest number. 
In the middle of the decade 1920-1930 I was greatly perturbed by the spoliation of Eskimo ruins in the Hudson Bay region, not by white persons so much as by the Eskimos themselves, who were finding a profitable and growing market among traders, missionaries, and the handful of tourists who travelled on the ressels that carried supplies each summer to the posts of the two trading companies then operating in the region, Revillon Freres and the Hudson's Bay Company. In one year, it was reported to me, 14 boxes of archaeological specimens were collected and shipped from two islands alone, Coats and Mansell, just inside the entrance to Hudson Bay. Now it so happened that during this same period an archaeological committee appointed by the old League of Nations had drawn up a series of regulations for the protection of archaeological remains, and the League was recommending their adoption by its various member nations. The eyes of the committee, it is true, had been focussed largely on the Mediterranean area, and its regulations were especially designed for countries like Greece and Egypt. However, with minor modifications, they seemed applicable to Canada also; and I therefore recommended their adoption by the Canadian government. Thus came into being Canada's "Ordinance Respecting the Care and Protection of Archaeological Sites in the North West Territories," an ordinance whose wording has been altered a little since it was first promulgated twenty odd years ago, but whose substance has remained practically unchanged. It represents an attempt to protect all archaeological, and historical, remains throughout northern Canada from its Arctic Alaskan boundary to Hudson Bay; but being a federal government ordinance, it offers no protection, as I have already stated, to Eskimo and Indian remains in the Labrador Peninsula.

I will not read the whole ordinance. Its meat is contained in five sections, $3,12,13,14$, and 16 . Section 3 reads;

No person shall excavate or investigate any archaeological site in the Territories or export from the Territories or collect any archaeological specimens unless he is the holder of a permit. 
Section 12:

(1) At the close of each season's field work, every holder of a permit shall furnish, in duplicate, to the Commissioner a report on the work performed.

(2) A report under subsection one shall contain

(a) full detaits of the work performed including details of any stratification or other chronological evidence encountered;

(b) a descriptive catalogue of all specimens collected;

(c) copies of all photographs taken, land maps and plans made in connection with the work, together with explanatory notes; and

(d) such other information as the Commissioner may prescribe.

Section 13:

Any archaeological specimen that is taken

(a) by a person who is not the holder of a permit, or

(b) by a person contrary to this Ordinance or the regulations or the terms of a permit

may be seized by a person authorized by the Commissioner to seize such specimens and may be disposed of as the Commissioner thinks fit.

\section{Section 14:}

(1) All archaeological specimens collected by the holder of a permit shall be submitted by him to the Commissioner for examination by the archaeological officers of the Government of Canada.

(2) The Commissioner may direct that any specimens submitted under subsection one be turned over to the National Museun of Canada or Public Archives of Canada, and, upon such direction being made, the specimens so directed become the property of His Majesty.

(3) Where specimens are not directed to be turned over to the National Museum of Canada or Public Archives of Canada, the Commissioner may return such specimens to the holder of the permit on condition that the holder undertakes to deposit them permanently in some public institution where 
they will be available for study or the Commissioner may otherwise dispose of them as he thinks fit.

(4) The Commissioner may allow the holder of a permit to retain the specimens collected under a permit during such period as the Commissioner may approve for the purposes of preparing a scientific report before they are submitted for examination and disposal under this section.

And, finally, Section 16:

A person who violates the provisions of this Ordinance or the regulations is guilty of an offence and is liable on summary conviction to a fine not exceeding one thousand dollars or to imprisonment for a term not exceeding six months or to both fine and imprisonment.

Just as important as the wording of any ordinance is the spirit that actuates it, and the manner in which it is administered. I need hardly state that the Canadian government has never wished to discourage archaeological work in any way, but only to ensure that it is carried out scientifically and the specimens preserved where they can be examined by other archaeologists. Foreigners are as welcome to dig in its northern territories as Canadians, but both alike must be accredited by recognized museums or other scientific organizations. Up until 1941, when I was detached from the National Museum of Canada for war work, the North West Territories administration used to consult me whenever it had any doubt about a man's credentials. At the present time it seeks the advice of Dr. Alcock, the Curator of the National Museum.

Some of you may regard as unnecessarily severe those clauses of the ordinance that require every investigator to present a detailed report of his discoveries to the Canadian government at the end of each field season and to submit for its examination all his specimens. In actual practice, however, they have operated quite smoothly and created little or no vexation, apart from one or two exceptional cases. The administration, understanding that it takes an archaeologist months and sometimes years to digest his material and prepare a full report, has been 
satisfied with only a general outline of his field work and discoveries, an outline such as might be given to Science or the Journal of American Archaeology. No genuine scientist will ever object to submitting a preliminary report of this nature, especially since without it the Canadian government could not maintain an adequate record of archaeological work within its Arctic.

More debatable than the clause requiring the presentation of a report are those dealing with the examination and disposition of the specimens. When first laid down this regulation had in view two purposes: first, to check the peddling for sale of archaeological specimens and to ensure their preservation in a public institution; and, second, to retain within Canada, if possible, objects of exceptional scientific or historical value-or at least replicas of those objects. The authorities had no intention of adopting a dog-in-the-manger policy, of letting any ultranationalism run away with them. On the contrary, they hoped by these clauses to encourage closer cooperation among Canadian and foreign archaeologists, recognizing that the scientist who is sponsored by a reputable institution works for the benefit of every one. In interpreting the clauses, therefore, they have tried to exercise tact and common sense, to follow the spirit of the ordinance rather than its literal wording. My impression is that they have succeeded very well, on the whole, and I think Dr. Collins and others will agree with me.

The penalties laid down for infringement of the ordinance are certainly severe-a fine of up to $\$ 1000$ and (or) imprisonment up to six months. As far as I am aware, these penalties have never been imposed, nor has any charge of infringement been actually carried to the law courts. Yet the liability to such penalties has certainly been a powerful deterrent to unauthorized excavations. One still hears, occasionally, of an ancient house ruin being dug into by a casual curio hunter, nearly always an Eskimo; but the wholesale destruction of archaeological sites that seemed to be impending a quarter of a century ago has been definitely averted.

The history of your own Antiquities Act has shown that it is 
futile to threaten a lawbreaker with penalties unless you have the force to back up your threats and are prepared to use it. The force behind the Canadian archaeological ordinance is the Royal Canadian Mounted Police, which has established its outposts far and wide throughout the Arctic. The men who have manned these outposts have been-until recently at least-handpicked individuals, adventure-loving and ambitious, who have found in the northland their readiest avenue to rapid promotion. Their duties are many and varied; but since the population of the territory is very small-only about half that of northern Alaska-they have little difficulty in keeping close watch on the movements and activities of every person within the boundaries of the Canadian Arctic.

Alaska lacks this close supervision by a federal police, and the strict enforcement of its Antiquities Act has proved quite impossible. I have sometimes wondered, therefore, whether it would be possible (and profitable) to enlist the help of the educational authorities, and to circulate among Alaskan Eskimo schools a small brochure outlining what we have already learned about the archaeology of northern Alaska, explaining that only the most painstaking excavations under skilled direction can throw any further light on Eskimo prehistory, and asking the Eskimos themselves to cooperate in protecting the sites that still remain undamaged. It would be helpful, also, if the same or a similar brochure, strengthened by a foreword from some high military official, were circulated among Alaskan military establishments, and would-be archaeologists in those establishments recommended to write to the University of Alaska or the Smithsonian Institution for advice and guidance. 


\title{
CONTEMPORARY PROBLEMS IN THE ANTHROPOLOGY OF SOUTHERN ALASKA
}

W. S. Laughlin

\author{
Assistant Professor of Anthropology \\ University of Oregon
}

Consideration of the anthropological problems of the Aleutian Islands and of southern Alaska can best be approached with the realization that much evidence acquired in the last few years suggests an early homeland for the Eskimos in southwestern Alaska. The linguistic and archeological evidence in particular point to over 4,000 years of Eskimo occupation in this area. Similarly, population figures and ecological data clearly indicate that this area was a climax zone for the Eskimos. The rich natural resources, including many kinds of marine animals such as sea-lion, hair-seal, fur-seal, sea-otter, whale, and fish, in addition to land animals and birds, made possible the growth of a large population nowhere else attainable by the Eskimos or the Alaskan Indians. Large quantities of driftwood compensated for the absence of standing timber in the Aleutian area. Many shell fish and edible sea weeds on the reefs, together with a number of edible roots and land plants, enabled the survival of communities when other food supplies ran short. The presence of nearly a third of all Eskimos on the Pacific Ocean coasts--27,300 Aleut, Koniag, Chugach, and Ugalak, out of a total Eskimo population of 89,700 at the period of European contact-reflects not only the ecological wealth, but also indicates that this area was an important source for the elaboration and subsequent diffusion of many traits. WVe may therefore expect to find that some of the traits shared in common by Eskimos and Indians were diffused from the earlier and more populous Proto Aleut-Eskimo population. The early growth of relatively large communities has many implications with reference to the genetic stability of a large population. 
Equally important to the anthropological problems of soutlrern Alaska is the existence of rich archeological sites, stratified as the result of centuries of continuous occupation and containing large numbers of skeletons. Accessibility of many of the native speakers of the various languages enhances the possibility of ethnological and linguistic studies. Thus, this is not only a significant area but one which also affords excellent opportunities to all the disciplines of anthropology.

\section{LiNGUISTICS}

In the field of linguistics one of the most puzzling problems is the origin of the Aleut language and of the abrupt division between it and the other Eskimo languages. According to present linguistic studies the Eskimo linguistic stock is divided into three branches: Inupik, Yupik and Aleut. Inupik includes all those dialects from the nortliside of Norton Sound, around the north coast of Alaska and Canada to Greenland and Labrador. Yupik includes all those dialects spoken from the south side of Norton Sound, including East Cape of Siberia and St. Lawrence Island, down the west coast of Alaska and the south coast of Alaska to Cordova, including Kodiak Island. Aleut was spoken from roughly the 160 th meridian west longitude, which transects the Alaska Peninsula west of Kupreanof Point, and the Shumagin Islands, westward, including all the Aleutian Islands. Within each of these branches there are three to five dialects. Though the Inupik and Yupik branches are mutually intelligible, with some difficulty as originally noted by Knud Rasmussen, Yupik-Inupik and Aleut are not mutually intelligible. How and why this split came into being will throw much light upon the relationships of these southern Alaskan inhabitants. An index to the degree of this difference is provided by the positive correspondence of $36.5 \%$ of the words in a selected vocabulary of modern Eastern Aleut and Proto Eskimo, Proto Eskimo here referring to the period before the Yupik and Inupik split. From this percent of words held in common by these two divisions Marsh and Swadesh estimate that the separation of Aleut from Proto Aleut-Eskimo took 
place 4,ooo years ago. This division in itself indicates a much longer period of Eskimo occupation in southern Alaska than in any other area from Alaska to Greenland. The separation of Yupik and Inupik is provisionally estimated by Swadesh to have taken place some 1500 years ago.

Corollary to the problem of the Aleut-Eskimo separation is that of the dialect diversity in the Aleutian Islands. There are at present three major dialects. The Eastern dialect includes the Aleuts of the Alaska Peninsula, the Fox Islands as far west as Umnak Island, and the Pribilof Islands where the Aleuts were first transplanted in 1786 by the Russians. The Central dialect takes in the region of the Andreanof and Rat Islands. The Western dialect includes only the Near Islands. The differences between these dialects are primarily lexical, with minor variations in phonology and morphology. As a consequence they are mutually intelligible. The Western dialect, spoken by the people from Attu Island, now living in Atka Village, is most in need of study. Little is known of sub-dialects which exist within the area of each of the major dialects and for which evidence can still be secured from native speakers. Most Attu speakers now live on Copper Island and most Atka speakers on Bering Island of the Commander group where they

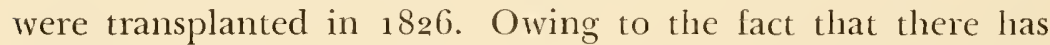
been less dialect mixture there, a study of them would be highly informative. Similarly, a study of Aleut on the Pribilof Islands would be useful though dialect mixture has gone on there for many years.

Linguistic information is not only of use for the study of language itself, and for the study of the cultures for which it is indispensable, but for the light which it throws on the past movements of the people. Thus, the linguistic evidence from the Aleutian Islands confirms the westward movements of the Aleuts which have been deduced from other forms of evidence. The earliest accounts of dialect divisions indicate the west side of Unalaska belonged to the same dialect as Umnak Island and that in the time of Bishop Veniaminov (1825-35) the Umnak people spoke the Central dialect rather than the Eastern dia- 


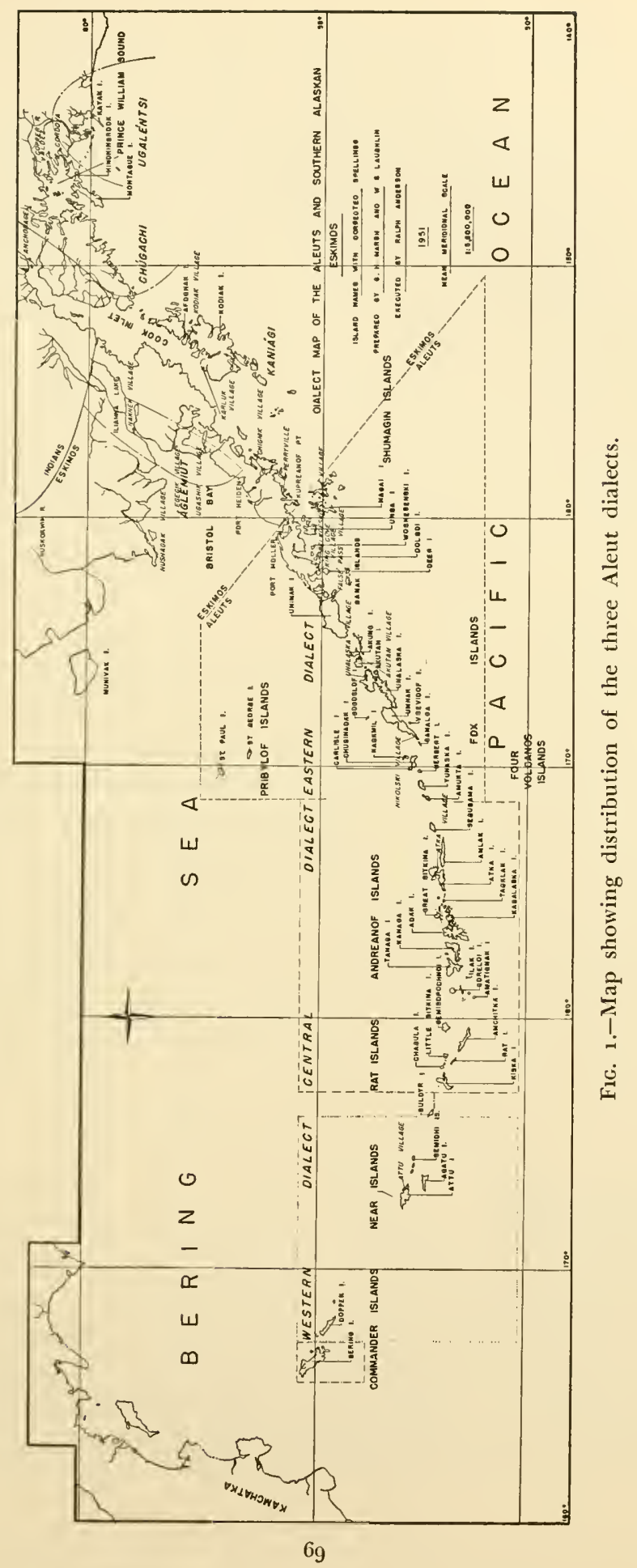


lect which they speak today. In addition, it has been found that all Aleut place names for the northern half of Unmak Island, insofar as they are identifiable, still keep Central dialect forms. Thus, the westward movement of the Eastern dialect appears to have progressed within historic times, continuing a trend already in operation long before the arrival of the Russians.

Another way in which linguistic studies have thrown light on the westward movement of the Aleuts is found in the historical legend of Chuning, told by the Attu Aleuts. This legend tells of the arrival of Umnak Aleuts and of the subsequent mixture of the former Attu dialect with the Umnak dialect. Certain structural resemblances between the Eastern and Western dialects, as contrasted with the Central dialect, confirm the historical value of this legend.

Comparative data are lacking for many of the southern Eskimos such as the Koniags of Kodiak Island, the Ugalak and the Chugach Eskimos. Many native speakers of Koniag still survive and informants for a study of the other dialects might still be found. Similarly, linguistic studies of the Indians, such as the Eyak and the Kenai, and of other Indians adjacent to the Eskimos, remain to be done. Owing to the fact that the younger speakers of these languages or dialects are not as conversant with the linguistic structure, and not only have smaller vocabularies but also less knowledge of the areas occupied by various speakers, it is important to conduct linguistic studies while the older informants are still alive.

\section{Physical Anthropology}

A new perspective is necessary in order to deal successfully with the problems of physical anthropology. It is necessary to realize that the Eskimo stock as a whole consists of many individual breeding isolates, each varying from all others in some respects. Therefore, it is not permissible to assume that any one contemporary breeding isolate of the Eskimos represents more accurately the "Eskimo type" than any other isolate. The Eskimos provide an exceptional opportunity for studies in 
human biology owing to the fact that they occupy perhaps the greatest linear expanse of any people in the world, ranging from Attu Island in the west, and Cordova in the south, along the coastline of North America and over into Greenland. Each breeding isolate has, with few exceptions, remained in contact with neighboring Eskimos and has exchanged genes with them rather than with Indian groups living inland. This means that each population or isolate of Eskimos, identified as such by dialectical, cultural and geographical factors, may be expected to differ from others genetically as manifested in such things as the morphology and blood groups. The various groups of Eskimos therefore provide ideal opportumities for the study of population genetics, as well as for the movement of the various populations in the past.

The population size of these Eskimos is of primary importance and possesses many implications for the culture as well as for the morphology. Thus, the large population size of these southern Eskimos, viz.: 16,000 Aleuts, 6-8,ooo Koniags, means that these populations were genetically more stable than the smaller populations. Small groups can change more rapidly than large populations, as a result of drift and of mixture. Change due to genetic drift takes place more rapidly in small breeding isolates, as neatly demonstrated by the loss or reduction of blood groups A and B among the Polar Eskimos. Coincident with this is the fact that the effects of racial mixture are more manifest in a small population, due solely to the relative proportions of the traits being introduced. The significance of these considerations for southern Alaska lies in the old allegation that the Eskimos of southern Alaska are mixed with Indians and do not represent, therefore, pure Eskimos when compared with various isolates of eastern or Greenland Eskimos. It is obvious that a population of 8,000 could not be as easily mixed to any appreciable degree as could the much smaller groups of eastern Eskimos, as for example, the Caribou Eskimos. The differences between southern Alaskan Eskimos and eastern Eskimos are not primarily due to mixture with Indians but to the fact that the Eskimos represent a polymorphic stock. This 
variability is seen most clearly in the head form. The intergradation is apparent when each of these isolates is compared with its neighbors rather than with Eskimos hundreds of miles removed. In effect, each of these Eskimo groups is most similar to its neighbors. To understand their relationships to each other it is necessary to acquire the genetic and anthropometric data for each group. At present there is actually very little data available for the southern Eskimos, and even less for the neighboring Indian populations.

The importance of knowing the contemporary populations in order to atgment the information gained from the skeletal populations recovered by archaeology is seen in the discovery of the two breeding isolates of the Aleuts. Though it has long been customary to speak of the Aleuts as a single, homogeneous population, it was evident from the reports of early Russian observers that there were distinguishable differences between eastern and western Aleuts. The previous finding of two skeletal populations by Dr. Aleš Hrdlička also indicated the probability that traces of the early population of Paleo-Aleuts would be found in the western Aleutians. An anthropometric study of living Aleuts revealed a number of differences between the Aleuts of Attu and Atka, forming one breeding isolate, and those of the eastern islands forming another isolate. Some of these differences corresponded, in the case of the western Aleuts to the Paleo-Aleut skeletal population, and in the case of the eastern Aleuts to the Neo-Aleut skeletal population. The fact that the Neo-Aleuts had not reached the western islands in sufficiently great numbers to obliterate the previous PaleoAleut population is in consonance with the linguistic evidence of the recency of the westward movement of the dialects. So far as the Aleutians are concerned, one of the most fruitful studies would be the examination of the skeletal populations of each island to detect the island variations from east to west in the Aleut populations. Similarly, studies of the various Eskimo and Indian populations of southern Alaska, with particular reference to their geographical divisions, may be ex- 
pected to throw much light on the prehistoric and early historic movements of these people.

The blood group studies of various southern and western Eskimos such as the Aleutian Eskimos and the Kuskokwim Eskimos clearly identify them as belonging to the Eskimo stock as a whole and serves to distinguish them from the Indians. When relatively unmixed with Europeans the Eskimos appear generally to have more group $\mathrm{A}$ than $\mathrm{O}$ and to have amounts of group B ranging from $2 \%$ to $12 \%$. The few figures for Alaskan Athabascan Indians indicate a much higher proportion of $\mathrm{O}$ than of $\mathrm{A}$ and no group B. Blood group data will therefore be useful in future studies to demonstrate the differences between Indians and Eskimos and various degrees of mixture if this has taken place. The use of the $\mathrm{M}$ and $\mathrm{N}$ types and of the $\mathrm{Rh}$ factors will make such studies even more discriminating and therefore more valuable. Blood group studies may also be of use in demonstrating the presence of gradients or clines among the Eskimos.

Anthropometric studies of the southern Alaskan populations are exceedingly meager. It appears from available data that the headform of the Eskimos becomes increasingly greater in breadth and in lowness of vault as one passes from Bering Strait south to Kodiak Island and the eastern Aleutians. Thus, it is not possible on the basis of present information to draw a sharp line between any two contiguous groups of Eskimos. The practice of ignoring contiguous groups and of comparing one series of southern Eskimos with a series of eastern Eskimos could only demonstrate larger differences because two opposite ends of the range of a continuous population were being compared. Brachycephaly and low vault height may reach their climax among the Koniags and the eastern Aleuts but we now know that the western Aleuts are all relatively longer headed than the eastern Aleuts and we may expect differences among the Ugalak and Chugach Eskimos.

Though large skeletal collections have been assembled for the Aleutian Islands, Kodiak Island and certain sites in southern Alaska, the fundamental problems of the sequence and 
relationship of populations can not be solved owing to the fact that few of them were stratigraphically excavated. It appears that the earliest people to enter this general area was a longheaded Eskimo population, and there is abundant evidence that this earlier population was superseded by a roundheaded population which is found arcliaeologically and which is represented in the living populations of the Aleutians, Kodiak Island, the Kuskokwim River and in Bristol Bay where studies of the living have been made. There are indications that this expansion of the broad and low vaulted Eskimos took place comparatively recently. At Umnak Island in the Aleutians they appear to have arrived within the last few hundred years of a total occupation span of about four thousand years and, as previously mentioned, did not succeed in obliterating traces of the former population in the islands to the west. The importance of stratigraphically excavated skeletons can scarcely be overemphasized. Once the skeletons of the earlier population are mixed in those of the later population there is no certain way of sorting them out. Though both Paleo-Aleut and Neo-Aleut skeletons are found in the late mummy caves of the Aleutian Islands, their recognition would not have been possible unless it had been demonstrated that they corresponded to two populations, one overlying the other in the excavated village sites.

One of the major results of the continued collection of stratigraphically excavated skeletons will be not only the elucidation of the direction and sequence of population movements in southern Alaska, but also valuable data on the changes taking place within populations. It has long been customary to look for an outside origin for any newly appearing population in a given area. The underlying assumption is the supposition that evolution takes place somewhere else, and population differences are therefore explained by the invasion of a people from some other area where studies have located a somewhat similar people. Thus, Aleuts have been compared to Tungus, Apache Indians and Japanese, but seldom to the neighboring Eskimos of Bristol Bay for whom there are as yet few studies. Hrdlička, 
for example, found what he believed to be a close resemblance between the pre-Aleuts, now termed Paleo-Aleuts, and the Sioux Indians, and suggested a possible relationship. Again, in his study of the pre-Koniags he made comparisons between them and a pooled series of western and eastern Eskimos, corresponding naturally to no particular population, with the inevitable result that he missed their closest relationship and postulated an Indian relationship. Future work should show that the possibilities for the study of micro-evolution are exceptionally good in this area. There are few places in the world where a 4 ,ooo year span of continuous occupation combines with the excellent preservation of large numbers of skeletons to present the raw data necessary for the detection of internal changes proceeding within a population. In brief, it is quite possible that the round headed Eskimos of southern Alaska arose in this area and expanded in numbers to the point where they dominated the earlier and more widespread long headed population.

To account for the presence of two distinguishable populations arising out of the primary population it is first necessary to recognize the variability or polymorphy of the early Proto Aleut-Eskimos who entered southern Alaska. Secondly, it is necessary to recognize the fact that it is possible for a change or genetic difference to become established in a breeding isolate by means of genetic drift, the chance loss or fixation of genes. Thirdly, it is thus possible for one isolated subdivision of the larger population to become brachycephalic solely by means of genetic drift. Then, given ecological factors which favor the relative enlargement of this particular isolate over its neighboring relatives, it is enabled to expand into the area of these other related peoples where it will supersede or mix with and obliterate the physical traits characteristic of these neighboring relatives.

In summary it may be useful to consider the possible occurrence of something approaching a population explosion in this area to understand the high population density. The early peoples coming into this naturally rich area were able to build 
up a far larger population than in the less favored areas to the north. After the necessary cultural immovations and adaptations, such as the kayak, had been made they were able to expand out into the Aleutian Islands and into other relatively inaccessible zones. There were, in all likelihood, many contractions and expansions of the populations, depending on variations in the food supply, climatic oscillations, disease and social disruptions.

\section{Archaeology}

In the early 1870 's Dall while with the U. S. Coast Survey conducted excavations on varions islands in the Aleutian chain, representing the first archaeological work in this area. Though his operations were haphazard and incomplete he concluded from his material that the Aleuts had left traces of three stages or periods of culture. In spite of the inadequacy and failure of this style of analysis to correspond to the actual sequences, there is still a tendency to resort to the traditional three period interpretation of these archaeological sequences. This kind of analysis is enhanced by the notable lack of stratigraphically excavated sites in southern Alaska.

Though the material culture of the Aleutians is basically Eskimo, essential questions concerning the actual sequences and relationships to other Eskimo cultures can not yet be dealt with in any satisfactory manner. On the entire island of Kodiak there is not one stratigraphically excavated site, although there are many large, deep and easily accessible middens. With the exception of De Laguna's work at Cook Inlet, of Larsen's work in Bristol Bay and Unalaska, and of Weyer's at Port Möller, there have been no scientific studies east of Ummak Island.

The significance of archaeological research in southern Alaska lies partly in the fact that there is substantial evidence of great antiquity and also in the suggestion that some of the essential elements of Eskimo culture may have taken form here before being diffused to the north. From our excavations at the Nikolski Village site, Umnak Island, Dr. W. F. Libby of the Institute for Nuclear Studies, University of Chicago, has de- 
termined the age of 3,000 years for radioactive carbon in samples of burned wood taken from one meter above the floor. The floor of the site will thus be several hundred years older, and earlier sites must lie closer to and on the mainland in view of the fact that the people came out here from the east. On the basis of known carbon-14 dates from sites to the north it appears that this is the earliest known Eskimo, or Proto Aleut-Eskimo culture. It is therefore imperative that archaeological sites in southern Alaska be carefully excavated in order to reveal the complete sequence preceding those found to the north. A fundamental problem is then the inventory of traits possessed by the earliest Proto Aleut-Eskimo culture.

In this Paleo-Aleut culture of 3 ,ooo years and more, which is a part of or close to this basic culture, we recognize a mininum inventory of stone tools consisting of lamps, bowls, adze blades with ground edges, drill bits, weights, pecking, pounding, and grinding stones, abraders, lamellar flake gravers, knives, points and scrapers, and a variety of chipped knives and points. Among the bone tools are three kinds of harpoon heads: those without stone points, some used without a socket; those with stone points inserted in an end slot; and toggle harpoon heads. The small two-piece socket, rib tools, wedges, eyed needles, compound fish hooks, leister prongs and the shovel are found. Ivory labrets and carred human figures were also a part of the earliest culture. It is obvious that they also possessed boats in order to have reached Umnak Island. The possibility that the kayak developed from the umiak in southern Alaska should be considered. In the succeeding 4 , ooo years the manufacture and use of kayaks reached a high degree of development. It is of interest to note that the Aleut word for kayak is a diminutive of the word for umiak. When the extent of the Proto AleutEskimo culture is known it will then be possible to deal more adequately with the problem of the American versus the Asiatic origin of many Eskimo traits.

Throughout the Nikolski site, six meters in depth, there is a continuous change in harpoon head styles with no evidence of any marked periods. Some of the latest traits, possibly aided in 
their diffusion by the Neo-Aleuts, include single piece sockets for sea otter harpoons, shallow stone lamps and the ground slate ulu. Significantly, the single piece socket retains the dual ending in its name. The objects found in the mummy caves correspond to those found in the upper levels of the village sites. The mummy caves in themselves constitute an excellent source of information but none have as yet been scientifically excavated.

Another basic problem is the location of lamellar flake industries similar to those found further north, as at Cape Denbigh. A core and blade industry existed in the Aleutians but it is not yet known whether it preceded the Paleo-Aleuts or was only part of their culture.

In summary it may be pointed out that our knowledge of Eskimo archaeology is meager for this area, but our knowledge of Indian archaeology is even less. It is not sound to categorize traits as Indian or Eskimo solely on the basis of their contemporary distribution. To understand the fundamental relationship of the Indian and Eskimo cultures it is necessary to know the history of each trait. Thus, many traits now attributed to the Indians may eventually be found to have diffused to them from the older Proto Aleut-Eskimo culture of southern Alaska.

\section{ETHNOLOGY}

The ethnology of the Aleuts, Eskimos and Indians is poorly known. For many of the villages there are only the remarks of early European visitors. In a few cases the Russians have described particular areas, for example Bishop Veniaminov's excellent account of the Fox Island Aleuts. Unfortunately, these sources have not been exploited owing in large part to the absence of English translations. Though the cultures of Bristol Bay, the south side of the Alaska Peninsula and the Aleutian Islands appear to present a continum in many respects, accurate comparisons can not be made until the primary information is secured. Of equal importance is the fact that Eskimo-Indian comparisons can not be made, for even less is known about many of the pertinent Indian cultures. Even for 
the comparatively well studied Indian groups such as the Tlingit, on the southern border of the Eskimo distribution, there is no time depth, so that it is not possible to state what traits have been borrowed by the Eskimos from the Tlingit or by the Thingit from the Eskimos. The great time depth of the Aleutian culture and of other Eskimo cultures in Alaska suggests that many ideas concerning the Indian origin of certain traits will have to be revised or abandoned unless greater time depth for the Indian cultures can be found. Fortunately there are many native speakers and many old customs still practised, especially in the more remote villages where the economy has not been completely altered. A great deal can be accomplished purely in descriptive anthropology which will lay the necessary basis for more abstract analysis at a later date.

To illustrate the nature and significance of the ethnological problems which can be dealt with it is useful to examine the attitudes toward the dead and the corresponding interest or lack of interest in anatomy. Among many northern and eastern Eskimos there is a fear of the dead and elaborate precautions are taken in some places to prevent any dangerous association with the deceased or their spirits. There is a notable change in western Alaska, and in the Aleutians quite the opposite is the case. Here, the dead were preserved by means of mummification, were visited and used as a source of powerful charms. Accompanying this is an incredible interest in and knowledge concerning human anatomy. This development of mummification was apparently an innovation of the Neo-Aleuts and did not exist among the earlier Aleuts, as indicated by the geographical distribution of the trait and also by the statement of an Attu informant that Attuans did not believe in mummies. How far to the east and south the practice of mummification was spread, with or without a corresponding study of anatomy, is not known. The practice of mummification probably arose from the use of many of the parts of the animals they killed for fabricational purposes, and their dissection of sea-otters in order to learn about the anatomy of humans, explaining this kind of comparative anatomy by their belief that the sea-otters 
were originally human beings. In addition the Aleuts possessed an enormous body of information and practices concerning health and physical education, how to develop a "strong man" and how to treat diseases. Most pertinent to this development, they autopsied the dead in an effort to find out why they died, and they sometimes dissected those killed in warfare. Mummification appears to have developed in southern Alaska from this orientation toward human anatomy and then to have contributed to its further elaboration. Certain features of the ethnology of the Aleuts form an intelligible picture only when it is realized that they had a belief in a supernatural power which resided in the liuman body. This power was maximized at certain critical periods such as puberty and widowhood, and could be strengthened by observing the pertinent practices. Thus, the joint binding of pubescent girls and of widows or widowers, and the dismemberment of enemies killed in combat can only be understood when it is realized that this power in the body must be regulated and can only be removed from an individual by dismemberment. Conversely, the most powerful amulet known to the Aleuts was a "piece of clead man," a piece taken from a nummy. The mummy retained its potency precisely because it was preserved as a whole body, and was thus useful for many purposes.

The western distribution of this anatomical orientation can perhaps be deduced from existing data, but specific inquiries are necessary to find its extent in the southern and eastern portions of southern Alaska. Similarly, the basic problems concerning the cultural adaptation to the ecological situation need analysis. It is evident that the Aleut people of the mainland and Unimak Island used bow and arrow for hunting land animals, and that out in the chain the throwing board and spears were almost exclusively used. To what extent was inland hunting an alternative method of securing game for a maritime people, and to what extent did it provide a means for the people to leave the sea and move inland permanently? The distribution of games is another one of those many areas for which information may be secured from living informants. Hand games 
were employed on Kodiak Island but seem to have been absent from the Aleutians where there were few or no games of chance. The Aleuts possessed the game of tossing a person on a hide as do many other Eskimos, but the distribution and the internal meaning of it are 1 mknown. In the field of social organization the Aleuts were characterized by the leadership of "strong men" or "owners" who dominated their villages by physical strength and wisdom, but again the extent of this among the other southern Eskinros has yet to be determined.

In summary it must be emphasized that many of the older native speakers are still alive and that in a number of cases they can write their orn language, Aleut or Koniag, using the alphabet and script provided them by the Russians. The people are friendly and knowledgeable so that ethnological studies can be carried out with good success.

\section{Applied Anthropolog Y}

The immediate problems of the Eskimos, Aleuts and to a lesser extent, the Indians are serious and in need of detailed attention. Perhaps the first and most objective criterion is that of the decline of population, resulting largely from disease and starvation. Where the village of Nikolski had some 120 inhabitants at the turn of the century, and 89 in 1938 , it has only 59 at present. Destruction of the original economy based on the hunting of sea-mammals and on fishing, has provoked a number of cultural and biological problems. Three of the most important problems which are amenable to the anthropological approach are:

1. Education. Most of these people have a very poor knowledge of English. In the village of Nikolski there is one competent English speaker. The Aleuts have expressed a desire to have an interpreter to explain government directives and they are also anxious to acquire a more adequate knowledge of the English language. Methods similar to those employed by the Russians and by the Danish Government in Greenland which have succeeded in bilingual instruction for the Eskimos would appear to be preferable to the system which ignores the linguistic problems and provides no preparation of the teacher for the particular people among whom he is to work. 
2. Social and Political Relationships. Among the Aleuts the old political system of control by a "strong man" was transformed by the Russians into a chain-of-command government with first chief, second chief, third chief, which the Aleuts now employ alongside the "tribal council" called for by American law, with 4 elected officers and a member at large. In Nikolski the Aleuts keep the two structures separate and distinct but in Atka Village they tend to merge with the first chief being also president of the council. The failure of the latest system in operation can be traced to conflicting systens of authority which must be clarified before any smooth functioning can be expected. All members of Aleut villages, and this applies to most other villages, are bound together by various social patterns involving reciprocity. These relationships often prevent individuals from giving information to law enforcement officers or school teachers. Other attitudes govern their relationships with outsiders as distinguished from established village members. Consequently members of different villages can often not be expected to live together in one village until these attitudes have been altered. A thorough investigation of the village organization and patterned behavior between all its members will be most fruitful in implementing any program of social or economic rehabilitation.

3. Food Supply. With diets rumning from 800 to 1400 calories per day for long periods of time, it appears desirable to augment the food supply. One of the many ways in which this can be done is to encourage rather than to permit ridicule of the use of native foods, particularly those foods such as cod livers, blubber, and a large number of plant foods. Certain industries, such as those connected with sheep raising which is eminently successful in the Aleutian Islands, can be introduced and will serve to raise the cash income of the people to the point where they can purchase foods not otherwise obtainable. The Russian Aleuts of the Commander Islands and the American Aleuts of the Pribilof Islands present a remarkable contrast with the Aleutian Aleuts in this respect. They also demonstrate the efficacy of attention to the problem of food supply in stimulating population growth and increasing resistance to disease.

In conclusion it can be pointed out that researches into the anthropological problems of the peoples of southern Alaska will provide much information of scientific value and also data 
that will be of use if these formerly numerous populations are to be reestablished in a way that will aid the rational exploitation of the natural resources of this naturally rich area.

\section{REFERENGES}

1. Alexander, Fred. A medical survey of the Aleutian Islands (1948). New England Journal of Medicine, 2fo: 1035-1040. 1949 .

2. Collins, H. B. JR. Review, The anthropology of Kodiak Island, and The Aleutian and Commander Islands and their inhabitants, by Aleš Hrdlička. American Joumnal of Physical Anthropology, 3 (4): $355-361$. 1945.

3. De Laguna, Frederica. The Archaeology of Cook Inlet, Alaska. The University Museum. Philadelphia. 1934.

4. Hrdulčka, Aleš. Anthropological survey in Alaska. 46th Annual Report, Bureau of American Ethnology. 1931.

5. - The anthropology of Kodiak Island. Wistar Institute of Anatomy and Biology. 1944.

6. The Aleutian and Commander Islands and their inhabitants. Wistar Institute of Anatomy and Biology. 1945 .

7. Jochelson, Waldemar. Archaeological investigations in the Aleutian Islands. Carnegie Institution, Washington. 1925.

8. History, ethnology and anthropology of the Aleut. Carnegie Institution, Washington. 1933.

9. Kroeber, A. L. Cultural and natural areas of native North Anerica. Univ. of California Press. 1939.

10. Lantis, Margaret. Alaskan Eskimo ceremonialism. Monographs of the American Ethnological Society, II. 1947.

10a. - The Alaskan Whale Cult and its Affunities. Amer. Anthropologist, 4o (3): $43^{8-464} \cdot 193^{8}$.

11. Larsen, Helge. Archaeological investigations in Southwestern Alaska. American Antiquity, 15 (3): 177-186. $195^{\circ}$.

12. Laughlin, W. S. Blood groups, morphology and population size of the Eskimos. In, Origin and evolution of Man, Cold Spring Harbor Symposium on Quantitative Biology, 15. $195^{\circ}$.

13. The Alaska gateway viewed from the Aleutian Islands. In, The physical anthropology of the American Indian. The Viking Fund, Inc. 1951.

14. Laughlin, W. S. and G. H. Marsh. A new view of the history of the Aleutians. Arctic, Journal of the Arctic Institute of North America, 4 (2). 1951. 
15. Marsh, G. H. and Morris Sivadesh. Eskimo Aleut correspondences. Internat. Journal of American Linguistics, I7 (4). 1951 .

16. Veniaminoff, I. Notes on the Islands of the Unalaska Division, 3 vols., St. Petersburg. 1840 (In Russian).

17. Weyer, E. M. JR. Archaeological material from the village site at Hot Springs, Port Möller, Alaska. Anthrop. Papers, American Museum of Natural History, $3 I$ (4). $193^{\circ}$. 


\title{
ANGIENT BERING STRAIT AND POPULATION SPREAD
}

\author{
J. L. Giddings, JR. \\ Department of Anthropology \\ University of Pennsylvania
}

An analysis of the Cape Denbigh materials excavated in the Bering Strait region during the past three seasons will necessarily entail some reappraisal of our views on broader anthropological problems. Some of this must await a detailed study. However, one or two problems of a more academic nature beg for consideration even before the full significance of the site is known.

The teacher of anthropology is faced, year after year, with the task of creating a background for students that will help to explain for them the diverse racial and cultural structures of the New World. He is encouraged to speculate broadly in order to satisfy this basic demand, even though concrete proofs may be lacking. The often-repeated explanations that one learned some years ago in college do not fully answer his own questions about recent discoveries and techniques in anthropology and how they fit together into a logical pattern. If he is therefore obliged to question certain emphases of the recent past in his attempt to evaluate horizons emerging in the far north, and to seek some alternative explanations of American cultures and peoples, it is with the greatest respect for the various points of view of his colleagues and those others whose findings he re-orients to his own purposes. The proposals outlined in the following paragraphs are offered in this spirit, in hopes that they may be later held up to more detailed scrutiny. ${ }^{1}$

A remarkable paradox in American archaeology exists in the willingness of almost all students of the New World to accept

\footnotetext{
1 The author is grateful to Doctors Henry B. Collins, Jr., Loren C. Eiseley, and Froelich G. Rainey for having read the first draft of this article.
} 
Bering Strait as an early doorway out of Asia in so far as a general theory is concerned, while at the same time many of them wish to see in the archaeological facts of the far north only a pattern, or ideal, called "Eskimo."

Perhaps this concentration on either the distant past or the present, with no discernible middle period, is traceable to the rather distinct and separate origins of studies of American Indian prehistory and of "early man." The one study, directed towards such continuities as from existing Pueblo tribes back through the cliff house periods to the Basket-makers, lias a local American tradition. Its basic concepts and terminology, whatever the area, can be traced from such mound-searchers as Thomas Jefferson, Caleb Atwater, and Squier and Davis, and geologists such as John Wesley Powell, on to the Boasian school of ethnographic detailers, and to historical stratifiers of ethnography such as Kaj Birket-Smith. Students of Early Man, on the other hand, whether Abbott or Roberts, have been flint-consciously oriented, in this aspect of their work, towards western Europe and to earth-ordering like that of de Mortillet. Their frame of cross-reference has lain horizontally in time when it has concerned Folsom and related discoveries, so that comparisons of like materials have tended to reach across wide areas. Thus, one may discuss flints from Clovis in New Mexico, Dent in Colorado, and Scottsbluff in Nebraska as though they were a result of the one set of natural agents that has controlled the earth sediments in which they occurred. The same investigators have not dealt in such broad areas when defining house pits and villages, however. The latter kind of site has been referred locally upward and downward in time, in a conscious effort to establish the regional and environmental ties demonstrated by living peoples. The emergence of Early Man as a scientifically proven reality after 1927 exaggerated the cleavage between the traditions.

More recently, a few "cultural" archacologists have been reaching back determinedly for the linkage to geologicallytreated "complexes" of flints and bone fragments. Radioactive carbon dating now threatens to erase the barriers between the 
two traditions and to help prove that prehistory in America has been remarkably connected since the first humans set foot in the New World.

Arcliaeology in Alaska is a fairly recent matter for research. It began, and has continted, as an offshoot of archaeology in the United States proper. It has been carried out mainly by investigators fresh from the States, or from Europe, and its interpretations have inevitably reflected the current methods and thoughts emanating from universities and museums far from the locus of operations. Dall interpreted the shell heaps of the Aleutians as it was customary in the 1870 's to interpret shell heaps of the eastern United States. Jochelson amended Aleutian interpretation to conform with the advances of the 1920's, and now Laughlin is finding the same field fresh with opportunities of re-ordering according to the multi-discipline approach which he and his Harvard associates have put to a test. Collins, de Laguna, and Rainey turned out their first major works in a period of re-birth of archaeological interest stimulated in part, some twenty years ago, by Folsom finds and the delineation of an eastern Thule culture. Threaded through two generations of researchers was the commanding personality of Aleš Hrdlička and his marvellous, statistics-based conservatism.

\section{The Recognition of Early Man in Alaska}

Until 1935, little attention was given to the theoretical probability that the campsites of Early Man might be numerous in Alaska, and less to the actual search for these sites. This was partly because of the greater urgency to explore the rich sequences of coastal sites for knowledge of Eskimo backgrounds, and partly because of umrewarding surveys of the vast, wooded inland regions. Analyses of Eskimo culture have often linked traits and complexes with those of other parts of the world. In the absence of detailed archaeological knowledge of either northeastern Siberia or the boreal forests of North America, this kind of study was necessarily dependent largely on the inferential evidence of ethnology. Two main problems existed 
for those who dug-that of the first migration to America somewhere in the distant past, and that of the various layerings of culture that combined in Asia to give rise to a squeezing-out of Eskimos as a sort of frosting over the coasts of the American Arctic. To be sure, Jenness, Hrdlička, and others were concerned also with transporting Indians across Bering Strait, but this remained primarily a theoretical problem connected with language dispersion and distributions of ethnological traits.

Eskimos have recently lived along all of the far-northern coast line of America, from Prince William Sound around the greater part of Alaska and eastward to Labrador and Greenland. They still maintain a great continuity, particularly in language. Towards the interior, and enclosed by the great arc of Eskimo-speakers, are the Athapascan-speaking tribes whose structure of culture is remarkably uniform throughout all but the coastal strip of their western domain. The latter inhabit the greater part of the American boreal forest. These facts have long been recognized and integrated with ethmological theory. In spite of all this, volumes have been written on Eskimo prehistory, while practically nothing is known about the archaeology of the northern Athapascans. The information secured from the inland regions has, with the exception of relatively recent sites investigated in central Alaska by Froelich Rainey, and along the lower Yukon River by Frederica de Laguna, shown little evidence of fitting into the ethmographic picture of northern Athapascan material culture. Many of these finds may now be tentatively placed in the Early Man category.

The most striking of these discoveries was placed on record in 1937 when N. C. Nelson published on an assemblage of flints from the University of Alaska campus, and compared it closely with similar associations on the Gobi Desert of Mongolia. The significant types were prepared cores and lamelles (variously described as lamellar flakes, microliths, and prismatic flakes) and a thin, delicate form of end scraper. This combination is also to be found in other parts of the Old World, and may have been first put together during the Capsian period of the Afri- 
can Paleolithic. This highly significant paper of Nelson's has been somewhat underplayed, however, because it brought into view flint techniques that were not yet widely known or stressed in America. One had to go to individual site reports to find that the small cores and blades had turned up in such widely separated places as the Antilles, Ohio and other areas in the East and Middle West, and all along the eastern coasts of Canada and Greenland. Here, in the micro-core and bladelet, is found a flint specialization of the lighest order-one that is as little likely to have been independently invented as is, for instance, the Folsom channel groove.

Later investigations in the far north have shown that the Campus Site combination is basic to Dorset Culture, and that it has, at early periods, characterized the inland areas of the Yukon Territory and Alaska. And Collins, drawing upon current reports from Eurasia in 1943, has found reason to connect the earliest Eskimo to Mesolithic developments in the northwesterly direction.

Since the middle 1930's, Rainey and succeeding University of Alaska archaeologists, and some others, have reported on chance finds in the gold-fields where frozen silts containing the bones of extinct animals are removed by hydraulic mining. These include several examples of large blades and fragments of the distinctive outlines and flaking styles that would place them in the "Yuma" or Plainview categories of Early Man work if they were to be found in the southwestern United States. In aggregate, these finds look impressive, but the fact remains that each is subject to the gravest doubt when one is faced with judging its provenience in the disorderly silt deposits, where curious conditions of ground thawing and refreezing in spots and over long periods may place mammoth tusks and tin cans side by side deep below the surface. Some of the artifacts from the silts, and surface artifacts from neighboring areas, are now more respectably linked with early times by association with a typology now emerging from a series of discoveries of the past five years.

In 1948 , R. H. Thompson of the U. S. Geological Survey 
reported on the finding of a Folsom point at a chipping station in the high platean area north of the Brooks Range, south of Point Barrow. Two years later, another survey party was accompanied by an archaeologist, Ralph Solecki, who discovered many chipping stations across a broad expanse of the same mountains and plateaus. Among Solccki's finds were two flaking stations in which prepared cores and blades or lamelles and associated materials duplicated in large part the Campus Site "microlithic" industry previously reported by Nelson and Rainey.

The sites that were to help tie together all of these fragments of evidence were those excavated at Cape Denbigh, and at the Trail Greek caves of northern Seward Peninsula. The first of these was a stratified site containing not only distinctive flint artifacts, but great numbers of artifacts, representing presumably the range of flint products of one people at one time.

The Cape Denbigh site, called Iyatayet, lies on a terrace some $5^{\circ}$ feet above sea level, at the mouth of a small creek flowing into Norton Bay. Here, during the years 1949, $195^{\circ}$ and 1951, were explored three cultural strata, conveniently separated from one another in parts of the site by either sterile layers or by sod lines resulting from abandonment for some time. The uppermost layer at Iyatayet is thick near the terrace slope, but thin elsewhere, and contains in well-preserved form the remains of "neo-Eskimos" who inhabited the site for an estimated 500 years-between 1100 and 1600 A.D. Beneath this capping lies a poorly-preserved thick stratum containing the basalt-flaked artifacts, thin, well-fired pottery and other materials of the "palae-Eskimos" whose material culture is closely related to that of other sites recently delineated for Point Hope, to the north, and Bristol Bay to the south. Two published radiocarbon dates, one from the top and one from a lower part of this deposit, may indicate very nearly the range of time in which this occupation took place. These are 490 A.D. and 66 B.C. While the term "palae-Eskimo" attributes linguistic relationships about which we have no knowledge to the people who left these remains, there can be little doubt that the ma- 
terial culture of this group was oriented towards the same pursuits of partly-coastal, partly-inland hunting that presently characterize some of the populations of the Bering Sea coasts of Alaska.

The earliest occupation of Iyatayet, on the other hand, is represented by a different sort of workmanship, and a different combination of artifact types from those of other known Alaskan coastal sites. Contained here in a normally pencil-thin layer on top of peri-glacial sterile deposits, and covered by sterile silt-loam and a peaty layer, are found types of artifacts familiar to us from distant places, but, with few exceptions, unlike those in neighboring coastal areas. More than half of the collection of 1500 artifacts uncovered in place are lamelles, cores, and retouched lamelles in a variety of delicate microlithic forms. A quarter of the collection represents several forms of a flint tool that was recognized here apparently for the first time in the New World-the burin ("graver" in the European sense), known best from its important status in the Upper Paleolithic of Europe. Other forms include a channeled (Folsom) point, several fragments of large obliquely-flaked "Yumas" like those of the American Southwest, and other flint types known from either Europe and Asia or more southerly parts of America.

Geologically, the site manifests features that clearly relate to climatic changes. These features are to be the subject of a paper by David M. Hopkins, of the U. S. Geological Survey, who visited the site. We may only say now, in the absence of radiocarbon dates or Mr. Hopkins' final conclusions, that the "Denbigh Flint Complex," as we designate the oldest materials, was probably laid down by as much as 6000 years ago.

With the Cape Denbigh sequence as a yardstick, we may then place other manifestations containing less definite stratigraphy, and fewer artifacts, into a probable time perspective. The Trail Creek caves, not yet described in full, have been indicated by Helge Larsen to contain a scattering of artifacts near the bottom of the deposit that recall aspects of the Denbigh Flint Complex, with a capping of palae-Eskimo and neo-Eskimo materials. 
The stratigraphy of these caves does not permit a close isolation of the sorts of artifacts used at one time, as does that of Cape Denbigh, nor is the aggregate of materials secured there comparable in size to that of the latter site. A radiocarbon date has been reported at about 6000 years ago for charred organic materials collected from an older level of one of the cave deposits. An absence of burins of the several types of the Denbigh Flint Complex may mean a later age for all of the cave deposits, or it may simply mean that the caves were occupied sporadically by hunters who had no need of burins on their inland excusions.

Sites were discovered during $195^{\circ}$ along the exposed ridges of the Brooks Range and in a divide at the head of Anaktuvuk River, that yielded in the one case apparently a pure site of the Denbigh Flint Complex, and, in the other, channeled points and other objects relatable as an aggregate to the same source. Work on one of these sites is in progress by the discoverer, Wm. Irving, as this is written in August of 1951 .

One sees at this time a relative time scale forward that would reduce the importance of the older techniques (those demonstrably old in terms of Old World and Southwestern prehistory), or that would remove these farther from the Bering Strait. This is to say, the focal position of Bering Strait at a point where ideas from two continents are blended would tend to reflect dynamically on culture. Innovations of the Neolithic, such as ground tools and pottery, would replace older techniques here and elsewhere along currents of strong diffusion, while a lag in replacement might be expected in peripheral areas. The degree of replacement, expressed statistically, might be expected to clarify factors of both time and distance. In order to apply this tentative scale, however, we need to reexamine two basic concepts of American archaeology. 
Migrations

The first concept to be considered is that so often advanced in the literature as "migration." 2 The first Americans "migrate" from Asia. Languages are transported from Asia (leaving no trace in their homeland!) by means of "migrations." What is meant by this magic aid that we have all used so freely in the past? What are its mechanics at the Bering Strait gateway itself?

Logical though the movement of groups of mankind across either a former land bridge or the present navigable waterway may seem from the vantage ground of a distant classroom, such movements become nebulous in the extreme when one tries to invoke them while in the Alaskan field. Let us see what might have led to the movements that may have populated America down through the millennia. A list of common assumptions might be as follows:

1. Man follows his game animals-caribou, mammoth, bison.

2. Man seeks more room in a new land-escapes the pressures behind.

3. Man searches for a milder climate-seeks a route southward.

One can have no argument with any of these propositions if he leaves out all the qualifiers of pre-direction, pre-determination-removes the "seek," and "search," and "follow," and substitutes "finds"-and allows an infinitude of time. But does he not then have, instead of migration, a mere population spread? "Migration" usually connotes more than a spread. Spilled molasses does not "migrate" across a table top. Let us then examine the propositions cited as though they retained an element of purposefulness.

The nomadic hunter does not follow his game, if we may judge from ethnographic evidence-he intercepts it. The animal migrates-man intercepts. Thus the caribou annually gather in herds in northern Alaska and move northward to-

2 The following remarks are directed towards the more theoretical approaches to the subject, rather than to those of Arctic specialists, whose reconstructions of movements at Bering Strait are defined by specific cross-relationships. 
wards the barren grounds, but in late August and September they return in herds to the forested interior, crossing the Yukon River and the mountain range to the south, to disperse later into small bands scattered among the valleys and plateaus for winter foraging. Their crossings of the rivers and mountains while in large herds are so strictly patterned in the spring and fall that Athapascan hunters bave been able to gather together and repair their diverting "fences" with full assurance that the caribou would come to them. The Athapascans are nomadic in the sense of moving their customary hunting sites when the caribou change their crossings, but they are not nomadic in the sense of following the herds from one seasonal range to another. In the off season, the hunters depend upon fish, birds, small game and vegetable products. They also know how to preserve meat when the supply is plentiful.

It is difficult to picture a human society, either in Paleolithic Europe or today, that is dependent on one source of food, and one alone. Although we lack evidence on which to compare the habits of caribou to such extinct animals as mammoths, it is even more difficult to picture a society that adapts itself to annual migrations. Therefore, when we say that man follows his game animals, we may mean simply that over many generations the locus of customary seasonal hunting at game crossings can slorwly change.

This process of slowly accommodating to the habits of game animals can be inferred from the archaeological record in some parts of the world, and in one or two cases it seems to have been relatively rapid-as in the spread of a thin population in search of whales carrying the Thule Culture along the shores of the Arctic Sea. However, we see little evidence for the mass migration within one generation beyond the customary range of band or tribe.

Again, from the ethnographical picture in thinly populated areas, there appears to be a strong tendency for stability over long periods of time. Hunters and gatherers who command many square miles per unit of population have no need to move because of invasions by hostile groups-a sparse population pre- 
sents no united front. They cherish their familial and other group contacts and arrange to meet in groups at least once within the span of a year. Under what circumstances can we visualize residents of the northern forests as falling under any population pressures that would force them to search for more land? The individual moves within a fixed radius of space within his lifetime. His children establish their own circles of range beyond. But this is not migration!

Finally, we must consider the possibility that something in the biological nature of man causes him to seek warmer climates, as a sunflower faces the sun. It is obviously impractical to attempt to investigate such an innate longing in the animal himself. If we may judge by the developments of culture, however, there has been a tendency over a very long period everywhere for man to adapt himself to colder and colder climates. This can be as readily seen as a desirable development as it can as a makeshift arrangement based on necessity. Surely Europe was not so populous in late Paleolithic and early Mesolithic times that man could not support himself without pushing into the Scandinavian peninsula. Nor would it have been difficult for the Central Eskimos recently to have moved southward into the forests, or even into the northern great plains, had they so desired. Of course peoples in thinly populated areas live where they do not because they are pushed there, nor may not find land elsewhere, but because by tradition and cultural adaptation they find their particular environment and locale the ideal ones in all the universe.

The coastal Eskimo does not move into the forest, even though friendly Eskimos may live there, since he does not wish to leave the excellent place that he believes is his on the coast. He does not care to catch fish in traps under the winter river ice as long as it is possible to hunt seal at the open leads. While it is quite reasonable to suppose that a family might shift its home many miles within its own environmental zone, it is difficult to understand how a migration could take place in any such purposive way as to lead to warmer regions.

It is clear from each of the preceding arguments that we 
do indeed assume spatial rearrangements of populations from one general period to another. Eskimo-speaking groups actually do live both on the coast and along the forested rivers. Our problem, then, concerns the relegation of this phenomenon to migration or to some other factor. We shall return to this question later.

\section{"Eskimo"}

The second concept that we have long been accustomed to use without often defining is "Eskimo." It is used to designate a people, a pattern of life, and a language stock. How are we to define the term when it incorporates all three aspects together? And how far back in time can we safely apply it?

One is on fairly solid ground in speaking of "the Eskimo language." The Eskimoan dialects are easily distinguished from Athapascan and Chukchee languages. However, the Aleuts are by no means the only Eskimo-speakers who experience difficulty in conversing with their nearest neighbors. When Knud Rasmussen journeyed by sledge all the way from Greenland to Alaska, he had no trouble in conversing with peoples along the way until he reached the Kotzebue Sound area. While at Nome later, he found it very difficult to take notes from visiting Bering Sea Eskimos. The fracturing of peoples of the Bering Sea coast and of Seward Peninsula into many dialect groups has long interested investigators, although none has questioned the appelation "Eskimo" for any of these. It is, nevertheless, significant that nearly half of the Eskimo-speakers of the world live in this area where there is the greatest difficulty in mutual understanding. In terms of age-area criteria, perhaps the term "Eskimo" should be applied first in this region, and only secondarily far to the east.

Is an individual an Eskimo, then, because of his bodily form? The "Eskimo physical type" that has become firmly entrenched in the text-books appears to have congealed in the central and eastern Arctic before a great deal of work had been done in any area. Hrdlička has pointed to the great departure of most western Eskimos from the long-headed, keel-crowned, short- 
legged archtype, and Shapiro has later stressed this point and suggested Algonkian parallels for Eskimos of both east and west. Very recently Laughlin has summarized as follows:

The majority of Eskimos lived in the western portions of Alaska and are brachycephalic. This brachycephaly distinguishes them from the longheaded eastern Eskimos who have previously been considered the classic or original Eskimo type owing in large part to the historical priority of studies on them, rather than upon their numbers or archaeological antiquity. Future archaeological studies may be expected to demonstrate the entry of Eskimos of various morphological types from Asia. (WM. S. Laughlin, The Alaskan Gateway Viewed from the Aleutian Islands, p. 124, in The Physical Anthropology of the American Indian, Viking Fund, 1951. New York).

Culturally speaking, we may point out that generally the Eskimoan peoples practice sealing with toggle harpoons where seals occur, they whale at peninsular areas where whales pass by regularly in abundance, they practice ice hunting where ice conditions are right, and their women all use a semi-lunar knife. It is impossible, however, to describe the material culture of one area and then apply it universally. Neither the snow house nor the soapstone pot appears in the Bering Strait area. Nor has dog sledding left incontrovertible evidence that it even existed in the west more than $25^{\circ}$ years ago. These particulars are not chosen to minimize the many similarities between east and west, but to indicate that the things used or thought by Eskimos in one area are not necessarily the parts of a universal formula.

If it is then difficult to categorize Eskimo-speaking peoples as a whole today, what are the criteria that we may apply freely to the information gained from archaeological sites to set apart "Eskimo" prehistoric cultures from all others? Archaeology near Bering Strait shows little evidence of "static survival" of a single culture, but records continual change within the limits imposed by environment. The Thule Culture appears to be valid as a concept both in the east and the west, but the Old Bering Sea Culture has thus far appeared as such only on the 
Asiatic side (assuming St. Lawrence Island to have long been a cultural extension of Asia rather than of America). At what point in time did the Eskimo language first emerge at Bering Strait? If this question is unanswerable, as it appears to be, we shall have to depend upon mutual agreement, rather than upon factual information, for that point in prehistory when we cease to deal with "Eskimos."

If we now agree that both the concepts of "migrations" and "Eskimos" are largely theoretical when applied to arctic American prehistory, we are free to consider a specific mechanism by which it is possible to account not only for the present populations and cultures of the Arctic, but for the peopling of all the Americas. This mechanism can be called simply "population spread."

\section{Population Spread}

The mechanics of population spread can most easily be understood in terms of an original family, or small group. If we may, for the sake of clarity, put aside the possibility that man was on hand when an early land bridge existed at Bering Strait, and assume a first crossing by water from Asia to America, ${ }^{3}$ the sequence may be seen more or less as follows:

1. Hunters one day sail or paddle their craft from East Cape to Big Diomede Island, in the middle of Bering Strait. They camp there for a few days, amassing local products. They return with their produce and report to the villagers, or campers, at East Cape that hunting conditions are good on the island. We may assume that these people who set out from East Cape in the first place are equipped to live under the climatic and environmental conditions of this coast-that they are provided with adequate cold-iveather housing, warm clothing, and means of heating and lighting their winter dwellingselse it would be extremely difficult to explain their presence in that latitude and area.

3 The author has no strong convictions in this direction, and feels that the following principles would apply to conditions of passage over either land or water. 
2. These hunters, with their family, or families, return year after year to Big Diomede for seasonal hunting.

3. Some members of this or a later generation establish permanent homes on the island.

4. The above processes are repeated towards the Alaska mainland at Cape Prince of Wales.

5. Now the American mainland has received its first permanent population. The original settlers return often to Asia, and explore the local land areas only so far as it is convenient to extend a normal hunting and gathering range in terms of their long-established cultural pattern for these activities.

6. Second and third generations of these peoples remain near the original settlement, because their traditions and social activities are centered there, but their actual dwelling sites and hunting ranges extend in wider circles both inland and along the coast.

7. With the normal increase of population of a group over a period of many generations, separate bands have differentiated, some placing more emphasis on the far-inland hunting of caribou and salmon, others on coastal sealing. Their culture contains, from Asia, the elements that make little or no invention necessary. A shift of emphasis in selecting elements from their background suffices to differentiate a land-hunting group from a sea-hunting group.

8. With the passage of many generations, local bands develop new traditions, new emphases, and exploit new terrain and climatic zones. Since they are semi-nomadic hunters and gatherers, their populations do not become dense, nor greatly concentrated, and over many centuries and millennia their normal increase of population extends into the other climatic zones of America. The population controls of birth and death manipulation, food scarcity, and feuding will operate in the older areas, but need not restrict numbers near the outer boundaries.

9. The backward direction is the only one in which this population spread is limited, for it is in that direction that populations have developed a stability, and have erected tribal boundaries. 
10. At Bering Strait itself there is a continuous moving back and forth of the related peoples, but no migration. Nor is there likely ever to be a movement of foreign peoples across the Strait in mass, so long as the original, culturally adapted population is not decimated in some unlikely way.

11. Ideas and devices diffuse freely across Bering Strait at all later times, but equally in both directions. Although shortterm hostilities may create temporary barriers that dam up the stream of diffusion, the resulting ponds of difference break locally, and trading of ideas and goods is resumed.

12. Although there are few generations, or close series of generations, for which there is violent cultural change, the people of Bering Strait are constantly altering their culture through diffusion. Their physique changes also, through free draft upon the genetic pool of their greater cultural area (and through the operation of "genetic drift" as a random element of small population change). Their language modifies through slow innovation.

13. Although we night not have associated the original families with the term "Eskimo" to any appreciable extent, the direction of change is continuously towards that ideal.

It is to be noted that in this view there is no room for violent change, nor for migrations, nor for the funneling into America of whole peoples who bring with them the characteristics now found in isolated parts of the two Americas. Such differences are explained by diffusion and invention working together, and by rearrangements of the genetic pool locally into varieties of physical norms. If there is no particular reason for the people of Bering Strait to look alike from one millennium to another, drawing freely as they may upon genetic combinations from both Asia and America, there is similarly no reason for all of the culturally differentiating groups farther to the south to cling to the physical prototype of the first arrivals on American soil.

Perhaps the most important premise in this highly speculative approach is the discounting of real migration of hordes, and any of the other unilinear theoretical explanations of the 
peoples of America, plus the assumption that diffusion of both ideas and genes among the sparse population would be equally as free from America to Asia as in the opposite direction.

\section{The Relative Sequence of Archaeology}

The facts of recent and earlier archaeological finds in the American Arctic may now be speculatively woven into the background of population spread.

The Denbigh Flint Complex represents a site of peoples who have been long established on American soil. Here are combined the microlithic burins, lamelles, diagonal flaking, and the like, that are a cultural heritage combined of Paleolithic and Mesolithic traits. The Paleolithic forms are already losing ground to new developments in the circumpolar drift. Along with these are channeled points more recently developed as an American by-product of the blade-and-core technique (a Folsom channel is the scar left after removal of essentially a parallelsided blade), and other American developments such as the Folsom "graver."

As time goes by, more of the Paleolithic and Mesolithic elements are dropped, and Neolithic substitutes (such as ground stone tools) are added. Similarly, backward and peripheral areas, such as a few inland groups and the Dorset people of the eastern seaboard, retain old elements as though for them time had stood still. Diffusion proceeds along certain mainstreams, however, so that the advance guard of population spread to the south may accept more new ideas from behind them than does the adjusted, peripheral group somewhere to the rear.

It is clear that certain sea-hunting elements of culture that are useful in Bering Strait will have been dropped by the populations who spread far inland, and that divellers on mid-continental plains will have either minimized or modified the techniques that may still be used far to the north.

The futility of attempting to arrange the archaeological sites of the Arctic into stratified sequences thus becomes apparent. We must deal in three dimensions, including areal spread and 
the forward march of time. We can say that Dorset Gulture retained more older elements longer than did cultures of Bering Strait, but we cannot be sure that small groups near to Bering Strait, yet to be discovered archaeologically, did not also retain as much of the old for an equally long time. To argue that the Campus Site and the lamelle-containing sites at Lake Kluane are older than certain coastal sites that do not contain lamelles is in vain so long as geological or more specific dating is not available for both. Until radiocarbon and tree-ring dates appear for numbers of sites throughout the area, we shall have to rank cultural manifestations not as to whether one is older than another, but as to whether or not it is more old fashioned. And, of course, we must reckon in those elements of isolation and distance from a center, or mainstream, of diffusion.

In summary, it appears that Bering Strait has never been subject to wide-scale migrations of peoples from Asia to America such as would account for the diversity of culture, physique, and language among American Indians, but that it has maintained from the distant past a locally modifying population and culture, based upon the combined food resources of the land and sea, and has served as a narrow conduit through which diffusion has freely vibrated in both directions at all times. 


\section{BOTANICAL RESEARCH IN ALASKA \\ William C. Steere \\ Professor of Biology \\ Stanford University}

A glimpse at the history of botanical research in Alaska reveals immediately the lack of any innate or guided tendency torvard integration or coordination, and makes very clear the necessity for our present Conference. Georg Wilhelm Steller, in 1741, "was not only the first white man to set foot on Alaskan soil, but was also the first naturalist to collect, study and describe Alaskan plants and animals at a time when the world did not even know of the existence of Alaska." Born and educated in Germany, Steller was naturalist to the last voyage of exploration of Vitus Bering, under the auspices of the Russian government. Following the pioneer work of Steller, further botanical studies were made through the years in a casual, more or less accidental way by other expeditions of explorationRussian, Spanish, English, Scandinavian, and American. The British voyages in search of a northern ship passage above the North American continent, and the land and sea parties sent out in search of Sir Joln Franklin about the middle of the last century, were all productive of considerable incidental botanical information. From 1867 , when the United States purchased Alaska from Russia, until norv, occasional botanical investigations have been made officially and unofficially by several agencies of the United States government and at the expense of the government: the Smithsonian Institution, the U. S. Bureau of Fisheries, the Bureau of Soils, the Forest Service and several other agencies of the Department of Agriculture, the Coast Guard, various branches of the Geological Survey, and other governmental organizations. During World War II, many Armed Forces personnel made botanical studies and collections in Alaska quite outside the line of duty. At the mo- 
ment, the most active and extensive botanical researches are being made under the auspices of the Alaska Terrain and Permafrost Section of the U. S. Geological Survey, as an essential part of a large and important investigation of Pleistocene and post-Pleistocene geological phenomena in Alaska. In this Section, the work of botanists and geologists is being integrated in a wholly admirable manner. Unfortunately for science, however, no single agency has been authorized-or given fundsto bring together the vastly important botanical knowledge about Alaska already in existence or to proceed with an integrated research program on a large scale. In truth, most botanical research in Alaska or on Alaskan materials has been carried on under other sponsorship than that of our government, and has depended in large part on the financial resources of universities, of philanthropic foundations, and even of individuals. In the summer of 1899 , Mr. Edward H. Harriman put a party of 25 scientists in the field in Alaska at his own expense, and the extensive reports of the extremely successful Harriman Alaska Expedition, published by the Smithsonian Institution, are familiar to all of us. It is a misfortune for us that the two volumes reserved for an account of the flowering plants have never been published, although it is rumored that the manuscript was completed. The important recent publications of the distinguished Swedish botanist, Dr. Eric Hultén ("Flora of the Aleutian Islands" (1937) and his still incomplete "Flora of Alaska and Yukon," appearing in sections since 1941 (in Lunds Universitets Arsskrift) serve to fill this gap. The fact that Hultén's field explorations were financed from Sweden and that his publications appeared there, although in English, is a further direct reflection of the lack of official interest in this country in the botany of Alaska. These remarks should not be interpreted as being at all chauvinistic in intent, since it is perfectly obvious that a Canadian or Scandinavian botanist will naturally be more familiar with the northern flora than most Americans. However, for simple reasons of convenience and availability, it would be desirable to have fundamental works of this sort published on this side of the Atlantic. Fortunately for 
us, Mr. J. P. Anderson lias nearly completed an excellent and extremely useful series of well-illustrated papers on the "Flora of Alaska" which makes possible the identification of the higher plants of Alaska. Mr. Anderson's contribution becomes all the more valuable when we realize that his extensive explorations and collections were made largely at his own expense, during a long residence in Alaska.

It may seem to you that I liave put undue weight on taxonomy in emphasizing the achievements of Hultén and Anderson, yet it seems to me that these are among the very few comprehensive publications on Alaskan botany. Furthermore, an inventory of the flora is the backbone of all botanical research, since the solution of even a completely nontaxonomic problem depends on an exact knowledge of the plant materials used. Because of the high physiological and ecological specialization of different species, improper identification of materials employed by physiologists, geneticists, cytologists, or ecologists may result in conclusions that are open to suspicion, if not actually misleading. The extremely practical considerations involved in the interpretation of aerial photographs in order to determine trafficability, water resources, etc., depend upon a thorough understanding of flora and vegetation. Many phenomena connected with permafrost may be very closely related, either as cause or effect, to definite species of higher plants or even of mosses.

Since most if not all of the other participants on this program are especially interested in higher plants as research material, it would seem appropriate for me to touch upon the need for research in the enormous field of cryptogamic botany in Alaska, insofar as my time allows. Although many groups of seedless plants far outnumber in species the seed plants of Alaska, no comprehensive study of any major cryptogamic group has been published since the reports of the Harriman Expedition a halfcentury ago, so far as I know. The series of researches on woodrotting and other higher fungi, both in the field and in the laboratory, by Professor Dow V. Baxter of the University of Michigan are internationally known. Many papers on Alaskan lichens have been published both in this country and abroad, 
and Dr. George Llano of the Smithsonian Institution is engaged in further researches. A very extensive study of the known distribution of mosses in Alaska was prepared by one of my students, Dr. A. M. Harvill, Jr., now at the University of Alabama, but its very comprehensiveness has so far prevented publication. The marine algae of Alaska have received some attention, especially in Setchell's studies on Pacific algae, but the fresh-water groups still remain relatively unknown. In my opinion, there is urgent need for comprehensive reports on each group of cryptogamic plants and for over-all studies on the whole field of cryptogamic botany. As already pointed out, a stock-taking or inventory of the flora is a basic research need, not necessarily as an end in itself, but especially to give us a knowledge of the materials available for research.

Since my research interests center primarily about the bryophytes, I will indicate some of the problems in which they provide useful research material. Because of their relatively small size and complete lack of roots, in a strict botanical sense, mosses and liverworts are very directly affected by the substratum upon which they grow. Because of their sensitivity to the nature of the substratum and to other factors of the physical environment, bryophytes are excellent indicators of these factors.

The recognition of this restriction of different species of bryophytes to specific habitats and conditions enables us to employ them in a very practical manner, although much serious research is needed in this relatively unexplored field. Already, however, we can say in a general way that the distribution of mosses and hepatics, if properly interpreted, will give us much information on extremes of soil temperature, soil texture, the chemical and physical nature of soils, the nature and composition of rocks, and the water supply. Some species are restricted to highly mineralized rocks, and careful research on this relationship might give practical results, since the members of the genus Mielichhoferia seem to indicate the presence of copper ion. The thick mats of mosses certainly influence the thermal regime of the underlying soils and may be very important in 
questions of permafrost, since the dry mat in summer serves as excellent insulation, yet when frozen radiates heat effectively. The generally undrained condition of much of Alaska is caused in large part by accumulations of Sphagnum, which holds an enormous amount of water and prevents run-off of surface water. Even on fairly steep hillsides, drainage is sluggish if Sphagnum is present. It may seem odd for a bryologist to recommend that some chemical means be sought for the eradication of Sphagnum, and that much research on this problem is indicated. The presence of a truly arctic element in the Alaskan moss flora is of real significance, especially since many of the species are larger in size than the temperate representatives of the same genus, indicating complete adjustment to the arctic habitat and perhaps reflecting an increase in chromosome number. Mosses and liverworts present especially favorable genetical material, since the conspicuous plant is gametophytic or haploid tissue. Any mutation, whether recessive or dominant, will be expressed at once in the phenotype, since it cannot be masked by the presence of an allemorphic gene. These will serve as examples of the more significant research problems presented by bryophytes, to be multiplied many times if all groups of cryptogams are taken into consideration. I have pointed out elsewhere that the field of bryology is an almost unstudied one in the whole of Arctic America, even though the bryophytes form an impressive part of the vegetation, both in number of species and in number of individuals.

We have every reason to be grateful for this opportunity to begin cooperative discussions on the problems of Alaskan botany, even if all the objectives set for us are not fulfilled. It is my most sincere hope that future conferences of this sort may be arranged at regular intervals in order that reports of progress may be made upon current research, and that new problems may be discussed. The most serious problem facing past and present botanical investigators in Alaska has been and still is the lack of coordination between researches in the first place and between publications in the second place. This lack of coordination and integration may be attributed rather 
directly to the withholding of governmental encouragementincluding funds-for substantial, comprehensive research on Alaskan botany, in spite of its extremely practical importance at the moment. This Conference, for the first time, gives us hope that this situation may be corrected, through the educational effect of the recommendations and resolutions drafted by the members of this section, who represent the botanists most active in Alaskan research.

All of us here should feel ourselves obligated to strive for the coordination of researches not only within the field of Alaskan botany but between this and other fields. In my opinion, this desirable objective may be attained only through free interchange of ideas at regular and not too infrequent intervals. Thc establishment of research and information centers in Alaska and the United States would greatly further the integration of research, on a year-around basis. I have already expressed a pious hope that further Alaskan science conferences be held. Such conferences might conceivably develop into a self-propagating organization or society of real importance and influence. Under any circumstance, my final suggestion for a successful approach to the problem of integration and coordination of research in Alaska-perhaps conditioned by my long experience in editorial work-would be the establishment of a journal dedicated exculsively to the scientific problems of Alaska. Such a journal would not, of course, pretend to publish all original papers based on Alaskan research but would render its greatest service through the publication of reviews, abstracts, bibliographies, outlines of research projects, and a complete coverage, in the news sense, of all scientific activities concerning Alaska.

\section{REFERENCES}

1. Anderson, J. P. Flora of Alaska and adjacent parts of Canada. Iowa State Coll. Journ. Sci., I \&-21; 23-24. 1943-50.

2. Bartram, E. B. Mosses of the Aleutian Islands, Alaska. Bot. Not. 1938: 244-256. 1939 .

3. Baxter, D. V. Occurrence of fungi in the major forest types of Alaska. Papers Mich. Acad. 3x: 93-115. $194^{8}$. 
4. Cardot, J., and I. Thériot. The mosses of Alaska. Proc. Wash. Acad. Sci. 4: 293-372. (Harriman Alaska Expedition 5:253307. 1910.) 1902.

5. Clark, Lois, and T. C. Frye. A small collection of Alaskan Hepaticae. Bryologist 52: $5^{8-61.1949 .}$

6. Dawson, E. Y. A guide to the literature and distribution of the marine algae of the Pacific Coast of North America. Mem. So. Cal. Acad. 3: 1-134. $194^{6}$.

7. Degelius, G. Lichens from southern Alaska and the Aleutian Islands collected by Dr. E. Hultén. Meddel. f. Göteborg Bot. Trädg. 12: 107-144. 1937 .

8. Evans, A. W. Report on the Hepaticae of Alaska. Bull. Torrey Bot. Club $f^{1}: 577^{-616.1915}$.

9. Frye, T. C. and Lois Clark. Hepaticae of North America (north of Mexico). 1-1022 pp. Univ. of Wash. Press, Seattle. $1937^{-1948 .}$

10. Grout, A. J. et al. Moss Flora of North America, north of Mexico. 3 vols. Newfane, Vermont. 1928-1940.

11. Fink, B. The Lichen flora of the United States. i-x; 1-426 pp. Univ. Mich. Press, Ann Arbor. 1935.

12. Harvill, A. M., JR. A phytogeographic study of Alaskan Mosses. 337 pages, typescript. (Unpublished doctoral thesis, University of Michigan; available by microfilm) 1948 .

13. - Notes on the mosses of Alaska. III. Some new or otherwise interesting records. Bryologist 53:16-26. $195^{\circ}$.

14. Holzinger, J. M. and T. C. Frye. Mosses of the Bureau of Soils Kelp Expedition to Alaska. Publ. Puget Sound Biol. Sta. 3: 23-64. 1921.

15. Hooper, F. F. Plankton collections from the Yukon and Mackenzie River systems. Trans. Amer. Micr. Soc. 66: 74-84. 1947. 16. Hultén, E. Flora of the Aleutian Islands. 397 pp. Stockholm. 1937 .

17. History of botanical exploration in Alaska and Yukon territories from the time of their discovery to 1940. Bot. Notiser pp. 289-346. 1940 .

18. - Flora of Alaska and Yukon. Parts I-IX. Lunds Universitets Arsskrift, N. F. 37-45. 1941-1949.

19. Kol, Erzsebet. The snow and ice algae of Alaska. Smiths. Mus. Coll. IOI (6): 1-36 1942.

20. Magnusson, A. H. Lichens from western North America, mainly Washington and Alaska. Ann. Crypt. Exot. 5: 16-38. 1932.

21. Merriam, C. H. (as editor). Cryptogamic Botany. Harriman Alaska Series 5: 1-424. (Fungi: Saccardo \& Trelease; Lichens: Cummings; Algae: Saunders; Mosses: Cardot \& Theriot; 
Sphagnums: Trelease; Liverworts: Evans; Ferns \& Fern Allies: Trelease.) 19 iо.

22. Persson, H. Further notes on Alaskan-Yukon bryophytes. Bryologist 50: 279-310. 1947 .

23. - Studies in the bryophyte flora of Alaska-Yukon. Svensk Bot. Tidskr. 43: 491-533. 1949.

24. Steere, W. C. Bryophyta of Arctic America. I. Species from Little Diomede Island, Bering Strait, Alaska. Am. Midl. Nat. 19: 436-549. $193^{8}$.

25. Musci. In Polunin, "Botany of the Canadian Eastern Arctic." Nat. Mus. Canada Bull. 97: 370-490. $194^{8}$.

26. - The distribution of Aloina brevirostris in North America. Bull. Torrey Bot. Club 77: 503-508. $195^{\circ}$.

27. Stejneger, L. Georg Wilhelm Steller: the pioneer of Alaskan natural history. i-xxiv; r-623 pp. Harvard Press. $193^{6 .}$

28. Thomson, J. W., JR. Some additional records of lichens from Alaska collected by Walter J. Eyerdam. Bryologist 53: 9-15. $195^{\circ}$. 


\title{
THE FUTURE OF BOTANICAL RESEARGH IN ALASKA
}

\author{
IRA L. IVIGGiNs \\ Scientific Director \\ Arctic Research Laboratory \\ Point Barrow, Alaska
}

In Alaska, as in all other parts of the world, it is necessary to know a good deal about the kinds of plants native to the area before investigations on the vegetation can be undertaken or research begun on the physiology, anatomy, morphology, cytology, or genetics of the discrete units within the flora. This necessity leads to exploratory work through which plants are collected and preserved, adequately labelled, and forwarded to herbaria for study and permanent storage. The specimens may be worked up by the collector himself, or very frequently at least a part of them are sent to specialists who make taxonomic determinations, describe the new species if any are present in the lot, and publish the results of the investigation. The duration of this basic phase of botanical research varies greatly from one part of the world to another, but the general pattern of its progress is much the same everywhere. This exploratory work may be carried on under one or more of several types of sponsorship. It may be done largely by persons who do the field work because of a love for, and an intense curiosity about, the plants of the region. It may be done by individuals or field teams carrying out government assignments; or by professional botanists in the employ of universities, learned societies, or other organizations. It is primarily taxonomic or systematic activities that occupy the time and absorb the energies of people interested in plants during the early years of exploration. Other phases of botanical research usually enter the scene at a later date.

Much of the early collecting in Alaska was done by men connected with government commissions. Exploring ships 
from England, Scandinavia, the United States and Russia paid visits to the shores of Alaska and members of their companies collected many of the native plants. The collectors often had other duties which had first claim on their time, the botanical field work being distinctly secondary. Some collectors were ships' surgeons, others were junior officers with little special training and a corresponding slight interest in the native flora. The former type of collector usually took keen delight in the work; the latter often endured it as one of the unpleasant but necessary tasks assigned them by superiors. But whether collected by enthusiastic medical men, by professional botanists attached to military units, or by junior officers performing uninteresting duties, large numbers of specimens, in the aggregate, were collected, returned to herbaria in various parts of the world, and information about the floras involved published.

These results were usually obtained in spite of obstacles and discouragement rather than because of their absence. Too often the botanist going ashore had only a few minutes or a few hours in which to secure whatever specimens he could. He worked frantically to get as many as possible of the nearest plants into press. In so doing he often had to neglect or completely ignore the smaller, or more scattered species. In high northern latitudes the constant concern least the ship be caught in advancing ice often caused a captain to signal immediate return to the ship whether or not the full potentialities of the collecting conditions had been exploited. One botanist, as late as 1923, was thus hurriedly recalled to the ship before he could obtain one-half of the total number of species on an attractive stretch of arctic Alaskan coast. Such short forays ashore were disheartening in the extreme to enthusiastic botanists. But with the passage of time the collections continued to accumulate until now they represent a high percentage of the total flora.

A departure from chiefly government-sponsored scientific excursions to Alaska began toward the end of the nineteenth century. As mining operations in Alaska and adjacent Canadian areas increased, more and more individuals interested in plants made collections and wrote about the vegetation of the region. 
At about this time, too, non-governmental expeditions were organized to explore the coasts and interior of Alaska. Examples of such were the Harriman Alaska Expedition, made up of twenty-five scientists and a number of preparators and artists, that visited Alaska in May and June of 1899 , and a similar, although smaller, expedition sent out by the University of California a little later in the same summer. Collections larger than any ever gotten together by a single Alaskan expedition prior to that time were taken out by each of these groups. Critical study of these collections resulted in the appearance of a number of important publications (2, 6, 19). These two expeditions are mentioned at the neglect of others chiefly because each resulted in a marked increase in knowledge about the flora of Alaska and stimulated a greater interest than had theretofore existed among American botanists. The botanical rewards from these explorational forays might have been even greater had all of the material been worked up expeditiously and published at once.

As Alaska attracted more permanent residents yet another broadening coverage of the flora developed. Amateur botanists (so called because they made their livings at other pursuits), began to observe the plants in the vicinities of their homes and to write about them. Some of these "amateurs," as in the continental United States, were remarkably keen and accurate observers. Their collecting was usually meticulous and their specimens beautifully prepared. Among the more outstanding of them in Alaska was J. P. Anderson, who lived in the Territory from 1914 to 1941 . He spent as much time as he could spare from his business in careful field work well out on the Aleutian chain, in remote sections of interior Alaska, on several islands in the Bering Sea, and northward along the arctic coast all the way to Point Barrow. His patient field work is now nearing complete fruition in the appearance of a series of papers entitled "Flora of Alaska and Adjacent Parts of Canada" (1), which, I believe, is within one number of completion. This work is the first one dealing with the whole Alaskan flora that includes keys to the genera and to all of the species treated. 
The keys, descriptions, and the outline drawings assembled into plates at the end of each part, constitute a book that can be used readily and fully by any person with an interest in plants and modest knowledge of botanical terms. This product of a devoted "amateur" botanist who worked patiently and diligently to good effect may well serve as a milestone in the trend toward the general utilization of technical information ably and brilliantly present in another monumental work, Eric Hultén's "Flora of Alaska and Yukon" (9). Some may hold that Dr. Anderson's work marks the close of a period that dealt primarily with the cataloguing and "keying out" of the known species of the area. I contend that it marks the beginning of an epoch that could not have been exploited fully until such a work was available. For, even to "professional" botanists, keys and accurate descriptions are often useful aids.

Please do not interpret my defense of the "key and descriptions" type of botanical treatment as indicating a belief on my part that critical works dealing with the taxonomic, phytogeographic, and ecological phases of botany are of little value. Such I do not believe nor wish to imply. Such work as that done by Hultén and by other phytogeographers and ecologists involves meticulous scrutiny of earlier works, the detection of flaws in interpretations of data, and a reorganization of much of the information produced by previous workers. It also brings forth new ideas and additional data essential in the ultimate solution of problems involving all sorts of botanical viewpoints. I wish only to emphasize that the tedious task of constructing keys and writing descriptions are among the first steps toward the full understanding of the flora, the vegetation, and the individual species within a circumscribed area.

The work of the phytogeographer involves many facets in the study of plants. These facets were so numerous and attractive in the arctic and subarctic botany of Alaska that Dr. Hultén felt, I assume, impelled to avoid some of the time-consuming task of writing descriptions and building keys to the genera, in order that he might devote more energy to the studies centering around details less frequently covered in most taxonomic 
treatments. The wealth of material in his book marks an accomplishment of considerable magnitude. It signals the embarkation upon a study involving a specialist's interest in a particular portion of the earth and the plants that it supports. In this study he has devoted himself to the taxonomic, phytogeographic, and ecological problems that are common to widely separated areas, which have a high degree of similarity in the types of habitats available to plants. He has kept this in mind throughout the full course of his work and has presented evidence that this similarity in the range of habitats in widely separated areas has resulted in a degree of similarity in the floral make-up among them that is greater than had been believed by most botanists. In this way, the botany of Alaska, under the hands of Hultén, has taken on an international aspect very different from the international scope of the botany involved when Hooker and Arnott (7) described plants collected in Alaska over a century ago. They-Hooker and Arnottwere pioneering in the early phases of botany, interested in what grew in particular areas. Our Scandinavian colleague, on the other hand, has placed the emphasis on the why and the how of the problems of plant distribution and phylogenetic relationships. Neither type of emphasis is out of place. The second logically follows the first. The main differences lie in the lapse of time between the taxonomic approach and the vegetational approach, not in the absence of either.

But to return to a more nearly chronological summary of the development of botanical research in Alaska may I go back to the time when the taxonomic investigations began to be accompanied by those involving the ecological aspects of botany? At this time the floristic approach was being supplemented by the vegetational slant. The differences between these two types of botanical research were succintly summarized by Dr. Polunin, who wrote, "The flora of an area is the sum total of different 'kinds' of plants inhabiting it, no matter whether they are scarce or plentiful. The vegetation, on the other hand, is concerned largely with the question of relative abundance, being the total 'display' that the plants make collectively' (14, p. 1). The trend 
toward dealing with the vegetation as well as with the classification of the components of that vegetation paralleled the upsurge in support of plant ecology in the continental United States that followed the work of Cowles in the region around the southern end of Lake Michigan (5). Some of the early ecological work in Alaska was done by W. S. Cooper, whose interest in, and report about, the relationship between plants and the influence of glaciers stimulated others to investigate various aspects of the ecological complex in Alaska (4). Cooper's interest in Alaskan botany continued for many years and resulted in repeated trips to Alaska and the publication of several papers dealing with the ecological aspects of Alaskan plants growing near glaciers. Other workers have continued to support this trend, some investigating the present position and composition of vegetational complexes, others interesting themselves in analyses of peat deposits, others studying the ecological inferences to be drawn from assemblages of fossil leaves in alluvial and lacustrine deposits, and still others probing the secrets of the age of forest trees with increment borers or the relationship between plants and frost action. The work of Polunin in Canada, resulting in the publication of three volumes, has considerable value for botanists working on vegetational problems in Alaska (12, 13, 14). For, although his work was on the Canadian eastern arctic, many of the plants with which he dealt occur in northern Alaska under conditions that make his observations as valid in our area as they are a few degrees farther east. The work on botanical ecology done in boreal North America was ably summarized by Raup (15) in 1941 , his own work in northern parts of the continent having added a great deal to the sum total of knowledge about boreal and sub-boreal vegetation on our continent.

The heavy emphasis placed on systematic and ecological work involving plants of Alaska in the foregoing discussion has been prompted by an attempt to block out the chief aspects of botanical research in, and relating to, the territory and not because of any belief that other aspects of botany are unimportant. The trends in research dealing with the cytology, 
anatomy, and genetics as applied to Alaskan plants appeared only recently or are yet to appear in any appreciable degree. The cytology of some Alaskan plants was touched lightly by the work of Clausen, Keck, and Hiesey (3). Their transplant work and the investigation of the cytotaxonomy of Achillea, and their breeding program involving various grasses, included Alaskan material. They hope that the use of plants from northern regions may help solve several problems in the cytotaxonomy and in the breeding of range grasses for higher and more prolonged yield under adverse conditions. Added impetus to the work in the cytology and cytotaxonomy of northern plants has been furnished, also, by the researches of Askell and Doris Löve, in their papers dealing with the chromosome numbers in arctic plants and in critical considerations of particular species in high northern latitudes $(10,11)$. Although they did not work in Alaska nor directly on material from Alaska, many of the species on which they reported are members of the Alaskan arctic and subarctic flora. This papers will, therefore, be of importance to botanists wishing to check the cytotaxonomic characteristics of arctic plants of the North American continent with those bearing the same names but growing in European areas. Some such comparative work has already been started in an attempt to determine whether certain Alaskan plants are identical with those bearing the same names in the European regions or merely similar in external appearances.

Plant breeding experiments carried on by the United States Department of Agriculture with crop plants with promise for use in northern areas, and similar work at the University of Alaska, indicate a healthy trend toward the utilization of proven techniques and new methods. No doubt the workers interested in this type of program will push the plant breeding work and new strains well adapted to Alaskan conditions will result.

Physiological work on plants in Alaska seems as yet to be in its infancy. There are indications that activity in this phase of botany may soon increase, both through investigations carried on in Alaska, and by those done elsewhere but utilizing Alaskan materials. Numerous problems involving growth under con- 
ditions of low temperatures, fruiting of plants within the short span of an arctic growing season, after-ripening of seeds or their ability to grow immediately after maturing, the water relations of plants with their roots partially in contact with frozen ground during the active season-all these and numerous others await the attention of able plant physiologists.

An increased interest in anatomical and morphological problems using Alaskan plants has been in evidence recently. A few months ago a graduate student in an Oregon institution inquired about the feasibility of collecting anatomical and morphological material during the summer months in Alaska, then working up part of the fixed material during the ensuing college year and distributing the bulk of it to interested workers in various parts of the world. A plant anatomist and morphologist in India requested material of a critical genus known to occur in Alaska in order that comparative studies might be made in his laboratory. Other plant anatomists also might find numerous intriguing problems and a wealth of material in the Alaskan flora!

Specialists in various groups of plants have visited Alaska to collect material for their own use and for distribution to colleagues and research laboratories. Others have had ferver opportunities to engage in the field exploration but have utilized Alaskan material in their studies. Bryologists $(8,16,17$, 18), algologists, lichenologists, pteridologists, and specialists interested in only one or two genera within various families of plants have studied Alaskan material within the past decade or two. Requests for specific items come to the Arctic Research Laboratory frequently, indicating a continued and stimulating interest in plants of the Alaskan arctic and subarctic regions. One person desired seeds of the more attractive wild flowers; another wanted cytotaxonomic material of a group of sedges; still another was curious about the chromosome numbers and configurations in the anthers of the Alaskan Scrophulariaceae. This list need not be prolonged, but the steady flow of requests for material and information indicates an awakening consciousness of the opportunities for intensely intriguing research on Alaskan material. 
The possibility of utilizing plants as indicators of underlying geological conditions, or their relationships to permafrost, to erosion and its prevention, has caused the U. S. Geological Survey to employ professional botanists to cooperate in field and laboratory with the geologists. This marks another significant trend in botanical research in Alaska-a trend toward teamwork among men interested primarily in widely different disciplines. The acceleration in the solving of different research problems when lines of demarcation between disciplines are crossed and the puzzles are approached collectively with each mind focusing on a particular aspect of the whole was demonstrated brilliantly during World War II. There is no excuse for disregarding the lessons taught during the bitterness of war. Such team work among botanists working on different phases within the science, and among botanists in association with workers in other areas of human knowledge inevitably will bring richer results, and with less waste of time, man power and energy, than could be realized if each individual continued to work in seclusion. Even we taxonomists, who at times are loathe to divulge some of our finds to colleagues, prior to publication, realize the value of inviting the aid of specialists. One taxonomist and plant geographer wrote, "In works comprising all groups of vascular plants it is desirable that critical genera should be worked up by scientists who have had the opportunity of devoting more time to the study of their special group than is possible for the author of a complete flora" (9).

Another trend, one which possibly may be as significant as any other, is that involving a careful consideration of the needs facing research in any particular discipline and then attempting to fill that need. Some of the needs that should be filled, if the future of botanical research in Alaska is to contribute fully to the benefit of the science, the nation, and to the people of the Territory itself, may profitably be mentioned. There is a need for realization among botanists in other parts of the country that Alaska and its flora offer rich fields for botanical investigations along several lines of specialization. There is need for more tangible support for botanical science in Alaska. 
There is need for a deeper realization of the importance of doing botanical research that may not have any immediate practical application. These needs are pressing if severe neglect of the botanical possibilities is to be avoided. Support can take the form of fellowships and grants-in-aid that will enable qualified botanists to do field work in Alaska. It can take the form of modest laboratory facilities at several strategic points in Alaska, where visiting scientists can work in close proximity to the living material of the region and have personal conferences with local botanists and with other visiting scientists. The Arctic Research Laboratory, sponsored by the Office of Naval Research, is located at Point Barrow and extends facilities to investigators who are able to secure contracts covering their research projects. But this one laboratory, situated as it is several hundred miles from the nearest steamship or rail terminal, is not enough. Another laboratory at or near Fairbanks, Anchorage, or Palmer would offer greatly increased inducements to "outside" botanists to carry on programs of research on Alaskan material within Alaskan territory. Still another form that support to botanical work can take is that of a substantial reduction in the teaching load of faculty members at the University of Alaska. Such a move would permit faculty members to engage in research in their own specialties and at the same time increase the prestige of the University through the publication of the results of that research.

Yet another need, and it is ever present in every science, is enthusiasm and drive on the part of botanists interested in Alaska and Alaskan plants. This drive must be the kind that carries through to the very end of the project-the kind that will result in completed investigations, full explanations of methods, techniques, and hypotheses, forcefully and directly phrased. Ideas in investigators' minds are essential. Without them there would be little productive research. But they become permanently valuable only after they have been translated into action and the results of their application made available to others through publication-less frequently by word of mouth. If we combine enthusiasm, energetic action, coopera- 
tion, and vision with persistence, objectivity, and intellectual honesty, future botanical research in Alaska will produce important, and possibly astounding, results.

\section{REFERENCES}

1. Anderson, J. P. Flora of Alaska and adjacent parts of Canada. Parts I-VIII (Pteridophytes-Campanulaceae). Iowa State College Journal of Science. 1943-50.

2. Cardot, J., and I. Theriot. The mosses of Alaska. In Harriman Alaska Series, Vol. V. Smithsonian Institution Publication No. 1994: 253-328, 1910.

3. Clauden, Jens, David D. Keck, and William M. Hiesey. Experimental studies on the nature of species, I. Effect of varied environments on western American plants. Carnegie Institution of Washington Publication No. 520. 1940.

4. Cooper, W. S. The Recent ecological history of Glacier Bay, Alaska. Ecology 4: 93-108, 223-46, 355-65. 1923.

5. Coivles, H. C. The ecological relations of the vegetation on the sand dunes of Lake Michigan. Botanical Gazette, 27: 95-117, 167-202, 281-308, 361-91. 1899.

6. Cummings, Clara E. The lichens of Alaska. In Harriman Alaska Series, Vol. V. Smithsonian Institution Publication No.1994: 67-149. 1910.

7. Hooker, W. J., and G. A. W. Arnott. Botany of Captain Beechey's voyage. 111-134. 1832 .

8. Howe, Marshall A. Contributions to the botany of the Yukon Territory. 1. An Enumeration of the Hepaticae collected by R. S. Williams, 1898-99. Bulletin of the New York Botanical Garden, 2: 101-05. 1901.

9. Hultén, Eric. Flora of Alaska and Yukon. Parts I-X. 1941-5o.

10. Love, Askell, and Doris Love. Studies on the origin of the Icelandic flora. I. Cyto-Ecological Investigations on Cakile. Iceland Department of Agriculture Reports, Series B, No. 2: 1-29. 1947 .

11. Chromosome numbers of northern plant species. Op. cit. No. 3: 1-131. 1948.

12. Polunin, Nicholas. Botany of the Canadian Eastern Arctic. Part I. Pteridophyta and Spermatophyta. National Museum of Canada Bulletin No. 92, Biological Series No. 24. 1-4o8. 1940 .

13. - Part II. Thallophyta and Bryophyta. Op. cit., Bulletin No. 97, Biological Series No. 26. 1-573. 1947. 
14. - Part III. vegetation and ecology. Op. cit. Bulletin No. 104, Biological Series No. 32. 1-304. 1948.

15. Raup, Hugh M. Botanical problems in boreal America. Botanical Review, 7: 147-248. 1941.

16. Steere, W. C. Bryophyta of Arctic America. I. Species from Little Diomede Island, Bering Strait, Alaska. American Midland Naturalist, 19: 436-439. 1938.

17. - Bryophyta of Canadian Arctic. Collection of Father Artheme Dutilly, O.M.I., Naturalist of the Arctic Oblate missions. Habitat of the Eskimo, Flora Arctica. Scolasticat Notre Dame, Village Richelieu. P. Q., Canada. 1-31. 1941.

18. - Musci. in Botany of the Canadian Eastern Arctic. II. National Museum of Canada Bulletin No. 97, Biological Series No. 26. 370-490. 1947.

19. Trelease, William. The ferns and fern allies of Alaska. In Harriman Alaska Series, Vol. V. Smithsonian Institution Publication No. 1994: 375-398, pl. XLIV. 1910. 


\section{GLACIOLOGICAL RESEARCH IN ALASKA \\ William O. Field, JR. American Geographical Society}

Glaciological Research in Alaska and the adjacent portions of Canada dates from 1863 when Professor W. P. Blake (5), as a guest scientist of a Russian Naval squadron, visited the lower Stikine River and reported on several of the glaciers in what was then called "Russian America." During the next four decades, the location and approximate extent of existing glaciers were determined. Since 1940, important gaps in our knowledge of their size and distribution have been filled by means of aerial photography, performed as part of the mapping operations of World War II. For the first time, therefore, we now have a record, perhaps 95 percent complete, of the outward appearance and characteristics of the glaciers in Alaska and adjacent British Columbia and the Yukon. ${ }^{1}$

The general features of Alaskan glaciation were known by 1900 , including the fact that Alaska has a little less than 20,000 square miles of ice with perhaps another 5 ,ooo square miles in the adjacent parts of Canada. Although this represents somewhat less than three and one-half percent of the land area of Alaska, the glaciers are nevertheless among the largest outside the Polar Regions, with only those in Patagonia and the Central Asiatic-Himalayan Mountain system attaining comparable size. As an area for glaciological research, both in terms of glacial geology and the study of existing glaciers, it is unsurpassed. By comparison with the Alps and Scandinavia or even our Pacific Northwest, the intensive investigation of these glaciers is more difficult because of their not being located near large centers of population, but, nevertheless, it may be said that no glaciers of comparable size are as accessible for purposes of detailed

1 The selected bibliography at the end of this paper lists the principal published accounts of the observations of individuals and expeditions cited in the text. 
study. Alfred H. Brooks wrote in 1902, "Southeastern Alaska is par excellence the region of the world in which to study glaciers. . . " (6, p. 31). Later, Ralph S. Tarr and Lawrence Martin added, "The Alaskan region is one of the most wonderful regions of glaciation in the world, both from the standpoint of number and size of its glaciers, and from the extent and variety of associated phenomena; and a thorough study of any of its facts is certain to yield important scientific results. The phenomena of advance and recession of the glacier termini, the former extent of the glaciers and their deposits, and the stupendous work which they have accomplished in sculpturing the wonderful series of fiords are among the phenomena demanding attention. The features exhibited have far more than local importance and application, for the fact that we have here large glaciers descending to sea level in a comparatively-warm, humid, north temperate climate gives rise to phenomena resembling those of the wasting margin of the great continental ice sheets of North America and Europe, and, therefore, throw light upon and furnish aid in interpreting these phenomena." (55, pp. 21-22).

During the last period of great ice expansion in North America, a large part of central Alaska apparently remained ice-free and glaciers appear to have been confined largely to the mountain areas and the adjacent lowlands. Thus we have the apparent paradox that, while New England and our Great Lakes area were covered in places to a depth of several thousand feet, there was no general ice cover in many parts of the Yukon Valley, some 20 to 25 degrees farther north.

It is impossible in a short report to enumerate all those who have been active in the study of Alaskan glaciers and glaciation. John Muir (34) in 1879 and 1880 was the first to report on the glaciers of Glacier Bay. He was followed by G. Frederick Wright (62) in 1886 and by Harry Fielding Reid $(39,40)$ in 1890 and 1892. The latter, with his mapping, photography and detailed observations, set the pattern for most of the studies of existing glaciers which have since been made. Israel C. Russell (41-43) visited the Malaspina and several of the other glaciers of the 
Yakutat Bay area in 1890 and 1891 . The Harriman Alaska Expedition $(21,35)$ of 1899 , which numbered among its scientists Grove Karl Gilbert and John Muir, visited Glacier Bay and Yakutat Bay and extended detailed studies up the coast to Prince William Sound and the Kenai Peninsula.

Another milestone was established by Tarr and Martin (28$3^{0}, 4^{8-55}$ ) in their work from 1904 to 1913 , mostly undertaken for the National Geographic Society, which in 1914 published their results in "Alaskan Glacier Studies," an unusually detailed and beautifully illustrated volume. Their studies covered the glaciers of Glacier Bay, Yakutat Bay, the lower Copper River, Prince William Sound, and parts of the Kenai Peninsula. In Yakutat Bay, the observed spasmodic advances of many of the glaciers were attributed to the earthquake of September, 1899 , and a hypothesis was proposed which was termed the "earthquake advance theory" (55, p. 168). In 19o6, F. E. and C. W. Wright (61), of the U. S. Geological Survey, made a detailed study of the glaciers of Glacier Bay, and C. W. Wright followed this up with a second visit to the area with H. F. Reid in 1931. These two observers thus returned to continue observations which they had begun respectively 25 and 39 years previously. Regretably, only summaries of Wright's observations have been published. In 1905, 1908, and 1909, U. S. Grant and D. F. Higgins (22), also of the Geological Survey, conducted a series of observations of the glaciers of Prince William Sound and the Kenai Peninsula.

In 1916, William S. Cooper (10-14), of the University of Minnesota, began a long-term systematic study of plant ecology in the areas recently vacated by the ice in Glacier Bay. In order to work out the schedule of vegetation growth and plant succession, he found it necessary to determine the clironology of ice recession. This contributed much to the study of glaciers as well as to plant ecology. His periodic visits began in 1916 and continued to 1935 and then were taken up by his associate, Donald B. Lawrence $(26,27)$, also of the University of Minnesota, in 1941, 1949, and 1950. This unique project, now in its $35^{\text {th }}$ year, has resulted in the publication of several very signifi- 
cant papers of interest to glaciologists as ivell as to plant ecologists and climatologists.

Other important contributions were made by Stephen R. Capps (7-9), of the Geological Survey, whose papers on Pleistocene glaciation and existing glaciers in various parts of Alaska are outstanding. From 1937 to 1940 , Bradford Washburn ( 5 6$5^{8)}$ took a series of magnificent aerial photographs of Alaskan glaciers which constitute a unique record of the positions of their termini and other features of glaciological interest. The U. S. Navy, in 1929 and again in 1948 , carried out special missions to photograph the glaciers of Southeastern Alaska. This aerial record, made especially for glaciological purposes, together with the trimetrogon and vertical photography undertaken by the Air Force and Navy for mapping purposes, constitutes an impressive source of information for which students of Alaskan glaciers will long be grateful.

Mention should also be made of the valuable data on glaciers and glaciation obtained by Geological Survey parties which have been concerned primarily with the study of other aspects of geology or have been engaged in topographic surveying; the largely unsung work of Canadian and American surveying parties (25) who delimited the international boundary and mapped surrounding areas from 1893 to 1912 ; the U. S. Coast and Geodetic Survey parties who have been charting the coast of Alaska and recording the position of many of the glacier termini which descend to tidewater; and the U.S. Forest Service which has sponsored observations of the glaciers situated within the national forests.

During the last seven decades, many travellers, ranging from casual visitors to field parties specifically organized for the purpose, have obtained data on the variations in size of the glaciers. The information obtained by them has contributed significantly to our understanding of the general trends of glacier variation and the resulting changes in the topography and growth of vegetation. Although much of this information has originated from non-scientific sources, it is nevertheless of definite value in the interpretation of glacial phenomena. 
Until the 1940's, practically all glaciological observations in Alaska were conducted in the terminal areas of the glaciers or immediately above in the zone of wastage. Largely because of the difficulty in making observations at higher levels, none but mountaineering or surveying parties could extend their activities above the névé line. However, during the past few years, more comprehensive studies have been begun which can be attributed primarily to three factors. First is the impetus provided by developments in the Alps, Scandinavia, and the islands of the North Atlantic, where new methods and concepts of glaciological research have been worked out and applied in the field $(2,31)$. A new comprehensive approach on a three, rather than a two, dimensional basis, and involving microclimatological and geophysical techniques, lias been developed to challenge glaciologists in this country. A second factor concerns the development of aerial techniques which have made possible an expansion of the scope of glacier studies in Alaska through aerial photography; aerial supply of field parties by parachute and free-fall; and the development of the ski-wheel plane, which can take off from an airport on wheels and land on a névé on skis, for transporting personnel, equipment, and supplies. In the future, we may expect that helicopters will also be used to reach areas on glaciers and ice fields where ski landings and takeoffs by airplanes are not feasible. New sources of support and cooperation form an important third factor. These derive largely from government sources, primarily from the National Military Establishment, which have made possible comprehensive studies involving more equipment and personnel than have previously been available for purely glaciological undertakings.

Largely as a result of these three factors, what may be termed a new era in research in the Alaskan area began in 1948 when the Arctic Institute initiated Project Snow Cornice under the leadership of Walter A. Wood (6o) with Robert P. Sharp (45) of the California Institute of Technology in charge of the glaciological studies. The work, which was continued in 1949, has been carried out on the Seward-Malaspina glacier system 
in the St. Elias Mountains, partly in Yukon Territory and partly in Alaska, and appropriately, by parties composed of both Canadians and Americans. Detailed observations of the firn have been macle, including thermohm records of ice temperature at depths; studies of the physical character of the névé in pits dug down to $5^{0}$ feet; density profiles; analyses of the free water content of the snow and firn; melt water percolation; rate of ablation by melting and evaporation; and rates of snow accumulation between what were believed to be annual horizons. Measurements were also made of ice movement at the surface and of ice thickness by seismic means, gravimeter, and radar (36). In 1949, Henri Bader conducted crystallographic and structural studies on the ice of the Malaspina Glacier. This is probably the most extensive single glacier system in North America and in the Malaspina, represents the largest and best example of a piedmont glacier outside the Polar Regions. The Navy, through the Office of Naval Research, and the Departments of the Army and the Air Force provided major support for this scientific program. A third field season is now planned for 1951 .

In 1948, another somewhat similar undertaking was begun by the American Geographical Society, near Juneau on the névé of the Coast Range, which for convenience is referred to as the Juneau Ice Field $(19,26,27,32)$. This project was continued in 1949 and $195^{\circ}$ and has had for its primary objective the detailed study of the regimen of a glacier system, the meteorological factors by which it is influenced, the structure of the névé and underlying ice, and the causes of its variations in volume. Four profiles to measure the thickness of the Taku Glacier were made by seismic means in 1949 (37), and the following year a drill rig was set up on the névé with which cores were obtained to a depth of nearly 300 feet. A pipe was left in the drill hole which will be surveyed periodically to determine its displacement and which will provide a means of measuring the temperature of the interior of the glacier. This project was made possible by the cooperation and support of a number of federal agencies. Of primary importance was a 
Research Contract with the Office of Naval Research, air iift provided by the Air Force and the Navy, equipment supplied by the Signal Corps, Quartermaster Corps, and Corps of Engineers, and personnel assigned by the Air Weather Service. Local facilities in Juneau were provided by the Forest Service, and substantial help was received from other institutions, among which may be mentioned the Arctic Institute, the Geological Society of America, and the U. S. Geological Survey.

Current investigations of Alaskan glaciers are along three distinct lines: first, the comprehensive and detailed studies at high level represented by Project Snow Cornice and the Juneau Ice Field Research Project; second, studies at low levels of the terminal portions of the glaciers and the moraine patterns resulting from variations in the recent past; and third, desk work in which all existing data gleaned from aerial photographs, maps, and contemporary and historical records may be correlated with current studies in the field. It should be emphasized that periodic visits to the glacier termini have not been superseded by the more specialized studies of regimen, structure, and ice mechanics on the glaciers themselves. Actually, there is a continuing need for both. The spot checking of the behavior of termini indicates the local and regional trends of glacier variations in the past and present, while the more intensive studies, especially at higher levels, provide an opportunity of determining the various causative factors involved in glacier variation, as well as affording a means of carrying out field research on the mechanics of flow and other characteristics of glacier ice and névé.

As Professor H. W:son Ahlmann has stated: "To serve its aims glaciology must in future be founded in the first place on physics, mechanics, crystallography and meteorology and must belong to the complex of sciences that in certain countries go by the name of geophysics." (1, p. 4). From the study of existing glaciers in Alaska, we may expect to broaden our knowledge of climatic change, both in the present and in the interval since the last Ice Age on this continent; further information may be gained on the delicate balance of meteorological factors which 
combine to produce conditions favorable to the existence of glaciers in various parts of the world; and research in certain fundamental problems in geology and geophysics, such as the mechanics of rock deformation and flow and the manner of recrystallization of mineral components under stress, may also be aided by a study of ice.

Glaciology thus has broader scope than merely the study of ice itself. It serves the fields of climatology, geology, physics, geophysics, geomorphology, and plant ecology. In looking ahead, it would seem desirable to continue and expand current field research by placing special emphasis on the study of the following: the structure and properties of glacier ice and névé, including the mechanics of ice flow; glacier regimen; the variations of glaciers and the relationship between these variations and climatic change; the character and extent of Pleistocene glaciation. In centers of learning one may hope that, while field research goes forward, adequate attention will also be paid to the work of systematically describing and classifying the glaciers, correlating existing data, compiling detailed base maps of existing glaciers as well as Pleistocene glacial deposits, and assembling source materials and bibliographies. There is room here for activity on the part of the trained scientist, the student, and even the very casual traveller.

At the same time, there is the need for close relationship between the individuals, institutions, and government agencies active or interested in this field of study. We must ensure that all existing records will be preserved for future generations and that, meanwhile, we may maintain maximum facilities for cooperation and an interchange of information. This is precisely one of the functions which the Alaskan Science Conference envisions, whereby each of us may know what other individuals, institutions or Government agencies are doing, and how one another's programs may be integrated for our mutual benefit. Glaciology, although playing a relatively minor part in Alaskan scientific research, does nevertheless involve the activities of many diverse groups. The relatively long list of government and private agencies which are concerned to a lesser or greater 
degree with Alaskan glacier studies indicates clearly how useful such liaison can be. Whatever coordination and mutual understanding can be engendered will produce, at no extra cost or expenditure of energy, far more useful results than can otherwise be attained. It is also important for those active in the study of Alaskan glaciers and glacial phenomena to maintain close relations with investigators in other parts of the world, for only through close cooperation and correlation of results will the broader aspects and basic purposes of glaciology be realized.

\section{REFERENCES}

1. Ahlmann, H. W:son. Foreword. Journal of Glaciology, $I: 3$. 1947 .

2. Ahlmann, H. W:son. Glaciological research on the North Atlantic coasts. R. G. S. Research Series: No. 1, Royal Geographical Society, London, 1-83. 1948.

3. Bateman, Alan M. Kennecott Glacier of Alaska. Bulletin Geological Society of America, 33: 527-540. 1922.

4. Blackwelder, Eliot. Glacial features of the Alaskan coast between Yakutat Bay and the Alsek River. Journal of Geology, 15: 415-433. 1907 .

5. Blake, W. P. The glaciers of Alaska, Russian America. American Journal of Science, 2nd Series, 44: 96-101. 1867.

6. Brooks, Alfred Hulse. Preliminary report on the Ketchikan mining district, Alaska, with an introductory sketch of the geology of Southeastern Alaska. U. S. Geological Survey, Professional Paper No. 1. 1902.

7. Capps, Stephen R. Glaciation on the north side of the Wrangell Mountains, Alaska. Journal of Geology, I8:33-57. 1910.

8. Capps, Stephen R. Glaciation of the Alaska Range. Journal of Geology, 20: 415-437. 1912.

9. Capps, Stephen R. Glaciation in Alaska. U. S. Geological Survey, Professional Paper No. 170-A. 1931.

10. Cooper, William Skinner. The recent ecological history of Glacier Bay, Alaska. Ecology, 4: 93-128, 223-246, 355-365. 1923 .

11. Cooper, William Skinner. A third expedition to Glacier Bay, Alaska. Ecology, 12: 61-95. 1931.

12. Cooper, William Skinner. The problem of Glacier Bay, Alaska: A study of glacier variations. Geographical Review, 27: 37-62. 1937 . 
13. Cooper, William Skinner. A fourth expedition to Glacier Bay, Alaska. Ecology, 20: 130-155. 1939.

14. Cooper, William Skinner. Vegetation of the Prince William Sound region, Alaska; with a brief excursion into PostPleistocene climatic history. Ecological Monographs. I2 (1). 1942.

15. Davidson, George. The glaciers of Alaska that are shown on Russian charts or mentioned in older narratives. Transactions and Proceedings, Geographical Society of the Pacific, Series II, 3: 1-98. 1904.

16. Field, William O., JR. The glaciers of the northern part of Prince William Sound, Alaska. Geographical Review, 22: 361-388. 1932.

17. Field, William O., Jr. Observations on Alaskan coastal glaciers in 1935. Geographical Review, 27:63-81. 1937.

18. Field, Willian O., Jr. Glacier recession in Muir Inlet, Glacier Bay, Alaska. Geographical Review, 37: 369-399. 1947.

19. Field, William O., Jr. and Maynard M. Miller. The Jumeau Ice Field Research Project. Geographical Review, fo: $179^{-1}$ 9o. $195^{\circ}$.

20. Flint, Richard Foster. Glacial map of North America. Part 1, Map: 2 sheets, scale 1:4,555,00o; Part 2, Bibliography and explanatory notes. Geological society of America, Special Papers, No. 6o. 1945 .

21. Gilbert, Grove Karl. Alaska: Glaciers and glaciation. Harriman Alaska Expedition, 3: Doubleday, Page and Company. New York. 1904.

22. Grant, U. S. and D. F. Higgins. Glaciers of Prince William Sound and the southern part of the Kenai Peninsula, Alaska. Bulletin American Geographical Society, 42: 721-738. 1910. 43: 321-338, 401-417, 721-737. 1911. Also U. S. Geological Survey, Bulletin 526. 1913 .

23. Hance, James H. The recent advance of Black Rapids Glacier, Alaska. Journal of Geology, 45: 775-783. 1937.

24. Kerr, Forrest A. Quaternary glaciation in the Coast Range, Northern British Columbia and Alaska. Journal of Geology, 44: 681-700. 1936 .

25. Klotz, Отто J. Notes on glaciers of Southeastern Alaska and adjoining territory. Geographical Journal, 14:523-534. 1899.

26. Lawrence, Donald B. and Elizabeth G. Some glaciers of Southeastern Alaska. Mazama, 3 I (13): 24-30. 1949 .

27. Lawrence, Donald B. Glacier fluctuation for six centuries in Southeastern Alaska and its relation to solar activity. Geographical Review, 40: 191-223. $195^{\circ}$. 
28. Martin, Lawrence. The National Geographic Society researches in Alaska. National Geographic Magazine, 22:537-561. 1911.

29. Martin, Lawrence. Alaskan glaciers in relation to life. Bulletin American Geographical Society, 45: 801-818. 1913.

3o. Martin, Lawrence. Jumeau-Yakutat Section, Guide Book No. 10, Excursion C 8, [International Geological Congress] Geological Survey, Ottawa. 121-176. 1913.

31. Matthes, Francois E. Glaciers, Chapter 5 Hydrology, Physics of the Earth, edited by O. E. Meinzer, 9: 149-219. McGrawHill Book Company, Inc., New York and London. 1942.

32. Miller, Maynard M. Progress report of the Juneau Ice Field Research Project, 1948. American Geographical Society, 1949. (Mimeographed).

33. Moffit, Fred H. Black Rapids Glacier, Alaska. U. S. Geological Survey, Bulletin 926-B: 146-157. 1942.

34. Muir, John. Travels in Alaska. Houghton Mifflin Company, Boston and New York. 1915 .

35. Murr, John. The Pacific Coast Glaciers. Harriman Alaska Expedition, $I$ : 119-135. Doubleday, Page and Company. 1902.

36. Northwood, T. D. and F. W. Simpson. Depth measurements in the Seward Ice Field by sonic echo-ranging, National Research Council of Canada, Division of Physics, Report No. PS-300. 1948.

37. Poulter, Thomas C. and C. F. Allen and Stephen IV. Miller. Seismic measurements on the Taku Glacier. Stanford Research Institute, Stanford, California. 1949.

38. RAY, LouIs L. Some minor features of valley glaciers and valley glaciation. Journal of Geology, t3: 297-322. 1935 .

39. Reid, Harry Fielding. Studies of Muir Glacier, Alaska. National Geographic Magazine, 4: 19-84. 1892.

40. Reid, Harry Fielding. Glacier Bay and its glaciers. U. S. Geological Survey, 16th Annual Report, 1894-95, Part I: 415-461. 1896.

41. Russell, Israel C. Mt. St. Elias and its glaciers. American Journal of Science, 3rd Series, 43: 169-182. 1892.

42. Russell, Israel C. The Malaspina Glacier. Journal of Geology, I: $219-245 \cdot 1893$.

43. Russell, Israel C. Glaciers of North America. (Chapter 6, Glaciers of Alaska, $74^{-1} 3^{\circ}$ ). Ginn and Company, Boston and London. 1897.

44. Sharp, Robert P. The Wolf Creek Glaciers, St. Elias Range, Yukon Territory. Geographical Review, 37: 26-52. 1947. 
45. Sharp, Robert P. Project "Snow Cornice." Engineering and Science Monthly, November, 1948. Published by California Institute of Technology Alumni Association.

46. Sharp, Robert P. Studies of superglacial debris on valley glaciers. American Journal of Science, 277:289-315. 1949.

47. Smith, Philıp S. Glaciation in Northwestern Alaska. Bulletin Geological Society of America, 23: 563-570. 1912.

48. Tarr, Ralph S. and Lawrence Martin. Glaciers and glaciation of Yakutat Bay, Alaska. Bulletin American Geographical Society, 38: 145-167. 1906.

49. TARR, Ralpi S. Recent advance of glaciers in the Yakutat Bay Region, Alaska. Bulletin Geological Society of America, 18 : 257-286. 1907 .

5o. Tarr, Ralph S. The Malaspina Glacier. Bulletin American Geographical Society, 39: 273-285. 1907 .

51. Tark, Ralph S. The Yakutat Bay Region, Alaska. U. S. Geological Survey, Professional Paper No. 64, 11-144. 1909.

52. Tarr, Ralph S. and Lawrence Martin. The National Geographic Society's Alaskan Expedition of 1909. National Geographic Magazine, 21: 1-54. 1910.

53. Tarr, Ralph S. Glaciers and glaciation of Alaska. Annals Association American Geographers, 2: 3-24. 1912.

54. TARr, Ralph S. The Glaciers and glaciation of Alaska. Science, New Series, 35: 241-258. 1912.

55. Tarr, Ralph S. and Lainrence Martin. Alaskan glacier studies of the National Geographic Society in the Yakutat Bay, Prince William Sound and Lower Copper River Regions. The National Geographic Society. 1914.

56. Washburn, Bradford. Morainic bandings of Malaspina and other Alaskan glaciers. Bulletin Geological Society of America, 46: 1879-189o. 1935 .

57. Washburn, H. Bradford, Jr., and Richard P. Goldthwait. The Harvard-Dartmouth Alaskan Expeditions, 1933-1934. Geographical Journal, 87: 481-517. $193^{6 .}$

58. Washburn, Bradford, and Richard Goldthwait. Movement of South Crillon Glacier, Crillon Lake, Alaska. Bulletin Geological Society of America, 48: 1653-1663. 1937.

59. Wentworth, C. K. and L. L. Ray. Studies of certain Alaskan Glaciers in 1931. Bulletin Geological Society of America, 47: 879-933. 1936.

6o. Wood, Walter A. Project "Snow Cornice." Arctic, I (2): 107112. 1948 . 
61. Wright, F. E. and C. W. The Glacier Bay National Monument in Southeastern Alaska: Its glaciers and geology (unpublished manuscript based on studies in 1906 and 1931 in the files of the U. S. Geological Survey); See also Reid, Harry Fielding. Variations of glaciers XII. Journal of Geology, 16: $5^{1-55}$. 1908.

62. Wright, G. Frederick. The Muir Glacier. American Journal of Science, Series 3, 33: 1-18. 1887.

In addition to these references, there exist many valuable sources of information in the unpublished reports, field notes, photographs, and map data of many of the public agencies and private institutions which have been responsible for conducting research in this field. 


\title{
SOME GEOGRAPHIC BASES FOR PLANNING NEW ALASKAN SETTLEMENT*
}

\author{
KIRK H. STONE \\ Department of Geography \\ University of IVisconsin
}

Additional settlement in Alaska appears certain. Whether spontaneous or induced, by individuals or groups, in disorganized or orderly manner, it is the permanence of this future population that commands our interest. The cheapest insurance of permanence is sound planning. This must be based on facts, not only about physical features but, also, cultural topics. Of the latter, one is the determination of the total experience of Alaskan settlement. Geographically, the subject amounts to the questions: who settled where, when, why, upon what bases, and how permanently? However, the main question is: how much knowledge about means of insuring the permanence of settlement may we carry to Alaska's future from its past? The answer at the present time is too little. The concern here is to summarize data about the areas of Russian and English settlement, where specific research is likely to yield useful data.

In general, Russian occupance of Alaska was exploitive and relatively brief. Permanent settlement took place during the $8_{3}$ years prior to 1867 , certainly for fur purchasing and perhaps as a part of Russian encirclement of the northern Pacific Ocean. No matter the motive, nearly 800 Russians lived in the Territory at one time. These people located on or near the southern and western coasts. In Southeastern Alaska Russian fur purchasing activities were overlapped by those of the English and the two were combined in that area for nearly half a century. In all, about 45 sites were settled by Russians and three by English, of which about two-thirds of the total have been occupied continuously to the present time.

* Based upon research supported by the College of Letters and Science and the University Research Committee at the University of Wisconsin. 
In detail, Russian settlement is divisible chronologically and areally into three periods. ${ }^{1}$ Only the last two periods were of permanent occupance. The earlier was 1784 to 1830 , a period of entirely Russian occupation. The latter was 1830 to 1867 , of English as well as Russian settlement. Then, in 1867 , Russian America was sold to the United States.

\section{Russian Settlement: 1784-1830}

Known permanent settlement in Alaska began with the start of organized Russian fur purchasing. The first village was established in 1784 off the southern coast of Alaska on Kodiak Island (fig. 1). Founding of the village, at Three Saints Bay, may be said to be the fourth step in more than a century and a half of Russian expansion eastward.

First of the preceding three steps was the conquest of Siberia. This expansion began at the western edge in $15^{80}$ and went rapidly eastward, reaching the Pacific shore by 1700 . Increase of the Czar's fur trade was the motive. The second step was the discovery of Alaska, credited to Bering as of the year 1741 and based upon the Czar's desire to learn what was to the east of Siberia.

Then, after 1741 , followed the third step, 43 years of unorganized fur hunting by individuals called "promyshleniki." This period was one of ruthless exploitation of the Aleutian Island resources and people. Probably there were a few thousand promyshleniki; they sailed from island to island and stayed on the larger ones only as long as necessary to force the natives to bring in large quantities of furs. Between 1741 and 1784 there were 80,000 sea otter and 280,000 fur seal pelts taken. Little, if any, settlement was undertaken (other than a temporary occupation of Iliuliuk, on Unalaska Island in the eastern Aleutians)

1 'The periods were defined by plotting the location and date of establishment of each settlement founded during the period of Russian ownership of Alaska. Determination of the dates and locations required a survey of a number of general and specific sources, documentary and cartographic, in English and Russian, a number too great for practical listing herein. Several of the dates may be interpreted from or found in references number $2,3,5,6,8,9,10,14$, and 15 . See particularly the many sources noted in reference number 12. 


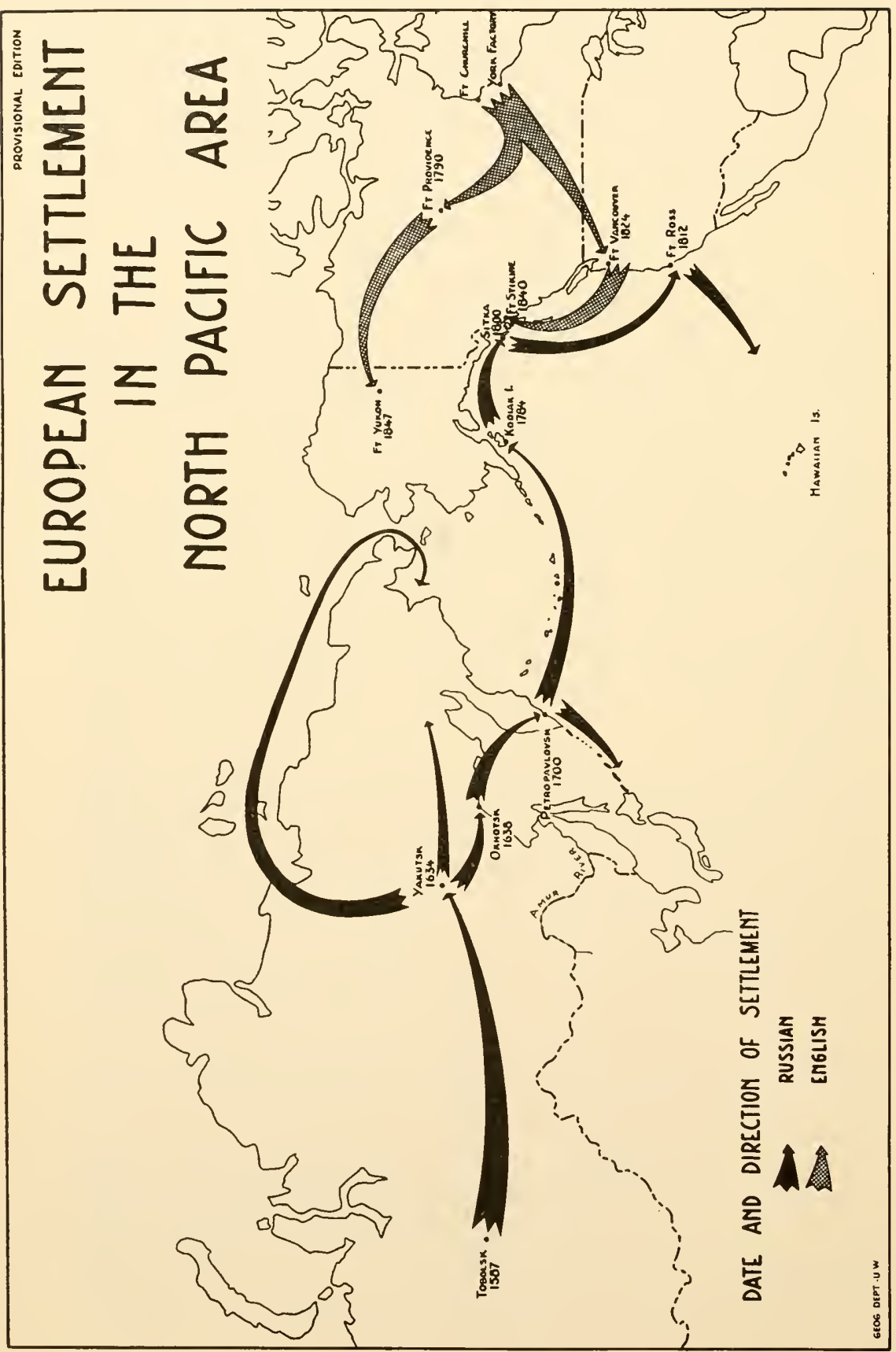


as is shown by the general continuity of the open arrow on figure 2. Yet, attention was focused on Russian America. Also, the Kodiak area was known, in the early 1780 , to be one in which the fur-bearing marine animals were still abundant in contrast to the badly depleted Aleutian Chain. Thus, the establishment of a village at Three Saints Bay was a logical eastward step for organized fur purchasing operations. ${ }^{2}$

In 1792 the site of the first settlement at Three Saints Bay was abandoned in favor of that at Kodiak village, then called St. Paul. There timber was available as well as a suitable harbor. Thence, representatives of two fur companies went northward into the Cook Inlet region where each stymied the expansion of the other. In the main, however, settlement spread eastward (fig. 2) after the formation in 1797 of the great Russian American Fur Company whose Alaskan headquarters were at Kodiak village. The movement was by a series of skips along the coast to Sitka by 1800 and Fort Ross, California in 1812 . The "backeddy" movement westward from Kodiak took place in the latter part of the period.

Two forces were behind the eastward advance of settlement after 1784 . One was the desire to find new sources of sea otter. They were the most important resource to the Russians and fur seal were second (fig. 3). By about 1790 the sea otter were becoming scarce in the Kodiak area and westward. Thus, attention was directed eastward to new sources. The efforts were worth it; annual returns in this period were the greatest in Alaskan history.

The other force leading to settlement was the will of Baranof, the first manager of the Russian American Fur Company. The company monopolized Alaska and Baranof sought to serve the Czar by extending Russian holdings through his managerial work. Some authorities (Ref. 11, p. 9) suggest that the Russian

2 Two additional preliminary stages of settlement are bare possibilities. The first is the possible discovery of Alaska in 499 A.D. by a Chinese explorer. The second is the reported migration of Russians in the 16th century from the lower Lena River in Siberia to an unknown site in the Territory. Neither requires analysis at this time because each occurrence apparently is unrelated to the continuous permanent settlement begun at Kodiak Island. 


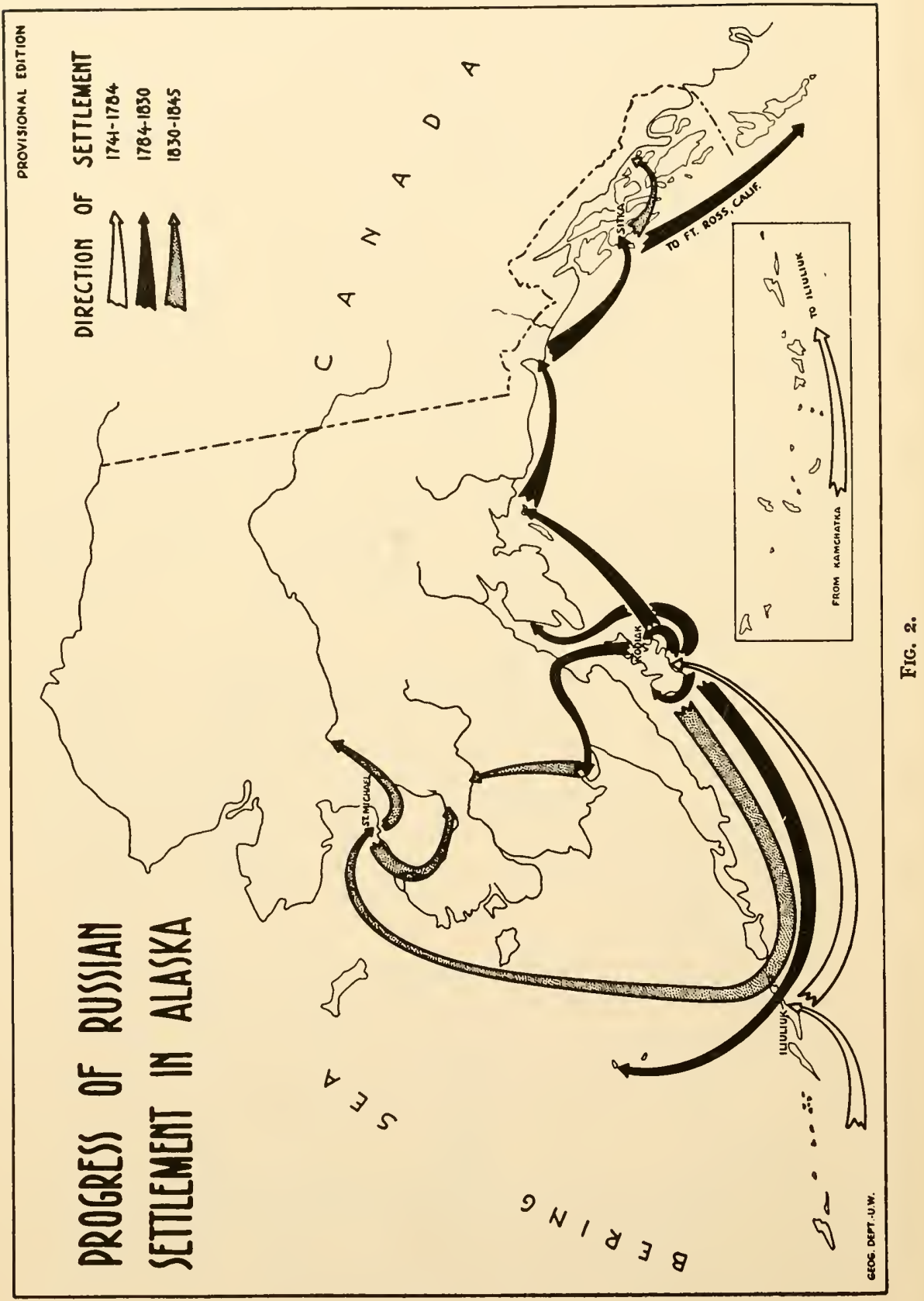




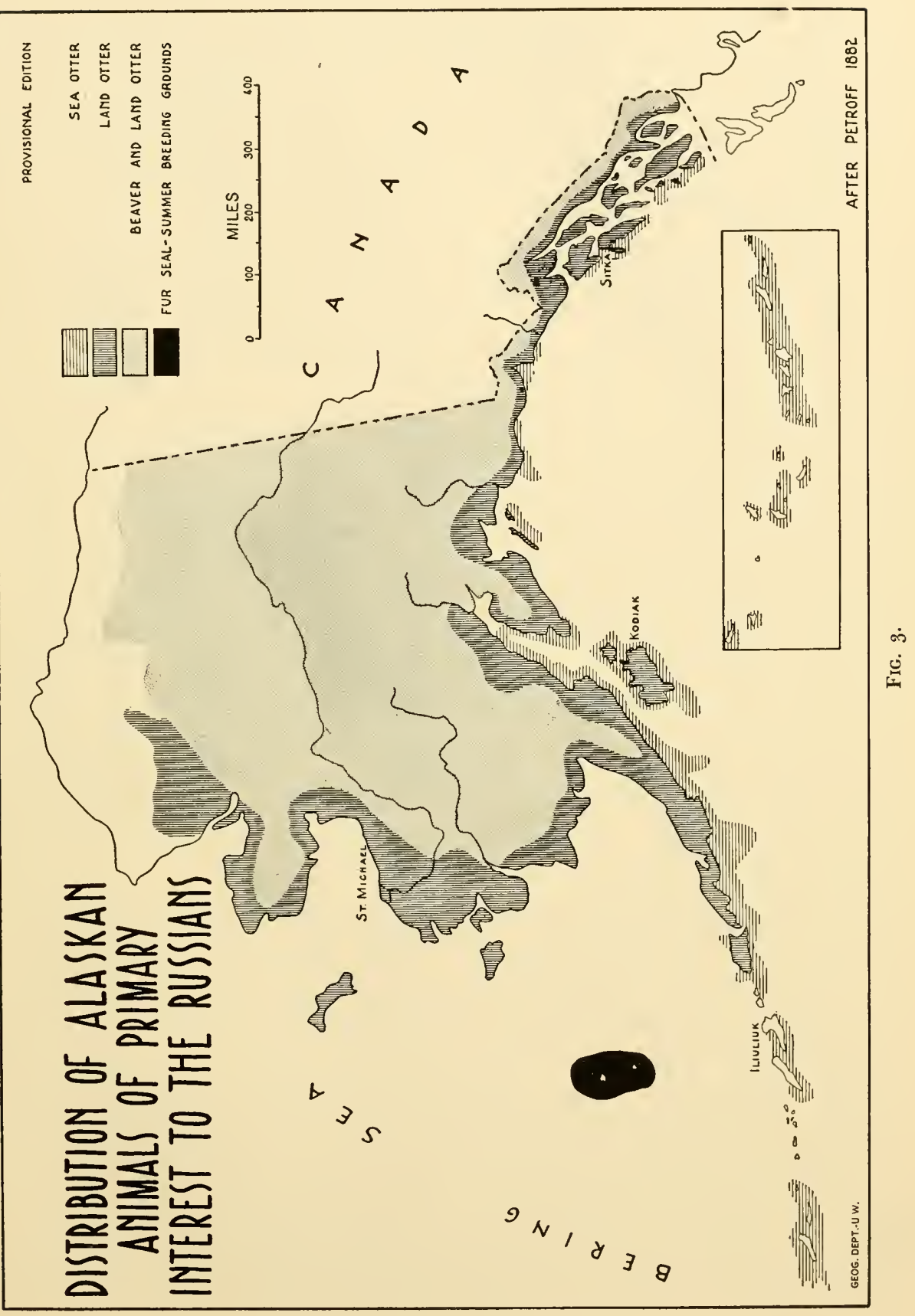


government wished to encourage expansion in the Pacific area. Kerner, however, maintains that Russia was not interested in expansion in the early 1800 's but, rather, in regaining the Amur River valley from China for commercial reasons (Ref. 12, passim). In addition, Russian communications with Kodiak were difficult enough over the 6900 miles from Leningrad to the island without adding $75^{\circ}$ miles more to Sitka and still another 1400 miles to Fort Ross. Nevertheless, Baranof favored expansion. The founding of the California colony (by Rezanof) fit Baranof's desires although the fort was intended, and served, to prevent starvation of the Russians in Alaska. Finally, it was from Fort Ross that Baranof's deputy made an abortive attempt to establish a settlement on the Hawaiian Islands (fig. 1).

Russian American villages or forts were always on water (fig. 4). Usually they were on the coast rather than inland. Also, the predominant function was fur purchasing in the settlements founded before $183^{\circ}$ in Southern and Southeastern Alaska. Exceptions, like Yakutat, were stated to be agricultural centers. To continue this practice is to use a classification employed by Baranof merely to secure more men from Russia. It is doubtful whether any Alaskan settlement established between 1784 and 1830 was truly agricultural. Certainly, however, at least the more significant centers, shown as solid symbols on figure 4 , were founded as permanent centers and have remained such. Also, some of them were multi-functional rather than only fur-purchasing centers.

About 40 per cent of the villages which Russians founded in this first period of settlement no longer exist. Most of these had a maximum white population of less than 10 people. Also, each of the abandoned sites was in a location of little value to later white settlement.

The total number of whites in Russian America during this period was less than in the time of the promyshleniki (Refs. 4, $6,8,9,10$, and 14 , passim). In 1786 a few more than $15^{\circ}$ Russian inhabitants were known to be there and two years later 422 were reported in the six newly-founded places. As time passed the number of settlements increased while the Russian popula- 


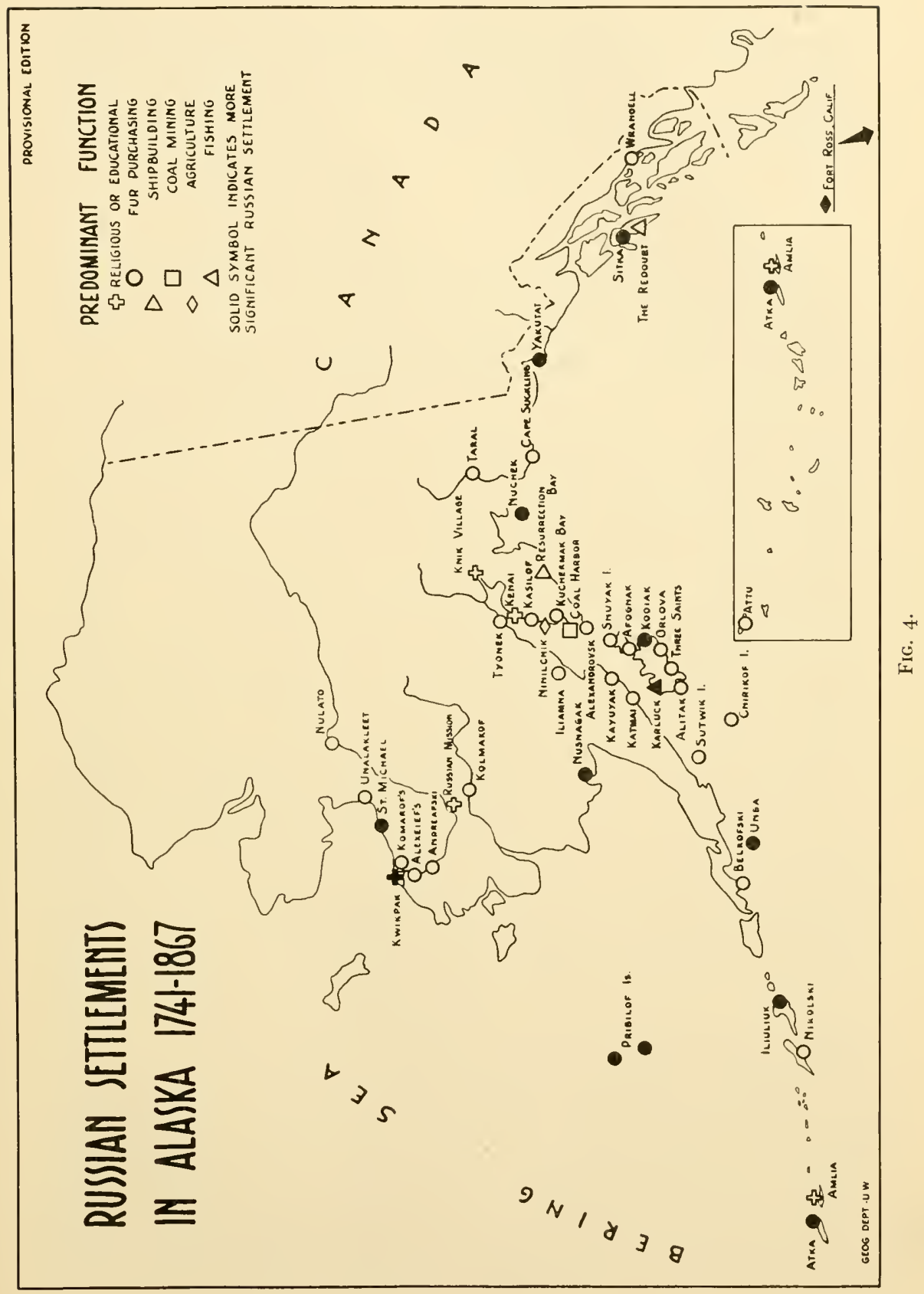


tion was stationary at about 400. In 1818 about 200 of them were in Sitka and 75 in Kodiak. Thus, the average Russian population for other villages at that time was about five while some places actually had but one. That these people were mostly men may be assumed.

\section{Russian and English Settlement: $1830-1867$}

From 1830 to 1867 Russian interest in Alaska as a permanent possession was maintained until near the end of the period. New settlements were founded until 1845 and the annual "take" of sea otter, fur-seal, and other pelts remained steady.

Settlement spread to western Alaska in this period (fig. 2). Like in the previous era most of the expansion was from Kodiak. The main route was southwestward around the Alaska Peninsula to St. Michael, founded northeast of the mouths of the Yukon River area. In the 1830 's the work of missionaries of the Russian Orthodox Church became significant and a few new settlements were primarily religious centers (fig. 4). Mineral resources were investigated. Traces of gold and copper were found and coal was mined temporarily near the mouth of Cook Inlet but major deposits were not known. Too, a decree in 1835 provided for the establishment of agricultural villages (as the cheapest way of retiring employees of the fur company) but Ninilchik, on Cook Inlet, is the only known result. In spite of these varied interests, procuring sea otter and fur seal apparently was still a, if not the, major motive for Russians being in Alaska. This contention is supported by the Russian American Fur Company's continued requests for extension of charter privileges and the fact that annual harvests of furs during this period were still relatively high. After 1845 , however, no new settlements were founded by Russians (fig. 2).

A general increase in Russian population was associated with the four decades before the sale of Russian America (Refs. 1, 2, $6,10,14$, and 16 , passim). The more reliable counts indicate a growth from about 400 in 1830 , to $65^{\circ}$ in 1832 , to 730 in 1836 , to a maximum of 784 in 1860 , and then a decrease to 577 . This population was a relatively large one to be $6500-75^{00}$ miles from 
home, in a mountainous or subarctic area, and in those years. Apparently it is unknown how many Russians remained in the Territory after the sale of it to the United States; Petroff enumerated $43^{\circ}$ whites in Alaska in 1880 but his accuracy and completeness have been questioned and United States fishermen had arrived in Southeastern Alaska by the time of this first census.

While Russian settlement progressed in Alaska so did English occupation move westward in Canada (fig. 1). For a time it appeared as if the Hudson's Bay Company and the Russian American Fur Company would clash head on after each had circled about half of the world's northern lands. Such was diverted two ways.

The furst diversion was the English following natural routes which reduced the possibility of conflicting interests. From Hudson Bay some of the traders went northwestward into the Mackenzie River valley and thence to the Yukon River system. Posts were established in the Liard area, near Southeastern Alaska (fig. 5), but expansion did not continue on westward the short distance through the coast ranges to the ocean. Other English fur traders went from the Ft. Churchill-York Factory area southwestward to what became the northwestern United States. Thence the interests of these men were northward along the coasts of British Columbia and Alaska.

In this maritime area long negotiations averted Russian English difficulties. From the discussions came the establishment of what was eventually accepted as the approximate inland boundary of Southeastern Alaska. Also, in $184 \mathrm{o}$, Southeastern was leased to the English. They administered all fur trade in the area from then until 1867 .

Two Hudson's Bay Company posts were established immediately in 1840 in Southeastern Alaska. Each was short lived, though, because the area could be more efficiently controlled from British Columbian posts. In the meantime, the traders moving northwestward reached the confluence of the Porcupine and Yukon Rivers and established Fort Yukon in 1847. This action began continuous permanent white settlement in Interior 


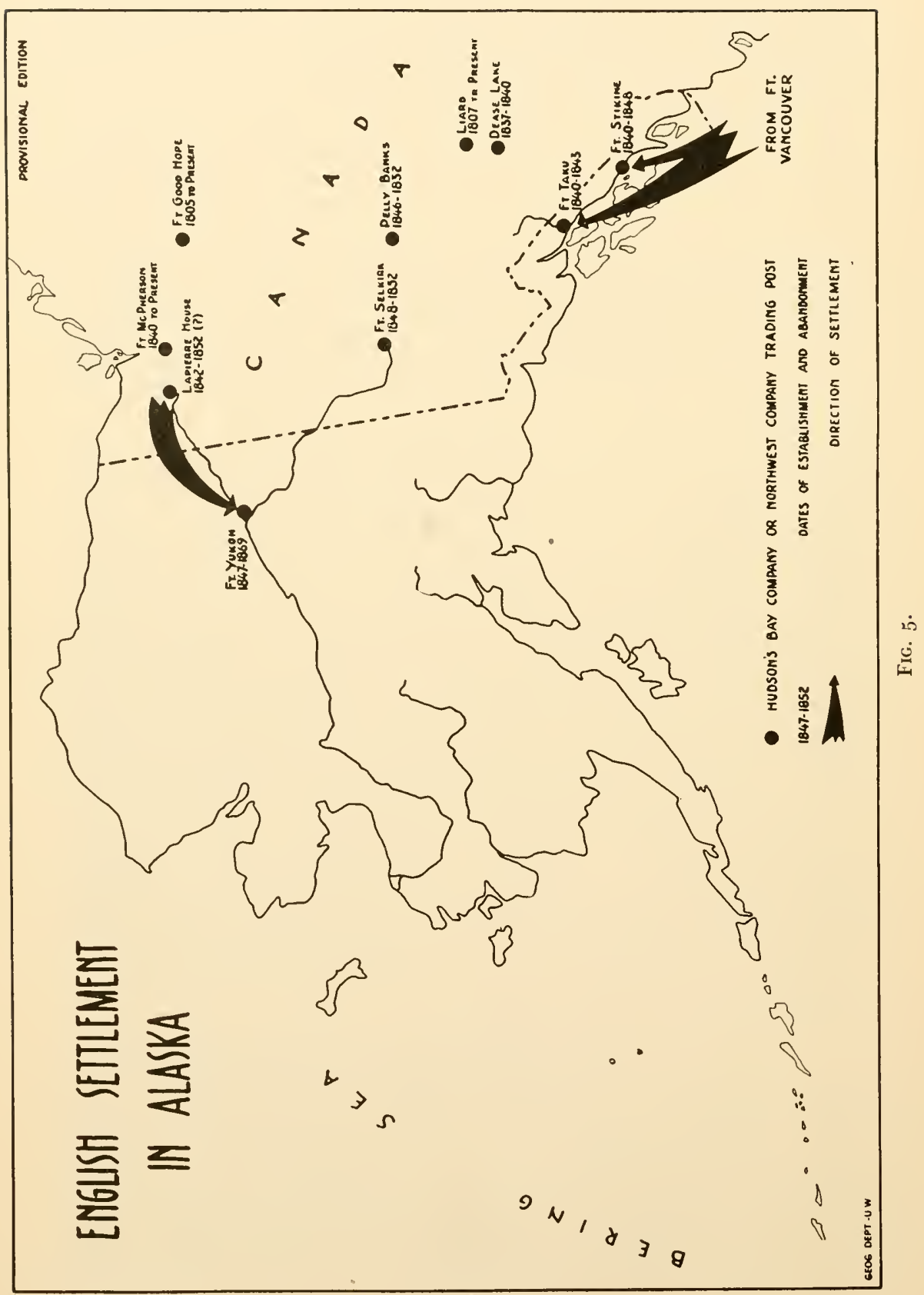


Alaska although the English had to leave two years after the sale of Alaska when the post was found to be within United States' territory.

Fort Yukon was the last center of Russian or English settlement to be established in Alaska. After 1840 Southeastern Alaska was blocked to the Russians by the leasing arrangement. Shortly the Russians sold Fort Ross to John Sutter and focused attention on western Alaska. Then, in 1867 , the circumstances of the isolated and distant position of Alaska from St. Petersburg, recurring losses of the Russian American Fur Company, the aftermath of the Crimean War, and declaration of the Monroe Doctrine by the United States combined to bring about the sale of the Territory.

\section{ConcLusions}

Five conclusions may be recognized from analysis of Russian and English settlement in Alaska. Some require further research for completeness. They are:

1) The total occupance by Russians may be interpreted areally in terms of influence, as shown in figure 6 (based on Refs. 3, $5,6,7,9,13,14$, and 15 , passim). The term influence is used because much of the effect of Russian occupance was in terms of cultural contacts with the natives rather than in permanent change of the landscape. Thus, the solid black areas of the Kodiak-Cook Inlet, lower Yukon-Kuskokwim, and Southeastern regions are the best places for the concentration of research on details of Russian and English occupance to learn experiences of possible use in planning for future settlement. These three areas are the ones of most numerous contacts between Russians and natives or of longest Russian occupance.

2) Villages established by the Russians form the nucleus of the present pattern of coastal population in Southern, Western, and part of Southeastern Alaska although fur purchasing is no longer the major occupation in those areas.

3) English occupance of Alaska was significant, though short, because it helped bring about the establishment of part of the 


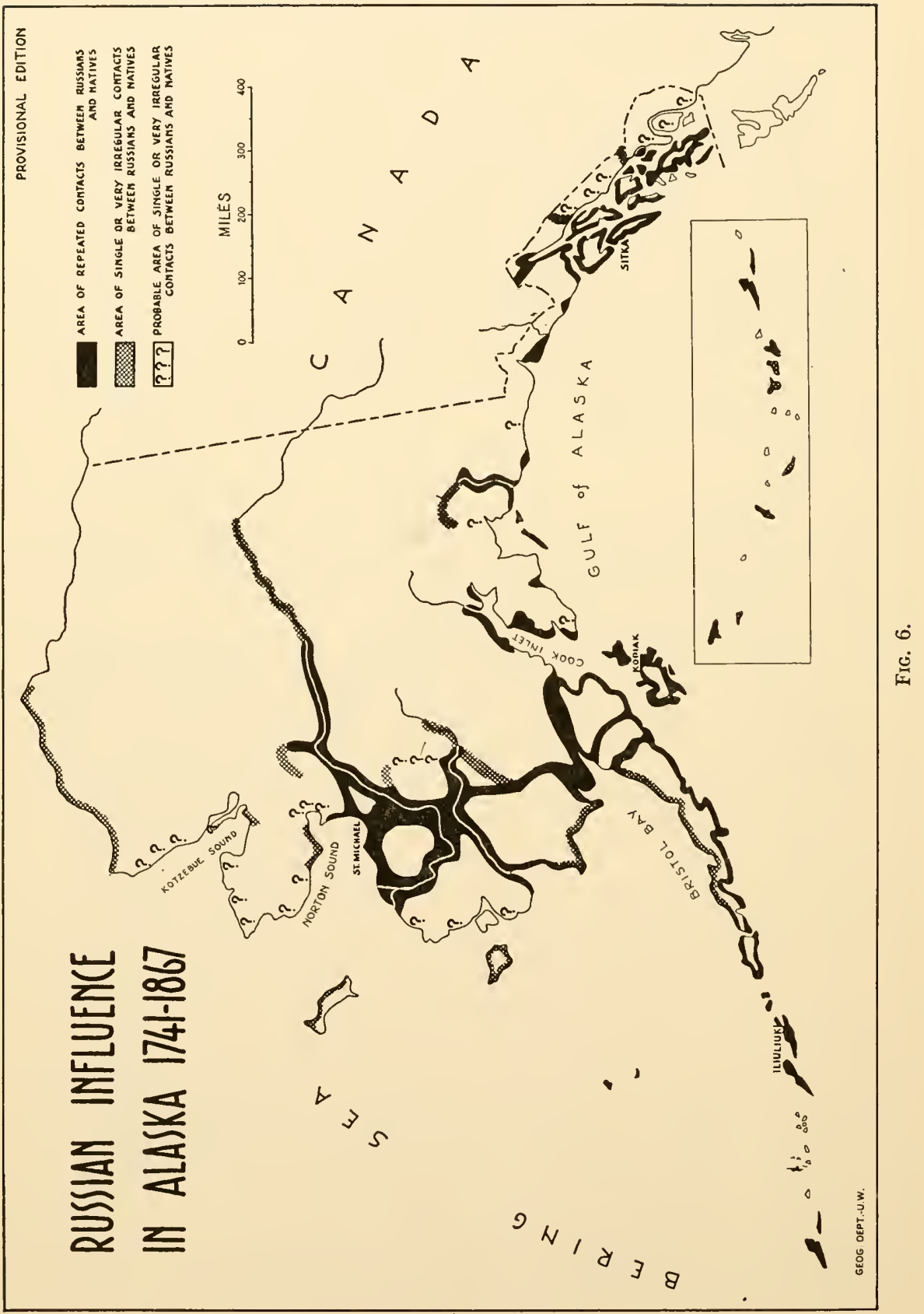


Alaska-Canada border. In addition, the English started permanent white settlement in Interior Alaska, also based upon fur trading and an occupation still practiced there.

4) The Russians may not have discovered the Territory. This fact, when proved, might be a blow to Soviet morale which has been supported by a succession of claimed "firsts" and the complaint that Alaska was not legally sold to the United States.

5) New Alaskan settlement might be conceived as permanent on a basis other than agricultural. There is discordance between the pattern of permanent Russian settlements and areas now classified as physically suitable for agriculture. This lack of agreement suggests that agricultural development may not be the climax, as so often is implied, or even a stage in the development of at least parts of the Territory.

Finally, we are, of course, greatly in need of facts. Alaska has been occupied under United States' ownership for only $8_{3}$ years. Even the total history of white men in the Territory, more than 200 years, is a short time. Our available knowledge for planning new settlement is too scanty to permit neglect of any information or hypotheses. To these data must be added those from geographic analyses of the Indian, Eskimo, Aleut, and non-native population of Alaska between 1867 and the present time. Through this research program it is possible to acquire some of the facts needed in order that the inevitable growth of Alaskan population may be guided so as to take place in an orderly manner.

\section{REFERENCES}

1. Anonymous. The population of the Russian American colonies. Zhurnal Ministerstva Vnutrennykh, Diel 13, 1894. (In Russian).

2. Anonymous. Statistical outline of Russian possessions in America, in Contributions to the knowledge of the Russian Empire and the bordering countries of Asia. Zhurnal Ministerstva Narodnago Prosvieshcheniia, 37, (2), pp. 45-7o. January 1843 . (In Russian).

3. Alaskan Boundary Tribunal. Atlas of Award, British Atlas, and U. S. Atlas. U. S. Senate Document No. 162, $5^{8 \text { th Con- }}$ gress, 2nd Session, Washington, D. C. 1904. 
4. Andrews, C. L. The story of Alaska. Caxton Printers, Caldwell, Idaho. 1938.

5. Baker, Marcus. Geographic dictionary of Alaska. U. S. Geological Survey Bulletin 299, Washington, D. C. 1902.

6. Bancroft, H. H. The works of Hubert Howe Bancroft. History of Alaska, 1730-1885, v. XXXIII, A. L. Bancroft and Co., San Francisco, California. 1886.

7. Brooks, A. H. The geography and geology of Alaska. U. S. Geological Survey Prof. Paper No. 45, pp. 104-132. Washington, D. C. 1906.

8. Coxe, William. Account of the Russian discoveries between Asia and America. London. 1803 (4th ed.).

9. Dall, W. H. Alaska and its resources. Boston. 1870.

10. Lieutenant Captain Golovin. Survey of Russian colonies in North America. U. S. House of Representatives, 4oth Congress, 2nd Session, Exec. Doc. No. 177, pp. 109-112. Washington, D. C. February 1868.

11. Gsovski, Vladimir and others. Russian administration of Alaska .... . U. S. Senate, 81st Congress, 2nd Session, Document No. 152, Washington, D. C. $195^{\circ}$.

12. Kerner, Robert J. Russian expansion to America, its bibliographical foundations. Papers of the Bibliographical Society of America, v. XXV, pp. 111-129. 1931.

13. W. C. Mendenhall. A reconnaissance from Resurrection Bay to the Tanana River, Alaska, in 1898, in Explorations in Alaska in 1898 . U. S. Geological Survey Twentieth Annual Report, Part VII, pp. 265-340. Washington, D. C. 1900.

14. Petroff, I. Report on the population, industries, and resources of Alaska in Tenth Census of the United States, 188o, Washington, D. C. 1882 .

15. Tebienkov, Capt. M. D. Atlas of the North West shores of America ..... St. Petersburg. 1852. (In Russian).

16. U. S. Department of the Interior, Census Office. Report on Population and Resources of Alaska at the Eleventh Census: 1890 , v. 8, Washington, D. C. 1893 . 


\title{
THE HYDROLOGY OF ALASKA
}

\author{
Arvi O. WaAnanen \\ Hydraulic Engineer, U. S. Geological Survey \\ Washington, D. C.
}

\section{INTRODUCTION}

Water is one of the most valuable and vital natural resources available to man-but water is more than just a resource. It has played a major role in geologic history because rain, rumning water and waves are the principal agencies in erosion and sedimentation; frost, ice and glaciers have made great changes in the earth's surface, and water has a great power for dissolving minerals.

The development of water resources requires the determination of certain physical conditions such as the head available for power-development, the favorable sizes for dams or diversion works, etc., but appraisal of the water supply, either flowing in the streams or available in the subsurface reservoirs, is often a problem requiring much study, particularly when adequate flow measurements are not available. These studies must include such items as distribution of precipitation; mean, maximum and minimum flors in streams; frequency of flood occurrence; volume of subsurface storage; evaporation losses, particularly from reservoirs, that may be considered; transpiration losses and probable ground water recharge from precipitation or spreading of surface waters.

The United States Geological Survey has been active in the investigation of our water resources since 1888 and makes basic studies of the occurrence, availability and quality of both surface and ground water. The Survey's activities have included some water investigations in Alaska in the past and further studies are in progress at the present time.

Resources development today is desirably accomplished following extensive scientific study and evaluation of the resources, 
development problems and techniques, and the needs for such development. Recognition of this principle brings current policy into sharp contrast with that in an earlier period of our history when the available resources were exploited without regard to their extent, conservation or best utilization, particularly of the non-renewable resources.

In the United States we have the foundation for efficient and systematic development of our natural resources because in recent decades much information regarding the extent and utilization of these resources has become available. The resources inventory program is still far from complete but tremendous progress has been made. Much of the early development in Alaska resulted from mining and fishing activities without much consideration being given to establishment of a permanent type of economy. Some resources investigations have been in progress for many years although factors such as the rugged terrain, remoteness, poor transportation, sparse settlement and lack of adequate research funds have limited these studies so that our present inventory of Alaska's natural resources is far from complete and many serious deficiencies are still present.

Natural resources investigations cover a broad field of scientific activity and include, among many others, studies of climate, topography, geology, geography, botany, biology and hydrology. The relation of the science of hydrology to resources development in Alaska is of particular interest to us today.

According to the widely accepted definition hydrology is the science that treats of the study of the occurrence and distribution of water over and in the earth's surface, and of the accompanying natural laws and phenomena. The science of hydrology thus deals with the natural phenomena, mostly quite familiar, which constitute the never ending cycle in which water evaporated into the atmosphere from the oceans, lands, and fresh water surfaces is returned to the earth as precipitation and then (1) flows over the surface into streams and thus back to the ocean, (2) percolates into the ground to join the ground water reservoir, returns to the surface through springs elsewhere or 
returns to the atmosphere by transpiration from plants and trees, or (3) evaporates directly back into the atmosphere. Hydrology is still a relatively new science; it is based upon meteorology, geology, hydraulics, soil physics, chemistry and ecology, and on the constantly increasing store of data obtained by observation and measurement. The student of Alaskan liydrology thus would be particularly interested in studies of precipitation, temperature, snow, glaciers, permanently frozen ground, seas, rivers, underground waters, erosion and alluviation as well as evaporation, transpiration, and the relations of runoff or streamflow to rainfall, snow melt, and glacier ice melt. His interest would also extend to the effects of geology, land management practices and vegetative cover on runoff and floods.

Hydrologic studies are of particular significance in the development of water resources. Through them we can determine the capacity or extent of our water supplies for, though surface and underground reservoirs may be drawn down or emptied they will fill again if rainfall and runoff are sufficient. Adequate hydrologic studies are the means for determination of the safe point for development and use of our water supplies.

Observation, measurement and appraisal programs in the United States have provided a large number of hydrologic data which are of tremendous help to the hydrologist studying the occurrence and distribution of water supplies, frequency and distribution of storms and floods, and related studies. Though there are important deficiencies the hydrologist nevertheless is able to make appropriate interpretations and adaptations of the available information for many localities and so work out reasonable and acceptable results. In Alaska not only is there a great lack of comprehensive hydrologic data but the situation is further complicated by the effects of glaciers and permafrost on runoff which preclude application of the assumptions and procedures utilized in the more southern latitudes.

To review briefly the general hydrology of the Territory, the climate of Alaska may first be summarized as follows:

1. Southeastern Alaska has a mild, moist climate with recorded precipitation ranging from annual averages of about 26 
inches at Skagway to more than 150 inches in the Ketchikan area. Temperatures seldom drop below $\mathrm{o}^{\circ} \mathrm{F}$. except at the higher elevations, or rise above the 8o's. The extremely rough topography and heavy precipitation produce high, rapid runoff. Stream flow records indicate that maximum precipitation at the higher altitudes in the southern portion exceeds $25^{\circ}$ inches annually. Maximum floods usually occur during the heavy storms of autumn.

2. The climate of the coastal region west from Yakutat is similar to that for southeastern Alaska. Recorded precipitation averages more than 100 inches along the Gulf of Alaska and about 60 inches in the Prince Williams Sound region. Precipitation at the high elevations undoubtedly is considerably greater. Winter temperatures are lower than those in southeastern Alaska. Major floods may occur in spring or fall.

3. In the Anchorage area and the region between the Alaska Range and the coastal mountains rvinter temperatures may drop to about $-40^{\circ} \mathrm{F}$. with summer highs about $90^{\circ} \mathrm{F}$. Precipitation is generally low in the valleys, averaging about 20 inches. Stream flow is characterized by one principal flood annually resulting from the melting of snow or ice.

4. In interior Alaska, the region between the Brooks and Alaska Ranges, making up the central Yukon Valley, average precipitation ranges from less than to inches to not more than 20 inches annually except at the higher altitudes. Temperatures range from highs approaching $100^{\circ} \mathrm{F}$. to lows in the - 70's. The winter season is long. Annual temperatures average about $25^{\circ} \mathrm{F}$.

5. The Aleutians have high precipitation with only a moderate range of temperature but the winter season is long.

6. The Bering Sea coastal region has precipitation averaging from about 12 to 24 inches annually. Summer temperatures reach the 80 's while winter temperatures drop to the -40 's. The winter season is long and frost may occur in any month. Annual temperatures range from $20^{\circ} \mathrm{F}$. to $34^{\circ} \mathrm{F}$.

7. The arctic coast region north of the Brooks Range has precipitation averaging generally from 4 to 10 inches though 
the precipitation at Shungnak is somewhat greater. Temperatures range from the low 8o's to the -50 's with sub-freezing temperatures prevailing over most of the year. Annual temperatures average about $20^{\circ} \mathrm{F}$.

The variations in climate and topography and the effects of permafrost and glaciers make the hydrology of Alaska highly complex. Permafrost is present in interior and northern Alaska. Though permafrost usually acts as an impervious layer there are opportunities for storage or release of water from the active layer between the ground surface and the permafrost, or changes may occur in the permafrost with resultant changes in the local water regimen. Glaciers may store part of one year's precipitation and release it in another year or years, thus distorting the usual pattern of stream flow and the precipitationrunoff relations.

Surface water supplies are available throughout the territory in summer. Minimum flows occur generally in winter. The streams in southeastern Alaska are least affected by winter conditions. In interior and northern Alaska the smaller streams are usually immobilized in the winter and the development of such streams for water supplies is complicated by considerations of storage, heating and transmission. In many areas, however, potential surface water supplies may be infeasible because of the distances from desired points of use.

Ground water supplies are available in many areas but up to date definite information has been obtained for only a few areas. Ground waters may provide useful sources at many locations, particularly where surface water supplies are not within easy reach. Little is known yet about the possibilities for ground water development in Arctic areas. As an example of the problem, Eskimos in northern Alaska sometimes obtain their summer water supplies from small wells dug into the permafrost which accumulate water from melting permafrost or ground ice. The subject of Alaskan water supplies is ably discussed by A. J. Alter, Director, Division of Sanitation and Engineering, Alaska Department of Health, in an article "Water 
Supply in Alaska" in the June $195^{\circ}$ issue of the Journal of the American Water Works Association.

Several agencies of the Federal Government collect hydrologic data in Alaska. The U. S. Weather Bureau and the U. S. Geological Survey are the principal basic data collecting agencies, but the Corps of Engineers, the Forest Service, and other agencies may collect limited additional pertinent data in connection with carrying out their respective responsibilities.

The Weather Bureau is currently collecting climatological data at about 115 locations well distributed throughout the Territory, usually at airfields or other places where personnel are available to make the necessary observations. Over $3^{0}$ of these records have been collected continuously over a period of more than 25 years. Records at Sitka, Alaska, are available since the early 1840 's but the consistency of the early records with the present Sitka record is open to question. Some of the findings were summarized in the preceding discussion of climate. The hydrologic data obtained by the Weather Bureau are published in the monthly and annual Climatological Data bulletins. As a result of the necessity for locating weather stations at points where local observers are available and the remoteness and inaccessibility of the high mountain areas the records generally do not reflect the extreme conditions. The Bureau is known to be well aware of this shortcoming, and will establish appropriate additional stations as rapidly as funds and opportunities permit.

The Geological Survey collects stream flow records regularly at about $5^{o}$ locations and miscellaneous discharge data intermittently at a number of additional points in southeastern, south-central and interior Alaska. The Survey started surface water supply studies on the Seward Peninsula in 1906 in connection with hydraulic mining operations. These were extended to the Yukon-Tanana region in 1907 and continued until 1912. In 1913 a water power reconnaissance was made in south-central Alaska. During the period 1915-21 surface water supply studies were conducted in southeastern Alaska in cooperation with the Forest Service to appraise the water power 
resources. These studies were continued by the Forest Service and others until 1946 when the Survey started its present program of water resources investigations. The results of the investigations prior to 1946 are published in the bulletins and water supply papers of the Geological Survey or the Forest Service-Federal Power Commission publication "Water Powers of Southeast Alaska." Records since 1946 are in the Survey's open files in Washington, D. C., or at Juneau and Palmer, Alaska. A few records, generally of an intermittent nature, have been collected by agencies or groups other than the Geological Survey or the Forest Service.

Stream flow records indicate that mean annual runoff in many streams in southeastern Alaska commonly exceeds the precipitation recorded at nearby stations, which generally are located at or near sea level. Mahoney Creek at George Inlet, near Ketchikan, for example, had a runoff of about 240 inches in 1948. In 1949 the runoff of many streams exceeded 200 inches. Records of stream flow in interior Alaska are insufficient to define the rainfall-runoff relation adequately.

Ground water investigations by the Geological Survey have been in progress since 1947. Because of limited funds and the extreme paucity of data from drillings or existing wells, progress has been slow. However, the progress to date may be summarized as follows:

1. Wells in the Fairbanks area have been completely inventoried and some exploratory test drilling has been accomplished. A report on the well data, including map delineating permafrost in the city, is in the Survey's open files at Washington, Juneau and Fairbanks.

2. Inventory of wells in the Matanuska Valley is about complete and a map and summary report are in preparation. Some test drilling has been accomplished and more is planned.

3. A general reconnaissance of water supplies for small communities has been made in cooperation with the Alaska Department of Health.

4. Test drilling carried out at Kotzebue. A test hole drilled to 325 feet produced only salt water and permafrost was found to be present to the 238 -foot depth. 
5. Test drilling and inventory of wells has been started in the Anchorage area. Experimentation with jet drill equipment indicates possibilities for use of such equipment in areas underlain by gravels.

There is every reason to believe that extensive ground water supplies are available in many areas, and frequently these supplies may be developed more readily and economically than nearby surface sources. Because there are very few existing wells an extensive program of test drilling and geologic study is necessary to define the major occurrences. Pumping tests would then define safe withdrawal rates. The availability of equipment and transportation problems are physical problems that must be met. It is evident, however, that many communities seeking to improve their water supplies, particularly under the Alaska Community Facilities Act, would do well to give serious consideration to study of possible ground water sources before developing remote or expensive surface water supplies. Fairbanks, Sitka, Anchorage and Talkeetna are examples of communities in this category.

At present the Survey's quality of water investigations in Alaska relate to determinations of the chemical quality of surface and ground waters. The analyses are made in a laboratory established at Palmer. Sediment sampling is to be included in the program.

The problem of sediment discharge of streams assumes major proportions in connection with streams draining glaciers. The channels of such streams are usually full of glacial debris, and construction of dans and reservoirs is complicated by considerations of dam-foundation problems and possible early filling of reservoirs by sediments. The rock flour remaining in suspension even after long periods of storage, as in lakes, may cause rapid wearing of waterwheels and turbines. Further, sediment discharge into tidal estuaries affects navigation. In order to obtain appropriate basic facts for use in the study of these problems the Corps of Engineers is collecting information on sediment discharge at a number of locations.

There is, of course, a close relationship between the occur- 
rence of ground water and permafrost in those regions where permafrost is present. Permafrost is being studied by several groups, including the Geological Survey and the Department of the Army. Some programs are concerned with means of identifying the occurrence of permafrost, while others are concerned with construction problems as for airfields, buildings, highways and runways. The results of these investigations can be of material assistance to the hydrologist in narrowing the scope of his inquiry.

Extensive research is in progress in the United States to determine further ways and means of applying hydrologic data to the efficicnt solution of clevelopment problems as they arise, as well as to provide additional helpful information. This research includes items such as runoff forecasting procedures, extensions of records, effects of long term variations in climate on runoff, erosion and sedimentation, and the effects of land use practices and watershed management on water supplies. In Alaska the deficiencies in basic data have precluded any extensive research of this nature. However, current investigations by agencies such as the Weather Bureau and the Geological Survey may well be classified as research. This is particularly true in connection with ground water and permafrost studies. Studies of permafrost or arctic and subarctic drainage conducted by the Corps of Engineers, and glaciological and ice field research yield much pertinent information.

Future research in Alaska should include in addition to the basic data studies, study of such items as (1) evaluation of the type and extent of data required in an ideal hydrologic study program, (2) relation of runoff to snow melt and glacial ice melt, and (3) effects of permafrost on streamflow and the recovery of ground water.

Although this paper is entitled "Hydrology of Alaska" the discussion has related principally to hydrologic studies. The various uses to which hydrologic data may be put may illustrate most effectively both the need for such data and the present deficiencies. A few of these needs are as follows:

1. The Bureau of Reclamation, in connection with prepara- 
tion of its "Alaska" report, in which it reviewed water power development possibilities, was forced to make extensive estimates of probable yields of watersheds.

2. The Corps of Engineers, in their current investigations of water resources of Alaska, have found a serious lack of stream discharge data. As a result, the Corps and the Geological Survey are collaborating in stream-flow studies in order to provide reasonably adequate bases for their studies.

3. In connection with development of water supplies under the Community Facilities Bill, many communities will require appraisal of the nearby surface and ground water sources. As indicated previously, the availability of ground water deserves more study.

4. In the construction of highways, bridges, and railway structures data on the magnitude and frequency of floods, particularly the flood heights at proposed bridge sites, would permit more economical design. Both under-design and overdesign can be wasteful of material and funds.

5. The Territorial Department of Health and the numerous small communities need and can use more hydrologic information to work out the best solutions to their water supply, sewerage and street problems. Arctic water supplies are a particularly pertinent problem.

6. In areas such as the Matanuska Valley, agriculture may be benefited by supplemental irrigation in those years when precipitation is deficient. Supplemental water may be of considerable value because of the short growing season. Presumably much of the water so used would come from ground water sources and be applied by sprinklers.

The deficiencies in hydrologic data have been met usually by application of estimates or criteria developed elsewhere. In some instances specific observations have been made to provide data of a reconnaissance nature. There is no doubt but that some of the deductions have been faulty but, since they represent the best possible estimates, they have served a useful purpose.

The more significant deficiencies are slowly being overcome 
by present observational programs. However, funds presently available do not permit the program expansion necessary to provide all desirable data promptly and it is essential therefore that the basic data collecting agencies and the action agencies coordinate their activities closely. Such is already being done by the Weather Bureau and the Geological Survey insofar as the needs of the Departments of the Army and Air Forces are concerned. Similar closer coordination with other agencies is anticipated as present programs become more stabilized and the relative needs can be evaluated.

In conclusion, Alaska is still a forward area insofar as natural resources investigations are concerned, and it is fortunate that we can utilize the many scientific skills that are available to us in the development of the resources of the Territory. Water is a resource without which man cannot survive. It is recognized more and more that plentiful supplies of water are a prime requirement of our modern civilization. Therefore, it is essential that data be collected in sufficient quantity and subjected to such appraisals, evaluations and studies as will assure the most efficient utilization and development of the water resources of Alaska.

\section{REFERENCES}

1. Alter, A. J. Water supply in Alaska. Jour. Amer. Water Works Assoc., 42: 519-532. 1950.

2. Canfield, G. H. Water-power investigations in southeastern Alaska. U. S. Geol. Survey Bulletins: 662, pp. 100-154, 1916; 692 , pp. 43-83, 1917; 712, pp. 53-90, 1918; 714, pp. 143-187, 1919 ; and 722 , pp. $75^{-119}, 1920$.

3. Cederstrom, D. J. Basic data on the results of test drilling in the Fairbanks area, Alaska, in the fall of 1948. U. S. Geol. Survey duplicated report. 1949 .

4. Dort, J. C. Water powers of southeastern Alaska. Report to Federal Power Commission. 1924.

5. Ellsworth, C. E., and R. W. Davenport. Surface water supply of the Yukon-Tanana region, Alaska. U. S. Geol. Survey Water Supply Paper 342.1915.

6. Ellsworth, C. E., and R. W. Davenport. A water-power reconnaissance in South-Central Alaska. U. S. Geol. Survey Water Supply Paper 372. 1915 . 
7. Henshaw, F. F., and G. L. Parker. Surface water supply of Seward Peninsula, Alaska. U. S. Geol. Survey Water Supply Paper 314. 1913 .

8 Henshaw, F. F. Surface water supply of southeastern Alaska, 1909-30. U. S. Geol. Survey Bulletin 836, pp. 137-218. 1933.

9. Climatological data, Alaska, monthly and annual bulletins. U. S. Weather Bureau.

10. Ground water data for Fairbanks area, Alaska. U. S. Geol. Survey press release, Feb. 1, 1948 .

11. Water powers of Southeast Alaska. Federal Power Commis= sion-U. S. Forest Service report. FPC P-9. 1947. 


\title{
GEOMAGNETISM-COSMIC AND PROSAIC
}

\author{
David G. Knapp and Elliott B. Roberts \\ U. S. Coast and Geodetic Survey
}

Geomagnetic research occupies a unique position in the realm of science. Aside from obvious uses in navigation, surveying, and radio wave-propagation studies, geomagnetism constitutes one of our few tools for probing the Earth's interior, and is the only field of study that takes for its province the whole sequence of concentric zones, from the earth's core to the ionosphere and beyond.

The student of geomagnetism finds much to hold his attention in Alaska. He may wish to specialize on the main field and its secular change, with due attention to the steep gradients and distorted forms characteristic of the Arctic magnetic field. Or he may delve into the complexities of the transient phenomena, finding that the Territory, with its broad regional coverage and its position astride the auroral zone, affords a great natural laboratory for such studies, unrivalled in scope and accessibility anywhere in the world. It is lience fitting to record that each forward step in Alaskan exploration and study has had its magnetic aspect, ever since Bering's first voyage to explore the coast of Kamchatka in 1725-30.

During the period of Russian sovereignty, significant contributions were made by Cook, von Lütke, Beechey, Wrangel, and Maguire. One of the early successes of the Central Physical Observatory of St. Petersburg was the establishment at Sitka of a magnetic and meteorological observatory. This actually was the first such station in North America (7), an able if primitive forerunner of the present first-class observatory at Sitka, which was established in 1901. An amusing sidelight on this early activity is found in the account of a difficulty experienced in using suspended-magnet instruments in winter, when the frozen ground brought to the instrument pier disturbing 
shocks generated in cutting firewood in the nearby forest. The solution was simple and direct; the commandant permitted no more woodchopping on observing days.

With the transfer to United States sovereignty in 1867 , there began in Alaska a steady accumulation of field observations by the Coast and Geodetic Survey, which has continued to this day. Significant of the early phases of this activity were the campaigns on the Yukon and Porcupine Rivers in 1889-91, including an entire winter devoted to the accumulation of data at two stations near the Canadian boundary (12). As part of this program, repeat stations were occupied every few years, to develop the secular-change characteristics at various points on the south coast and notably at Sitka. This work has been continued and expanded, so that Alaska now has a distribution of repeat stations almost as good as the United States proper (3). The same cannot be said of the nonrepeat stations which serve to fill in the permanent field patterns. For Alaska the nonrepeat stations are largely confined to clusters along the accessible shores, with the natural result that we have had scant knowledge of the detailed interior distribution, although a general pattern has emerged that cannot be far wrong.

The prospects are now bright for rectifying and adjusting this general design, as well as for outlining the coarser features of the local patterns, by means of airborne surveys. In fact, the first large-scale survey of relative total intensity to be accomplished with the new saturable-core airborne magnetometer was devoted to an area of some $\mathbf{1 8}$, ooo square miles in Northern Alaska (1). The local patterns hold great interest for their possible clues to the depth to basement rock and other features bearing directly on the development of natural resources in a relatively new region like Alaska.

Alaska occupies a strategic area in the attack on one of the perennial riddles of Arctic magnetism, the vexing question of the magnetic pole or poles. The magnetic pole found by James C. Ross on the Boothia Peninsula seems to have migrated somewhat to the north and west (9), but it still falls in an unsymmetrical position with respect to the general distribution 
of the field in the Arctic (8). The circumpolar field is distributed in an elongated pattern with the pole inexplicably near one end of the area. The possibility of a second magnetic pole to reconcile the disparity was advanced by Hansteen and has lately been revived $(6,13)$. It is easy to see why the matter remains in doubt, when we realize the tremendous problems entailed in making magnetic observations in the heart of the Arctic Ocean. Nevertheless, progress has been made and will certainly be accelerated in this matter, in Alaska itself as well as in areas lying within range of Alaska-based operations.

The short-time fluctuations comprise a large and fruitful area of study in geomagnetism, having numerous practical and theoretical aspects. In this field, the important role of Alaska was recognized long ago. Protracted schedules of observations were maintained by Rochfort Maguire at Point Barrow during his two winters there $(1852-54)$ in connection with the search for the lost Franklin Expedition (11), and the same place was chosen for one of the two stations conducted by the United States during the International Polar Year of 1882-83. Fifty years later, two Alaskan stations were occupied during the Second Polar Year of 1932-33-one at Point Barrow by the U. S. Weather Bureau (2), and one at College, near Fairbanks, by the U. S. Coast and Geodetic Survey and the Carnegie Institution of Washington (5).

The daily variation and other transient phenomena, taking their origin in overhead electrical activity, must reflect any regional features of such activity (4). It was Sir Edward Sabine who pointed out that the daily magnetic variation "is in fact constituted by two variations superimposed upon each other, having different laws, and bearing different proportions to each other in different parts of the globe." The two constituents are known today as the quiet daily variation, $\mathrm{S}_{\mathrm{q}}, \mathrm{S}$ referring to the solar day and $q$ to a period of quiet magnetic conditions; and the disturbance-daily variation, $\mathrm{S}_{\mathrm{d}}$, the $\mathrm{d}$ of course referring to disturbed conditions.

The most striking of the differences in distribution lies in the fact that whereas the quiet daily variation is weak through- 
out the Arctic and is essentially unrelated to the auroral zone, the disturbance daily variation has a virtual discontinuity there, and is greatly intensified in the neighboring areas-so much so, indeed, that only on exceptionally calm days can we perceive $S_{\mathrm{q}}$ in Alaska through the overlying effect of the disturbance field.

To assist in visualizing the facts, we may conceive the Earth to be girdled by a magnetic barrier in the form of a cosmic doughnut that deflects and channels the "flash floods" of ionized matter streaming out intermittently from the sun or its corona. Along that barrier (that is, along certain lines of force of the Earth's magnetic field), these ionized particles form concentrations pouring into the hole of the doughnut from either side like water rumning into a drain. The circles where this great barrier meets the globe are the northern and southern auroral zones. During severe disturbances or magnetic storms, they do not remain at precisely their habitual latitude, but advance somewhat toward the temperate regions, receding again with the abatement of the disturbance. (The image invoked here is a provisional one, involving a tentative choice among several theories of magnetic storms, none of which has achieved universal acceptance.)

Each auroral zone probably represents a sort of curtain of activation, with strong electric currents that are replenished with every new effusion of material from the sun. This curtain terminates in the ionosphere, which it feeds with horizontal currents contributing to the world-wide pattern of $S_{d}$. The quiet daily variation, on the other hand, is primarily a phenomenon arising within the ionosphere-probably at its lower boundary where the ultraviolet absorption yields the needed direct-current conductivity-and stems from tidal and thermal dynamo action in latitudes well below that of the auroral zone. The ionosphere also has an effect on the irregular fluctuations, in that it tends to shield the Earth from the most abrupt features of the external field changes. These irregular changes, like $S_{d}$, are greatly intensified in the vicinity of the auroral zones. 
As an illustration of the role played by the auroral zones in the distribution of $S_{d}$, Olsen (10) found that the amplitude of this constituent at a station in Greenland just north of the auroral zone showed a decided periodicity connected with the sun's rotation. This effect could not be discerned at all for stations lying south of the auroral zone. Whether similar effects are observable at other high-latitude stations remains to be seen; in the instance just mentioned it was found that several years' data were needed to establish the effect.

It is clear that the study of magnetic storms and of the associated variation known as $S_{d}$ calls for data from points in the auroral zone and on both sides of it. Moreover, it has been found that the auroral-zone effects cannot be isolated by comparing records obtained at different latitudes if at the same time there is a divergence of longitude; the tilt of the Earth's magnetic axis causes the auroral zone to react differently on stations in widely different longitudes. To avoid the complication of longitude effect it is desirable to have observatories linked in north-south chains across the auroral zone. Such a chain is now provided in Alaska by the Sitka, College, and Barrow observatories, each of which secures continuous graphic records of the time variations of the declination, horizonal intensity, and vertical intensity of the Earth's magnetic field, with appropriate control by means of frequent absolute observations.

The recording apparatus used at each of these observatories is planned to meet the rather stringent requirements imposed by a chain of this character. The magnetograph at Barrow is a special low-sensitivity one, chosen to guarantee a complete record despite the frequency and severity of the magnetic disturbances encountered there. Furthermore, it has a strip recorder which permits records to accumulate for several days during protracted snow storms when the instrument cannot be tended. At both Sitka and College there are standard highsensitivity instruments supplemented by low-sensitivity auxiliary instruments to safeguard the continuity of the record during severe magnetic storms when the regular trace goes off the edge of the paper. 
These three observatories may be expected to contribute materially to the understanding of magnetic phenomena, not alone in the Arctic but in lower latitudes as well. Their work is correlated closely with other geophysical activities in the area, and it goes without saying that the records they produce are invaluable in the reduction of all magnetic field work in Alaska as well as in ionospheric studies. In the aggregate, we see that Alaskan magnetic work merits vigorous support, both for its fundamental import as a segment of Earth science, and for its vital contributions to practical affairs.

\section{REFERENCES}

1. Balsley, James R., JR. The airborne magnetometer. U. S. Dept. of Interior. Geophysical Investigations, Prelim. Rept. No. 3. 8 pp. (Processed). Washington. 1946 .

2. DAvies, F. T. The diurnal variation in magnetic and auroral activity at three high-latitude stations. Terr. Magn. Atmos. Elect., 40: 173-182. 1935 .

3. Deel, S. A. Alaska magnetic tables and magnetic charts for 1940. U. S. Coast and Geodetic Survey. 42 pp. Washington. 1944 .

4. Hasegawa, M. Provisional report of the statistical study on the diurnal variations of terrestrial magnetism in the North Polar regions. Internat. Assn. Terr. Magn. and Electr. Bull, 11, Trans. Washington Meeting, pp. 311-318. 1940.

5. Howe, H. H. Magnetic observatory results at College, near Fairbanks, Alaska, for the second Polar Year, October 1932 to March 1934. 179 pp. Washington. 1944.

6. KnapP, D. G. Arctic aspects of geomagnetism. In, Vilhjalmur Stefansson, Encyclopedia Arctica, $I$ (in press).

7. Kupffer, A. T. Recueil d'observations magnétiques faites a St. Pétersbourg et sur d'autres points de l'empire de Russie. 727 pp. St. Petersburg. 1837.

8. Масит, H. G. Das erdmagnetische Feld der Polargebiete. Zeitschrift für Meteorologie, 1 : 289-297. 1947.

9. Madill, R. G. The search for the North Magnetic Pole. Arctic, Journal of the Arctic Institute of North America, I (1): 8-18. 1948.

10. Olsen, J. Persistent solar rotation period of 26.875 days and solar-diurnal variation in terrestrial magnetism. Nature, 157 : 621. May 11, 1946 . 
11. SABINE, E. On the amount and frequency of the magnetic disturbance and of the aurora at Point Barrow. British Assn. Report, Part 2: 14-15. 1857 .

12. Schotr, C. A. Results of magnetic observations at stations in Alaska and in the Northwest Territory of the Dominion of Canada. U. S. Coast and Geodetic Survey, Annual Report for 1892. Appendix 11: 529-533. 1892.

13. Weinberg, B. P. Symmetry of the magnetic field in Polar regions. Akademiia Nauk USSR, Comptes Rendus 3I (2): 117 . 1941 . 


\title{
THE GEOPHYSICAL INSTITUTE AT THE UNIVERSITY OF ALASKA
}

\author{
WM. S. WILSON \\ Acting Director, the Geophysical Institute
}

Research in Arctic Natural Science has become of major importance in recent years. This large gathering, the first Alaskan Science Conference, emphasizes this. The particular area of research of concern in this paper was recognized soon after the founding of the University of Alaska in the third decade of this century. The importance of research in geophysics increased to such an extent that in 1946 Congress passed the authorization (P.L. 580-79th Congress) and later provided funds (P.L. 4918oth Congress) for the establishment of a Geophysical Institute in Alaska. In this paper there will be presented (1) a brief history of the University of Alaska, (2) a general review of early research in Arctic Geophysics at the University of Alaska, (3) the history of the procedures and legislation authorizing the establishment of the Geophysical Institute at the University of Alaska, (4) a description of the facilities provided and a statement of the provisions for operating the Institute, (5) a brief review of Research in Geophysics at the University of Alaska, and, finally, (6) a proposal for the future role of the Geophysical Institute in Alaskan research.

\section{History of the University of Alaska}

An act of Congress approved March 4, 1915 , set aside sections of land for a Territorial College and School of Mines and provided for a site for the College near Fairbanks, now known as College, Alaska. The Territorial Legislature on May 3, 1917 by its acts accepted the grants of land previously authorized by Congress, and created "The Alaska Agricultural College and School of Mines" and appropriated money for the first building. In 1921, the Hon. Charles E. Bunnell, then Federal Judge of 


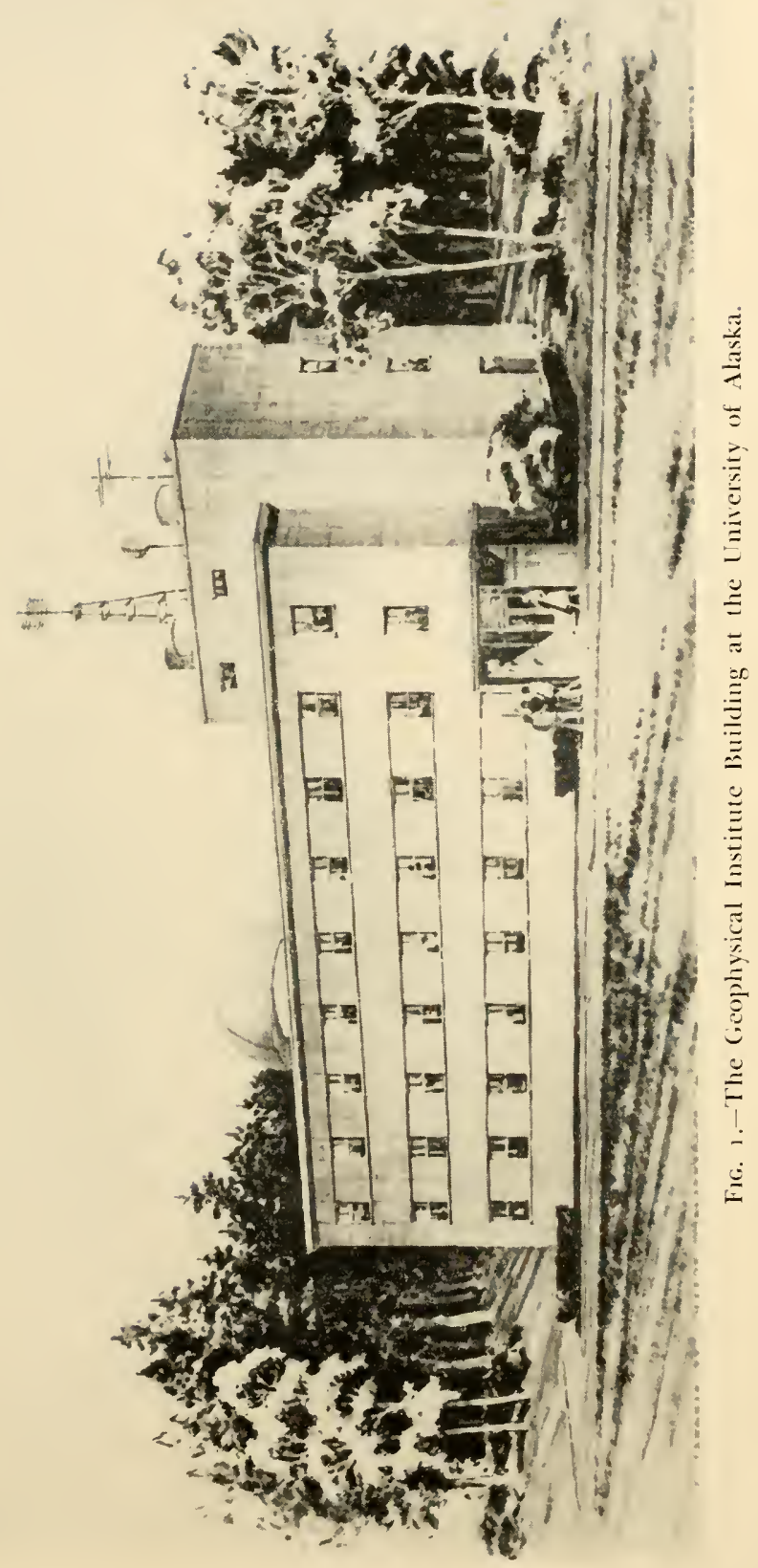



the District Court located in Fairbanks was elected President of the College and assumed his duties. In September 1922, the College was dedicated and opened with six students. After this very humble beginning, the College grew slowly. In 1935 by Territorial Act it became the University of Alaska, a land grant institution. The University now sponsors, either on its own resources or jointly with various Territorial and Federal agencies, a Summer School, an Agricultural Experiment Station (three branches-Fairbanks, Matanuska, Petersburg), a Cooperative Agricultural Extension Service, Veterans-on-the-Farm training, a Mining Extension Service, and gives resident instruction at the main Military Establishments in Alaska (Ladd Field, Eielson Air Force Base, Elmendorf and Richardson Fields at Anchorage, and the Naval Base at Kodiak), and cooperates and participates in research directly or by loan of equipment in many fields. Of these the most significant at present is geophysics.

Early Research in Geophysics at the University of Alaska

Research in Geophysics at the University of Alaska was initiated in 1929 by a grant of $\$ 10$,ooo from the Rockefeller Foundation for auroral height measurements. During the second International Polar Year, 1932-1933, the University of Alaska was designated a first-order station in a world wide network of stations engaged in measurements of various kinds: electric potential of the earth and its atmosphere, changes in terrestrial magnetism, heights of the aurora, random properties of the ionosphere and intensities of seismological disturbances. From 1934-1941 a portion of the polar year program was continued with the assistance of the Coast and Geodetic Survey, the Navy Department, the Carnegie Institution of Washington and others. During his period as Instructor at the University of Alaska, Henry K. Joesting, now Chief of the Geophysics Section of the United States Geological Survey, made an extensive series of magnetometric mineral surveys for the Territorial Department of Mines. In 1941 the Carnegie Institution asked for the cooperation of the University of Alaska in undertaking 
a vigorous attack on problems in arctic geophysics with especial emphasis upon the ionosphere, terrestrial magnetism, high frequency long distance radio propagation, and zenith auroral activity. This important program will be discussed in some detail later in this paper. Following the entry of the United States into World War II there was an increased activity in arctic geophysical research. The program at the University was enlarged by studies concerned with the deviation of radio waves from a great circle course, examination of rapid fluctuations in the earth's magnetic field, measurenent of night sky light, scattering of light by gases, and studies of refraction. Seismological and magnetic work sponsored by the Coast and Geodetic Survey was continued until 1948 when that agency established its own permanent observatory on the University campus. The expansion of the program from these beginnings and the plans for the immediate future will also be discussed later.

\section{The Polar Year}

An interest in auroral research by investigations from all over the world developed rapidly following the recognition that aurorae were closely associated with magnetic disturbances. Early observers had noted disturbances of the magnetic needle coincidental with auroral displays. By far the greater number of the observations of the first part of the 2oth Century had been made in Norway by Carl Störmer and his colleagues. The establishment in 1930 of a first order auroral station, almost on the opposite of the pole, at College, Alaska, for the purpose of obtaining information from another part of the globe was highly fortunate. The work at this station had as its objective the gathering of factual information on aurorae from the photogrammetric determinations of their form and position in space, accompanied by systematic visual observations. This program was initiated by a $\$ 10,000$ grant from the Rockefeller Foundation. Measurements on auroral heights extended from August 1930 to April 1932 and the results of visual observations to December 1934. The measurements of auroral heights are all 
based on simultaneous photographs with especially constructed cameras located at College, Alaska, and at a point $22.28 \mathrm{~km}$ away in a southeasterly direction. Several thousand successful photographs were taken during the period. The visual observations included records of form, color, intensity, direction, extent, and altitude, supplemented by weather conditions and other miscellaneous data. The taking of data was discontinued in December 1934 for reasons of economy. A somewhat closer view of difficulties encountered may be of interest. The early work was under the direction of Veryl R. Fuller, Professor of Physics in the Alaska Agricultural College and School of Mines. Professor Fuller's death occurred before the calculations were completed. George B. Henton continued the computations and constructed network charts for the graphical determination of auroral heights. W. W. Walton assisted with the visual and photographic observations. The calculations were completed by Professor Erwin H. Bramhall, successor to Professor Fuller, with the able assistance of John A. Fleming, Director of the Department of Terrestrial Magnetism of the Carnegie Institution of Washington. The results were included in the Miscellaneous Publications of the University of Alaska, Volume II, entitled "Auroral Research at the University of Alaska 1930-1934." This publication gives in considerable detail data, photographs, and graphical organizations of the results to show the number of visible aurorae, their form and extent, their times of occurrence and duration, their distribution by day, month and year. A somewhat brief account is given by Veryl R. Fuller: Auroral Observations at the Alaska Agricultural College and School of Mines for the Year 1930-1931, Terr. Mag. 38, 207-238 (1933), 36, 297-308 (1931) and 37, 159-166 (1932).

Other activities during the polar year in Alaska included extensive measurements of magnetic, electrical, meteorological, and ground phenomena at a network of stations, many of which were maintained by volunteer workers. These were integrated with the world wide network. 
History of the Geophysical Institute Building

As early as 1936 the Board of Regents of the University through the Martin Harrais Resolution offered to provide for the creation of an arctic research center at the University of Alaska. This resolution was as follows:

"WhereAs, In the building of the University of Alaska it is the duty of the Board of Regents to make ample provision for the education of those enrolled as students, and

"Whereas, It is also the duty of the Board of Regents to build the institution so that it can render a full degree of service to all the people of the United States, and

"WhereAs, By virtue of its strategic location, the University of Alaska, if properly equipped will be able to contribute immeasureably to research in anthropology, archaeology, astronomy, atmospheric electricity, aurora, ethnology, formation and testing of the soils, geology, geophysics, ionosphere meteorology, terrestrial magnetism, and other branches of research, and

"Whereas, The Territory of Alaska is unable to provide funds sufficient to build, equip, and maintain a building calculated to be of the greatest service in conducting scientific research as herein outlined, but is able to provide heat, water, light, power, janitor service, and maintenance of building.

"Now Therefore Be It Resolved, That the Board of Regents of the University of Alaska offer to the United States a site on its campus on which to erect a building or buildings, to accomplish any or all of the aforesaid purposes and agree in the event specified to the end that the several departments of the Government of the United States in prosecuting research in Alaska shall have the advantages offered by the laboratories, library, and cooperation of the University of Alaska."

This action followed many requests for research in arctic natural science by various departments of the Government and by the various scientific agencies. This was made more apparent as a result of the interest in the activities of the Polar Year and the minor definite realization of the fact that the United States had no research facility in the Arctic. The proposal to construct such a research institute soon aroused interest in international scientific circles. It was evident that a station in the 
northwestern part of North America in typical arctic surroundings and within or close to the zone of maximum auroral activity, would be a valuable asset to any comprehensive study of the Earth by international agencies. Such a laboratory would put the United States on a par with Russia, England, Greenland, Norway and Finland-each of which has had at least one such institution for years. In 1944 the American Geophysical Union and the National Academy of Sciences adopted a resolution endorsing the creation of a Geophysical station in Alaska and suggested its location at the University of Alaska.

\section{Early Legislative Procedure}

Just before and during World War II the necessity for increased knowledge of the Arctic became apparent. Activities were initiated sceking to obtain support from Congress for the establishment of a research institute in Alaska. Workers in the small Geophysical Observatory and members of the University staff were much interested and aided materially in initiating action which finally led to the presentation of the bill for the appropriation. Members of national and international scientific organizations became definitely interested and participated in the hearings, as did representatives of the various defense agencies, the Coast and Geodetic Survey, the Geological Survey and the Department of Commerce. Among the many individuals who appeared before the various congressional committees were E. L. Bartlett, Delegate from Alaska; Dr. John A. Fleming, then Advisor in International Scientific Relations to the Carnegie Institution of Washington, President of the International Council of Scientific Unions and General Secretary of the American Geophysical Union; Stuart L. Seaton, representing the University of Alaska; Rear Admiral L. O. Colbert of the Coast and Geodetic Survey; J. H. Dellinger of the Bureau of Standards; Robert Patterson, Secretary of War; Julius A. Krug, Secretary of Interior; Irwin W. Silverman, Chief Counsel, Division of Territories and Island Possessions, Department of Interior; Roger Revelle, Commander U. S. Naval Reserve, Office of Naval Research, Navy Department, Washington, D. C.; 
Colonel O. A. Heinlein, Member of the Research and Development Division of the War Department General Staff; Henry R. Joesting, Chief of the Geophysics Section of the Geological Survey; Dr. L. H. Adams, Director of the Geophysical Laboratory, and President of the American Geophysical Union.

\section{The Legislation}

As a result of the efforts described the following Public Laws were passed by the 79th and 8oth Congress. These are quoted below:

Public Law 580-79th Congress-Chapter 119-2nd Session H.R. 6486 providing authorization of the appropriation for the establishment of the Geophysical Institute:

\section{"AN ACT}

To Authorize an Appropriation for the Establishment of a Geophysical Institute at the University of Alaska

Whereas, The need for a geophysical station in this country, dedicated to the maintenance of geophysical research concerning the Arctic regions, is recognized; and

WhereAs, The University of Alaska has been performing geophysical research in cooperation with the Department of War, the Department of the Navy, the Federal Communications Commission, the United States Coast and Geodetic Survey, the United States Weather Bureau, and other agencies since 1941; and

Whereas, Said research has produced results not only of direct military application in the war emergency but also of value as a contribution to scientific knowledge; and

Whereas, There is a necessity for indefinite continuation of geophysical research in the Arctic in the postwar period; and

Whereas, Geophysical exploration can lead to increases in supplies and reserves of important minerals and can furnish information of direct value both for military and nonmilitary projects; and

Whereas, The University of Alaska, because of its unique location and the work it has accomplished in the past, is a logical site for a permanent geophysical research station; Now therefore,

Be It Resolved by the Senate and House of Representatives of 
the United States of America in Congress Assembled, That there is hereby authorized to be appropriated, out of any funds in the Treasury not otherwise appropriated, not to exceed the sum of $\$ 975,000$ for the construction and establishment of a geophysical institute at the University of Alaska, College, Alaska:

Provided, That not to exceed 20 per centum of the funds herein authorized shall be expended for construction of housing accommodations to be used by the personnel carrying out the program;

Provided Further, That, subject to the then existing security regulations, the facilities of the institute shall be extended, without charge, to the duly qualified and authorized representatives of the Federal departments engaged in geophysical research who shall have priority in the use of the housing accommodations constructed as a part of said geophysical institute:

Provided Further, That in the discretion of the director the facilities of the institute may be extended, without charge, to the duly qualified and authorized representatives of non-profit scientific societies engaged in geophysical research;

Provided Further, That in the discretion of the director said facilities may be used by others engaged in geophysical research, under such terms and conditions as said director may specify:

Provided Further, That all funds derived from the operation of said geophysical institute shall be used in geophysical research:

And Provided Further, That no portion of the funds herein authorized shall be expended for maintenance of the buildings constructed it being an express condition of this grant that the University of Alaska undertake to furnish heat, light, water, electric power, and custodial service, and to staff the institute with (1) a director, whose appointment by the regents of the University upon the recommendation of the president of the University shall be with the approval of the president of the National Academy of Sciences; (2) a librarian; and (3) a secretary.

SEC. 2. All buildings and equipment constructed or acquired with funds herein authorized shall, upon the establishment of the institute become the property of the University of Alaska."

Approved July 31, $194^{6}$. 
The Appropriation Act:

"Geophysical Institute, Alaska: For the establishment of a geophysical institute at the University of Alaska, as authorized by the Act of July 31,1946 (48 U.S.C. $175,175^{\mathrm{a}}$ ), $\$ 100$, ooo to be immediately available and to remain available until expended, and in addition thereto the Public Buildings Administration is authorized to enter into contracts for this purpose in an amount not exceeding $\$ 875$,ooo: Provided, That no part of this appropriation shall become available unless and until title to the land upon which said institute is to be constructed shall have been conveyed to the United States:

Provided Further, That, notwithstanding the provision of any other law, all buildings and equipment constructed or acquired with funds herein appropriated or under authority to contract shall, upon the establishment of the institute, be the property of the United States."

\section{The Establishment of the Geophysical Institute}

The passage of the Public Laws was soon followed by laying out a practical Geophysical Institute plan. The recommended building plan provided for a three-story specially designed, reinforced concrete structure approximately sixty feet by one hundred twenty feet which would provide laboratory and office space for seismographs, natural illumination records, ionospheric measuring equipment, magnetographic master pendulums for geodetic work, radio wave measuring equipment, spectrolielioscopes, chronographs, auroral cameras and other equipment needed for a comprehensive attack on geophysical phenomena. In addition housing accommodation for the scientists carrying out the various programs was to be provided. The plans further included a well equipped machine shop. The University provided a ten acre tract, bids were let and the construction started in the spring of 1949 and was scheduled for completion in June $195^{\circ}$.

Stuart L. Seaton, then director of the Geophysical Observatory, University of Alaska, was appointed Director of the Geophysical Institute and took office the day of the cornerstone 
ceremony, July 1, 1949. Thus the plans of the many who were interested in this project came to be a reality.

The United States could now add her name to the list of those countries possessing polar research facilities: in England, the Scott Polar Research Institute at Cambridge; in Russia, the Arctic Institute at Leningrad; in Greenland, the Commission for Scientific Research; in Norway, Spitzbergen and Arctic Sea Research Institute at Oslo; and in Finland, the Geographical Society of Finland at Helsinki. Realization of the plans has progressed rapidly. Shortages and the like have delayed progress a little. Today the plant is about $95 \%$ complete.

\section{Facilities for Research at the Geophysical Institute}

The facilities for geophysical research at the University of Alaska include the laboratory building, the staff residences and the basic equipment provided by the Public Law. These have been supplemented by field sites and stations as indicated in the following description.

\section{The Laboratory Building}

The Geophysical Institute Building is a three story reinforced earthquake-proof concrete structure, $5^{6}$ feet by 112 feet, with the long dimension running due east and west (Fig. 1). The building provides offices, laboratories and other specialized rooms. The roof is an especially constructed instrument deck with an astronomical dome at one end. The main features of the building are evident from its floor plans, figures 2-5.

Each laboratory will be provided with water, gas and compressed air. The laboratories and offices will be lighted with fluorescent lamps. The building provides conduits for carrying all services to all parts.

The first floor (figure 2) is set aside for laboratory space and service rooms. It provides four large laboratories, a reception room, a machine shop, a dark room, utility rooms and a storeroom. One of the large laboratories has pillars resting on bedrock for the support of delicate instruments used in seismological and gravimetric studies. A dust-proof room is provided. 


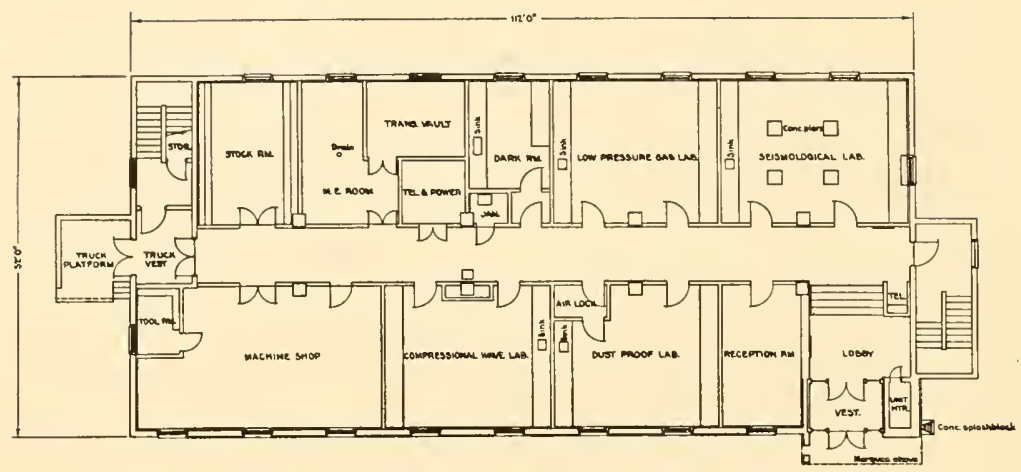

Fig. 2.-First floor plan, Geophysical Institute Building.

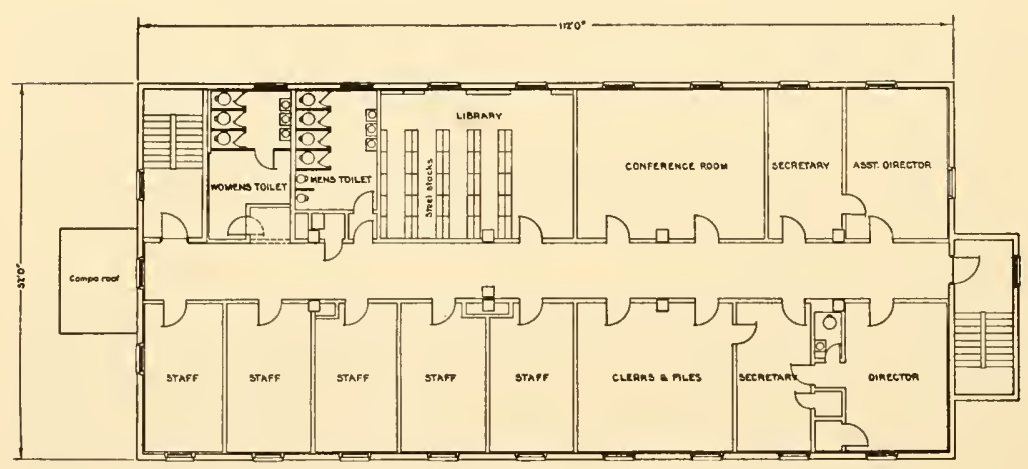

Fig. 3.-Second floor plan, Geophysical Institute Building.

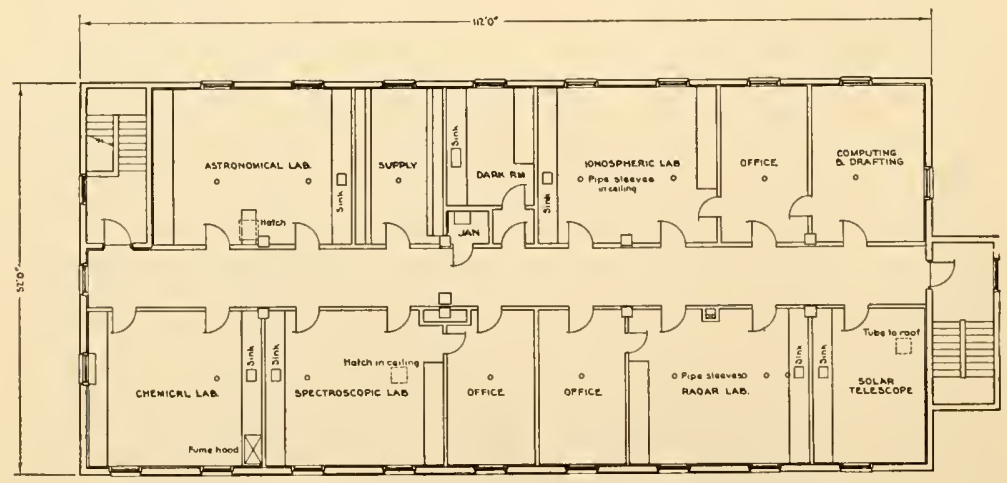

FIg, 4--Third floor plan, Geophysical Institute Building. 
The second floor (figure 3) is given over to administrative staff offices, the library, a file room and a conference room. The staff offices measure approximately 10 by 20 feet.

The third floor (figure 4) and the roof (figure 5) constitute the effective working section of the building. Conduits and hatches are provided to facilitate proper arrangements between the equipment on the roof and recording instruments in the rooms below. A penthouse for housing recording instruments and for mounting the usual meteorological station instruments is situated at the east end of the roof. A hand operated aluminum dome toward the west end encloses a mounting to serve

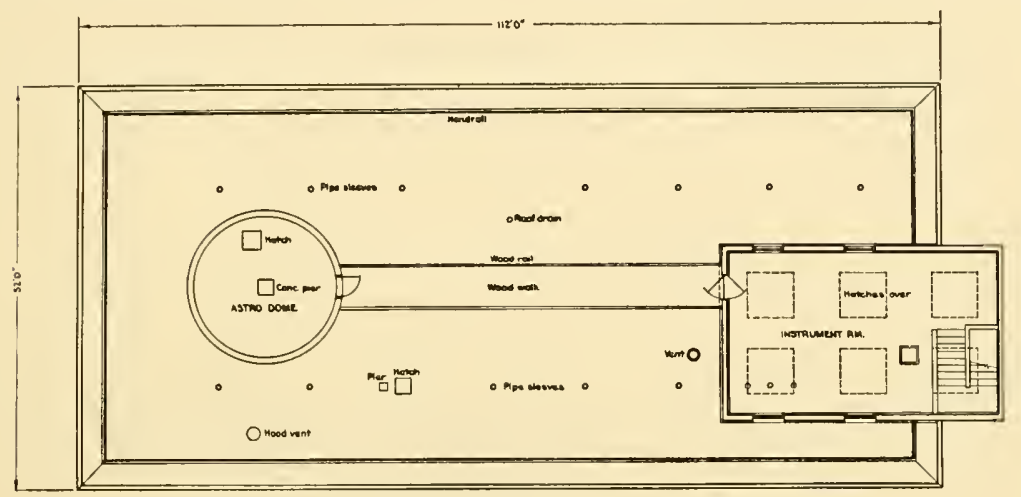

FIG. 5.-Roof plan, Geophysical Institute Building.

an eight or ten inch telescope or other equipment. This entire arrangement provides very effectively for the study of phenomena in the sky.

\section{The Library}

Particular attention was given by those who planned the building to provide space for a technical library. Provision was also made for the services of a librarian. One of the main rooms on the second floor will become the library and reading room. Subscriptions have been entered for about 125 current journals in Geophysics. Collections of pertinent data from appropriate observatories are being assembled. As funds are made available classical, as well as modern, books will be added to those already 
on hand. Probably this will be at an early date. The floor space will have to be increased considerably. It is conceivable that an information center may be operated in conjunction with the library so that the combination will serve the Territory of Alaska both as a depository and a source of information on all matters pertaining to the geophysical sciences.

\section{The Shop}

The shop occupies a room of 20 feet by 60 feet. Its facilities are to include standard machine tools, wood working equipment, and facilities for glass blowing, heat treating and welding. A competent machinist has been employed and is now installing the shop equipment. It is planned that shop assistance can be provided for research groups working in this territory whether or not directly connected with the Institute.

\section{Residences}

In accordance with the provisions of the law, a nucleus of six modern two bedroom residences has been constructed. These are to accommodate scientists who are engaged in research at the Geophysical Institute. Each is equipped with a modern bathroom, an automatic oil-furnace, an electric range, and a refrigerator. It is planned to furnish them more completely at an early date. A nominal rental is charged for their use by the Geophysical Institute to cover depreciation and to provide for replacement of furniture and buildings. Water is supplied from the main University system. The sewage is disposed through the University line.

The residences are intended to house new senior staff members on a more or less temporary basis, and to provide for outstanding visiting scientists who may spend time at the Institute. However, Congress has established a definite priority for government employees sent here during times of stress, and lias delegated the Director of the Institute to administer its regulations. 


\section{The Field Stations}

Numerous investigations in the general program of the Geophysical Institute require field locations because of the need for isolation, triangulation or space. Five such stations are in use. One is on the main grounds of the Geophysical Institute and houses the new recorder for vertical incidence studies. Ballaines Lake field station was established earlier by the Army as a location for the study of radio signal intensities. It is merely a wooden shelter on University property about a mile from the main building. The searchlight experiment is located at two sites, the transmitter being on the Campus and the receiver 11.6 kilometers away on the Steese Highway. The fifth station is maintained as the second observation point for auroral height studies.

\section{Personnel}

The Public Law provides for the existence of a basic administrative staff for the Geophysical Institute. This is to include the director, appointed by the Board of Regents on recommendation of the President of the University subject to the approval by the President of the National Academy of Sciences, a secretary, a librarian and custodian. It was the intent of the founders that the Geophysical Institute maintain a staff under this administration to pursue a program of research in basic geophysics and offer graduate study through appropriate departments in the academic division of the University. At present such an independent staff does not exist in reality, as the contracts for research in geophysics are written to the University of Alaska and assigned to the Geophysical Institute for completion. However, those employed in the Institute are recognized as a working group under the director. This group has been organized in four divisions: the administrative staff, the scientific staff, the technical staff and the custodial staff. The administrative staff includes the director, honorary directors and committees, the secretary, the librarian, the business manager and their assistants and secretaries; the scientific staff-those engaged in actual research and graduate 
instruction; the technical staff-those engaged in specialized services, including the machinist, the draftsman, electronic technicians and the like; the custodial staff-the janitor, stock clerks, truck drivers. The honorary and permanent ranks of the staff are described as follows:

Honorary positions are held by men outstanding in their fields of science and as a rule indicate activity only in a general advisory capacity.

Visiting Fellows actively promote the work of the Institute and are definitely connected with a particular problem. In fact, their appointment in general follows time and effort spent elsewhere in the field of this problem. The line between the Visiting and Honorary group cannot in all cases be sharply drawn.

Associated Faculty, as the name implies, indicates a division of time between teaching, research and other duties at the University of Alaska. Subdivisions within this group are determined by the usual academic and research qualifications. They are normally employed on a full year ( $10 \frac{1}{2}$ months) basis and are paid partly from teaching and partly from research funds.

Members are engaged in research full time. Minimum qualifications are either the doctoral degree (Ph.D. or Sc.D.) or three years of pertinent experience beyond the master's degree or five years beyond the bachelor's. Unusually desirable experience may reduce these requirements by one year.

Associates are also engaged in research full time, but need have only the bachelor's degree with appropriate majors and minors.

Research Fellows are engaged in basic research and are normally candidates for advanced degrees either at the University of Alaska or at some other institution. They may or may not receive a stipend, as conditions warrant.

Graduate Assistants serve on a part time (usually half time) basis. They must be satisfactorily pursuing a part time program of graduate studies at the University of Alaska commensurate with their Institute duties. Work assigned to them will be of a routine nature, not suitable for academic credit.

Observers are normally part time students at the University of Alaska, either graduate or undergraduate. They perform necessary duties on some project while gaining experience in a research laboratory and earning some money to help defray academic expenses. 
Their duties are accordingly limited to a maximum of sixteen hours per week, and they are required to maintain satisfactory academic standing during the period of their employment.

At present there are 15 full time staff members, 8 part time associated faculty members and 10 part time assistants and observers making a total working group of 33 members. They are engaged on contracts to the University of Alaska by the Airforce, the Signal Corps and the National Bureau of Standards. Graduate work will be started in the near future. It is contemplated that several graduate assistants and fellows will be engaged as this program of graduate studies is developed.

It is planned to include on the staff as soon as possible, a group of outstanding scientists who will serve as advisors to the workers in the various branches recognized as comprising basic geophysics. This group of honorary and visiting fellows will, with the permanent staff, assure the broadest possible program consistent with the opportunities and capacities at the Geophysical Institute.

\section{Research in Geophysics at the University of Alaska}

Research in Geophysics at the University of Alaska at this time (November 1950) is chiefly concerned with the Upper Atmosphere. It involves investigations mostly of an applied nature, studying radio propagation, auroral and night-sky phenomena, and sounding the ionosphere by radio pulse techniques. These are supplemented by an extensive series of measurements on the state of the atmosphere in the Arctic. This work is supported by contracts with the Signal Corps, Department of the Army, the Geophysical Research Directorate of the Air Force, Cambridge Research Laboratories and the Central Radio Propagation Laboratory of the National Bureau of Standards, though small programs in photometry and cosmic radiation are supported by University funds.

\section{Ionospheric Measurements}

Multifrequency ionospheric equipment has been in operation at College, Alaska, since June 1941. The initial equipment, 
a D.T.M. Model \#3 Multifrequency Ionospheric Recorder, was on loan from the Department of Terrestrial Magnetism, Carnegie Institute of Washington, and was manually operated. This was later modified for automatic operation. Every 15 minutes a survey is made of radio wave energy reflected from the ionosphere throughout a frequency range of $0.5^{2}$ to 6.00 megacycles per second. The resulting photographic records are reduced to tabulations of numbers giving for each hour the penetration frequency of the $\mathrm{F}_{2}, \mathrm{~F}_{1}$ and E-layers, minimum virtual height of the $\mathrm{F}_{2}, \mathrm{~F}_{1}$ and $\mathrm{E}$-layers, minimum frequency of returning echos at normal incidence, maximum frequency of boundary E-layer reflections, $\mathrm{F}_{2}$-layer, $\mathrm{F}_{1}$-layer maximum usuable frequencies for 1500 and $3000 \mathrm{~km}$ distance, height of maximum electron density for the $\mathrm{F}_{2}, \mathrm{~F}_{1}$ and E-layers, and notes as to intensity of fadeouts. At present the D.T.M. machine is being replaced by a National Bureau of Standards C-3 Ionospheric Recorder with increased output power, variable pulse repetition rate and direct recording on motion picture film.

Summary data are transmitted daily to the Central Radio Propagation Laboratory at the National Bureau of Standards, Washington, D. C. Complete tabulations are mailed to the Central Radio Propagation Laboratory at the end of each month together with a report giving logs of operation, comparison of current with previous results, notations of propagation mode, and fade-out summaries. Original records and reproductions of the tabulations are retained at the Geophysical Institute.

These basic data are extremely useful for determining ionospheric structure, variations of this structure with time, mechanism of ionization agents involved, state of the upper atmosphere, and the influence of both terrestrial and extra-terrestrial phenomena. The data are also extremely useful in the prediction of radio wave propagation conditions in the Arctic. The series of observations, unbroken since June 1941, constitute one of the most powerful tools for research in this field particularly because many of the basic phenomena must be investigated by 
statistical devices. Several investigations based on this set of data have been reported:

1. CRPL D-Series, F-Series and E-Series

2. Carnegie Institution of Washington, Ionospheric and Auroral Studies at College, Alaska, 1941-46.

3. Tidal Effects in the F-layer, M. IV. Jones and J. G. Jones, Physical Review, 76, 581, (1949).

4. Thickness of Winter F-layer in Polar Regions-M. W. Jones,

Trans. Am. Geophys. Union, 31, 187-19o (1950).

5. State of the Upper Atmosphere-S. L. Seaton, Jour. Met. 4, 193 (1947).

6. Magnetonic Multiple Refraction at High Latitudes, S. L.

Seaton, Proc. Inst. Radio Eng., 36, 450-454 (1948).

7. Generalized Magneto-Ionic Theory-N. C. Gerson and S. L. Seaton, J. Frank. Inst., 246, 483-494 (1948).

8. A Correlation between Ionospheric Phenomena and Surface Pressure-M. W. Jones and J. G. Jones.

9. State of the Earth's Atmosphere in the Arctic-Research Reports Nos. 1-8, Contract W28-o99-ac-445 Airforce Cambridge Research Laboratories, Cambridge, Mass.

\section{Signal Intensity Measurements}

Continuous measurements of the strengths of radio signals traversing various long and short paths ending at College are being recorded. These data supplement the ionospheric measurement program. The records of variations of signal strength with time over the longer distances give information which permits verification and extension of wave propagation theory for use in establishing and maintaining satisfactory long distance communications in all parts of the world. Recordings over short distances are applicable to studies of absorption of wave energy in the ionosphere locally and to extension of knowledge of the upper atmosphere generally. The results from this pliase of the work are transmitted to the proper contracting agency and are part of the internal operations of these agencies.

The sky-wave radio propagation in the auroral zone is subject to peculiar variations. Part of Alaska is in the maximum 
auroral zone. Hence Alaska is an exceptionally favored region for the study of these variations. The measurements of signal behavior at College reveal definite correlation with magnetic (and hence auroral) activity. Such correlations are being made and in the future will become a more significant part of the activity at College.

\section{A uroral Heights}

Beginning in 1948-49 the National Bureau of Standards provided for the resumption of auroral height determinations as part of its general ionosphere program. The old cameras used in the Polar Year were used at the previous locations. These manually controlled cameras were replaced after the first season by automatic, unattended $\mathrm{K}-24$ cameras (coated optics, f/2.5; exposure $5^{o}$ seconds) operated by a radio link between the camera stations which are 7.6 kilometers apart. The heights determined for all types of aurora vary from $5^{0}$ to $25^{\circ}$ kilometers with a mean at 116 .

\section{Intensity of the Light of the Night Sky}

The light of the night sky at College, Alaska, usually includes the aurora in addition to the airglow, zodiacal light, starlight and light from the milky way. Measurements of the illumination of the night sky at College have been made from time to time and will be continued through this winter. Early efforts were made during the winters of 1941 through 1946, first by means of a visual photometer, and later by means of photographs of the zenith at 2.5 minute intervals. The earliest measurements with the visual photometer were difficult to make and therefore crude. The equipment was cumbersome. Measurements made later in this period were made on the equipment modified by the introduction of comparison wedges and by the careful control of processing. Even with these changes it took one man's full-time efforts for 18 months to analyze six months' film.

In recent years the measurements of the intensity of the light of the night sky have been revived. The measurements are 
now being made by a low-brightness photometer developed by Hulburt, and by a photoelectric recorder. The measurements using Hulburt's photometer have been extended through the first part of the $1949-5^{\circ}$ winter season. Observations of the entire sky were made at $15^{\circ}$ intervals. They furnish an absolute calibration of the zenith sky light recorder. Low values of about 50 millimicrolamberts are found at the zenith. Horizon values run three times as large. Typical night sky light contours at College, Alaska have been reported in the following:

Seaton, S. L., Night Sky Brightness at College, Alaska, J. Geophys. Res. 55, 43-46 (1950)

Wilcox, J. B., A Survey of Night Sky Brightness at College, Alaska, Trans. Am. Geopliys. Union, 3I, 540-544 (1950).

Values up to around 40,00o millimicrolamberts are observed during auroral displays.

Measurements of the intensity of the light from the zenith night sky by the photoelectric recording system were begun in September 1949. The recording system consists of an ${ }_{1} \mathrm{P}_{21}$ electron multiplier type photocell feeding a two-circuit Brown recorder. It gives a continuous record of the intensity on charts, easy to reduce because of having a linear range from zero to 100,000 millimicrolamberts. This range has been found to embrace all night sky light intensities from the darkest sky well into twilight. These measurements are supported by the ionospheric and signal intensity contract of the Central Radio Propagation Laboratory. Results have been reported in the research reports to the National Bureau of Standards.

\section{Seismological Studies}

Alaska has several regions of earthquake and volcanic activity. Two central regions lie along the Aleutian chain and in the Tanana Valley. The recent work of Pierre St. Amand on the earthquake swarm of late 1947 has been published in the paper entitled "The Central Alaska Earthquake Swarm of October 1947 " in the October 1948 issue of the Transactions of the American Geophysical Union. 
In 1948 the seismographs were moved to the new magnetic observatory of the Coast and Geodetic Survey. Records are still being made of all tremors and are reported to Washington. In the near future the Geophysical Institute will collaborate with this observatory and study the data.

State of the Atmosphere in the Arctic

Work on the state of the atmosphere in the Arctic was proposed in 1948-49. The problem has been attacked along several lines:

(1) The Exploration of the atmosphere into the mesosphere by probing with a searchlight

Experiments to determine the atmospheric density, composition, temperature, and polarization, in the height range between $3^{\circ}$ and 100 kilometers are underway. Two 6o inch General Electric Company searchlights were made available through the Airforce Cambridge Research Laboratories. One serves as a transmitter, but the original carbon arc has been replaced by three high pressure quartz mercury arcs. The other has been modified so serve as a receiver; an elliptical mirror has been mounted so as to collect the light from the large mirror and focus it upon an electron multiplier type phototube. This equipment, with attached electronic components, is designed to enable explorations up to approximately 100 kilometers. Preliminary work at lower altitudes has given satisfactory results. In connection with this project, the theory of the scattering of light by atmospheric gases has been re-examined. It may be of interest to remark that the best results have been obtained at the isolated stations when the atmosphere is clear, still and at a temperature of about $40^{\circ}$ below zero Fahrenheit. The results have been given in detail in the progress reports on the State of the Earth's Atmosphere in the Arctic. In general the results verify those of the NACA. 


\section{(2) Theoretical Studies}

Theoretical studies on the state of the atmosphere in the arctic were started in the spring of 1948 . They are still in progress and are naturally based upon existing theories of the upper atmosphere and such new postulates as have become necessary. Data obtained from the programs in progress at the Institute have been used to test the hypotheses. Some of the problems attacked are the magnitude of the lunar diurnal wave in the ionosphere $300 \mathrm{~km}$. above the surface of the earth, the correlations (almost inverse) between ground barometric pressure and the F-layer semithickness and a delineation of wind systems in the ionospheric regions. (See references at end of the discussion on ionospheric measurements.)

\section{(3) The determination of ozone in the atmosphere}

A series of measurements of the daily concentration of ozone in the atmosphere near the surface was started in January $195^{\circ}$ and is still in progress. Ozone is absorbed in a solution of sodium arsenite following a method described at length by Dauvillier (Polar Year, Scoresby Sund, 1932-33). Comparative experiments with sodium thiosulfate indicate that the arsenite method gives more uniform results due to the greater stability of these solutions at the low concentrations involved. These daily determinations show certain extremely high values which seem to be significant even though a few may represent experimental eccentricities. However, certain exceptional values such as those of February $8 / 9$ did correspond to an isothermal sounding of the atmosphere, and are thus comparable to Dauvillier's value and probably have the same explanation. The amounts of ozone present in winter are nearly 10 times those observed in summer. The average values are many times as great as those in the temperate zones. A study of the monthly averages shows a maximum in March to April and a secondary maximum in the summer. A similar progression of values for total ozone concentration in the Northern latitudes has been noted by several observers. 
The method is being studied critically in this region of high concentrations in order to resolve differences between values based on sodium thiosulphate and sodium arsenite. Extended studies of ozone are planned for the future to include measurement of total ozone using a Dobson Spectrophotometer. Attempted correlations with meteorological parameters have not been particularly successful. Observations at shorter intervals may make correlation possible. Information on the circulation of the atmosphere may be deduced from, or given explanation of, the high values mentioned. A study is being planned to test the effect of this high concentration of ozone on the deterioration of materials exposed to the Arctic atmosphere. (For reference to this work see reports to the Air Force Cambridge Research Laboratories.)

\section{(4) Ionization studies}

In recent weeks a Compton ionization chamber has been under construction. When completed it will be used to make continuous records of the total ionization at the earth's surface. The records will be correlated with auroral phenomena and later with high altitude measurements of cosmic radiation that it is planned to initiate in the future.

\section{General}

Certain items should be mentioned to make this report complete.

During the $1949^{-5}$ o season a series of microwave-meteorological studies were carried out under the sponsorship of the Air Force Cambridge Research Laboratories.

The Signal Corps, Department of the Army, carries on an intensive study of Radio Propagation in collaboration with the University.

No report of work done at the University of Alaska should fail to mention specifically the extensive support financially and by loan of equipment from the various agencies such as the Rockefeller Foundation, the Carnegie Institution of Washington, the 
Air Force Cambridge Research Laboratories, the National Bureau of Standards and the Signal Corps.

\section{Future Work}

Long term plans call for a well-organized general program of research under the guidance of the administration and staff of the University of Alaska and the Geophysical Institute. This should involve studies over the entire range of subject matter recognized by the American Geophysical Union as being within the realm of basic geophysics, i.e., investigations in the eight general areas of Terrestrial Electricity and Magnetism, Seismology, Oceanography, Meteorology, Geodesy, Hydrology, Volcanology and Tectonophysics, and also in the related fields of Astronomy, Astrophysics, Geology, Geography and Radiophysics. Work in applied geophysics though not the direct mission of the Geophysical Institute should not be entirely omitted as it is one of the outcomes of basic research. For the near future several specific programs and projects are planned, those nearest actual inception are described briefly herewith.

\section{High Altitude Observatory}

Some of the highest peaks in the Americas are within Alaska. Alaska lies in the region of high geomagnetic latitude. It is crossed by the auroral zone. This makes an ideal situation for certain studies at high altitudes including cosmic radiation, the aurora above the dense lower atmosphere, other terrestrial and extra terrestrial radiations at the same altitude and high altitude meteorology. The work on cosmic radiation may reveal much that will supplement existing knowledge of it and auroral phenomena. More definite knowledge of the nature of the particles existing at high altitudes, their energies and direction of travel may reveal much as to the origin of particles coming into the earth's atmosphere. Definite observations over a long period of time are necessary to supplement the short time observations of balloons, aircraft and rockets. Work at sea level and in mines on cosmic radiation may also be conducted. 
Auroral Research

The few references to auroral research already made in this report indicate a group of specific problems. It should also be mentioned that Daniel Barbier and Don Williams of Naval Test Station had made a short spectrographic study of the auroral radiations in the winter of 1949. The field of auroral physics both from the point of view of exploratory science and of practical applications might in itself constitute a program for the Geophysical Institute. It may be that the Geophysical Institute and the University of Alaska would do well to concentrate in this area for some time to come as the chief topic of their scientific endeavor. This winter Dr. Louis Herman of the Paris Observatory will initiate a program in this field. He will bring spectroscopes from Paris and will seek to identify many lines in the spectra of the aurora that he and his coworkers have studied in the laboratory. The Institute is naturally procuring some auxiliary equipment for this program. It is planned to seek funds for equipment for more extended spectroscopic studies. Recently Dr. Franklin E. Roach of the Naval Ordnance Test Station visited College bringing plans of his equipment for a photometric survey of the aurora and night sky. It is planned to incorporate work in this field with his close cooperation into an enlarged auroral program.

\section{Night Sky and Twilight}

Investigations of the radiation of the night sky, distinct from the aurora are planned, using the selective photometric technique of Roach and co-workers. The long periods of twilight at College give excellent opportunity for studying this somewhat unknown field. Both topics will form a part of the world wide survey of these radiations now being planned by workers in these fields.

\section{Permafrost}

This is the last of the topics that will be specifically mentioned. It is of unusual interest and has been the subject of 
numerous investigations as is indicated by the papers presented at this meeting. The observatory has on order portable seismic equipment which will be available for investigations in this field.

\section{Micrometeorology (and Meteorology)}

The unusual frequency and scope of temperature inversions and other localized phenomena in the Tanana Valley are of intense interest. They give rise to unusual weather effects, e.g., the ice fog which is localized over populated areas. This suspension of ice in air is a hazard to air traffic over towns. An investigation of its nature and the conditions of its formation and dispersion presents a problem of unusual interest to the meteorologists which at the same time is of practical importance to those who live under its cover.

\section{Future Role of the Geophysical Institute in Alaskan Research}

If the intent of the originators of the idea of establishing the Geophysical Institute, as well as the Public Laws providing the authority and the appropriation be studied, it will be evident that the Institute is to provide a center for research in the Far North open on an orderly basis under the control of the Director to those institutions and other agencies which may desire to study basic geophysics in the Northwest corner of the North American continent. Its facilities, including housing, are open to all; however by the Federal law an order of priority has been established. The Director must administer this regulation. Federal agencies, especially those involved in the national defense and security, are accorded first priority. At present the University of Alaska, through its program of research by contract with various Federal agencies, utilizes many of the facilities. However, there is still some unused space open for additional research through contract with the University or by those agencies and responsible groups who care to send research crews. It should be stated here that housing for personnel is critical and is at present limiting the expansion of all activities at the 
University. Therefore arrangements should be made in advance of arrival by any interested agencies. Naturally recognition must be given to the priority of the University of Alaska resulting from its obligations under the Public Law to provide in perpetuity for an administrative staff and for the cost of maintenance of the building. This cost must be borne in part or in full, and without profit to the University, by those using the facilities. It is also to be noted that if any funds are made available through the operation of the Geophysical Institute, they must be expended in the interest of basic geophysical research.

In conclusion attention should be called to the fact that the Geophysical Institute is a unique organization. It has an advantageous location. It can under proper guidance develop into one of the most important research establishments in its field in the world. It provides facilities in the Arctic region of North America for the study of the earth in its broadest sense. These facilities are, subject to their limitations, open to all. The aim of the Institute should be to become the mecca for prominent scientists from all countries of the world. As the Institute is in Alaska, it will naturally seek to lend impetus first and foremost to the development of scientific knowledge in and about Alaska. 
AGRO-CLIMATOLOGICAL INVESTIGATIONS IN THE PERMAFROST REGION OF THE TANANA VALLEY, ALASKA

\author{
Basil M. BENSiN \\ Agronomist, Alaska Agricultural Experiment Station \\ of the University of Alaska
}

Agricultural exploration and development of Alaska are among the present vital problems of national defense. According to the last Census, only 421,799 acres, $0.1 \%$ of Alaska's total territory of $365,681,000$ acres is farm land. The number of farms is not growing but decreasing due to unfavorable climatic and economic conditions. The greater part of the food used in Alaska is imported from the States by sea, truck or air freight. "Airborne" eggs, tomatoes and other perishables are among the commodities sold in Alaska groceries for very high prices.

The potential agricultural area of Alaska, as estimated by G. W. Gasser, Territorial Commissioner of Agriculture, is $7,098,000$ acres, located along the river valleys in the interior. Most of this area has never been surveyed or explored systematically. Last year the Soil Conservation Service planned to make a soil survey of various agricultural regions covering an area of 4,104,320 acres during the coming years. However a soil survey alone, without proper climatological analysis, is not sufficient for proper evaluation of land.

Climatic factors are an essential part of the marginal agricultural environment of Alaska requiring special investigations and analysis. The aim of this report is to present some basic agro-climatological data of the Tanana Valley region obtained by the author during six years of observations and experiments conducted at the Agricultural Experiment Station of the University of Alaska. This is part of an agro-ecological analysis of this region, which is the largest and the most promising area for agricultural use, and considered as a potential granary of Alaska. 
Geographical location and general climatological data of the region

The Tanana Valley lies between parallels 64 and 66 Northern latitude and 146 and 149 West longitude, extending from Big Delta River, approximately 205 miles in width with an estimated area of 4.5 to 5 million acres. About $8 \%$ of this area, or 400,000 acres is probably suitable for agriculture (Fig. 1).

The Alaska Agricultural Experiment Station of the University of Alaska is located at $64^{\circ} 51^{\prime} \mathrm{N}$. latitude and $147^{\circ} 52^{\prime} \mathrm{W}$. longitude on the gentle slope of a hill facing south adjoining the flood plain bottom land of the Tanana valley. The meteorological station is located on this slope 510 feet above sea level. Two additional stations were established for microclimatological observations by the author with the agreement of the U. S. Weather Bureau in 1947: one is on the top of the hill, elevation 620 feet, and the other on the bottom land at 475 feet elevation. A diary of the agro-climatological observations during the growing season was published in "Jessen's Weekly," Fairbanks, as a special column: "Alaska's Nature, Climate and Agriculture" from $194^{6}$ to 1950. Besides regular meteorological data this column described some results of acclimatization work with grains, legumes, grasses and vegetable crops, as well as of microclimatological observations and experiments. Special attention was given to phenological data for native and cultivated plants, and to data on soil temperature movements at depths of 6, 12,24 and 36 inches both on hillside and on the bottomland.

General climatological data for the Tanana valley recorded over a period of years by the U. S. Weather Bureau are given on Table 1 , including normal mean temperatures and precipitation recorded at 5 stations of the region.

The general character of the climate of this region is distinctly continental with low annual precipitation of 12.8 inches and highest precipitation during the months of July and August. The greater part of the Tanana valley is located within the July isotherm of $60^{\circ} \mathrm{F}$, as is shown on Fig. 2, being the warmest spot in Alaska during the summer months. Due to the 


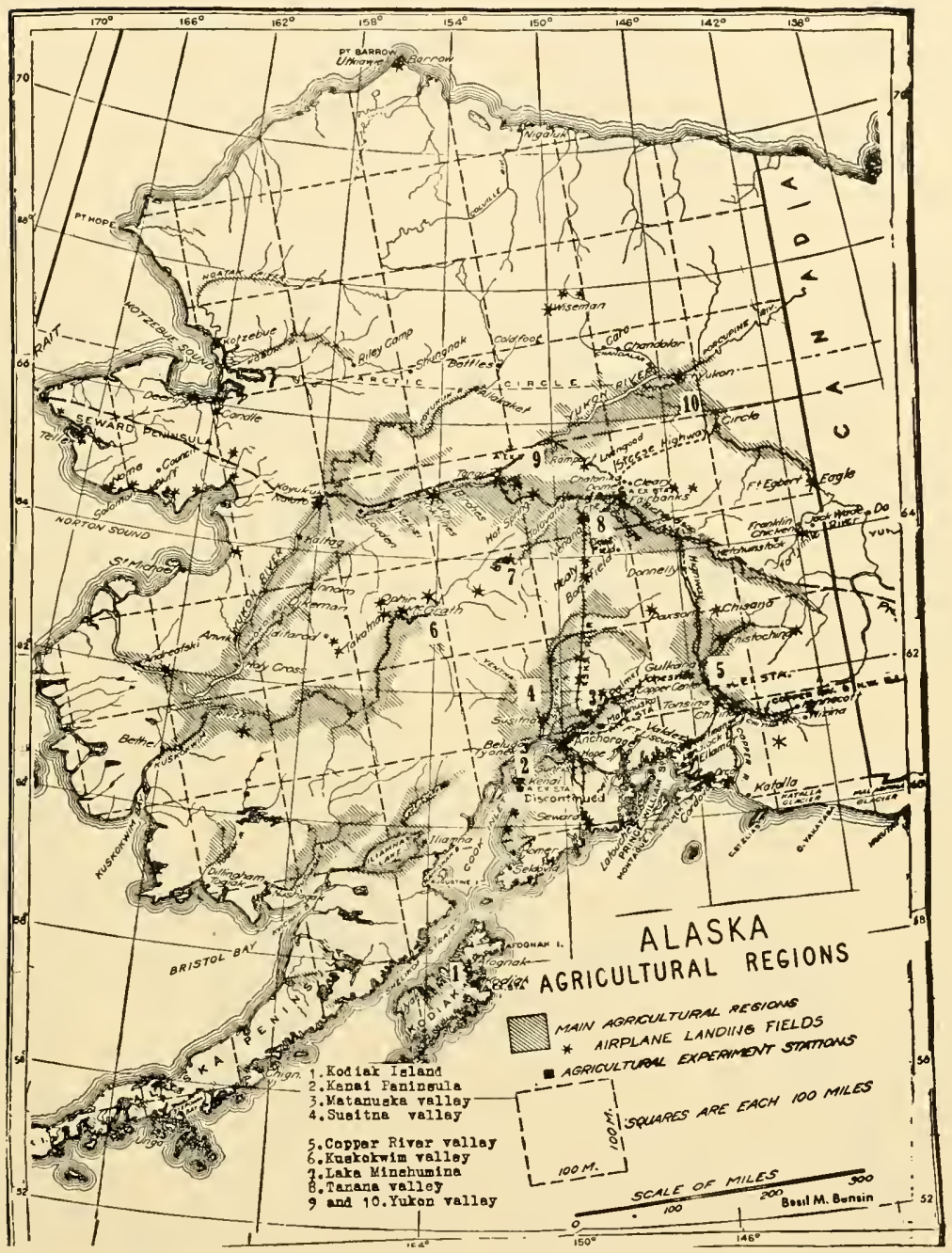

FIG. 1.-Alaska Agricultural Regions. Tanana Valley region (8) located in the heart of the interior of Alaska. 


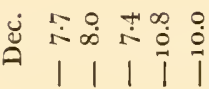

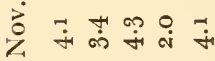

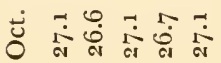

芯

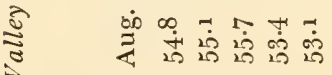

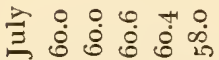

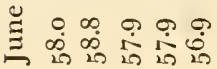

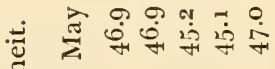

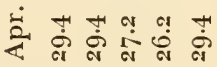

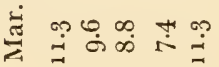

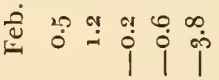

घี

?

$\vdots \vdots \vdots \vdots$

$\vdots$

ฐี

ฏ

总

这

ॠ్

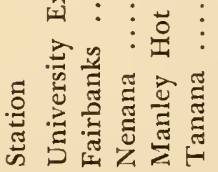

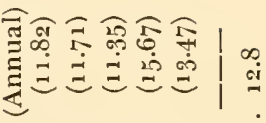

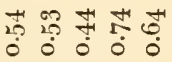

茴

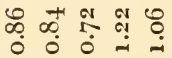

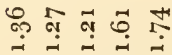

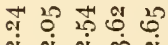

जิ की

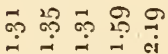

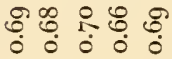

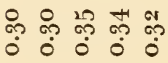

$\begin{array}{lllll}8 & 0 & 0 & 0 & 01 \\ 0 & 0 & 10 & 10 & 0 \\ 0 & 0 & 0 & 0 & 0\end{array}$

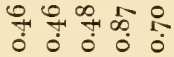

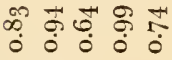




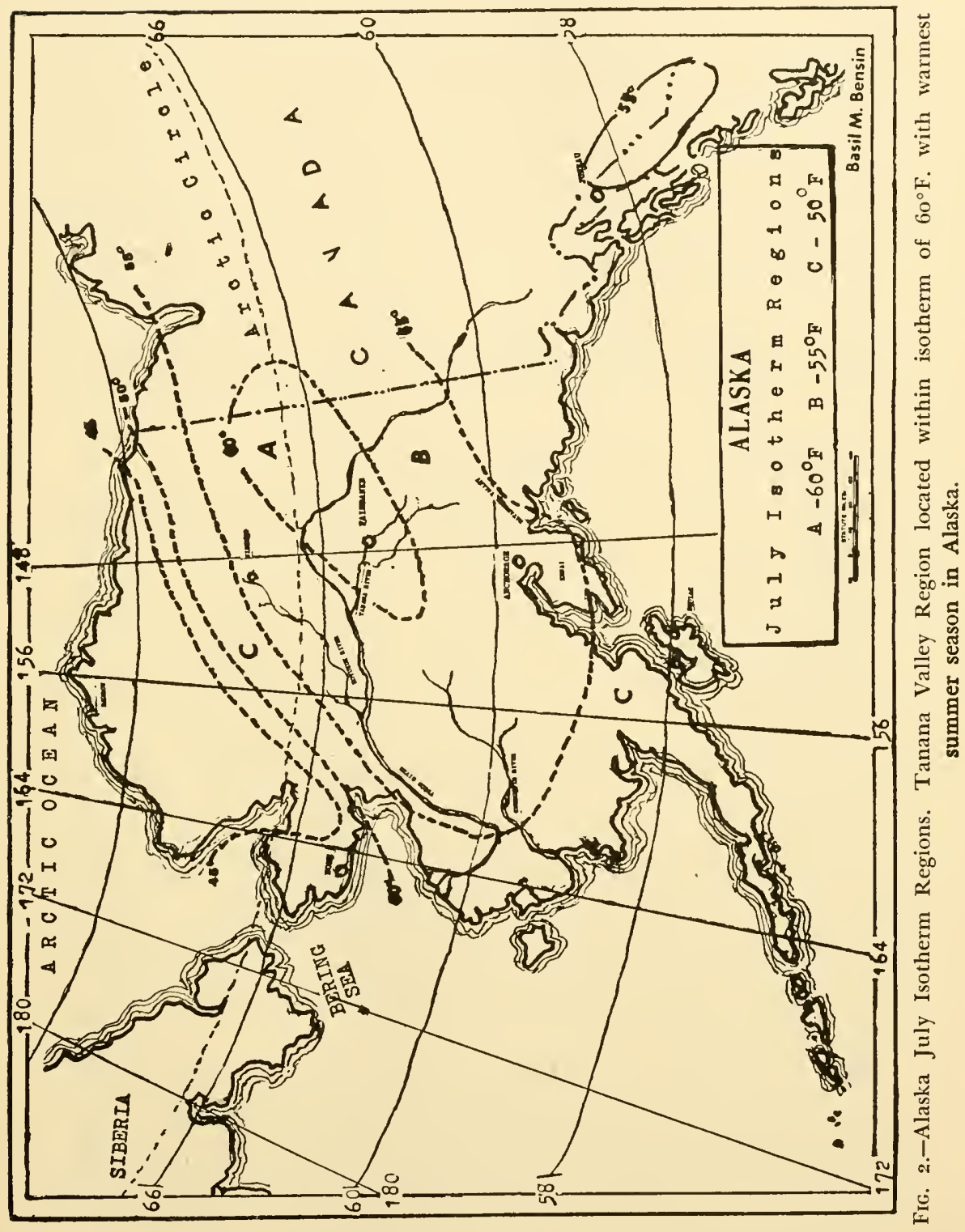


high latitude there is a long day of over 20 hours during June and part of July with a high percent of possible sunshine during the months of May to August, as is shown on Table 2. There are over 9 hours of sunshine daily during these months.

During the winter months days are short and temperature is low, sometimes with $-50^{\circ} \mathrm{F}$. and even $-60^{\circ} \mathrm{F}$. recorded in the mainland of Alaska during the month of January. However these low temperatures are associated with windless days or "calms" occurring in December and January. These calms and clear sky make winter cold more pleasant than windy cold weather in the coastal regions of Alaska. The cold winter weather of the interior of Alaska is connected with the Siberian

TABLE 2.-Character of the day and number of sunshine hours, normal at Fairbanks, Alaska

\begin{tabular}{|c|c|c|c|c|}
\hline Month & $\begin{array}{l}\text { Partly } \\
\text { Cloudy }\end{array}$ & Cloudy & $\begin{array}{c}\text { Sunshine } \\
\text { Hours }\end{array}$ & $\begin{array}{l}\text { Percent of } \\
\text { possible }\end{array}$ \\
\hline April $\ldots \ldots \ldots \ldots \ldots \ldots 11$ & 5 & 12 & 309 & 68 \\
\hline May $\ldots \ldots \ldots \ldots \ldots \ldots$ & 12 & 12 & 324 & $5^{6}$ \\
\hline June $\ldots \ldots \ldots \ldots \ldots \ldots$ & 13 & 11 & $35^{2}$ & 54 \\
\hline July $\ldots \ldots \ldots \ldots \ldots \ldots, 7$ & 10 & 14 & 282 & 45 \\
\hline August $\ldots \ldots \ldots \ldots \ldots \ldots$ & 9 & 17 & 169 & 33 \\
\hline September...$\ldots \ldots \ldots$. 5 & 8 & 17 & 125 & $3^{2}$ \\
\hline
\end{tabular}

anticyclonic high pressure prevailing at this time in the northern hemisphere.

Prevailing winds in the valley are southwestern in summer and northern in winter with low velocity of 5 miles per hour. The frostless period in Fairbanks, located at the center of the region, extends from May 29 to August 26, or 89 days. However there is great variability, the season extending in some years over 135 days.

The amount of the thermal units-degree days during the growing season in various parts of the region is shown on Table 3. In this table three types of the thermal units are indicated: (A) number of degree days above freezing point $32^{\circ} \mathrm{F}$. ( $0^{\circ} \mathrm{C}$. $),(\mathrm{B})$ degree days about $41^{\circ} \mathrm{F}$. $\left(5^{\circ} \mathrm{C}\right.$. $)$, temperature which is considered by plant physiologists as a minimum for the beginning of plant growth, and (C) degree days above 
$5^{\circ} \mathrm{F} .\left(10^{\circ} \mathrm{C}\right.$.) which is the minimum temperature for growing warm-season crops, like tomatoes, beans, etc.

The small number of thermal units in this subarctic region indicate thermal deficiency, as this is the most important environmental factor limiting the kind and varieties of crop plants adapted for growing here. Only a limited number of crops and varieties could be grown in this region, selected and adjusted to this environment by careful acclimatization work.

According to the German plant physiologist Hildebrandt, the amount of thermal units needed for growing grain crops in the

TABLE 3.-Number of thermal units-degree days-in degrees of Fahrenheit

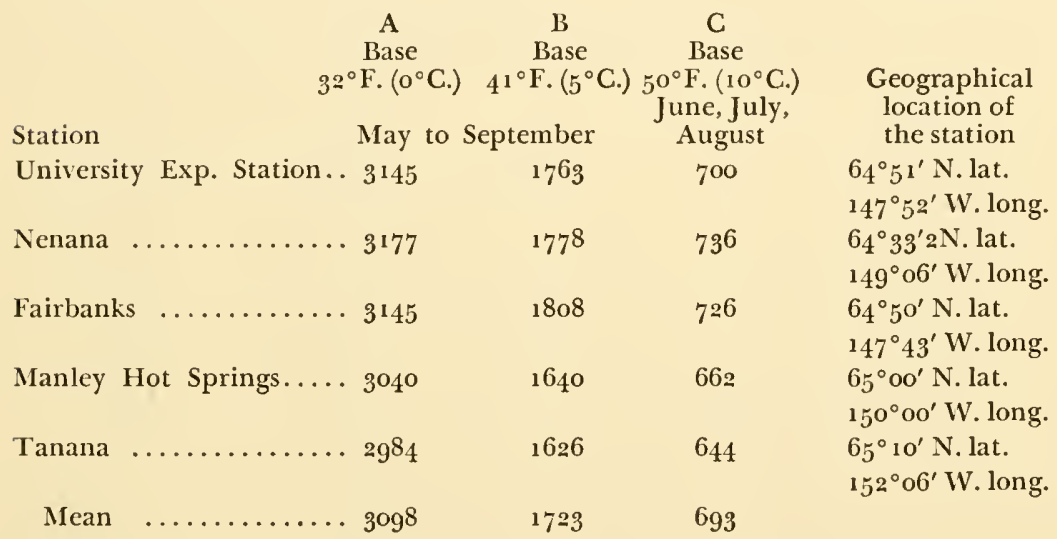

temperate zone of Germany could be designated as $2800^{\circ} \mathrm{F}$. $\left(1600^{\circ} \mathrm{C}\right.$.) for barley and $3828^{\circ} \mathrm{F}$. $\left(1960^{\circ} \mathrm{C}\right.$.) for oats. According to G. T. Selianinoff, in European Russia the requirements for barley are $3060^{\circ} \mathrm{F}$. to $4500^{\circ} \mathrm{F}$. $\left(1700^{\circ} \mathrm{C}\right.$. to $2500^{\circ} \mathrm{C}$.), for wheat $3204^{\circ} \mathrm{F}$. to $4086^{\circ} \mathrm{F}$. $\left(1780^{\circ} \mathrm{C}\right.$. to $2270^{\circ} \mathrm{C}$.) and oats $3492^{\circ} \mathrm{F}$. to $45 \mathrm{Oo}^{\circ} \mathrm{F}$. $\left(1940^{\circ} \mathrm{C}\right.$. to $2300^{\circ} \mathrm{C}$.). These European standards of thermal units for grains are very near to those of the American temperate zone. In the Wisconsin Agricultural Experiment Station, for example, average used thermal units base $32^{\circ} \mathrm{F}$. for the grains grown in 1944-1948 were as follows: for barley $2929^{\circ} \mathrm{F} .95$ days, for wheat $3373^{\circ} \mathrm{F} .103$ days and oats $2823^{\circ} \mathrm{F} .87$ days from planting to maturity. 
Although the number of degree days in the Tanana valley for growing grains is much lower than in the temperate zone of Europe and America, nevertheless grains are growing here quite successfully by the use of acclimated varieties and strains. The fact that days in the high latitude sub-arctic regions are much longer than in temperate zones having more hours of solar and sky radiation, particularly during the month of June, has a profound effect on plant growth and its phenological phases. Length of the solar radiation hours during the day in June is essential for native and cultivated plants which are in the blossoming phase at this time. During the month of

TABLE 4.-Normal number of the solar and sky radiation units in gram calories per square centimeter $\left(\mathrm{gmcl} / \mathrm{cm}^{2}\right)$ Fairbanks, Alaska

\begin{tabular}{|c|c|c|}
\hline Month & $\begin{array}{l}\text { Daily } \\
\text { mean }\end{array}$ & $\begin{array}{c}\text { Total } \\
\text { per month }\end{array}$ \\
\hline May & 477 & 14,787 \\
\hline June .... & 499 & 14,970 \\
\hline July ...... & 447 & 19,857 \\
\hline August & 314 & 9,734 \\
\hline September & 176.5 & 5,295 \\
\hline
\end{tabular}

June solar and sky radiation recording began in Fairbanks at 4: oo a.m., while in Madison, Wisconsin, at 10: oo a.m. and continued to 7:30 p.m. However the total number of solar and sky radiation units is higher at Madison than in Fairbanks (Table 4 and Fig. 3).

Our phenological observations in this region during the last six years indicate that most of the native sedges (Eriophorum sp. Carex sp.), grasses (Poa arctica, Calamagrostis canadensis, Bromus arcticus, Bromus pumpelianus) and legumes (Astragalus sp.) have completed their blossoming during this month. Our perennial fire weed (Epilobium augustifolium) blossoms in the first part of July, coinciding with the beginning of heading of our barley and wheat. 


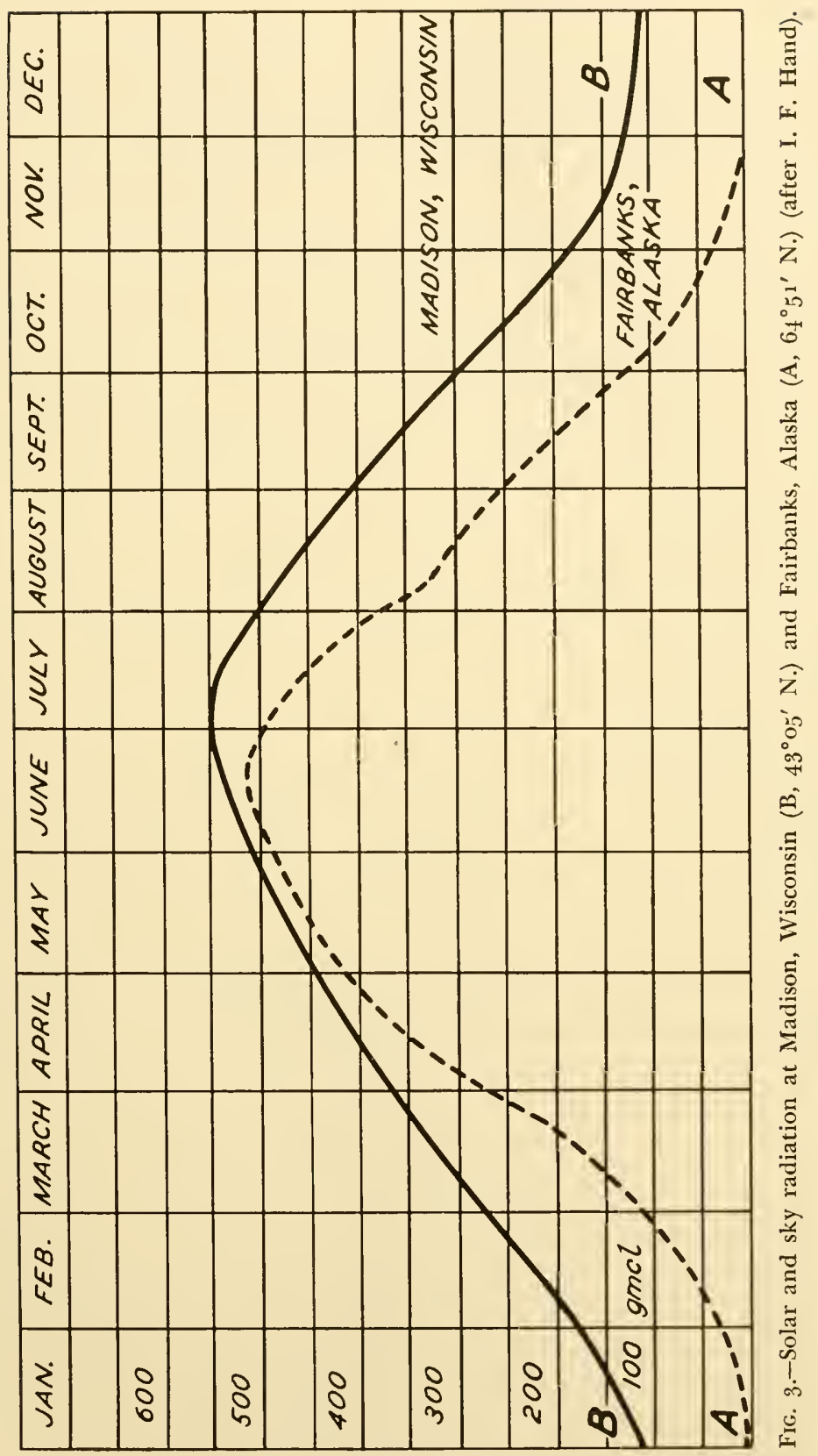


Soil Climate of the Region

The greater part of the land of the Tanana valley lies on the permanently frozen ground-permafrost. This is a very significant environmental factor for agricultural land use. It has a profound effect on the soil climate, soil temperature and soil moisture as well as upon the soil type and microflora. Our information about these facts is scarce and fragmentary.

Our observations and experiments were limited chiefly to soil temperature and pedothermal deficiency. During the season we recorded soil temperature variations at various positions

TABLE 5.-Soil temperature profiles at the depth of 6 and 12 inches, May-August I919, degree days above ${ }^{\circ}{ }^{\circ} \mathrm{F}$.

A. On the Hillside Field-Elevation 510 feet (College, Alaska).

(Degree days in degrees of Fahrenheit)

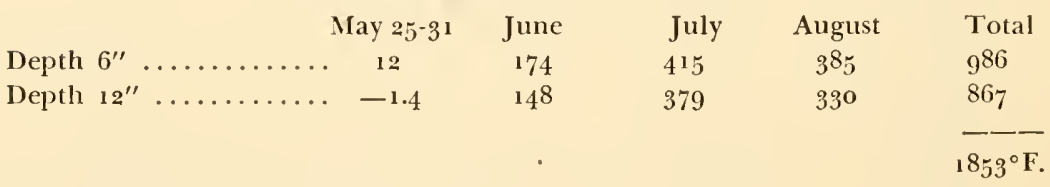

B. On the Bottomland-Elevation 475 feet (College, Alaska).

\begin{tabular}{|c|c|c|c|c|c|}
\hline Depth $6^{\prime \prime}$ & -0.9 & 19 & 283 & 264 & $5^{61}$ \\
\hline Depth 12" & -9.5 & -123.5 & $14^{0.5}$ & 137 & 144 \\
\hline
\end{tabular}

in the hillside field and bottomland of the Station. The hillside field was cleared in 1907 and the permafrost table is at 40 feet, as has been found by digging a well, while on the bottomland, which was cleared 15 years ago, the permafrost table is lowered only to 15 feet. Soil temperature in both fields during the season is quite different as shown on Table 5. Soil temperature on the bottomland, particularly at the depth of 12 inches, is considerably lower than on the hillside field, the total difference being only $38 \%$ of the hillside temperatures. A temperature of $5^{\circ} \mathrm{F}$. was reached at the depth of 6 inches on the hillside July 3 and on the bottomland July 9 , while at the depth of 12 inches on the bottomland the highest was $4^{\circ} \mathrm{F}$. reached July 24 .

These temperatures are evidently correlated with the mois- 
ture content of the soil. While soil on the hillside is drying rapidly during the month of June after snow melting in April and early May, soil on the bottomland retains moisture because the snow melting and refrosting of the soil on the flat land is slower. As a matter of fact water stands on the frozen soil until the first part of June.

During a dry season, like in 1946 , temperature on the hillside field at the depth of 6 inches reached $65^{\circ} \mathrm{F}$. on July 10 , as shown on Fig. 4. On the bottomland soil temperature movement is much slower even in a warm season as $195^{\circ}$, as slıown on Fig. 5 .

During the long warm season of 1949 , with a rainy June, the highest soil temperature on both fields was observed in the middle of July, as shown on Fig. 6.

In most cases soil temperature in the lower levels moves slowly and root movement is limited by the low temperature of the soil. As a result the root system of crop plants is bound to be very shallow which is a quite distinct morphological feature of the regional types of all crop plants including vegetable crops, grains and perennial legumes like alfalfa and clover (Bensin, 1928). This cool soil also has an effect upon the potato, tubers being flat and roots turning toward the south. Pedothermal deficiency therefore is among the basic environmental factors of this subarctic permafrost region, limiting agricultural land use and production of several field crops of the temperate zone such as soy beans, corn, sweet potatoes and warm season vegetables such as tomatoes, etc. The problem of warming soil by the proper cultural methods is basic for Alaskan agriculture and horticulture.

\section{Microclimate Problems and Experiments}

Microclimatogical observations and experiments made by the author in the Tanana valley in $1945^{-195^{\circ}}$ indicate the great significance of the microclimatic factors of the sub-arctic environment for agricultural land use. By clearing land we actually are creating a new microclimate affecting soil temperature and lowering the permafrost table. Topography, location and dimensions of cleared field are among the microclimatic 


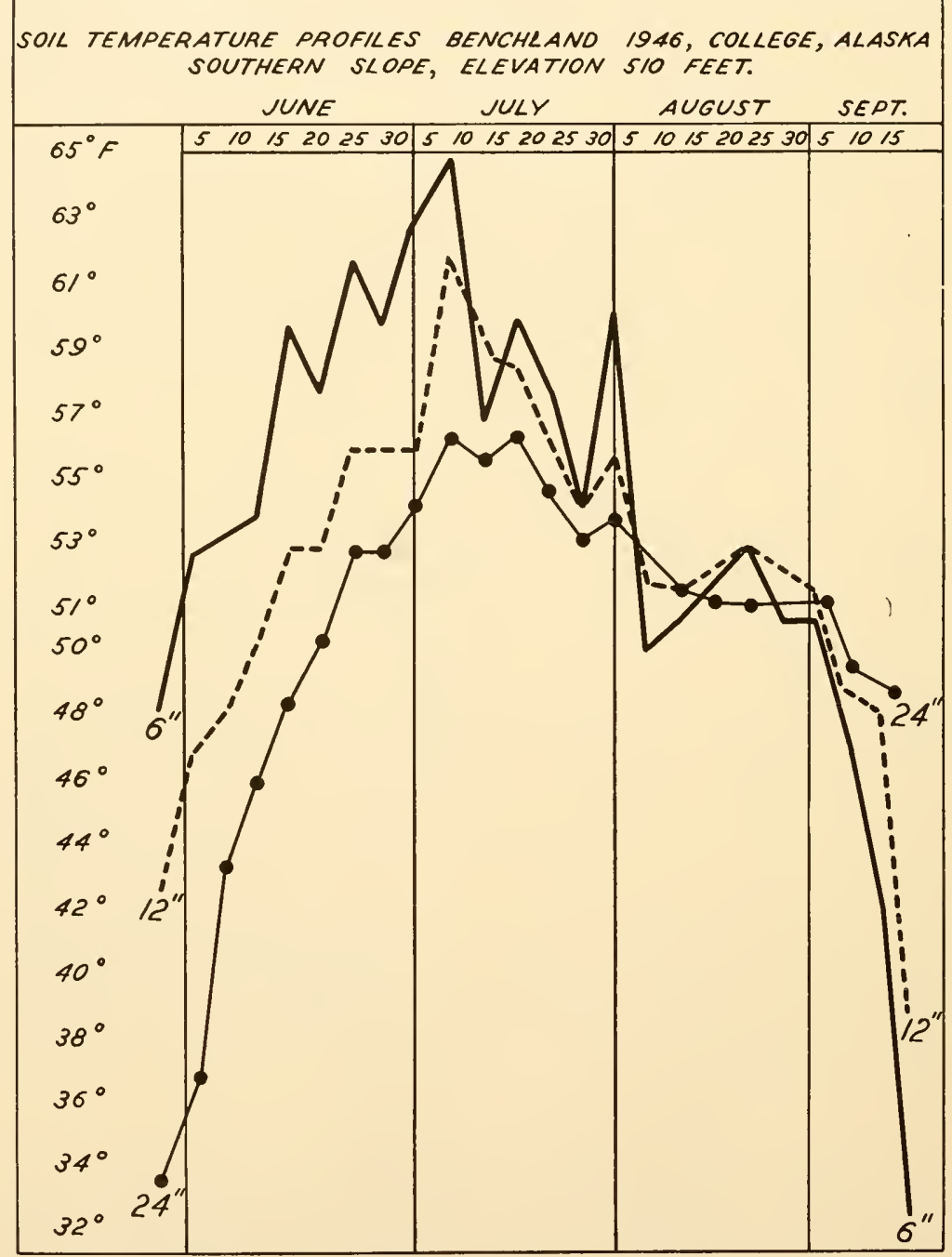

Fig. 4.-Soil temperature profiles at depths of 6, 12, and 24 inches, 1946, College, Alaska. 
SOIL TEMPERATURE PROFILES BOTTOM LAND 1950, COLLEGE, ALASKA ELEVATION 475 FEET.

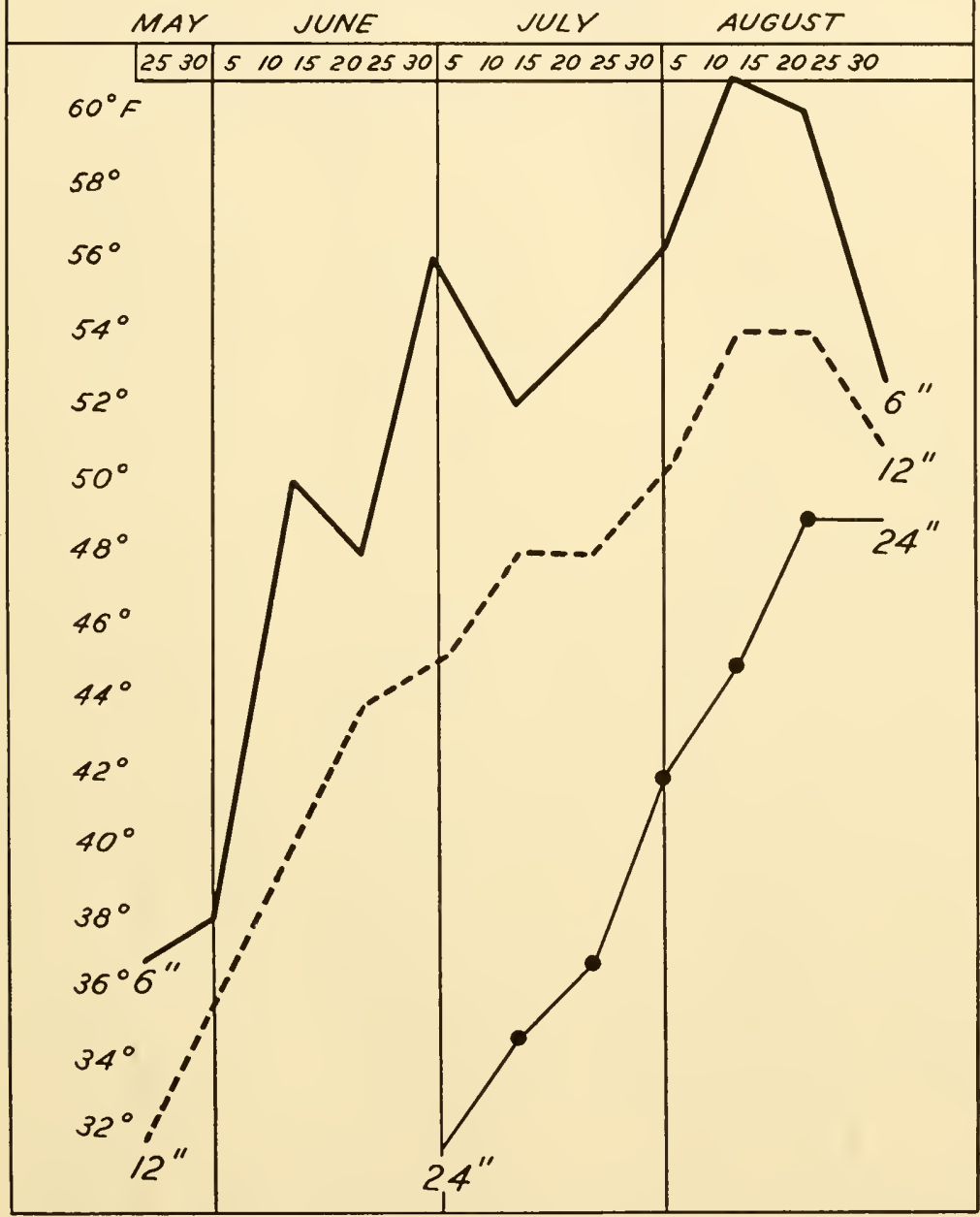

Fis. 5.-Soil temperature profiles at depths of 6, 12, and 24 inches, 1950, College, Alaska. 


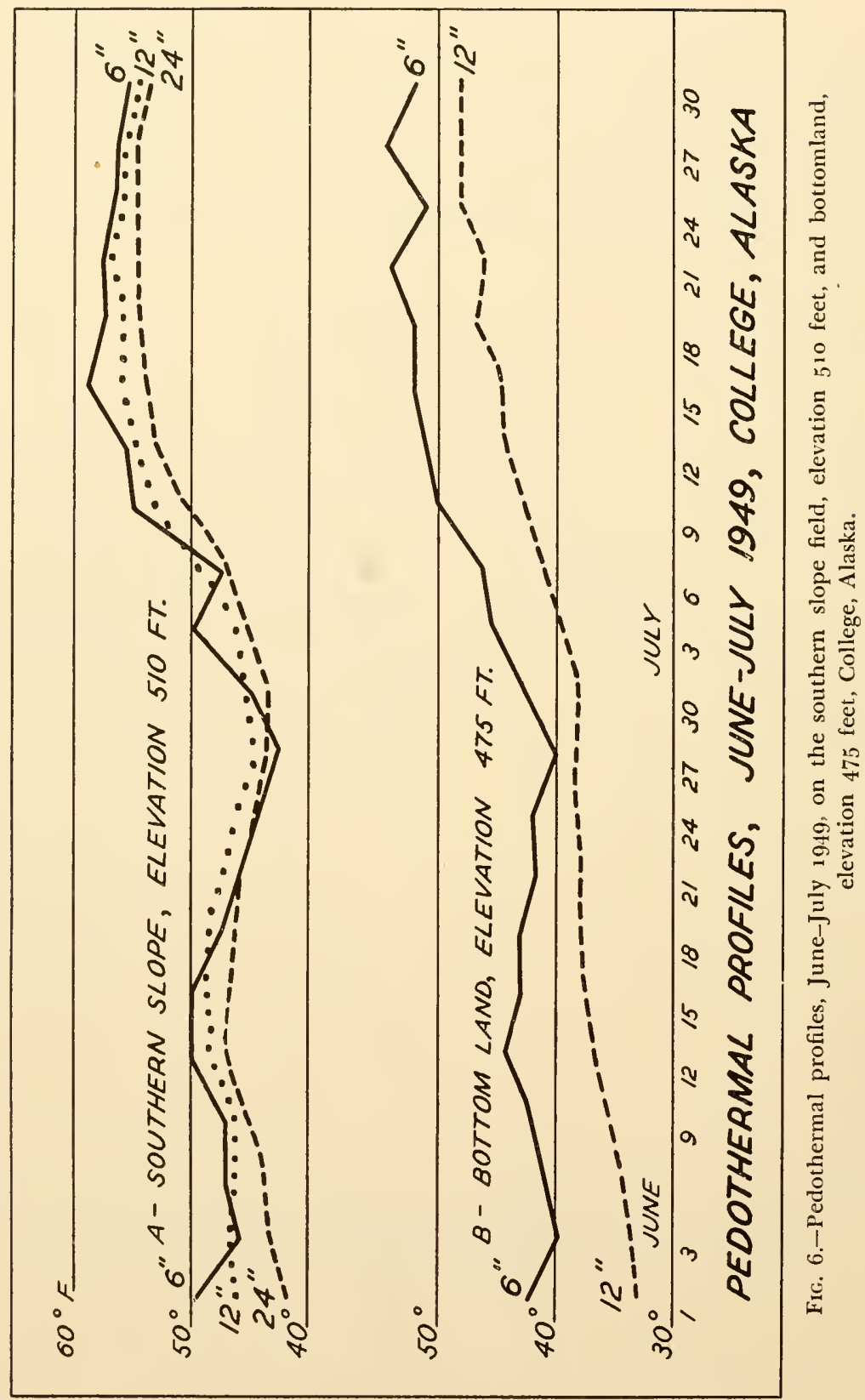


features to be considered. The presence of high hills or air drainage around the fields has a profound effect upon crop growth during the growing season and particularly on air temperature. Temperature rccords made during the month of July 1949 on our 3 stations at different elevations of $620,5^{10}$ and 475 feet indicate the highest temperature on the southern slope at 510 feet during the day, as is shown on Fig. 7. During the night higher temperature was noted on the top of the hill, elevation 620 feet, while the bottomland temperature recorded was higher than on the hillside. This is probably due to night radiation of dark colored soil of the bottomland field.

The southern slope of the land is the warmest spot, and should be used for agriculture with considerable advantage. On uncleared land natural vegetation of the southern slopes is conspicuously different from vegetation of northern slopes, in this region. Aspen trees (Populus tremuloides) and high bush cranberry (Viburnum pauciflorum) can be considered as indicators of the warmer land of the southern slopes, where the permafrost table is low and the peat moss (Sphagnum sp.) associated with a high permafrost table is absent.

We can create favorable microclimatological conditions on the limited areas of land used for agriculture. Several experiments in this direction were originated and conducted by the author at the Alaska Agricultural Experiment Station. The main object of these experiments was to overcome thermal and pedothermal deficiency of the region in small field and garden areas. These experiments comprise (a) removal of snow from the field and garden early in the spring ahead of the season, and (b) increasing soil and air temperature in the small garden areas by the use of coal dust and specially constructed solar radiators and reflectors.

Experiments on the removal of snow were conducted in 1947-1949 both on hillside and bottomland fields. Local lignite dust of the Healy Valley Coal Mine has been used for this purpose. In 1947 coal dust was scattered on one yard squares with application of two pounds of lignite per square at the end of March. Bright sunshine in the first days of April cause rising 


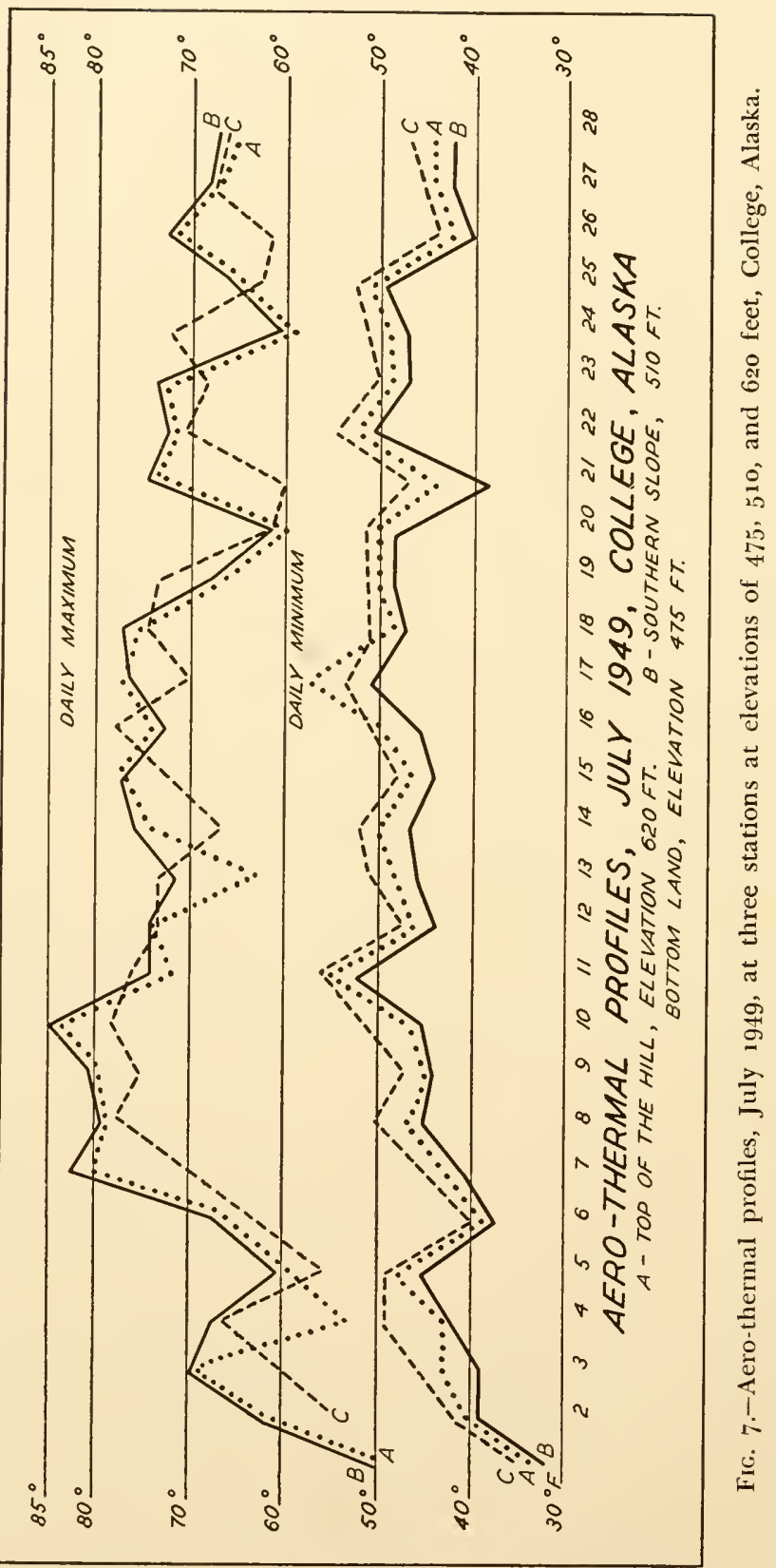


temperature on the surface of snow upon which lignite was scattered. A rise of temperature of $4^{\circ}$ above the check plots was observed in the afternoon hours. As a result all snow on the coal dust coated plots melted within 12-14 days while in the adjacent area depth of snow remained about 24 inches.

In 1948 smaller amounts of coal dust were used per square with similar results. Local gardeners interested in this experi-

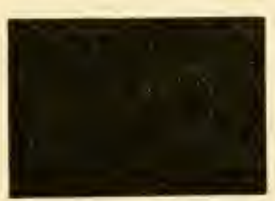

SOLAR AADIATOR

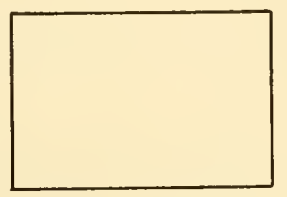

SOLAR REFLECTOR ALUMINUN

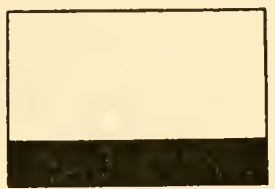

SOLAR RADIATORREFLECTOR

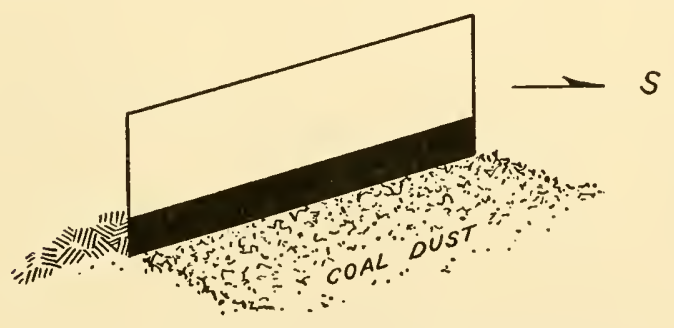

SOLAR RADIATOR-REFLECTOR
PLACED ON THE RIDGE

FIG. 8.-Solar radiators and reflectors for growing warm-season vegetables.

ment were using about 1 ,ooo pounds per acre of the same material. This removal of snow enables the beginning of the field work of the season 10 to 14 days earlier. During the same seasons coal dust has been used in gardens by spreading along the seed beds and east-rvest ridges with the side exposed to the south coated with coal dust. This method increased soil temperature near the surface up to $4^{\circ}$. Response of the vegetable crops (particularly beans and onions) was very favorable.

In 1948 experiments on growing cucumbers in black painted 25-gallon tubs with white painted reflectors placed behind them 
were quite encouraging. The crop of pickling cucumbers planted in the tubs was good. In 1949 galvanized iron reflectors painted with aluminum paint were used successfully in the garden for growing beans. In $195^{\circ}$ several types of solar radiators and reflectors were successfully tested with various warmseason vegetable crops. Tomatoes, squashes, pumpkins and cucumbers were grown in the tubs and on the ground with radiators and reflectors, and over 100 pounds of tomatoes were harvested. By means of these reflectors and radiators temperature of the soil was increased $15^{\circ}$ above the maximum temperature of air near the surface.

The real aim of the solar radiators and reflectors is to obtain the additional amount of light and heat needed for growing warm-season vegetables in this region and in other parts of Alaska. All these vegetable crops require mean temperatures above $50^{\circ} \mathrm{F} .\left(10^{\circ} \mathrm{C}\right.$.), and more intensive light than the normal of subarctic latitudes since they are of subtropical origin. Assuming that the mean temperature for growing tomatoes is $60^{\circ} \mathrm{F}$. we need during the months of June, July and August 920 degree days (base $5^{\circ}{ }^{\circ} \mathrm{F}$.), while we have only about 700 (see Table 3). Therefore it is necessary to increase the temperature of air and soil at least 20\%. This can be achieved by means of solar radiators and reflectors. Reflectors and radiators and coal dust scattered on the soil surface actually create a convection current surrounding the growing parts of the plant while the heated soil surface stimulates the growth of the root system. Additional light intensity obtained by reflection stimulates the photosynthetic activity of the plant and assists in the accumulation of carboliydrates in the plant as manifested by the remarkable increase in leaf area. Aluminum foil could be used to advantage for construction of hot beds, cold frames and green houses in Alaska with solar reflectors.

\section{Climate and Crops}

In agronomic work with field crops in Alaska environmental climatic factors are of primary importance. Most of this work is inevitably devoted to the acclimatization of the introduced 
seeds and plants from other regions with analogous climatic environment. By ecological tests and study of the best adapted varieties we are trying to establish standard varieties for the region. These varieties have definite ecological and morphological features and are described by the ecologists as ecotypes (Turreson 1922), agrotypes (McGregor 1927) or as regional agrotypes-chorotypes (Bensin 1928). Character and behavior of these chorotypes is the subject of careful experimental in-

TABLE 6.-Number of degree days for maturity of grain crops in 19.19 and 1950, College, Alaska

\begin{tabular}{|c|c|c|c|c|}
\hline \multirow[b]{2}{*}{$\begin{array}{l}\text { Kind and variety } \\
\text { of grain crops }\end{array}$} & \multicolumn{2}{|c|}{1949} & \multicolumn{2}{|c|}{$195^{\circ}$} \\
\hline & $\begin{array}{l}\text { Days to } \\
\text { maturity }\end{array}$ & $\begin{array}{l}\text { Degree days } \\
\text { Base } 32^{\circ} \mathrm{F} \text {. }\end{array}$ & $\begin{array}{l}\text { Days to } \\
\text { maturity }\end{array}$ & $\begin{array}{c}\text { Degree } \\
\text { days }\end{array}$ \\
\hline Wheat average. & . . 99 & 2256 & 90 & 2160 \\
\hline Siberian No. $1 .$. & .. 95 & 2167 & & \\
\hline Barley average. & $\cdots 76$ & 1726 & 76 & 1824 \\
\hline Olli $\ldots \ldots \ldots \ldots$ & $\ldots 73$ & 1625 & & \\
\hline Oats average ... & $\ldots 85$ & 1971 & 86 & 2064 \\
\hline
\end{tabular}

TABLE 7.-Solar radiution units per one pound of grain in 1949, College, Alaska, Hillside Field

\begin{tabular}{|c|c|c|c|c|}
\hline Kind and variety & $\begin{array}{l}\text { Days to } \\
\text { maturity }\end{array}$ & $\begin{array}{l}\text { Total solar } \\
\text { radiation } \\
\text { gmcl } / \mathrm{cm}^{2}\end{array}$ & $\begin{array}{c}\text { Yield } \\
\text { bushels } \\
\text { per A. }\end{array}$ & $\begin{array}{c}\mathrm{Gmcl} / \mathrm{cm}^{2} \\
\text { per } 1 \mathrm{lb} \text {. }\end{array}$ \\
\hline Wheat average . & .. 99 & 39,822 & 40.4 & 16.4 \\
\hline Siberian No. $1 .$. & ․ 95 & 39,573 & 37.0 & 17.8 \\
\hline Barley average .. & $\ldots 76$ & 32,539 & 47.1 & 14.3 \\
\hline Olli $\quad \ldots \ldots \ldots \ldots$ & ․ 73 & $3^{1,150}$ & $54 \cdot 7$ & 11.8 \\
\hline Oats average & $\ldots 88_{5}$ & 35,937 & 101.1 & 11.2 \\
\hline
\end{tabular}

vestigations and analyses. Climatic relations comprising phenological observations and the study of responses to the environment and to the seasonal variability during wet and dry seasons is the first step. The best adapted chorotypes indicate a considerable stability manifested by the length of the phenological phases and production of grain, while less well adapted varieties indicate great fluctuations in growth and production.

A summary of the data for this ecological analysis of the acclimatization of grain chorotypes for the grain varieties grown on the fields of the Alaska Agricultural Experiment Station in 1949 and $195^{\circ}$ are shown on Tables 6 and 7. The data show 
that the degree day requirements for growing grains in the Tanana valley are much below the standards of the temperate zones of Europe and America, barley being earliest and the best adapted cereal crop here. All adapted sub-arctic grain varieties mature in considerably shorter time than in the temperate zone. This shortening of the growing period is evidently associated with the second phenological phase extending from emergence to first heading. Adapted chorotypes head in 40-5o days after planting or 30-4o days after emergence, while in the Wisconsin Experiment Station, for example, their chorotype grain varieties head in 55 to 70 days after planting. Consequently Wisconsin grown grains use more degree days and solar radiation units for grain production than the Tanana valley grain chorotypes. This is possibly explained by the longer hours of solar radiation during the month of June in Alaska. Solar radiation may be considered to stimulate early heading of grain crops in the beginning of July.

Another feature of the Tanana vallcy grown grains is the high food value with the highest protein content on the American continent. By a series of chemical analyses made by several private laboratories and by official tests by the U. S. Department of Agriculture average content of protein in 1948-1950 in our grains was: wheat 17.1; barley 14.0; oats 15.3 .

Analyses of the same varieties of grain tested at Matanuska Experiment Station were considerably lower: wheat 11.5; barley 10.4; and oats 10.4. High quality of grain, therefore, is a characteristic of the Tanana valley regional types of grain, the chorotypes, developed by the complex environmental factors and particularly by the climatic elements of this regional environment.

Long summer days with long hours of solar radiation also have a definite effect on several biennial vegetable plants, like spinach, Chinese cabbage and radishes, which tend to become annual. This behavior of crop plants in the sub-arctic region is just the opposite to the tropical zones where crop plants like flax and cotton tend to becorne perennial. 
Summary and Recommendations

Agro-climatological investigations should be considered as a basic part of agricultural explorations and research in Alaska and should be included in programs of Agricultural Experiment Stations and Soil Conservation surveys.

Microclimatological or micrometeorological investigations also should be arranged in cooperation with above-mentioned institutions.

Permafrost investigations in relation to climate should be coordinated with the Army and agricultural projects in Alaska.

U. S. Weather Bureau should secure needed equipment for agroclimatological investigations such as soil thermographs, thermo couples, sunshine recording apparatus and soil moisture apparatus in cooperation with the U.S. Department of Agriculture.

Specially trained personnel for agricultural climatological work in Alaska could be secured by arrangements with agricultural colleges where an agricultural climatology department has been established.

Agro-climatological publications in foreign languages should be secured for Alaska's libraries.

\section{REFERENCES}

1. Baum, W. A. and A. Court. Research status and needs in microclimatology. Trans. Geophysical Union. 30 (4): 488-493. August 1949 .

2. Bensin, B. M. Characteristique agro-ecologique, description des sortes locales du maïs-les chorotypes. Bul. Association Intern. Select. Plant. $I$ : 172-18o. Paris 1928.

3. Bensin, B. M. Agroecological analysis of the crop plants root system in the Tanana Valley region of Alaska. Bul. Ecol. Soc. Amer. 27 (4): 54. April 1946.

4. Bensin, B. M. Alaska's nature, climate and agriculture, Season's Calendar 1946, 1947, 1948, 1949, $195^{\circ}$ in "Jessen's Weekly." Fairbanks, Alaska.

5. Bensin, B. M. Thermal and photo-coefficients for various crops and varieties grown in Alaska. Bul. Ecol. Soc. Amer. 30 (2): 27. June 1949. 
6. Bensin, B. M. Problems of agricultural microclimatology in Alaska, The Farthest North Collegian, 30 (1), 5-8. March $195^{\circ}$.

7. Bensin, B. M. Growing warm-season vegetables in Alaska. Ext. Bul. 452, Agr. Ext. Service, University of Alaska. 1951.

8. Geiger, R. Das Klima der bodennahen Luftschicht. F. Vieweg und Sohns. Braunschweig 1942.

9. HAND, I. F. Weekly mean values of daily total solar and sky radiation. Technical paper No. 11, U.S. Weather Bureau. Washington, D. C. 1949 .

10. Litzenberger, S. A. and B. M. Bensin. Golden rain oats for Alaska, Circular 16, Alaska Agr. Exp. Station, University of Alaska. Palmer, Alaska.

I 1. Litzenberger, S. A. and B. M. Bensin. Edda barley for Alaska, Cir. 17, Alaska Agr. Exp. Station, University of Alaska. $195^{1}$. 


\title{
WATER SUPPLY PROBLEMS IN LOW TEMPERATURE AREAS
}

\author{
Anos J. Alter, Director \\ Division of Sanitation and Engineering \\ Alaska Department of Health \\ Juneau, Alaska
}

"Ice" water is the rule in the Arctic. Melted ice and snow are the most common sources of water for domestic and household purposes. Why must the water be melted from ice and snow?

Readily available supplies of pure water for year around use are scarce in the regions of low temperature and permafrost. The existence of such a supply of water may govern the location of communities, industry and development of low temperature regions. Although problems of location of adequate and safe sources are of prime importance, construction of water works facilities and operation of them under low temperature conditions present almost equally significant problems.

The low temperature regions are considered to consist principally of that geographic area north of latitude $58^{\circ}$ North. Permanently frozen ground or "permafrost" exists in a large part of this geographic area, but it is not entirely limited to this area. Permanently frozen ground is frozen continuously from a few feet to several hundred feet in depth. However, above the permafrost a shallow layer of ground from a foot to several feet in thickness thaws seasonally, but permanently frozen ground may be found below this. Near the southern limits of the permafrost region, a thin layer of thawed soil may be found to exist continuously between the seasonally thawed stratum and the permanently frozen strata. Also in this southern sector of the permafrost zone, portions of the ground may be found to be completely thawed and void of permafrost. Many thawed areas may be found along water courses, lakes, 
and at points where the quantity and temperature of ground water exhibit a heat of fusion sufficient to prevent freezing of the earth.

The areal extent of permafrost is equal to about one fifth of the land surface of the world. About 60 percent of the land surface of Alaska is underlaid with permafrost. Climatological data presented in Table 1 are characteristic of the low temperature areas discussed in this paper.

Low temperatures and permafrost present many obstacles to providing a community water supply and distribution system of the type common in continental United States. These obstacles are grouped and discussed as follows:

1. Location of continuous and adequate water sources capable of supplying the demands of industry and communities.

2. Production of water which is palatable and free from contamination.

3. Continuous distribution of water under pressure.

4. Construction of stable structures in permanently frozen ground and use of methods, materials and equipment which are suited to use under low temperature conditions.

5. Development of low temperature area water supply methods which are safe and practical.

\section{- Locating a Community Water Supply in Permafrost}

Melted snow and ice, surface water, rain water, water from the shallow strata of the ground and ground water from deep wells have all been considered as sources of water in the low temperature regions. Examples of all of these sources may be found in the Arctic, but melted ice and snow are by far the most common sources.

Numberless small lakes and ponds exist throughout the tundra portions of the permafrost regions. The Eskimo depends largely on water dipped from these sources during the warmest months of the year. In the fall he cuts ice from these sources and stores it for his use during the long winter. Ice is either stored in a permafrost cellar or stacked on the ground at a convenient location. 
Table 1.-Low temperature areas

\begin{tabular}{|c|c|c|c|c|c|}
\hline Station & $\begin{array}{l}\text { titude } \\
\text { ALASKa }\end{array}$ & $\begin{array}{l}\text { Mean } \\
\text { Jan. } \\
\text { Temp. } \\
{ }^{\circ} \mathbf{F} \text {. }\end{array}$ & $\begin{array}{c}\text { Mean } \\
\text { July } \\
\text { Temp. } \\
{ }^{\circ} \mathbf{F} \text {. }\end{array}$ & $\begin{array}{l}\text { Extr. } \\
\text { Min. } \\
\text { Temp. } \\
{ }^{\circ} \mathrm{F} \text {. }\end{array}$ & $\begin{array}{c}\text { Annual } \\
\text { Precip. } \\
\text { In. }\end{array}$ \\
\hline$\ldots \ldots \ldots \ldots 66$ & $34 \mathrm{~N}$. & -20.3 & $57 \cdot 7$ & -70 & 13.10 \\
\hline Anchorage $\ldots \ldots \ldots \ldots \ldots \ldots$ & $13 \mathrm{~N}$. & 11.2 & 57.0 & -36 & $14 \cdot 32$ \\
\hline Barrow $\ldots \ldots \ldots \ldots \ldots \ldots \ldots$ & $23 \mathrm{~N}$. & -17.0 & 40.2 & $-5^{6}$ & $4 \cdot 34$ \\
\hline Cordova $\ldots \ldots \ldots \ldots \ldots \ldots$ & $32 \mathrm{~N}$. & 27.2 & 54.8 & -19 & $145 \cdot 43$ \\
\hline Dillingham $\ldots \ldots \ldots \ldots \ldots$ & o $3 \mathrm{~N}$. & 16.1 & 55.6 & $-4^{1}$ & 26.12 \\
\hline Fairbanks $\ldots \ldots \ldots \ldots \ldots \ldots$ & $51 \mathrm{~N}$. & -11.6 & 60.0 & -66 & 11.87 \\
\hline Fort Yukon $\ldots \ldots \ldots \ldots$ & $34 \mathrm{~N}$. & -21.6 & 61.2 & $-7^{8}$ & 6.88 \\
\hline Holy Cross $\ldots . \ldots \ldots \ldots \ldots$ & $16 \mathrm{~N}$. & -0.4 & $5^{6.5}$ & $-5^{8}$ & 20.06 \\
\hline Juneau $\ldots \ldots \ldots \ldots \ldots \ldots \ldots$ & $18 \mathrm{~N}$. & 27.5 & 56.6 & -15 & 83.25 \\
\hline Kotzebue $\ldots \ldots \ldots \ldots \ldots \ldots$ & $55 \mathrm{~N}$. & -9.2 & $5^{2.4}$ & $-5^{8}$ & 6.32 \\
\hline Matanuska & $30 \mathrm{~N}$. & 12.6 & $57 \cdot 7$ & -36 & 15.61 \\
\hline Nome $\quad \ldots \ldots \ldots \ldots \ldots \ldots$ & $30 \mathrm{~N}$. & $3 \cdot 4$ & 49.8 & -47 & 17.82 \\
\hline Nulato $\ldots \ldots \ldots \ldots \ldots \ldots$ & $43 \mathrm{~N}$. & $-7 \cdot 5$ & 57.5 & -62 & $16.5^{\circ}$ \\
\hline
\end{tabular}

Canada

Chesterfield Inlet .........6 63 $45 \mathrm{~N}$.

Fort Good Hope.......... $66{ }_{25} \mathrm{~N}$.

$\begin{array}{rrrr}26.5 & 47.2 & -17 & \\ -22.9 & 59.6 & -79 & 10.45 \\ -5.7 & 47.1 & -42 & 19.30\end{array}$

Hebron

$5^{8} \quad 12 \mathrm{~N}$.

\section{Greenland}

\begin{tabular}{|c|c|c|c|c|c|c|}
\hline Angmagsalik & $\ldots \ldots \ldots \ldots \ldots \ldots 6_{5}$ & $3^{6} \mathrm{~N}$. & 16.9 & 43.9 & -23 & 35.67 \\
\hline Godthaab & $\ldots \ldots 6_{4}$ & $10 \mathrm{~N}$ & $14 \cdot 4$ & $43 \cdot 9$ & -20 & $23 \cdot 73$ \\
\hline Ivigtut & 61 & $12 \mathrm{~N}$. & 18.5 & 49.8 & -20 & 44.85 \\
\hline Jakobshavn & 69 & $13 \mathrm{~N}$. & -0.4 & $45 \cdot 9$ & -46 & 9.09 \\
\hline Upernivik & 72 & $47 \mathrm{~N}$. & -7.6 & $4^{1.0}$ & -44 & 9.0 \\
\hline
\end{tabular}

\section{ICELAND}

Vestmanno $6326 \mathrm{~N}$.

$34.5 \quad 52.5 \quad-6$ $5^{2.91}$

\section{Finland}

Helsingfors $6012 \mathrm{~N}$.

$21.4 \quad 63.8 \quad-23$ 27.75

NORWAY

\begin{tabular}{|c|c|c|c|c|c|}
\hline Bergen & $24 \mathrm{~N}$. & 34.2 & 57.9 & 5 & 81.02 \\
\hline Oslo $\ldots \ldots \ldots \ldots \ldots \ldots \ldots \ldots$ & $55 \mathrm{~N}$. & 24.1 & 62.6 & -26 & 23.21 \\
\hline Tromso $\ldots \ldots \ldots \ldots \ldots \ldots 69$ & $39 \mathrm{~N}$. & 26.6 & $5^{1.8}$ & -1 & 41.35 \\
\hline Trondhjem $\ldots \ldots \ldots \ldots \ldots 63$ & $26 \mathrm{~N}$ & $27 \cdot 3$ & 57.2 & -15 & 31.09 \\
\hline 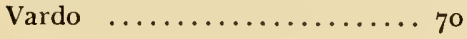 & $22 \mathrm{~N}$. & 21.9 & $47 \cdot 5$ & -11 & 25.86 \\
\hline
\end{tabular}


TABlE 1.-Low temperature areas (Continued)

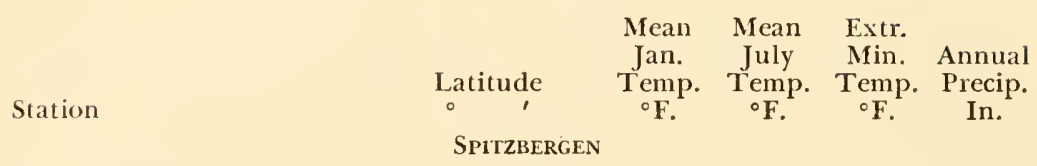

Green Harbor $\ldots \ldots \ldots \ldots \ldots .78 \quad 02$ N. $\quad 2.7 \quad 41.7 \quad-57 \quad 11.68$

SWEDEN

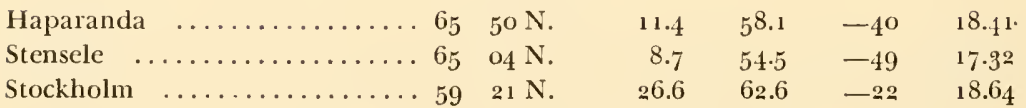

Union of Soviet Socialist Republics

\begin{tabular}{|c|c|c|c|c|c|}
\hline Archangel $\ldots \ldots \ldots \ldots \ldots 6_{4}$ & $34 \mathrm{~N}$. & 8.1 & 59.5 & -49 & 17.21 \\
\hline Bulun $\ldots \ldots \ldots \ldots \ldots \ldots 7^{\circ}$ & $45 \mathrm{~N}$. & -40.0 & $52 \cdot 7$ & -75 & 8.75 \\
\hline Dudinka & $07 \mathrm{~N}$. & -20.7 & $5^{6.3}$ & -70 & $8.4^{\circ}$ \\
\hline$\ldots \ldots \ldots \ldots \ldots 59$ & $5^{6} \mathrm{~N}$. & 18.3 & 63.5 & -39 & 0.44 \\
\hline Nizhne Kolymsk .......... 68 & $32 \mathrm{~N}$. & $-4^{0.0}$ & 53.8 & -57 & $17 \cdot 5^{8}$ \\
\hline Novo Mariiski Post......... 64 & $45 \mathrm{~N}$. & -10.5 & $5^{1.6}$ & -50 & $7 \cdot 45$ \\
\hline Okhotsk $\ldots \ldots \ldots \ldots$ & $21 \mathrm{~N}$. & -10.5 & $54 \cdot 3$ & $-5^{0}$ & 11.22 \\
\hline Olekminsk $\ldots \ldots \ldots \ldots \ldots \ldots 60$ & $22 \mathrm{~N}$. & -31.9 & 66.9 & $-7^{6}$ & 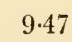 \\
\hline Ust Zylma $\ldots \ldots \ldots \ldots \ldots \ldots 6_{5}$ & $27 \mathrm{~N}$. & -0.8 & $57 \cdot 9$ & -61 & $16.3^{8}$ \\
\hline Verkhoyansk ............6 67 & $33 \mathrm{~N}$. & $-5^{8.2}$ & $59 \cdot 9$ & -90 & \\
\hline Vologda $\ldots \ldots \ldots \ldots \ldots \ldots$....... 59 & $15 \mathrm{~N}$. & 10.4 & 63.7 & $-4^{2}$ & \\
\hline Yeniseisk $\quad \ldots \ldots \ldots \ldots \ldots \ldots 5^{8}$ & ${ }_{27} \mathrm{~N}$. & -8.5 & $67 \cdot 3$ & -65 & \\
\hline
\end{tabular}

Special melting tanks equipped with steam coils have been provided in some schools, hospitals and government buildings, but in the majority of homes ice is melted by placing it in a barrel in the heated home and leaving it there to be used later as water. Fresh water lakes and streams are plentiful and the collection of ice does not usually present a problem. However, fresh water ice is occasionally obtained from the sea ice, or snow is melted. Relatively high cost of fuel and the labor necessary to procure an adequate melted ice or snow supply make such a method impractical for obtaining large quantities of water to serve a community.

Many shallow lakes and ponds freeze to the bottom and do not afford a continuous source of supply. Bodies of water more than eight to ten feet deep may be expected to provide some water throughout the entire year. In most places ice cover 
probably does not exceed eight feet. However, much of the storage space in a lake is unusable when a thick ice cover exists. The majority of lakes would probably not provide adequate storage for a community of more than a few people. Lakes which are fed by underground springs or receive an appreciable amount of shallow subsurface drainage may provide an adequate supply of water. A thorough study of lake depths, temperatures and geological features is obligatory. Many lakes are deceiving in that they are principally the result of retarded drainage through permafrost rather than evidence of a large source of water.

Broad, treeless expanses of permanently frozen water sheds tributary to streams in much of the low temperature areas allow rain water to run rapidly into the principal streams. In general 300-400 square miles of watershed are necessary to maintain continuous flow in a stream. Facilities are necessary for storage of water on small streams if a constant source of supply is maintained. Both conventional and underground dams have been used to provide storage.

Annual precipitation is very small in many parts of the low temperature areas and cistern water supplies are usually inadequate.

Water which percolates down into the soil collects in the soil at the top of the permafrost or permafrost table. In the southern sector of the permafrost zone, where there is a continuously thawed stratum between the seasonally frozen layer and the permafrost table, appreciable amounts of this "supra-permafrost" water collects. Many shallow wells draw water from this source. Such shallow sources are not dependable and usually do not provide sufficient quantities of water for a community.

Hot springs and other spring water supplies which issue from below the permafrost may be found in some places. These sources may be detected at unusually warm areas of a lake or stream or may exhibit themselves as water within the permafrost (intrapermafrost water). Extensive icing or mounding at the surface of the ground may also indicate the location of a spring source. Deep spring sources with appreciable discharge 
and little seasonal variation in water temperature offer much promise as a continuous source of water for a community.

At several points in interior Alaska, deep wells which draw water from below the permafrost (subpermafrost water) have been developed to provide continuously adequate amounts of water. In the Arctic coast communities of Alaska, wells which have been drilled to a point below permafrost have produced only salt water. The majority of deep wells drilled in the Fairbanks section of Alaska have produced water with a relatively high iron content. However, subpermafrost water sources appear to be the most dependable sources of water supply in the low temperature areas.

Production of Water Which is Palatable and Free from Contamination

Environmental conditions such as extremely low temperatures, retarded biological and chemical reactions, practically continuous light during a portion of the year, and clianges in the physical state of organic material, fluids and solids may all play an important part in the provision of safe and palatable water. Low temperature area conditions appear conducive to prolongation of the life of pathogenic bacteria. These same conditions promote careless disposal of sewage and other wastes as well as foster the indiscriminate use of possibly contaminated surface and shallow ground waters.

In Greenland (5)* during the period of 1928 through 1930, 88 cases of typhoid fever were reported in a population of 9,455 . In Alaska during the period 1937 through July of $195^{\circ}, 94$ cases of typhoid fever were reported in a population between 75 , ooo and 130,ooo. Cases in Alaska (26) have been reported from all parts of the Territory and cases have been reported each year during the period 1937 to July 1950. Typhoid has also been reported to be common in parts of the Soviet Arctic.

Three hundred twelve cases of bacillary dysentery were reported from Alaska during the period 1937 through 1949.

* The bibliographical references for this and the following paper are combined on pp. $25^{1-253}$. 
Even though recognition and reporting of illness from primitive and undeveloped areas are commonly considered to be incomplete and inadequate, these data do show that filthborne disease does occur in the low temperature areas in significant amounts. In view of general disregard for safety of water supply and careless waste disposal in these regions, these data are not only significant but also they are alarming.

In many villages of the Arctic sledge dogs eat human feces. There are more dogs than people in many of the Arctic villages of Alaska and these dogs may frequently have opportunity to contaminate ice and surface water supplies. Dr. Krogh-Lund (6) in his work in Greenland during the period 1928-1931 has shown that sledge dogs fed Salmonellae typhosa mixed with their ordinary food were capable of passing the bacillus on in their feces in a viable state. Dr. Krogh-Lund was able to recover the bacillus from the dog feces for a period as long as three weeks after ingestion. It is possible that the sledge dog may be found to play some part in the dissemination of typhoid fever in the low temperature regions.

The need for protection and treatment of water supplies in the low temperature regions seems obvious, although insufficient investigative work has been done in the Alaskan Arctic to specifically show the significance of Arctic water supplies as a mode of transmission for typhoid fever and other filthborne illness.

Waters at low temperature are capable of carrying a much greater load of suspended material than is carried at tempera-

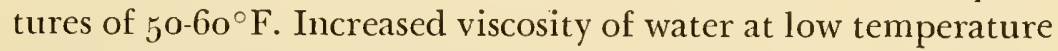
may also be significant in certain treatment processes. Coagulation, settling, filtration and other treatment processes such as aeration and disinfection are all affected by temperature. Much more investigative work is indicated in the treatment of Arctic waters.

\section{Continuous Distribution of Water Under Pressure}

In the low temperature areas water is distributed by sledge and barrel, tank conveyance, seasonal distribution mains laid 
on the surface of the ground, placement of water mains in utilidors (heated conduits), recirculating water mains and by use of a conventional water distribution system. The most common methods for distribution are by sledge and barrel and by tank conveyance. These methods subject the water to undesirable handling and possible contamination, and are also very inconvenient. Some distributors heat the water while it is on the tank truck. Batch chlorination of the water and care in dispensing it are desirable but not common.

Very few homes include water flush toilets and bath tubs in the communities where water under pressure is dispensed seasonally by surface distribution system. During a period of about eight or nine months of the year the distribution system is dismantled and left to lie along the street to collect filth. This method of water distribution in permanent communities is very inadequate and only serves to delay interest in an adequate system.

Distribution mains placed in heated conduits called utilidors provide a positive means for maintaining continuous service. Utilidors may be constructed of concrete or wood or they may consist of commercially produced metal, wood, or terra cotta units which are sold in prefabricated sections. The utilidor is usually heated but may in some installations depend entirely on heat in the fluids contained in the mains within the conduit. Heating of utilidors may be accomplished by placement of steam or condensate lines within the conduit or by forcing warmed air through the conduit. Heat may also be added to fluids passed through the lines in the utilidor. Figure 1 shows a design for a cast-in-place concrete utilidor and Figure 2 shows construction details for a small wooden utilidor. Steam, water, sewer, communications and power utilities may be placed in the utilidor. The cross-section of the utilidor may be of sufficient size to allow maintenance personnel to walk through the utilidor or it may be of small cross-section possibly no larger than necessary to encase the utility lines.

Drainage of utilidors constitutes a problem and in some installations housing both sewer and water lines the latter have 
been completely submerged in servage and the domestic water supply has been contaminated with sewage. Utilidors must be constructed in such a manmer that they will not be flooded with suprapermafrost water. Flooding of water lines with either ground water or sewage creates a very undesirable and unsafe condition. Figure 3 illustrates the manner in which utilidors may become flooded with ground water and it also shows how waste heat may maintain a thawed area around a utilidor.

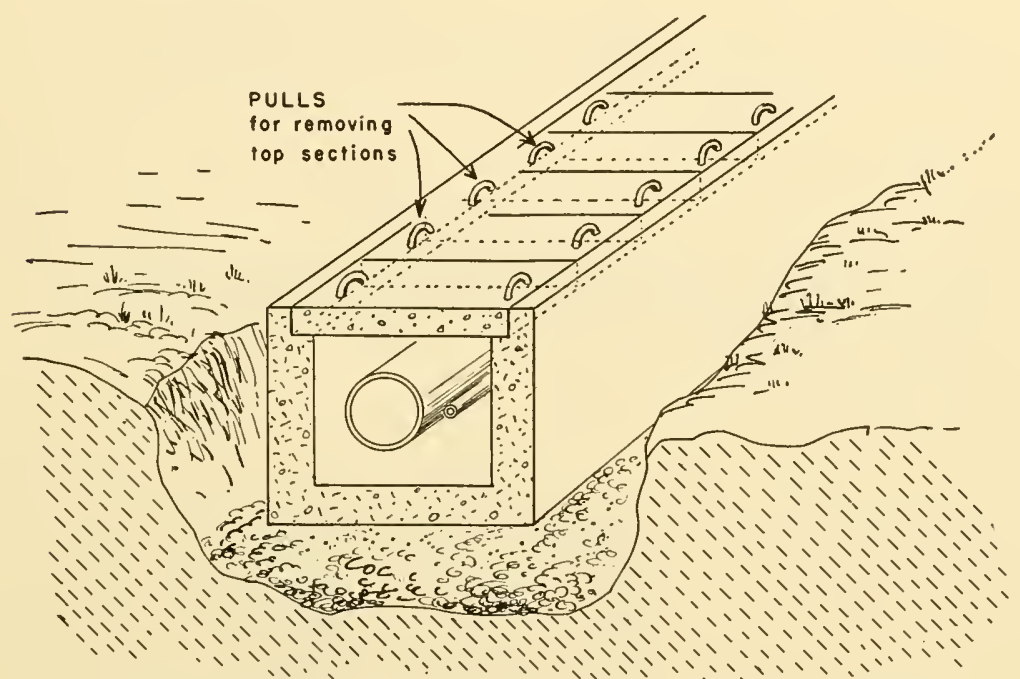

REMOVABLE TOP ON CAST-IN-PLACE UTILIDOR

FIG. 1.

Recirculating water mains, as the name implies, are distribution lines in which the water is circulated. The water may be circulated continuously or at intervals necessary to keep the system from freezing. The mains are constructed so that they constitute a closed circuit and a heating plant is placed near the point where the water enters the system. Sufficient heat is added to the water at the source of supply to maintain temperatures above freezing throughout the distribution system.

Recirculation may also be maintained in the service connection either by use of a dual main distribution system or by use 

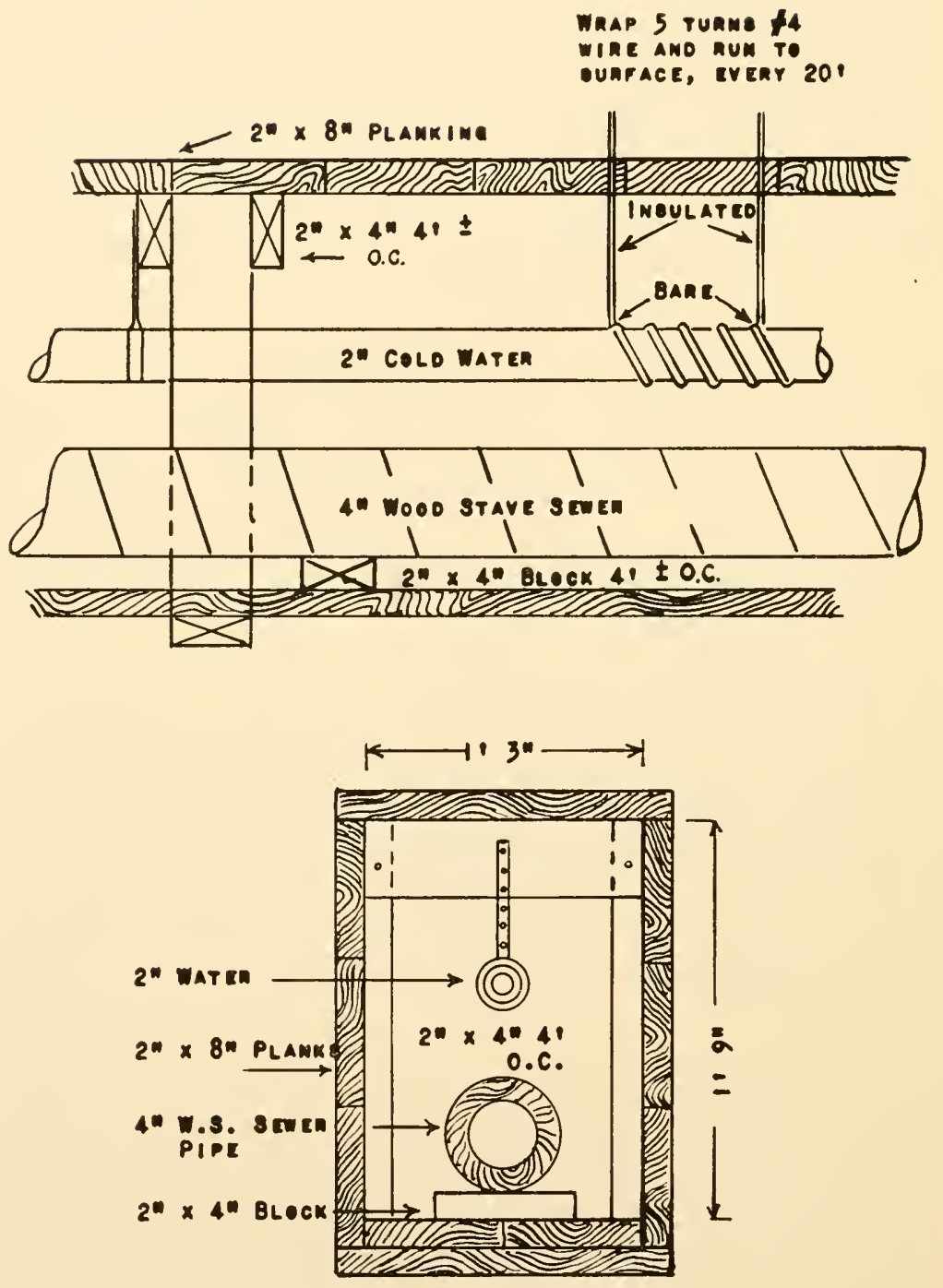

WOOD UTILIDOR DETAIL

FIG. 2. 
of a single main distribution system and a Pitot type tap. Service connections may be kept from freezing by use of electrical resistance tape or by use of short house-to-street utilidors.

Day, of the Arctic Health Research Center at Anchorage, reports successful laboratory experimentation with the Pitot type tap. Day states, "From the data obtained by observations on model pipe main and double house service pipe system, it is concluded that circulation of flow will occur in the house service
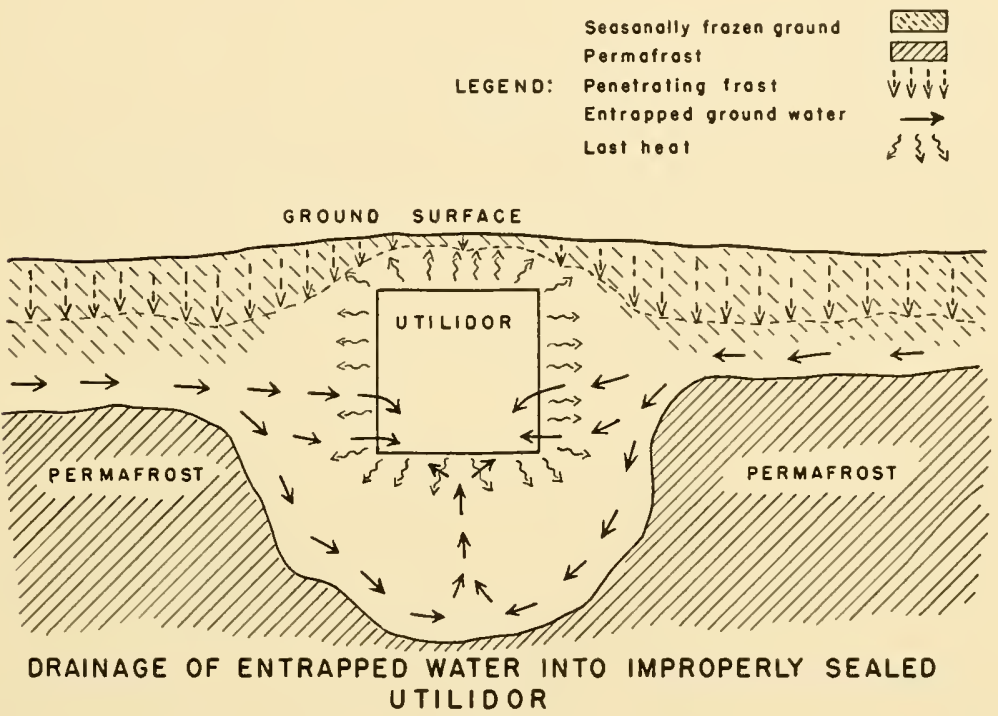

Fig. 3 .

connection. The velocity of flow in the street main will apparently have to be capable of being maintained at two to three feet per second. Special orifices must be used in place of the standard corporation cock. The total length of house service pipe should probably not excecd 125 feet for dependable operation" (11).

At Fairbanks, means of protection for house service connections has presented the greatest problem of design and installation of a community water distribution system. Dual main distribution systems and utilidors are much more costly than a functionable single main recirculation system. 
Many precautions must be taken to make a conventional water distribution system function in the permafrost region. Kojinov (15) has shown how clay may be placed around a main to protect it from freezing and he has also shown how location of mains with respect to shade and snow cover play an important part in protection. The clay maintains moisture around the pipe and thus frost penetration is retarded. Snow cover insulates the surface of the ground over the pipes; and by locating the pipes where they will receive maximum sunlight, advantage is taken of all heat possible. Even by taking advantage of all heat available, it does not appear practical to use conventional water distribution systems, except possibly in parts of the permafrost region in which there exists a thawed layer between the permafrost and the lower limit of seasonal frost.

Construction of Stable Structures and Use of Equipment Suited to Low Temperature Conditions

Construction of dams, foundations, buildings, well casings and curbings, settling basins, treatment structures, and other miscellaneous facilities must be designed to withstand or prevent destructive frost action. Design and operation of all facilities must provide for conservation of heat. The effects of temperature and frost are mighty and sure. Exacting standards of design and performance must be the rule for successful operation of Arctic water supply facilities.

A dam design which is structurally stable on permanently frozen ground must also remain stable after accumulation of water behind it and resultant alteration of the thermal regime of soil on which it stands.

Foundations must be constructed in such a fashion as to minimize the effects of freezing, heaving, thawing and shifting of the soil. Insulation is necessary under certain conditions to prevent heat from the structure from being conducted through the foundation to the permafrost where it will change the thermal regime of the permafrost.

Heating and proper ventilation of buildings are especially difficult under low temperatuire conditions. Figure 4 shows 
Arctic well house weatherproofing details. Condensation causes icing on walls, on nail heads and in insulation. In some parts of the low temperature regions, temperature differences between heated interiors and the ouside air may be as much as 130 to $140^{\circ} \mathrm{F}$. Air Temperature and Frost Penetration Data at Alaska Stations which are shown in Table 2 present a general summary of considerations pertinent to design of water supply facilities.

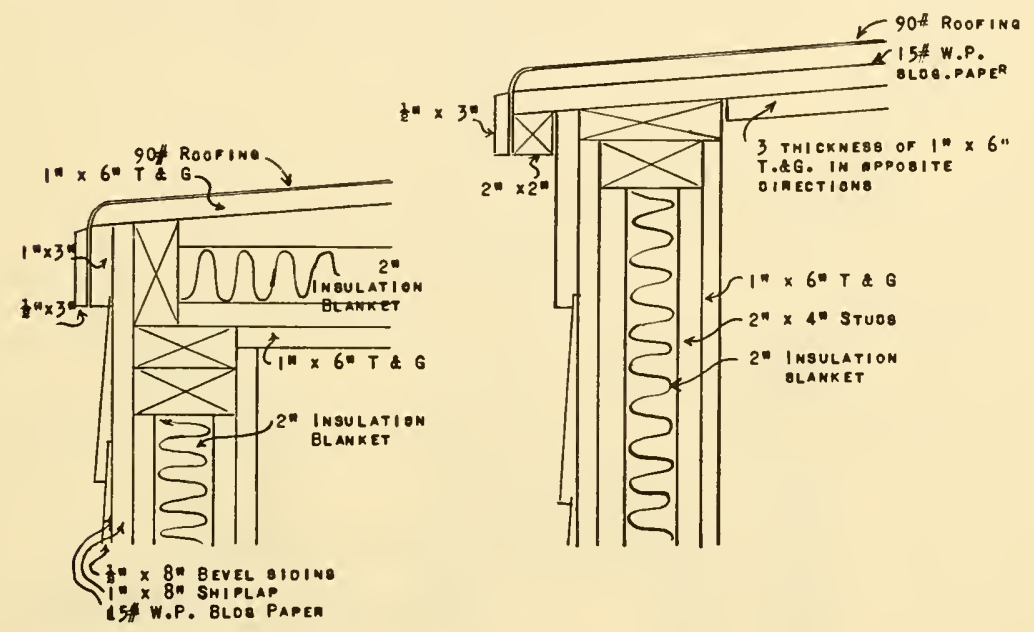

\section{ARCTIC WELL HOUSE WEATHERPROOFING DETAIL}

FIG. 4.

Low temperatures and permafrost affect the construction and maintenance of wells and well appurtenances. Drilling wells through permafrost necessitates continuous work in order to prevent freezing of casing and equipment. After development of the well, continuous and moderate pumping is necessary to prevent freezing of water in the casing or possibly freezing of the aquifer. Well casings should be anchored securely in permafrost and constructed so that seasonal freezing of the surrounding soil does not disjoint, crush, or otherwise damage the casing. It is difficult to provide proper protection of a well from surface drainage around the casing and yet provide cohesionless material around the casing so that the effect of seasonal frost 


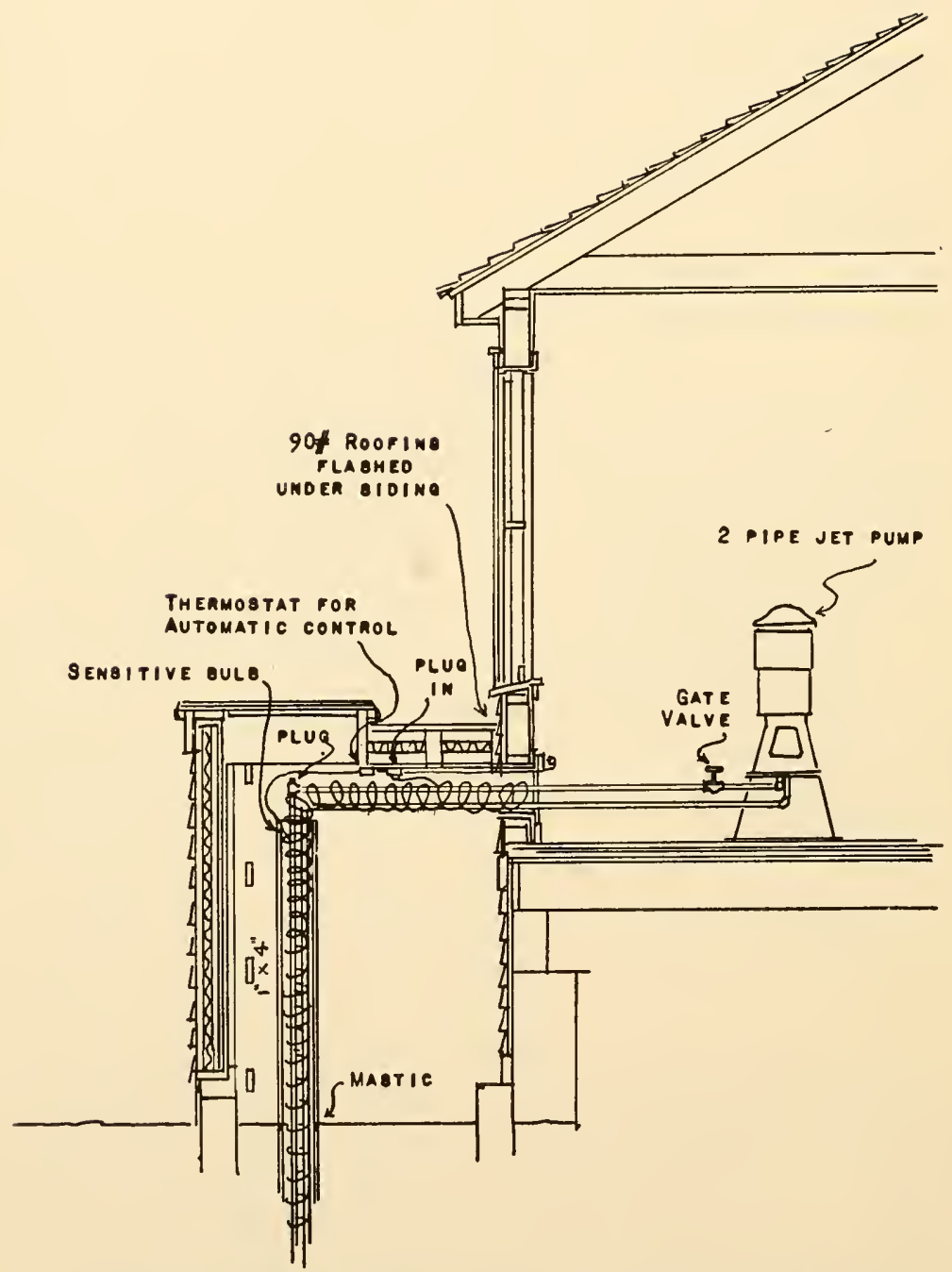

ARCTIC PUMP AND WELL INSTALLATION

Fig. 5. 
is minimized. Figures 5 and 6 show an Arctic well installation and details of weather protection. An electrical heating cable is used in this installation to prevent freezing of the casing. A well house is also placed over the well and a pit which might disturb the thermal regime of the ground as well as increase the chances of contamination of the supply has been eliminated. A mastic seal is placed in the annular space between the well casing and the pump house floor.

A submersible type deep well pump installation has been suggested for use in low temperature areas. The suitability of

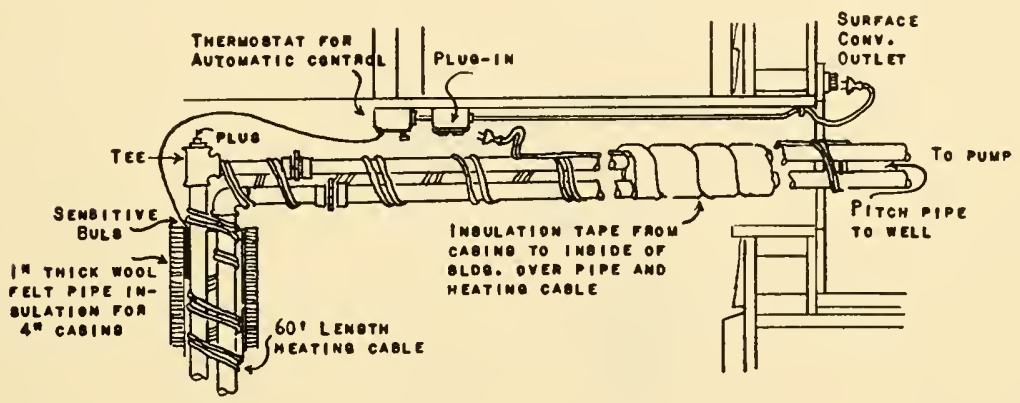

\section{WELL PIPING DETAIL}

FIG. 6.

this type of equipment for use under such conditions is not known. Figure 7 shows a submersible type pump.

Structures such as settling basins, filters and clear wells may conduct significant amounts of heat to the surrounding soil unless proper insulation and construction measures are followed. The result in permafrost is that ground water may accumulate around the structure and thus destroy stability.

Figure 8 shows a comparison of annual degree days for cities in temperate climates and for selected points in the low temperature regions. A glance at this chart further emphasizes the significance of the problem of heating water supply facilities under low temperature conditions. 


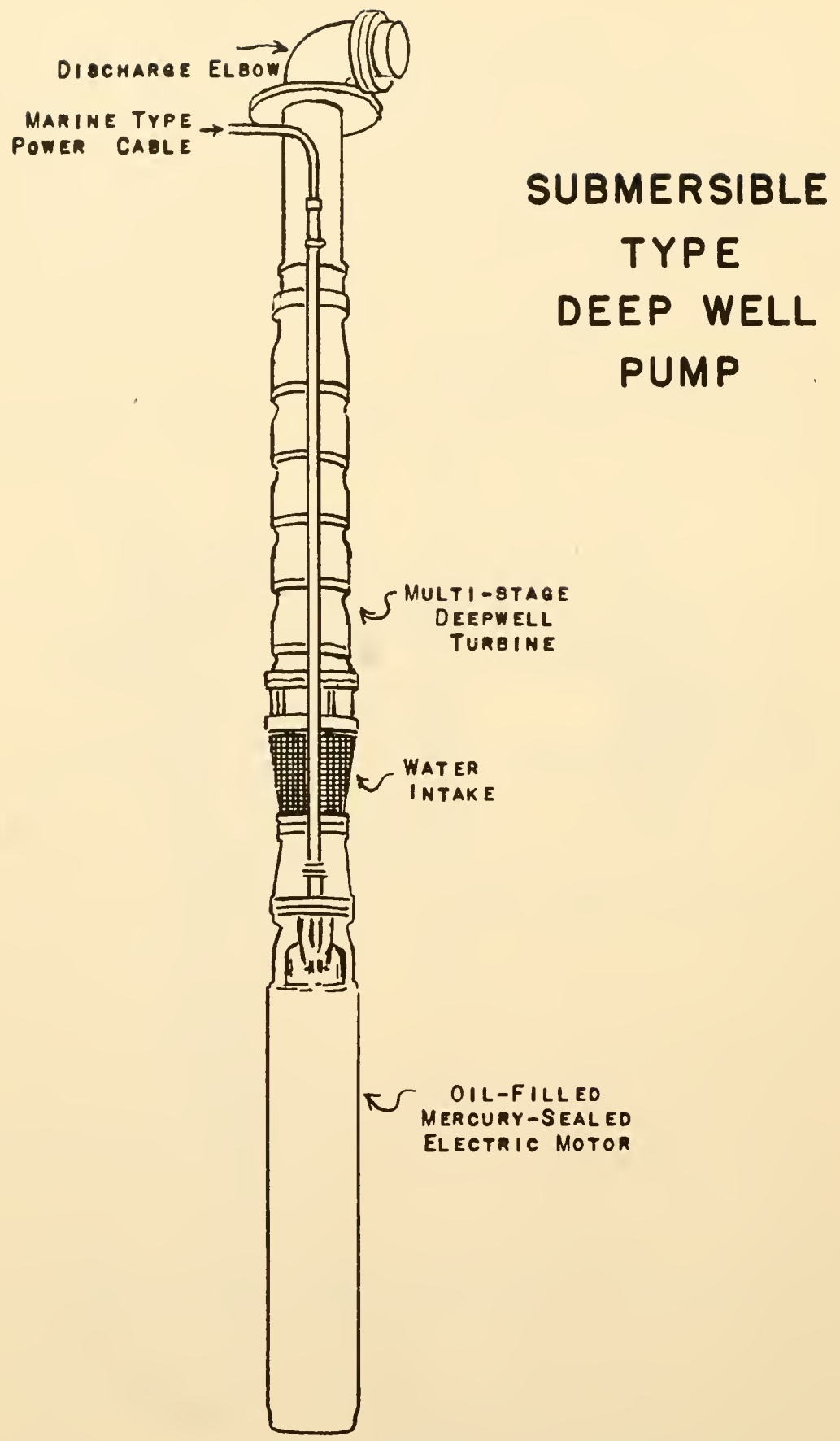

FIG. 7 . 
Pumps, control equipment, disinfection equipment, meters, fire hydrants, etc. must all be constructed in a manner which provides maximum protection from low temperatures.

Extended periods of daylight may play some part in the algae content of waters in the low temperature regions. Figure 9 shows approximate hours of daylight that may be expected in

TABLE 2.-Air temperature and frost penetration at Alaska stations

\begin{tabular}{|c|c|c|c|}
\hline $\begin{array}{c}\text { Annual } \\
\text { Temp. }{ }^{\circ} \mathbf{F} \text {. }\end{array}$ & $\begin{array}{l}\text { No. Days Max. } \\
\text { Temp. } 32^{\circ} \mathrm{F} \text {. } \\
\text { or Less }\end{array}$ & $\begin{array}{c}\text { Approxi- } \\
\text { mate } \\
\text { Annual } \\
\text { Degree Days } \dagger\end{array}$ & $\begin{array}{l}\text { Reported } \\
\text { Depth of Frost } \\
\text { Penetration } \\
\text { in feet }\end{array}$ \\
\hline Anchorage $\quad \ldots \ldots \ldots \ldots .34 .7$ & 125 & 11,000 & 8 \\
\hline Barrow $\ldots \ldots \ldots \ldots \ldots .9 .9$ & 280 & 20,000 & * \\
\hline Bethel $\ldots \ldots \ldots \ldots \ldots \ldots . . \ldots 9.9$ & 140 & 13,000 & - \\
\hline Cordova $\ldots \ldots \ldots \ldots \ldots 4^{0.6}$ & 60 & 10,000 & - \\
\hline Dillingham $\quad \ldots \ldots \ldots \ldots 34 \cdot 3$ & - & - & 4 \\
\hline Fairbanks $\ldots \ldots \ldots \ldots 26.0$ & 160 & $1_{4}, 000$ & 10 \\
\hline Ft. Yukon $\ldots \ldots \ldots \ldots \ldots 19.7$ & - & - & - \\
\hline Galena ............ 25.0 & 180 & 14,000 & 10 \\
\hline Gambell $\ldots \ldots \ldots \ldots \ldots 23.4$ & 205 & 15,000 & - \\
\hline Juneau $\quad \ldots \ldots \ldots \ldots \ldots 4^{2.1}$ & 55 & 8,000 & 5 \\
\hline Kotzebue $\ldots \ldots \ldots \ldots 20.7$ & 205 & 16,000 & * \\
\hline McGrath $\ldots \ldots \ldots \ldots \ldots .25 .4$ & 165 & 15,000 & 7 \\
\hline Nome $\ldots \ldots \ldots \ldots . . . .25 .7$ & $18_{5}$ & 15,000 & * \\
\hline Northway .......... 23.0 & 165 & 16,000 & - \\
\hline Umiat $\ldots \ldots \ldots \ldots \ldots \ldots \quad 9.8$ & 240 & 20,000 & - \\
\hline
\end{tabular}

* Seasonal frost extends down to permafrost.

f For any one day, when the mean temperature is less than $65^{\circ} \mathbf{F}$, , there exists as many degree days as there are Fahrenheit degrees difference in temperature between the mean temperature for the day and $65^{\circ} \mathrm{F}$.

different northern latitudes. Some algae are found in very cold waters and even in snow. Smith in his work on Fresh Water Algae of the United States reports that temperature is not generally a determining factor in the nature of algal flora. However, very little work has been reported on the algal flora of Arctic water supplies. Specific investigation should be made to determine the need for and methods necessary for providing algae-free and palatable water supplies in the Arctic. 
MIAMI

FLA.

ㅁ 185

DALLA 8

TEX.

WABHINGTON

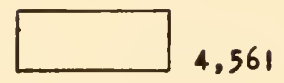

MINAEAPOLIS

MINN。

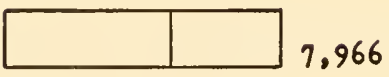

JUNEAU

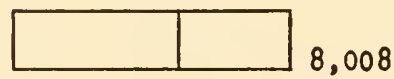

ALABKA

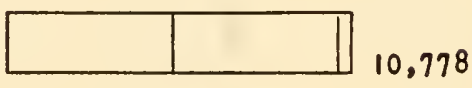

ANCHORAOE

ALA8KA

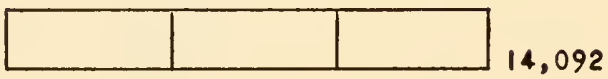

Alaska

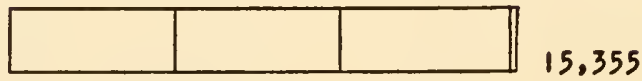

Y.T. CAN.

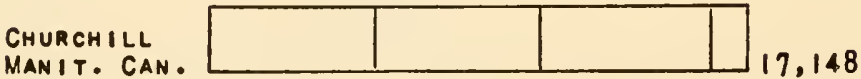

BARROW

ALA SKA

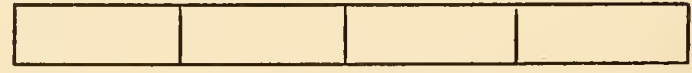

\begin{tabular}{lllll}
0 & 5 & 10 & 15 & 20 \\
\hline THOUSANDS OF DEQREE DAYS &
\end{tabular}

\section{AVERAGE ANNUAL DEGREE DAYS}

FIG. 8. 
Water Supply Problems in Alaska-Alter

24

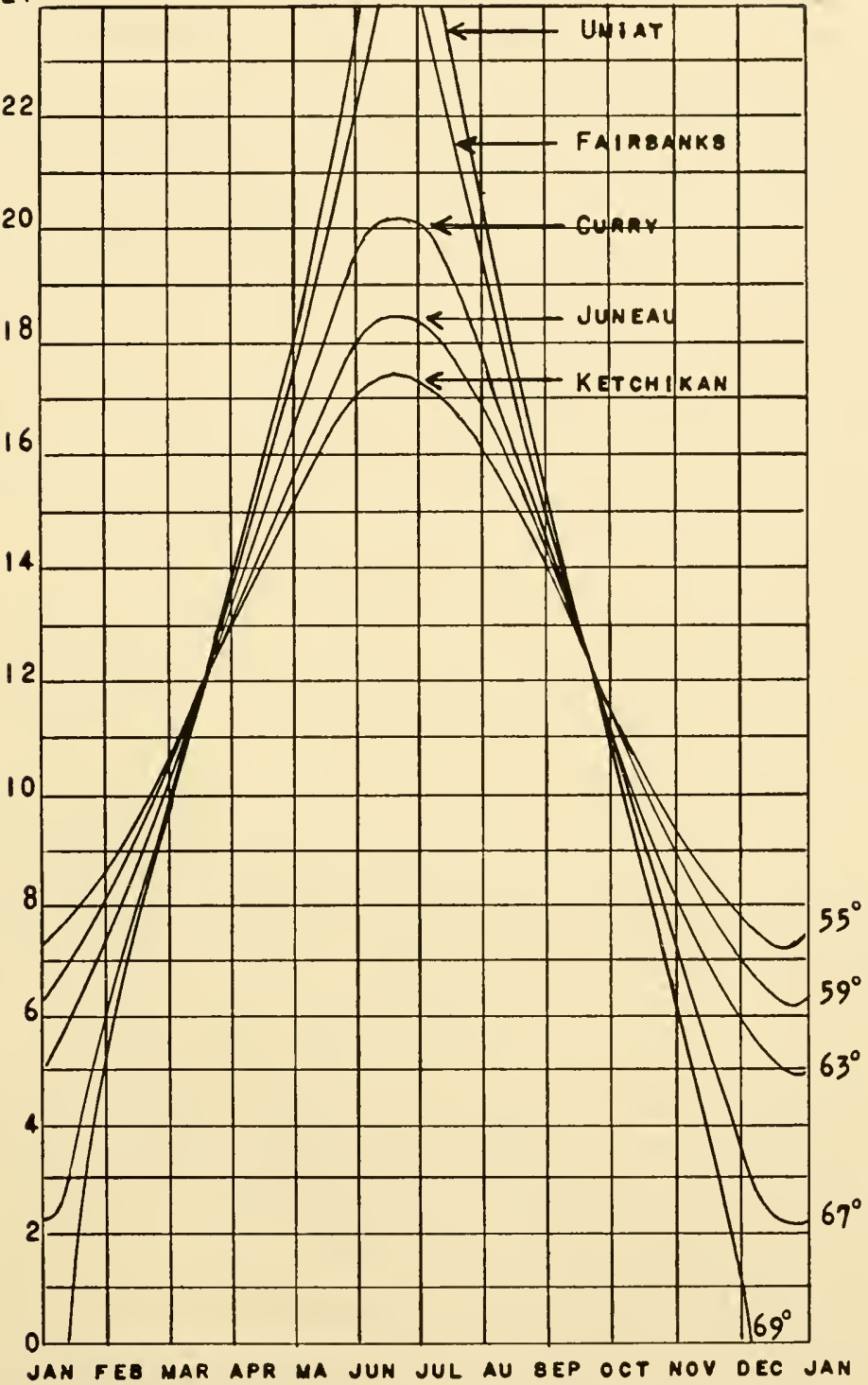

HOURS BETWEEN SUNRISE \& SUNSET

Fic. 9. 
Development of Low Temperature Area Water Supply Methods Which Are Safe and Practical

Present water supply methods in use in low temperature areas are expensive (3). The development of suitable sources, distribution of water under pressure, and provision of structures and facilities necessary to development and distribution are far beyond the economic reach of the majority of inhabitants of the low temperature regions.

The result is that adequate and safe water supplies are noi being provided in most Arctic communities. They probably will not be provided until we learn more of the physical features of low temperature areas and more about sources of water. We must also adapt our treatment and distribution methods to the economy and needs of the Arctic diveller.

We must make safe water supplies for these people obtainable as an initial step toward comfortable and healthful living in the North. A good water supply must be purchasable wherever it is needed.

I am certain that through a concerted effort and a redoubled investigation and research program that we will be able to solve these many problems in the low temperature regions just as we have in other parts of the world.

\section{SuMMARY}

Adequate and safe water supplies are difficult to locate and develop in the low temperature regions. Water is scarce and much of what is available must be used as ice and snow.

Temperature has an appreciable effect on practically all treatment processes.

Permafrost complicates distribution of water and special means must be used to keep pipe lines and service connections from freezing. Permafrost also affects the design of other water supply structures. Design must minimize the effects of unstable soil conditions which result when the thermal regime of the soil is disturbed. 
Present water supply methods and practice must be modified and adapted to the economic structure of the Arctic.

Research and investigation are indicated in practically every facet of Arctic water supply. Greatly needed investigation and research are a must if we are to solve the many problems of adequate and safe water supply in the low temperature regions.

(The references for this paper are given at the end of the following article.) 


\title{
RELATIONSHIPS OF PERMAFROST TO ENVIRONMENTAL SANITATION
}

\author{
Amos J. Alter, Director \\ Division of Sanitation and Engineering \\ Alaska Department of Health \\ Juneau, Alaska
}

Every section of the world has environmental peculiarities which make sanitary practices difficult. The most serious problems which the sanitarian in Alaska faces are caused by existence of permafrost in almost 60 percent of the land area of the Territory. The design, construction, and operation of every sanitary engineering project in northern Alaska are affected by perennial frost. Most of us are convinced that since permafrost cannot be legislated out of existence, we should adapt our sanitation practices to it.

Our objectives in sanitation must remain the same as those in warmer countries. We need, however, to adapt our procedures to fit the environment in which we live.

Permafrost is a thickness of soil or other superficial deposit or even bedrock, at variable depths beneath the surface of the earth, which has continually existed for thousands of years at a temperature below freezing. Polar regions constituting 20 percent of the land area of the world are underlaid with permafrost.

In this paper, I propose to discuss (1) the need for environmental health control measures in the permafrost regions, (2) a few of the physical features of permafrost, (3) the manner in which these features affect present environmental health control measures and facilities, and (4) practical and economical means for exercising sanitary control. 
Need for Environmental Health Control Measures in the Permafrost Regions

Occurrence of the so-called filthborne diseases in permafrost regions is a well established fact. During the period 1937 to date in $195^{\circ}$ typhoid fever has been reported each calendar year in Alaska. Population in Alaska during this period has been between 75,00o and 130,0oo; yet, as many as 21 cases in a single year have been reported. Cases (26) have been reported from all regions of Alaska from the most northern point to the southern end of the Territory. Probably many cases of typhoid have not been reported. Inaccuracies are common in morbidity and mortality clata obtained from primitive populations. Medical attention has been scanty in many of these areas and the reasons for gathering such information have not been apparent to either the natives or local whites.

Three hundred twelve cases of bacillary dysentery were also reported from Alaska during the calendar years 1937 through 1949. Fevers resembling typhoid have been described in Greenland since 1839 (6). In 1864, Lange reported that epidemics of typhoid fever are not rare in Greenland. Bertelsen reports treatment of significant numbers of patients for typhoid in Greenland shortly after 1902. In 1916, Andersen at Sukkertoppen, Greenland, isolated the typhoid bacillus, and cultures were identified at the Danish State Serum Institute in Copenhagen. During the period 1928 through 1930, reports from Greenland indicated the occurrence of 88 cases of typhoid fever in a population of 9,455 .

It is apparent from these data that permafrost and the low temperatures that are common to these regions do not in themselves tend to suppress the occurrence of filthborne diseases such as typhoid and bacillary dysentery. The high incidence of filthborne disease in the permafrost regions has long been known.

\section{Physical Features of Permafrost}

Permafrost in the northern hemisphere is found in a great part of the Union of Soviet Socialist Republics, Alaska, the 
Canadian Arctic and Subarctic, Greenland, Svalbard Archipelago, and numerous islands in the Arctic Ocean.

In some sections of the permafrost zone, permanently frozen ground is found in sporadic fashion. Immediately adjacent to some streams and lakes the ground remains unfrozen. In some places the permafrost is disappearing while in other places it may be forming.

Permafrost at some locations is near the thawing point while at other places the temperature of the frozen ground may be several degrees below the freezing point. Sewers, water lines, treatment structures and other sanitary facilities must be designed to function satisfactorily under any of these conditions.

Seasonal frost may extend down until it reaches permanently frozen ground in some areas while in other areas a thawed layer may exist between the seasonally and permanently frozen strata. At some points the permafrost has been reported to extend down to a depth of more than goo feet. The problems of foundation design and the procurement of water supplies from the earth are obvious under conditions such as these.

Permafrost which is made up of finely divided soil particles and appreciable amounts of soil moisture exerts an entirely different influence upon sanitary facilities than is exerted by dry permafrost or a permafrost which consists principally of frozen gravels.

Areal extent, continuum, temperature, depth, and type of permafrost have a direct effect upon selection of sanitary measures and facilities used in low temperature regions. These features limit the means for procurement of safe and adequate ground water supplies, disposal of harmful wastes, housing, insect control, and change foodhandling practices. They hamper the provision of structurally stable sanitary facilities.

A thorough site study is a prerequisite to planning all sanitary facilities for use in the permafrost region. Complete understanding of subsurface conditions may well mean the difference between having environmental health control and not having environmental health control.

Under permafrost conditions, construction and operation 
costs of facilities commonly used in continental United States are so high that such facilities are not economically feasible for most inhabitants of the Arctic.

\section{Effects of Permafrost on Environmental Health Control Measures and Facilities}

Inadequate water supplies (29), unsafe disposal of human excrement, accumulations of refuse, substandard housing, diffi. culties in insect control, and unusual yet careless foodhandling are the rule throughout the Alaskan Arctic. They serve as monuments to remind us of our past unsatisfactory control of environment in the permafrost regions.

\section{Water Supply $(2,3,4)$}

Surface waters such as shallow lakes and small streams may remain completely frozen during most of the year. Much of the ground water is continuously frozen. Rain water is scarce. Consequently, melted ice and snow serve as the principal sources of water supply in the Arctic.

Permafrost constitutes a relatively impervious stratum which prevents ready downward percolation of the meager precipitation. Rain falls and runs rapidly into the principal drainage courses. Permanently frozen soil complicates construction of impounding reservoirs suitable for water storage. Stored water changes the thermal regime of the soil and tends to render impounding structures unstable in thawed soil.

Accumulations of ground water above permafrost strata are quickly exhausted, subject to ready contamination and may also remain frozen most of the year. Wells extending through permafrost will freeze unless pumping is properly regulated. Under-pumping permits the well to freeze and over-pumping may in some places cause freezing of the aquifer.

Temperature exerts an appreciable effect on water treatment processes. Water from the permafrost is cold. Use of chemicals, filtration, and settling practices must be adjusted to make such practices economical, efficient and usable in the Arctic. 
In communities where adequate sources of water have been found, distribution of it is difficult under low temperature conditions. Distribution by use of barrels or tank conveyances is common in these communities, but such methods expose the water to contamination and are inconvenient. Special precautions in construction and operation are necessary to keep water mains, buried in permafrost, from freezing. Very low air temperatures make insulation of water mains necessary if the mains are located above ground. The present relatively high cost of dispensing water under pressure from community systems in permafrost regions almost precludes the possibility of general installation of such systems. Primitive water supply and distribution methods will continue in most communities until we develop better methods for water supply which are economical in the permafrost regions.

\section{Sewage Disposal (3)}

In temperate climates, natural processes reduce and destroy great quantities of organic and infectious material through normal action of the soil. Excrement placed in appropriate zones of the soil is decomposed and rendered harmless by the complicated reductive forces of nature.

The soil has been described as a living thing presenting many of the vital phenomena that characterize life: digestion, metabolism, assimilation, growth, respiration, motion, and reproduction. The soil absorbs oxygen and exhales carbon dioxidethrough complex metabolic processes, it digests vast amounts of organic material-it excretes wastes and if the wastes are retained, it becomes choked with the accumulation of its own poisons.

The rise and fall of ground water is analogous to the movements of the diaphragm and assists the respiratory functions of the soil. The soil is teeming with life such as bacteria, molds, and many forms of the animal kingdom.

Permafrost and the extended period of seasonal frost in the Arctic interfere with normal breathing and metabolic processes of the soil and retard the assimilation of organic material. 
Permafrost frequently does not permit proper drainage of the soil and it becomes water-logged when it is not in a frozen state. Permafrost actually preserves organic materials shown by various reports of recovery of almost perfectly preserved specimens of mastodon from permanently frozen ground after thousands of years of existence in the ground.

Very little investigation has been made concerning the specific role the soils of the Arctic may play in carrying on processes necessary to render organic wastes harmless. At present, it appears that the biological state and the difficult physical state of Arctic soils almost preclude use of common temperate climate sewage disposal methods without modification.

At the present time wastes are dumped near the homes or placed on river or sea ice. Dogs eat some of the wastes and the remainder accumulates in a dangerous and disagreeable mess. Arctic soil conditions may retain pathogenic organisms, present in the wastes, viable for great lengths of time.

Community sewerage systems now installed in permafrost have been difficult to operate. Permafrost has affected vertical alignment of sewers, stability of manholes, sewage flow, loss of sewage heat in miscellaneous appurtenances to the system, and the structural stability of basins and buildings.

Permafrost may prolong the life of pathogenic bacteria, retard decomposition of wastes, and it complicates the construction and operation of sewerage systems.

\section{Garbage and Refuse Disposal}

Burial is a common means of disposal for garbage and refuse in temperate climates, but in the permafrost regions, burial is difficult and probably unsatisfactory for decomposition of the wastes. The attached Figure 1 showing "Air, Ground and Water Temperatures at Fairbanks, Alaska," indicates the undesirable physical conditions for disposal of garbage by burial in this subarctic community. Digging in the permanently frozen ground is difficult. Bones, tin cans, and other garbage and refuse are found strewn on the ground near homes in many of the Arctic villages. The Greenland Commission has 


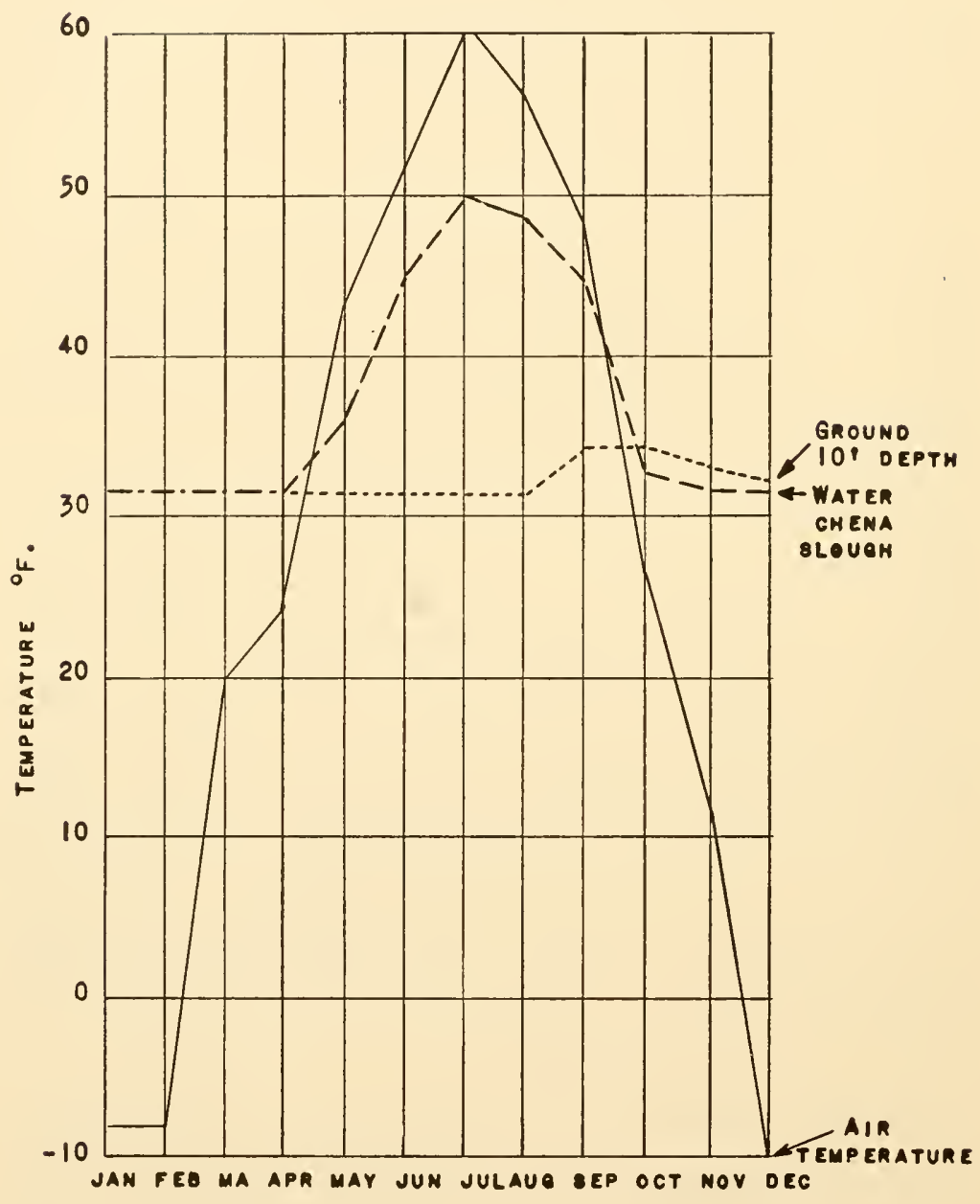

\title{
APPROXIMATE GROUND, WATER AND AIR
}

\section{TEMPERATURES AT FAIRBANKS, ALASKA}

\author{
Fig. 1.
}


indicated that in North Greenland the most common refuse in the communities is the significant amount of dog feces (5). The disposition of even a corpse presents a problem where the ground is permanently frozen. In 1898 , Call (8) reported, "The most interesting graveyard in Alaska is at Point Hope. It is situated about a mile from the village, on slightly elevated ridges. . . Most of the bodies are raised four to six feet from the ground and supported with structures made preferably of the jaws and ribs of the whale, while others are constructed of driftwood. Should a death occur in winter, when the snow lies on the ground hard and deep, the bodies are laid out on the surface until summer, when the snow disappears and enables the rejlatives to find material to build one of the scaffolds, on which the body is then placed. The most reasonable explanation for this method of disposing of the dead and that of leaving them on the surface is that the ground is always frozen liard even in summer and the thaw never extends deeper than 12 to 18 inches. These elevated graves are in all stages of ruin and decay, and scattered about beneath them, almost entirely hidden by the beautiful for-get-me-nots, are the bones and skulls of the dead of many past generations." It is also interesting to note from the data given in Figure 1 that by placing a body in the air, it was placed at about the warmest possible point during the summer.

Permafrost is a significant consideration in development and operation of garbage and refuse disposal systems.

Housing $(16,19,20,25)$

Low temperatures and permafrost have probably been instrumental in causing early Eskimo people to build their homes half underground and half above ground. Frozen ground makes burrowing difficult and the cold Arctic winds in the tundra regions make it difficult to keep even a well built house warm above ground. Local materials suitable for constructing warm houses above ground are not readily available in the treeless Arctic. Stone is available in some regions and is used. Recent housing has been of frame construction with use of specially 
prepared insulation; however, permafrost affects the stability of frame houses. Vigorous frost action in the top layer of the soil causes shifting, heaving and settling of structures which are not constructed in such a manner that these forces do not have an opportunity to damage the structure. More than two thirds of the Eskimo houses in Greenland (5) are now of frame construction and probably more than half of the Eskimo homes in arctic Alaska are of frame construction.

The existence of permafrost complicates provision of satisfactory housing. Special construction practices are necessary to prevent shifting and settling of structures. It is difficult to secure proper drainage for underground structures. Low temperatures, permafrost and a very small income dictate a small house for the Alaska Eskimo. The usual house of commonly

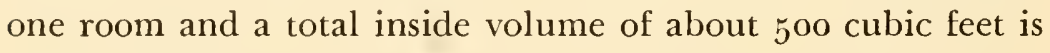
almost all the Eskimo can heat on his existence economy.

\section{Insect Control}

Hordes of sucking and biting insects are found in the permafrost regions $(23,27)$. Permafrost prevents proper drainage of the soil and causes the accumulation of myriads of shallow water breeding areas for insects. Vegetation typical of the poorly drained permafrost areas also is capable of holding much water. These shallow accumulations of water are warmed sufficiently by the long summer days to allow rapid breeding of insects.

Conventional methods for drainage of breeding areas appear impractical and almost impossible in the permafrost regions. More than 150 species of mosquitoes, black flies, horseflies, deerflies, blowflies, and other flies and midges are commonly found in the permafrost regions. Many of these insects are pests and have no doubt retarded development in the permafrost regions. Some may also serve as mechanical carriers of filthborne disease. Insects of the Arctic may serve as vectors for other diseases, but at present this has not been proven. 
Food Handling

In some parts of the Arctic, permafrost plays an important part in the foodhandling methods of the people (12). Permafrost or

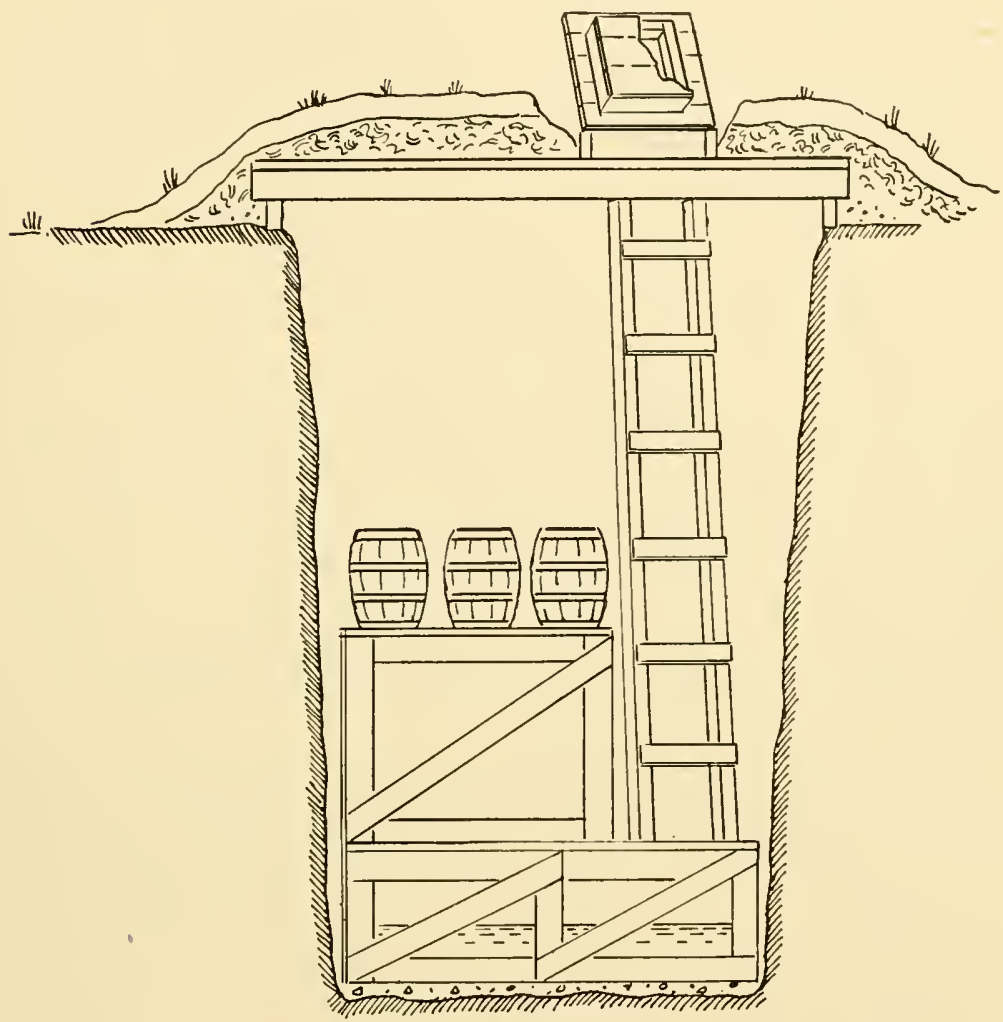

\section{FOOD STORAGE PIT FOR USE IN PERMANENTLY FROZEN GROUND}

FIG. 2.

ice cellars are used for storage of foods and ice. These shafts into the ground or excavations into the side of a hill are used for storage of food for both man and animal. A typical permafrost cellar is shown in Figure 2. At Barrow, Alaska, the average annual air temperature is about $10^{\circ} \mathrm{F}$., and the average annual 
temperature in the typical permafrost cellar is probably around 16 to $20^{\circ} \mathrm{F}$. Blocks of ice which are cut in the fall may be stored in the cellar for use as the winter water supply and foods may be preserved in the cellar during both winter and summer.

Although the permafrost provides excellent temperature conditions for food storage, the attendant unsatisfactory drainage creates a hazard to such food storage. Lack of provision of means for preventing surface water from entering the cellar and careless placement of food in the cellar may cause it to become contaminated with sewage or other wastes.

\section{Means for Environmental Health Control in the}

\section{Permafrost Regions}

Adequate water supplies with treatment facilities and distribution mains can be provided and are provided in some communities in the permafrost regions. Practically unlimited use of heat, use of utilidors (heated conduits) and large expenditures of money have provided for establishment and operation of such systems. Sewerage systems placed in utilidors have functioned satisfactorily in permafrost. Garbage and refuse may be burned for ultimate disposal.

Importation of materials and construction of excellent housing is an accomplished fact in the Arctic. Daily air shipments of fresh vegetables from continental United States to the permafrost regions of Alaska prove that an adequate supply of safe fresh greens and other foods can be made available to Arctic divellers.

But most of these accomplishments have been made at great expense and in spite of the physical conditions imposed by permafrost rather than in harmony and accordance with Arctic environment. Extra heat, concrete, reinforcing steel and effort have been literally poured in to attain these accomplishments.

However, a deeper insight into the strange ways of nature in the Arctic and development of ways and means for maintaining a healthy environment through utilization of more economical materials and resources at hand is mandatory. We must adapt our temperate climate practice to the region in which it is to 
be applied. Research, investigation and a fuller understanding of permafrost and related factors are essential to environmental sanitation in the permafrost regions.

\section{SUMMARY}

Reports of general prevalence of filthborne disease in the permafrost regions indicate a significant need for environmental health control in this section of the world. The existence of permafrost complicates provision of safe and adequate water supplies. Proper disposal of sewage, garbage and refuse is difficult in areas where the ground is permanently frozen. Severe frost action, lack of soil drainage and resultant threats to the stability of buildings make many Arctic homes unsatisfactory. Inadequate drainage of the vast Arctic slopes is closely related to the existence of permafrost and results in provision of endless breeding areas for insects. However, permafrost does provide inexpensive refrigeration for food for both man and animal in many parts of the Arctic.

Environmental health control in the permafrost regions, requires learning the laws of permafrost behavior and devising economical ways to use them to the greatest advantage. Through further investigation and research and careful evaluation and use of knowledge at hand, we will find further means of overcoming present obstacles.

\section{REFERENCES}

1. Ackerknecht, Edrin H. The Eskimo. Ciba Symposia, io (1). July-August, 1948.

2. Alter, A. J. Water supply problems of the Arctic. Alaska's Health, 7 (3). March, 1949 .

3. - Arctic sanitary engineering. Alaska Department of Health. Juneau. June, 1949.

4. Water supply in Alaska. Jour. American Water Works Assoc., 42 (6): 519-532. June, $195^{\circ}$.

5. Anonymous. Beretning fra den af sundhedsstyrelsen til Gronland udsendte Legeekspedition. Beretninger Vedrorende Gronlands Styrelse, Nr. 1, 1949. 
6. Bertelsen, A. Grønlandsk medicinsk Statistik og Nosografi, 4. Kobenhavn, Reitzels Forlag. 1943.

7. Borum, V. Greenland-Denmark's colony. Danish Foreign Office Journal, 1 and 2, 1948.

8. Call, S. J. In, Report of the cruise of the U.S. Revenue Cutter Bear and the Overland Expedition, Nov. 27, 1897 to Sept. 13, 1898. Washington. 1899 .

9. Chernyshev, M. J. Water services in regions with perpetually frozen ground. Jour. American Water Works Assoc., 22 (7): 899. July, 1930.

10. - Search for underground water in perpetually frozen areas. Jour. Amer. Water Works Assoc., 27 (4): 581. April, 1935 .

11. DAY, E. K. A study of a recirculating house water service connection with a single water main. Unpublished paper. Arctic Health Research Center. Anchorage.

12. Easton, P. S. Food resources of Alaska. Nutrition Unit, Alaska Department of Health. Juneau. April, $195^{\circ}$.

13. Hartwig, G. The polar and tropical worlds. Philadelphia. 1871 .

14. Isachenko, B. A. and T. L. Simakov. Bakteriologicheskie issledovaniia pochv Arktiki (Bacteriological study of the Arctic soil). Trudy Arkt. Inst., 9: 107 ff.

15. Kojinov, V. E. Russian water supply systems in areas where the ground is perpetually frozen. (Unpublished paper).

16. Krulish, Emil. Sanitary conditions among the Eskimos. Public Health Reports. December 12, 1913.

17. Ponomarev, V. "Vechnaia" merzlota i rudnichnye vody v Arktike ("Eternal" congelation and mine waters in the Arctic). Sov. Arkt., 4: $111 \mathrm{ff} .1936$.

18. Redman, Walter. Mains above ground in spite of forty below zero weather. Water Works Engineering, 103 (2): 120-122, 158. February, $195^{\circ}$.

19. Roberts, Palmer W. Effects on materials in Arctic cold. Military Engineer. May and June, $195^{\circ}$.

20. Roberts, P. W. and F. A. F. Cooke. Arctic tower foundations frozen into permafrost. Engineering News-Record, I44 (6): 38-39. February 9, $195^{\circ}$.

21. Stirling, Matthew W. Nomads of the Far North. National Geographic Magazine, 96 (4): 471-504. October, 1949.

22. Taracouzio, T. A. Soviets in the Arctic. New York. 1938.

23. Twinn, C. R. Studies of the biology and control of biting flies in northern Canada. Arctic, Journal of the Arctic Institute of North America, 3 (1): 14-26. April, $195^{\circ}$. 
Relationships of Permafrost to Sanitation-Alter 253

24. VarshavskiI, A. A. Energetika Arktiki (Sources of energy in the Arctic). Sov. Arkt., 2: 75 ff. 1937.

25. Whittaker, Harold A. Sanitation needs in Alaska. Alaska Department of Health. Juneau. 1949.

26. Williams, Ralpi B. Summary of Samonella and Shigella of Alaska. Northwest Medicine, 49 (5): 340. May, $195^{\circ}$.

27. Wilson, Charles S. Aerosol spray units for control of biting insects. Mosquito News, ro (2): 5 1-54. June, $195^{\circ}$.

28. Climate and Man. U. S. Department of Agriculture. Washington. 1941.

29. Community facilities in Alaska. Alaska Department of Health. Juneau. 1949 .

30. Vechnaia Merzlota. Sbornik (Eternal frost. Collection of Works). Izd. Akad. Nauk S.S.S.R., Moskva. 1930.

31. Zhilishchnye usloviia naseleniia Krainego Severa (Housing conditions of the population of the extreme North). Sov. Sever, 3: 78 ff. 1932 . 


\section{THE PSYCHOLOGICAL ASPEGTS OF ARGTIC AND SUB-ARCTIC LIVING \\ Ernest L. McCollum, Captain, USAF \\ Arctic Aeromedical Laboratory}

The purpose of this paper is to present a brief appraisal of some of the psychological factors which tend to assume a predominant role in the dynamics of Arctic and sub-Arctic existence. Obviously, this is not an attempt to enumerate all of the minute aspects of behavioral phenomena peculiar to the Arctic peoples, nor is it an effort to evaluate the relative magnitude of these factors as they relate to individual communities or groups.

The primary source for this concise overview rests in the research program of the Arctic Aeromedical Laboratory at Ladd Air Force Base, Fairbanks, Alaska. While the mission of this organization is military in nature, the implications of the work being conducted there have general application and are meaningful to the civilian community as well. Basically, there is little difference between the drives, the needs, and the wants of the service man and his family in Alaska and those of the resident civilian, the itinerant summer laborer, or the sourdough.

The stresses of the Alaskan environment are, for the most part, vastly exaggerated. There is little objective evidence to support the position that is commonly gleaned from stateside accounts of the hazards of life in the northern latitudes. The first task of basic orientation for the newcomer to Alaska is the dispelling of the many fantastic notions he may have concerning the Far North. In place of these, he must be supplied with a factual knowledge of the people, the climate, the terrain, etc. Once these preconceived errors are eliminated, a great step has been taken in the direction of good adjustment.

For the past eighteen months seventy-three airmen, all in 
Alaska for the first time, have been subjected to intensive psychological testing. The test battery was designed to elicit the changes which occurred in the personality patterns of the men, in their attitudes and opinions, and in their general efficiency as members of a military unit. While there was evidence that certain stresses had developed, these stresses were minimal and were not traceable to the peculiarities of Arctic and sub-Arctic duty (1).

In this connection, it should be stated that after careful investigation of both the large military installations near the centers of Alaskan population and the small auxiliaries located at the far-flung reaches of the territory, the morale of the men at the outposts many times excelled that of the men at the larger bases (2).

The first large focal point about which a great deal has already been written is the shortage of adequate housing. The social consequences of this bottleneck cannot be overestimated. Most of the "worries" registered by married servicemen in a recent survey at Ladd Air Force Base and Elmendorf Air Force Base $(3,4)$ clustered around marital misunderstandings fostered by forced separation from their families because of the housing shortage, problems arising from prolonged substandard existence, and financial encumberment incurred in an attempt to solve the housing problem. The advantages accruing to both the military establishment and the civilian community from an adequate housing program are self-evident.

A second source of tension is the lack of common social and sexual expressions. The numerical predominance of males makes impossible any kind of normal social balance. In such a state the incidence of delinquent behavior increases, alcoholic beverage consumption rises, and anti-social sexual expressions are more numerous. Our findings indicated that the men were often lonesome and without anything interesting to do. Recreation was largely confined to various forms of vicarious escapes such as the movies, reading, etc. No participant sport engaged more than seventeen percent of the men at the maximum. The outdoor recreational aspects of Alaskan living 
receive undue emphasis. Only about fourteen percent of the service persomnel buy Alaskan small game and fishing licenses, and only five percent qualify and purchase large game permits. The primary reason more people did not engage in these outdoor activities was the lack of suitable transportation to and from the areas where they may be enjoyed (2).

In relation to the social unbalance mentioned in the foregoing, a word should be added about those who adjust to this total environment most poorly. A study was made of one hundred men who exhibited a pattern of frustration and maladjustment to the demands of Air Force duty in Alaska (5). The purpose of this investigation was to determine the relationship between "low" morale and personality structures. Without question, the poorest risk in terms of productive efficiency in the environment described was that individual commonly known as the "psychopathic deviate," the person who demonstrates a lack of deep emotional responses, the inability to profit by experience, and a disregard for the accepted - social mores. These persons incessantly rebel against the limitations imposed upon them and express this rebellion in a variety of anti-social media.

Another personality type which appeared to find the environment described especially unfriendly was the hypomanic, that individual exhibiting chronic, mild, manic excitement. These persons are commonly characterized by marked over-productivity without direction or control. Their interests rapidly fluctuate from one endeavor to another. Many times they become habitual drifters. These persons showed marked inability to cope with some of the common elements of the Alaskan social milieu.

Without further elaboration concerning those who find reasonable adjustment difficult, it should be stated that this investigation confirmed the basic premise that in any challenging environment the best risk is the individual who is mentally well poised and well integrated. The selection of borderline individuals for assignment to areas where the known problems 
are many is to invite frictions which, in the long run, prove to be very uneconomical.

Probably the most forceful common factor in determining human behavior in most of Alaska is the weather. In large areas a great portion of one's time in the winter must be spent combating the elements. The difficulties of transportation, labor, amusement, etc., are multiplied by the sub-zero temperatures, the deep snow, and the long hours of darkness. Basic groups tend to become, of necessity, more isolated and selfsufficient. With the range of activity restricted, the most common psychological problems encountered are those which arise from frictions caused by prolonged close association.

In summary, the Arctic and sub-Arctic areas of Alaska do not pose the psychological problems which are commonly attributed to them. There are, it is true, certain principal sources of unusual social friction such as a shortage of adequate housing at a reasonable cost, the absence of normal social and sexual outlets in many communities, and the limitations imposed by the weather. In spite of these, however, the normal individual finds little difficulty in making the necessary adjustments intelligently and effectively.

\section{REFERENCES}

1. Selection of men best qualified for Arctic and Subarctic duty, Project 21-01-007, Program B, An Eighteen Month Longitudinal Study of Airmen Assigned to Alaskan Duty.

2. Survey of human adjustment problems in the northern latitudes, Project 21-01-022, Program C, Part I-C, Morale Survey of Alaskan Air Command.

3. Survey of human adjustment problems in the northern latitudes, Project 21-01-022, Program C, Part I, Morale Survey of Personnel Assigned to Ladd Air Force Base.

4. Survey of human adjustment problems in the northern latitudes, Project 21-01-022, Program C, Part I-B, Morale Survey of Personnel Assigned to Elmendorf Air Force Base.

5. Survey of human adjustment problems in the northern latitudes, Project 21-01-022, Program C, Part I-D, Relationships between Low Morale and Personality Structures. 


\section{PLANNING FOR ALASKA'S BIG GAME Olaus J. Murie \\ President, The Wildemess Society}

Nowhere on the continent do we have a greater variety of big game species than in Alaska. Consider the list of them: Moose, caribou, black-tailed deer, mountain sheep, mountain goats, black bear, brown bears and grizzlies in great variety, polar bears, and walrus-to mention only those large mammals that have been hunted for sport. Add to these the interesting non-game species and you have an assemblage of wildlife that is an asset in any country. Certainly such an asset deserves the most thorough study and planning for its perpetuation.

I should like to give prior attention to moose, caribou, and mountain sheep. These three present the diversity of character and variety of habitat that pretty well typify the big game conservation problem for Alaska.

Thirty years ago some of us who were then in Alaska could on occasion drive our dog teams within rifle shot of large bands of mountain sheep. On upper Chena River we could view an impressive caribou migration. As I recall it, each person was entitled to five caribou, three mountain sheep, and one or two moose each year, and without a license. If you were travelling in the back country you could take as many as you liked. You could find mountain sheep, caribou or moose on the menu in restaurants.

Today the big game picture is far different. What has happened?

We know some of the factors, but others are still obscure. We know that Alaska has had a tremendous growth in population. A road now crosses the route of the principal caribou migration, providing easy access to the biggest game herd. With road building and the prevalence of air travel there are no longer remote areas in the old sense. These changed conditions, 
reflecting historical events that we have already experienced in the more settled parts of our country, point to an inevitable trend that should give us clues to intelligent planning for the future.

In recent years a striking up-swing in the wolf population has been a dramatic factor in the wildlife situation, and this deserves our attention. During the period of extreme public interest in the wolf the only intensive work done on the game in a selected locality took place in Mt. McKinley National Park, jointly by the U.S. Fish and Wildlife Service and the National Park Service. This was followed by further research and checkup by the National Park Service over a period of years.

I shall not attempt to present the large mass of data assembled, but it is of interest to note some significant findings on mountain sheep.

Results of the studies were published by the National Park Service as a bulletin, "The Wolves of Mt. McKinley" by Adolph Murie, and we learn that the winters of 1928-29 and 1931-32 were disastrous for mountain sheep in the park and they died in large numbers. Unfortunately, we did not have comparable research from other parts of Alaska for those years. At the same time the wolf population was increasing in a striking manner, and these animals took toll of the remaining sheep. The result was a drastic reduction of the once numerous mountain sheep population of interior Alaska. In his report Adolph Murie commented: ". . . . it seems apparent that the wolf is the chief check on the increase of the Dall sheep in Mt. McKinley National Park."

He had recommended a limited control of the wolf and a continued check-up on the mountain sheep population, but about this time the wolves themselves became scarcer in that area and even the small number recommended for removal were not obtained. Furthermore, the mountain sheep population showed signs of being on the up-swing again.

Prior to the time of the heavier wolf predation the large sheep population could not be accommodated by the forage present on the more rugged, protected terrain. As a result, 
many of them had become accustomed to feed on the lower, gentler slopes, away from the protection of rough country. Then came the two adverse winters, and heavier wolf pressure, which reduced the sheep numbers and placed them back in rugged territory, where they found greater safety. This meant, of course, a smaller total population.

In 1920 I found that there was a small group of mountain sheep in the White Mountains, between Fairbanks and Circle. Recently I learned that they are still there. It is significant that after 30 years, in spite of the unprecedented, widely publicized wolf numbers in the north, and living in a place that has had no special legal protection, that handful of sheep has persisted.

This is precisely the experience we have had in some other places. Large populations have suddenly declined, for obscure reasons, but after reaching a low point they have persisted and in time began a slow recovery. That appears to be what happened in Mt. McKinley National Park, where the numbers are now once more on the upsiving. Furthermore, some reports are to the effect that in the Brooks Range, in spite of the wolves, the mountain sheep are holding their own.

In some of the arid portions of the southwestern United States, where climatic factors severely affect forage growth and consequently animal populations, poaching has in some cases proved to be an upsetting factor that prevented sheep population recovery.

The Alaskan moose may in time present a problem, but we have here the advantage that moose are widely distributed and they are not confined to a highly specialized habitat. They do require browse, and it is essential that they continue to have access to areas of heavy willow growth. I shall refer to the moose again later.

We have a problem with the Alaskan caribou. In 1921 my estimate of the Yukon-Tanana herd was 568,0oo, and it appeared at that time that the caribou of Alaska and Yukon may have numbered over a million. Today the numbers of caribou are reported to be but a fraction of what they were.

We know that increase in human population, and greater 
accessibility by roads, has resulted in a great increase in shooting. The high wolf population has no doubt had an appreciable effect. But what other factors are there? Is it possible that the number present in 1921 was the high point in a cycle? Is such a cycle beneficial for recovery of range? And what really causes a cycle, if one exists?

Years ago L. J. Palmer, of the Bureau of Biological Survey, made thorough studies of lichen growth. He found that when lichens are destroyed they require about as long for recovery of full growth as does a destroyed forest. On the caribou migration route of the Yukon-Tanana highlands I found lichens abundant in 1921. Yet it was noticeable, even then, that where animals were particularly abundant the lichen growth was pretty well scuffed up by numerous hooves, and did not present an even growth.

In 1923, when my brother and I spent a winter in the Brooks Range, we found large areas on the Alatna River watershed where lichens were unusually luxuriant, and undisturbed. No caribou had been there in the memory of some of the Indians. In the early winter of 1924 , when my wife and I visited much the same country, we witnessed an unusual event. The caribou herds that had formerly migrated along the route to the eastward, this time swung westward so as to take in the virgin range of the Alatna.

May we look upon this as an instance of natural rotation of use, letting a range lie fallow for a time? It is reported that the Arctic herd, north of the Brooks Range, has actually increased in recent years. How shall we interpret that fact? Had a previously hard-used range up there recovered, permitting another increase in animals? Have some of the Yukon-Tanana herd moved north to augment the numbers on the Arctic slope? Must we conclude that we cannot maintain an animal population at a high level, continuously, without fluctuations to lower levels?

There is not a clear answer to these questions. In fact, when we begin to discuss the big game problem of Alaska, it becomes a series of questions. Yet we have had experience with wildlife 
management in North America and we have discovered certain dependable principles. I should like to mention a few of these, two of which I want to stress particularly: 1. The need for preserving the labitat, and 2, the need for planning. They are, of course, closely related.

1. Animals require a habitat to which they have become adapted, with the proper food and shelter and other requirements. Mountain sheep and goats have the advantage of occupying a type of mountainous terrain that is not likely to be sought for the usual economic purposes, and the preservation of such habitat should be compatible with human use. The deer of the southern coast are not highly specialized in habitat choice and should survive in the large forested areas available to them, since their presence there is compatible with other land uses in that region. To some extent this applies also to moose. But the caribou are a problem. Apparently their food supply, particularly lichen, is critical. There is evidence that to thrive the herds must have plenty of room in which to travel about and be dispersed, in order to preserve their range. I might point out that this principle of moving the animals and keeping them dispersed is the principle that national forest supervisors in the States attempt to put into effect in herding domestic sheep.

2. To accomplish habitat preservation, particularly for caribou, broad scale land-use planning for Alaska is desirable. Social and economic needs are both to be considered, such as agriculture, mining, hunting, tourist travel, and the wilderness type of recreation which is having so much attention today, all the interests that contribute to public welfare in the most comprehensive sense.

We have had discouraging experience in many parts of the States. We have in many instances discovered a herd of animals on our hands with no place to put them. Animals need a place to be, with the proper food. Yellowstone Park, for example, was established in 1872 , dedicated in part to preserve the animal life. But the lowland winter ranges outside have gradually gone into agricultural use and we now have to reduce the 
Yellowstone herd to low figures, and we don't know what the end will be. It has been urged that the surplus animals be shipped alive to other parts of the country. But where? We can find no more places for elk. IVe had no planning for wildlife in the early stages of the development of the West. Even today, present reclamation plans, drawn up without adequate consideration of all public needs, will in some instances shrink wildlife winter range still further.

Alaska had a unique opportunity to study the failures in the States, to study the needs of caribou and other big game, to study the social and economic needs of the foreseeable future, and to make long-range plans for land use in one of the most interesting areas we have. Alaska could take the lead by putting into practice integrated planning, and thereby do a service to the Nation. This is nothing more disturbing today than the spectacle of public agencies making their blueprints for the future, each in its specialty, and ignoring the needs in other fields of human endeavor. The recently established Kenai National Moose Range, with a qualified biologist in charge, capable of putting into effect management plans with regard for the balance between forage supply and game, and with consideration of the total fauna and flora, is a most encouraging step in the right direction.

Reindeer raising is not compatible with maintaining wild caribou. It has been proven that when the two interests occupy the same ground, one must go. There is range for only one. In some instances the caribou are deliberately killed off, since they interfere with reindeer herding. This has happened over much of the reindeer country along Bering Sea. Or the caribou will lead away the reindeer in their migrations, until few or none remain. A classical example was the unfortunate attempt years ago to place a federal reindeer herd in Broad Pass. It was doomed to failure from the start, for this was in the migration route of the caribou.

A zoning system is essential, reserving certain areas for domestic reindeer, and other areas for caribou. Perhaps a fresh, objective inquiry into the status of reindeer is desirable. In 
past years there have been instances when reindeer were placed where they were not wanted and not needed; for example, on Atka Island, where the inhabitants didn't care for them; on Umnak Island, where for years everybody had forgotten about them; and on Alaska Peninsula, where hybridizing is doing arvay with the native species of Grant's caribou. These are examples of single-track planning without regard for other interests. We must insist on coordination of activities of different bureaus.

I would point out that the dedication of extensive areas for conservation of caribou herds could be combined with other compatible uses. Sportsmen, and those who take game primarily for home use, of course welcome provisions for maintaining a substantial game supply. Many of these areas could also be considered primitive or wilderness land, useful in the field of science, particularly ecology, for education, and for many types of recreation. Certain non-agricultural portions of Alaska could well be designated for such multiple use, featuring the caribou herds as the special object of concern.

Certain well meaning people have proposed that elk be brought into interior Alaska. I can think of nothing more dangerous to Alaska's game animals, if the elk should succeed in establishing themselves. Elsewhere we have found elk competing with mountain sheep and moose. Some years ago I had several sacks of reindeer lichens shipped from Alaska to Wyoming to try out on elk. Though this was a strange food to the elk, and it had been dried a long time, they ate it. We know that elk eat other lichens native to their range. We can not afford to add to the caribou problem by introducing another herd animal that would deplete their favorite food.

Unfortunately, there are also proposals to introduce the coast black-tailed deer into the moose range on Kenai Peninsula. Here again the present forward-looking program aims to keep a famous moose herd in balance with the browse supply. Such worthy effort should not be thrvarted by placing there a competitor.

A word should be said about the walrus. From ancient times 
the walrus herds living in Bering Sea and adjacent parts of the Artic Ocean moved over their migration routes with the seasons, and contributed to the livelihood of the original inhabitants of those shores. The walrus supply was maintained, since only enough was taken by the people to meet their personal needs.

Today it is different. Two major changes have been made. There is an outside demand for ivory products, beyond the personal needs of the Eskimo. And the Eskimo are using modern firearms.

Formerly the walrus were harpooned, with little waste. Today, when walrus are shot with rifles, an alarming percentage of the animals killed sink and are lost.

The Eskimo, when governing themselves in their original society, showed wisdom in meeting their problems. The present walrus problem should be approached by consultation with representative Eskimo leaders, who should be in a position to offer practical suggestions for solving a problem that concerns their own future so directly.

A game management program should be based strictly on scientific findings, with emphasis on ecology and with consideration of the total interest in wildlife. Any animal population must exist in accordance with biological, ecological, law. It is necessary to discover those laws and apply them.

Furthermore, it is desirable that the public be made familiar with scientific management of wildlife. Recently the U.S. Fish and Wildlife Service and the University of Alaska have completed arrangements for a Cooperative Wildlife Research Unit at the University. This is another of several developments in Alaska that point the direction toward effective management of wildlife and public appreciation of the true problem.

Predation is a subject too complex to discuss in detail here, but it has had great publicity in Alaska in recent years. When predation becomes serious it should not be ignored, and control should be applied as needed. But in such instances it is difficult to maintain public objectivity. The subject lends itself so well to journalistic writing and emotional expression that it becomes 
extremely hard to get facts before the public. Too often the subject of predation, with all its heated repercussions, beclouds the real problem and draws attention and enthusiasm way from the fundamental ecological basis for management.

In the final analysis, should wildlife management be an isolated field apart from other public planning? Conversely, should commercial fisheries, agriculture, any one business venture, be planned and established as special fields of endeaṿor, apart from each other, and apart from wildlife management? And should wildlife management be pursued without consideration of all the facets of recreation? We are discovering that a single field of planning can not be successful in the democratic sense if it exists with complete indifference toward other fields. The conservation effort today has taken new direction. The emphasis lies in a widespread plea for integration of the many phases of public planning. The earnest plea is for sympathetic consideration for each interest that may be in conflict with another. Especially, the plea is for the elimination of political bias from planning, for a sharing of opportunity, for democracy.

Wildlife planning for Alaska is part of a wider endeavor. It is being recognized that mountains, streams, forests, and wildlife are an important part of human environment, which contribute in diverse ways to the many kinds of human aspirations and enjoyment. Physical welfare alone, of material goods and opportunities for individual accumulation of dollars, are useless without the opportunity for contentment in a suitable environment.

To be more specific, planning for wildlife in Alaska involves a procedure that completely ignores the spirit of personal exploitation of resources. It means careful study of land use possibilities, on a regional basis, with an eye to determining what areas are best fitted for agriculture, what localized places, if any, are suitable for national parks, which should be left in a primitive state for the wilderness type of recreation. Several of these needs, especially in the diverse field of recreation, can be combined in the same area, provided that the management 
or administrative plan is not too narrow in application. For example, conservation of caribou and mountain sheep could well be combined with a system of wilderness areas, selected so as not to encroach on agricultural land. These two purposes go very well together.

Above all, in planning for Alaska's big game, personnel should be called on who are competent to evaluate the emerging human needs.

I would repeat, that Alaska today has a unique opportunity to study the mistakes and disasters that have occurred in the more settled parts of our country. Alaska has the opportunity to offer leadership in wildlife management on a scientific basis, leadership in land use planning that will contribute most to the satisfactions we are all striving for.

\section{REFERENCES}

1. Murie, Adolph. The wolves of Mt. McKinley. Fauna Series No. 5, U. S. Nat. Park Service. 1944

2. $\quad$. Another look at McKinley Park sheep. The Living Wilderness, 2, No. 19. December, 1946.

3. Murie, Olaus J. Alaska-Yukon caribou. North American Fauna No. 54, U.S.D.A. 1935 .

4. Wildlife introductions in Alaska. Trans. Fifth North American Wildlife Conference. 1941.

5. Nelson, Edward W. Report upon natural history collections made in Alaska between the years 1877 and 1881. No. III, Arctic Series of Publications issued in connection with the Signal Service, U.S. Army. 1887.

6. Palmer, Lainrence J. Progress of reindeer grazing investigations in Alaska. U.S.D.A. Bulletin no. 1423. 1926.

7. $\longrightarrow$ Improved reindeer handling. U.S.D.A. Circular No. 82. 1929.

8. No. 207. 1934.

9. Sheldon, Charles. The wilderness of Denali. New York. 1930. 


\title{
PRESSING PROBLEMS IN ADMINISTRATION OF WILDLIFE RESOURCES IN ALASKA
}

\author{
W. A. Elkins \\ Fish and Wildlife Service \\ Juneau, Alaska
}

Administration of fish and wildlife resources in Alaska is a function of a federal agency, the Fish and Wildlife Service. Since Alaska is a territory the Service is operating both as the federal wildlife agency and the Game and Fish Department as constituted in many states. In addition, a regulatory and policymaking body, the Alaska Game Commission, represents the people of each of the four judicial divisions of Alaska. In Alaska, the Service is organized in three operating divisions: commercial fisheries, law enforcement and wildlife management.

To describe adequately the range of problems would require first a description of the varied wildlife habitats from the dense coastal rain forests of southeastern Alaska to the Arctic tundra and the variation from the windswept treeless heath of the Aleutians to the dry cold interior. Instead I have chosen here to consider three types of problems: those involving land and climate, problems of animal behavior and those wildlife problems brought about by the human population. There are important differences and many similarities to stateside wildlife problems. One difference can best be understood by comparing the motives of the stateside hunter and the Alaska hunter. Here in Washington the term "meat hunter" would be generally regarded as a form of name-calling with considerable stigma attached. Most Alaskan hunters would consider it a compliment and look down their noses at the "sportsman" or "sport hunter." We are dealing with a resource that means food and clothing to the people and not with game harvested by a recreational group out for a weekend pheasant hunt. Fish, fur and 
game is the basis for the economy of much of Alaska particullarly the Arctic and Subarctic regions and without these resources these regions and much of the interior would not be habitable by man.

\section{Basic Land-Climate-Wildlife Relationship}

Agriculturists are well aware of the limitations Alaska's soil and climate impose on the yield of grain and livestock. Iowa magnitude hundred-bushel-to-the-acre grain yields or a cow to every two acres is not claimed and we accept the fact that neither the climate nor the soil will permit such yields or such density of animals. With fish and wildlife, however, we are not so inhibited and the outdoor magazines carry Alaska hunting and fishing stories that seem to say, "come to Alaska where the brown bear and caribou abound and every lake and stream is teeming with fish." I suppose the impression of great abundance results from the telescoping of a month long hunt into a few brief pages; the gameless days and the endless miles of spruce between fishing holes do not stand out in such an account.

A few years ago the Tanana Valley Sportsmen's Association posted a notice at Tok Junction where Alaska Highway visitors entered the territory from Canada. The notice began, "Alaska is not teeming with game and fish-." But practically nobody believed it until they had been in the territory for some time. Here then is a basic problem; to determine actual wildlife population densities in the various soil and cover types and in the several climates of Alaska. Some of the findings to date in this type of survey have been significant; for example a winter moose density of $11 / 2$ per square mile was found on the Kenai National Moose Range in contrast to 3 moose per mile in the Susitna Valley. Yet both areas were short of winter food, the difference being that the Kenai had supported a large winter moose herd for many years and in that time the forest succession had matured and some moose browse such as birch had grown out of reach of moose and other such as willow had been replaced by spruce. The remaining browse in the concentrated 
wintering area around Kasilof and Kenai is severely overbrowsed each hard winter. The Susitna moose population has been building up in recent years but is now beginning to exceed the winter browse supply in years of deep snow.

The remedy is simple: cut down the moose heard to the carrying capacity of the winter range; but putting that remedy in practice may be far from simple considering the uneven distribution of hunting effort according to accessibility. A step in this direction was taken this year by opening to hunting the Susitna section of the Alaska Railroad and by lengthening the season on the Kenai.

Relationship of wildlife to land forms is especially pronounced among ducks and geese. Table I (1) shows relative densities of breeding waterfowl as determined from the aerial transects:

TABLE I.-Density of Breeding Waterfowl

\begin{tabular}{|c|c|c|c|}
\hline \multirow[b]{2}{*}{ Region } & \multicolumn{3}{|c|}{ Waterfowl per square mile } \\
\hline & $194^{8}$ & 1949 & $195^{\circ}$ \\
\hline Arctic Slope .......... & $3 \cdot 9$ & 2.5 & 2.6 \\
\hline Interior-Innoko-Lower Yukon ............. & - & 10.7 & 14.0 \\
\hline Interior-Minto Lakes $\ldots \ldots \ldots \ldots \ldots \ldots \ldots$ & - & - & 8.7 \\
\hline Kotzebue Sound-mainly river deltas.......... & - & 36.2 & $3^{0.2}$ \\
\hline 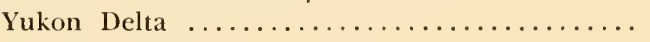 & - & 16.5 & $17 \cdot 4$ \\
\hline
\end{tabular}

The pronounced difference between the Arctic tundra (3 waterfowl per sq. mile) and the delta areas ( 17 to $3^{\circ}$ per mile) provides a clue to the reasons for the contrast in productivity. It also tells us the type of habitat with highest priority for waterforvl management. Like deltaic formations the world over, the Yukon Delta contains the concentrated fertility from the whole drainage basin.

With fresh-water fish, the myth of uncounted numbers has, like the big game, been repeated in glowing terms. Actually the fresh waters are relatively low in productivity when considered as a year-round habitat. The huge runs of anadromous species give the impression of great abundance in streams and lakes accessible to salt water but these salmon and trout have been feeding and made most of their growth in the sea. Land-locked 
fish, on the other hand, must depend on the plankton, bottom fauna and small fish present, without the assistance of the ocean to furnish tons of organic material. It is patent that lakes and streams reflect the productivity of the land in their drainage. A lake surrounded by rocky ridges and sparse spruce will be relatively infertile and management must be geared to that hard and uninviting fact.

This then is the basic problem: the climate and soil of Alaska is capable of producing on a sustained yield basis a low crop of game and fish per unit of area. There are some important exceptions to this statement but successful management must recognize the need to disperse hunting and fishing pressure widely. Equally necessary is continued recognition that most of the land in Alaska is better suited for producing a crop of game and fur than for any other purpose.

\section{Animal Behavior Problems}

A second set of problems to which answers are badly needed concern the behavior patterns of game animals.

Caribou are the most numerous big game animals and the least understood. For example we need to know what makes the caribou run. We need to know why some caribou migrate while others remain as resident herds. If anyone doubts the importance of this line of investigation let him consider that we now have three or possibly four caribou herds that migrate back and forth across the Yukon-Alaska border. We need a great deal more knowledge if these herds are to be perpetuated, harvested within reason, and protected properly on both sides of the international boundary.

According to Murie (2) the large caribou herd between the Yukon and Tanana Rivers numbered between one-half and one million animals. This herd is no longer present. There are some indications that these caribou migrated northwest to the Noatak Valley, an airline distance of nearly 600 miles. If they did, think of the complexities that can arise when 100,00o or more caribou leave one range and appear on an entirely different range. Neither the native economy nor the machinery of 
regulations, patrol and protection is flexible enough to meet such drastic changes without some hardship and turmoil.

The Nelchina caribou are an example of a more or less resident herd that remains in a definite area the year around. This tendency simplifies greatly the broad management practices of protection from predators and regulation of the take.

Why do caribou migrate? And what determines the time and route? Why do some herds follow a pattern while others appear completely erratic in their movements? And why do still others not migrate at all? Do caribou always move into the prevailing wind? Or is it lack of food or harassment by wolves that starts the herd moving? What of the influence of insect pests or the disturbance by man? Has highway or railroad construction been a factor in changing migration routes? And what of the effect of the airplane? Or is the answer not to be found in external factors but instead in a temperature change or some other stimulus affecting the internal physiology of the animal?

We now have information on the approximate caribou population, the kill by licensed hunters and the winter foods. Also the effect of tundra fires on the caribou range is known. Beyond that a great many answers are needed before intelligent management of caribou becomes a reality.

Obviously neither time nor the caribou will stand still until all the answers are in. The present caribou surveys are financed by Federal Aid in Wildlife Restoration funds with active cooperation from several agencies maintaining field parties in the caribou country such as the Geological Survey, Arctic Institute, Public Health Service, the Air Force, the Navy and the Alaska Native Service. New measures adopted as a result of the findings to date include: closure of the Mt. Sanford area to hunting in order to protect a remnant herd, more liberal bag limits north of the Arctic circle, and intensive predator control on the Nelchina range.

\section{Sea Otter}

The original sea otter range in Alaska included all of the North Pacific coast and islands and extended in Bering Sea 
especially on the Pribilof Islands. The present range, Aleutian and Shumagin Islands, Prince William Sound and Cook Inlet is very restricted and is unusual because of the spotty pattern of distribution. Otter are now found at widely separated locations with apparently similar habitat between and it would be relevant to know whether these are remnants of the original population or whether they have become established by migration from the Aleutian Islands nucleus.

How important this question looms may be appreciated by the difference the answer would make in attempting to repopulate much of the original sea otter range. On the one hand we would transplant animals to unoccupied islands and build up new pods while, on the other hand, if migrations take place we would intensify protective measures on the presently occupied otter islands and attempt to build up breeding pods.

The Aleutian Chain and other otter locations are not easy places to work, one good reason why we know less about sea otter than other fur animals. The Aleutian Island Refuge manager and his assistant located at Cold Bay near the tip of the Alaska Peninsula are presently the chief Service source of information on the status of the sea otter.

\section{Waterfowl}

Unsolved waterfowl problems in Alaska are sufficient to stagger the imagination. I will here touch on only one segment of one problem-migration behavior in three species of geese and one species of duck.

In 1948, we began banding waterfowl in the Innoko River area of west central Alaska and in 1949 the work was expanded to include the concentrated goose nesting grounds of the Yukon Delta. At that time we did not know whether most of the black brant from the delta moved down our Pacific coast or if they followed the Aleutian chain to Siberia and on down the Asiatic coast. The recoveries from the 1949 bands, however, came mainly from California and we know that some of the Yukon birds were going to the Pacific coast states. There was still no tie-up, however, with the fall brant concentrations at Cold Bay 
on the tip of the Alaska Peninsula. Just two weeks ago Yukon Delta bands were recovered from three black brant at Cold Bay so we now are beginning to fill in the blanks on this migration from the Yukon Delta, along the Bering Sea side of the Alaska Peninsula, thence across the Gulf of Alaska to the British Columbia coast and on to Washington, Oregon and California.

Cackling geese, the smallest sub-species of the Canada goose is believed to follow much the same southward route as the brant. Of 38 band recoveries in recent years all but one have been from California and Oregon or near the banding area. Peak concentrations estimated up to one million geese occur at Cold Bay and while there is still no established connection through banding between Yukon Delta cacklers and those at Cold Bay, radar tracking shows a great circle route of about 1,400 miles over water to the vicinity of Vancouver Island. The absence of band recoveries from other parts of Alaska and British Columbia seems to confirm this surmise. The importance of this information in protection and a regulated harvest of these geese is obvious. In addition, we would like to know how many are heading for our states and how many for the iron curtain.

In nrarked contrast to the narrow flight routes of the brant and cackler is the behavior of the white-fronted geese and pintail ducks. The white-front is the only species to date which shows migration out of the Pacific flyway at least as far as the prairie provinces of Canada. Based on 66 recoveries of pintails banded at widely separated locations-Innoko, Kotzebue Sound and the Arctic Slope-it appears that these ducks go mainly to the Pacific Coast with a spread into the Central Flyway, recoveries ranging from Alaska to Mexico and from Nebraska to California.

Most of the waterfowl problems faced in the states are encountered in Alaska, the single exception being waterfowl depredations on grain and other crops. Problems unique to Alaska involve the Emperor goose and the Western Canada goose, neither of which apparently ever leaves the Territory, and the European teal with an essentially east and west migration between the Aleutians and Asia. 


\section{Problems Relating to the Human Population}

It has been said that America needs not so much game management but more hunter management. This is almost as true of Alaska as it is in the states.

One of the most important of stateside problems we do not have in Alaska, the problem of getting on the land to hunt. Most of Alaska is public land and the Alaska hunter is seldom confronted with "No Trespassing" signs. Near some of the towns there are exceptions to this condition and the amount of land in private ownership is increasing. In the foreseeable future, however, there will be no shortage of places to hunt, our problem will be to maintain a game population on these public lands. Of a gross acreage of 365,481 , ooo some 486 ,ooo acres were in private ownership in 1947 (7) and some 7,00o,0oo acres in National parks and monuments. These private areas can be closed to hunting at the owner's discretion and the park lands are closed to hunting and trapping but open to fishing. There are some restrictions on hunting in the military reservations and Indian reservations and in the Aleutian Island $\mathrm{Na}$ tional Wildlife Refuge but considerable hunting is possible in these reservations and the two large wildlife areas, Kenai and Kodiak are open to hunting. The nearly $21,000,000$ acres in the National Forests are open to all. Thus approximately $35^{8}$ million acres are open to some form of hunting. This amounts to $9^{8}$ percent of the land area of Alaska and is a reassuring guarantee that the American system of free hunting ranges will be with us for some time.

The first great problem relating to human use is caused by the transient population. Alaska's population in 1940 was 72,000 (4); while preliminary estimates for the $195^{\circ}$ census are about 131,000. About 35, 0oo comprise the native population which has shown no marked increase. The increase then has been largely in the white population, an increase of 156 percent. Many of these people are transients, construction workers as well as civilian government employees whose tour of duty in Alaska is frequently less than two years. Others, including the 
homesteaders, intend to become permanent residents but instead move on in a year or two and so far as their relationship to the wildlife population is concerned can be considered transients. Added to the civilians are the military personnel: Air Force, Army and Navy who are rotated usually in two years to posts outside Alaska. Figures on the military strength are not available for this report. In addition there are large numbers of even more transitory workers-the summer temporary employees not included in Alaska census figures.

Transients are not likely to have the same deep interest in conservation of game, fish and fur as do the long-term residents. Many transients' recreational pursuits included hunting and fishing in the states, many others turn from golf, tennis or baseball to hunting and fishing because the latter are the chief recreational outlets for them in Alaska. But the expert and the novice have caused a critical upswing in the hunting and fishing pressure.

The resident sportsman is interested in a permanent sheep population in his favorite sheep hills and grayling for all time to come in the nearest stream. Your transient hunter is motivated by the souvenir instinct, he must have a brown bear rug, a set of caribou antlers or a goat head to show the folks back home. What matter if he shoots three bears before getting one in the trophy class or if his first two goats are crippled or fall down the cliff.

Among transients there are careful, conservation-conscious sportsmen as well as many who hunt with the camera instead of the gun. Also it should be recorded that military personnel are individually better disciplined than their civilian contemporaries. A check made last year in the Anchorage area showed fewer violations of game and fish regulations by the military than for a comparable group of civilian license holders. The fact remains, however, that both because of sheer numbers and through a "get it now-we won't be here tomorrow" attitude, the transient population has caused a serious wildlife management problem.

Continued close cooperation between the National Military 
Establishment and the Fish and Wildlife Service, including indoctrination with the rudiments of conservation of Alaskabound troops, is the best answer to the military part of the problem. For those transients who can be interested in active participation in the Izaak Walton League or other conservation clubs the battle is half won. For the remainder a vigorous enforcement program is the only answer.

The second great problem concerns the native people: Eskimo, Aleut and Indian, and their dependence on wildlife for a living. This is a subject that will undoubtedly be described in more detail by other speakers. We can narrow the problem in order to get at the critical portions of it. In southeastern Alaska, at Kodiak and at Bristol Bay, commercial fishing provides a livelihood for most of the natives as well as whites. Hunting and trapping are important but are not the basic resource. In these areas and in parts of the Interior, the native people have left the primitive way of life and have come to the white man's ways.

Along the Arctic coast, on parts of the Bering sea coast, on the Yukon-Kuskokwim delta, and in the interior villages such as Christian, Stevens, Arctic Village, Shungnak, and Noatak, the primitive life is still lived. These people must live by fur, fish and game; the alternatives are charity, the dole or starvation.

Pressing problems of wildlife resource administration and the native are of several types:

1. Should the native and the white be bound by the same hunting and trapping regulations? Generally speaking, except for the license requirement, that is now the situation and the recently liberalized regulations in the Arctic apply to all.

2. What can Alaska learn from Canada's experience? In the Northwest Territories preserves are set aside where only natives may hunt and trap, and in the unorganized portions of some of the provinces special provisions apply to natives. Recognizing that the training and environment of the Eskimo requires living off the land some special provision may be necessary but the reservation idea is a doubtful solution. At present there 
are not enough white hunters in the Arctic to cause a conflict. In the sub-arctic portions of the interior, horvever, there is considerable conflict especially on trap lines.

3. As would be expected the policy and practices of the leading white man in the primitive villages greatly influences the conservation attitude in the district. Usually this individual is the trader, in some villages it may be the teacher but the teacher's tenure is frequently temporary while the trader is a permanent resident. Besides, the trader controls the purse strings and the credit. If the trader has a reasonable respect for wildlife conservation the people in the village reflect this. If, on the other hand the trader buys summer-caught beaver or condones a caribou slaughter, waste and poor conservation practice results.

4. Migratory waterfowl and the native villages pose a unique question. Here we are concerned not with resident game, but with a resource produced in Alaska, overwintered largely in the states and Mexico, and harvested all along the Pacific Flyway. In the spring when food is scarce in the villages and the rat camps, few rould begrudge the Indians and Eskimo some fresh meat and the total effect is probably not great. But it is poor management to kill the breeding birds, those that have survived the vicissitudes of the long flight south and the return trip northward, and especially is it undesirable if birds are killed before they nest. It may not be completely fantastic to suggest that a few carloads of Spam might be the best investment duck hunting clubs could make as insurance for their sport, at least that portion of it dependent on the Alaska nesting grounds.

One school of thought holds to the view that the native cannot be changed. Those who have seen him adopt the outboard motor for water travel, the 30 -o6 rifle for hunting and the white man's rain gear for wet weather hold the opposite view. They believe that if convinced of the reason and need and ultimate advantage to himself and family, the native will respond to conservation education. The great need, however, is for education of the right sort probably much of it by means of visual 
aids. Certainly the teachers need help on this, and existing textbooks with examples of corn and pheasants, quail and lespedeza are not to the point.

Many other wildlife problems in relation to the human factor come to mind, such as airplane hunting and public attitudes toward bear and toward sea lion. Also there is the critical problem of public awareness and support for an adequate system of waterfowl refuges at the great nesting and concentration areas where the hunting pressure is increasing each year.

The problem which I wish to touch on briefly, however, is something which might be called the lack of an incentive for husbandry. The problem is best illustrated by the fur resources. A trapper handles his trap line conservatively and takes a reasonable crop from his marten line and a reasonable crop from his mink line. Another trapper takes every last pelt he can from his line including most of the seed stock and then moves on to greener pastures. One year his movements may bring him to the first trapper's line and there is the end of the conservative trapper's carefully-husbanded fur crop. Another abuse is the practice of town and city part-time trappers taking the cream of the fur crop from an area where fur is the basis for the economy of the local inhabitants.

In some places, registered trap lines have proved to be a reasonably successful solution. In others, trapping areas assigned to either the individual or a group or a village, have resulted in a sustained yield and more stable income. We need many more facts on which to base a sound wild-fur management program for Alaska. This is one of the principal objectives of the Cooperative Wildlife Research Unit at the University of Alaska. The present research is concentrated on beaver and muskrat but will later be broadened to include other species.

Some measures in fur managenent have been taken on an extensive rather than intensive basis. Alaska has been divided into eight fur districts with regulations varied to meet conditions in the individual districts. Also a sealing system has been put into effect which limits the trapper to 10 beaver, the only species so regulated. Neither measure is tied in with the 
land, the fur animals and the trapper. This must be accomplished if the fur crop is to be sustained and increased in the face of increasing trapping pressure. Trappers will welcome relief from cutthroat competition for trapping grounds and an opportunity to manage a fur crop on a trap line that is theirs to use so long as they take care of it.

\section{Summary}

Fish and wildlife resources of Alaska are administered by the Fish and Wildlife Service with the Alaska Game Commission as the regulatory and policy-making body.

Basic soil and climatic limitations result in low densities of game and fish per unit of area. Except in the case of anadromous fish, heavy crops of game and fish are not produced but there is a huge acreage comprising most of Alaska which is more suitable for game and fur production than for any other purpose.

Animal behavior patterns pose serious problems in wildlife management. For example the migrations of the caribou have to date proved unpredictable. Studies have shown the total population and the licensed kill but more information is needed on factors causing migration. The present discontinuous distribution of the sea otter may be caused by remnant relatively stationary pods or by migration from a nucleus in the Aleutians. Restorative measures will be quite different if the otter prove sedentary instead of migratory. A third example of animal behavior is the migration pattern of waterfowl. Banding studies show the fall migration of the black brant from the Yukon Delta, out along the Alaska Peninsula thence straight across the Gulf of Alaska presumedly to the British Columbia coast thence south to the Pacific states. Migration of the cackling goose is similar to that of the brant. White-fronted geese, on the other hand, tend to cross to the Central Flyway and pintail ducks nesting in Alaska spread out quite widely in the southward migration. These variations in migration pose serious problems in regulation and protection. 
Wildlife problems relating to the human population do not include one common stateside problem-that of getting on the land to hunt. The three most important problems are those caused by the influx of transients, those related to the economy of the native people, and those caused by competition for trap lines. A better system for handling the fur resources is one of the first priority management jobs.

\section{REFERENCES}

1. Elkins, W. A. Pacific Flyway report-Alaska. Pacific Waterfowl Flyway Report, 11: A1-A6. $195^{\circ}$.

2. Murie, O. J. Alaska-Yukon caribou. North American Fauna No. 54. 1935 .

3. Scott, Robert F., Edward F. Chatelain, and Winston A. ElKıns. The status of Dall sheep and caribou in Alaska. Trans. $15^{\text {th }}$ North American Wildlife Conference. $195^{\circ}$.

4. Alaska Almanac. Tewksbury Publishers. $195^{\circ}$.

5. Alaska Game Commission. 1oth and 11th Annual Reports, Alaska Game Commission. $195^{\circ}$.

6. Lands and Development Services Branch, Ottawa. The Northwest Territories-Administration-Resources-Development. 1948.

7. Statistical Abstracts of the United States. 1947. 


\title{
MANAGEMENT OF THE MARINE RESOURCES OF ALASKA
}

\author{
SETON H. ThOMPSON \\ Chief, Branch of Alaska Fisheries \\ U. S. Fish and Wildlife Service
}

Alaska's sea fisheries currently are her most valuable asset. They are the basis for her most important industry, the greatest field of employment for her citizens, and the chief source of her tax revenue. The wealth of the Territory and the welfare of her citizens parallel exactly the success or failure of fishing. Times are good when fishing is good; gloom and depression prevail when fishing is poor.

The marine resources of Alaska which have been subjected to commercial utilization include some 25 species of fish and shellfish, as well as several marine mammals, including whales, fur seals, hair seals, sea lions, and walruses. The fur seals have been exploited intensively and continuously for 164 years; salmon have contributed substantially to the annual fishery harvest for more than 80 years, and halibut for about 60 years. Herring, clams, crabs, shrimp, cod, flounders, lingcod, sablefish, rockfishes, sharks, skates, and trout have had a more varied record.

Having withstood the drain of commercial utilization for so many years, it could very well be expected that the problems of management have been solved. Such is not the case, however. These are dynamic resources, ever changing, and the exploiting forces also are highly variable. They must be kept under constant surveillance so as to limit commercial utilization to surplus stocks. Protective measures must be adjusted to meet changing conditions both in the resources and in the industries dependent upon them.

Let us examine resource management as it has been applied to several of the marine fisheries of the Territory.

The salmon fishery probably is best known, and rightly so for it yields two-thirds of the world's entire production of 
canned salmon. Few of the world's fisheries exceed this one in productivity and value, and none has shown such remarkable growth. The exploitation of this resource began in 1878,11 years after the purchase of the Territory from Russia, when the first salmon cannery was built at Klawock. There had been some salting of salmon by both Russians and Americans before that time, and, of course, salmon was a major item in the diet of the Indians. Not until the spectacular development of the canning industry, however, were any real inroads made on this resource. Salmon canning operations were inconsequential until about 1885 , but after that there was a steady increase until 1918, when 135 plants packed about 6,6oo,ooo cases, representing more than 100 million salmon. During this period of rapid growth, operations were extended throughout even the remote areas of the Territory, and all five species of salmon were sought whereas initially only the more valuable red salmon were taken. The production of 1918 has been exceeded only six times, although there have been many technological improvements both in fishing and canning methods. Nearly every year since 1918 has seen this resource fully utilized, and the average annual production of canned salmon has been $51 / 4$ million cases.

Fishing was virtually unrestricted in the early years of the industry and bitter competition over control of the fish supplies led to the use of stream barricades and other destructive methods. The inevitable result was depletion of the runs where these devices were used. This is not reflected in the total production figures because output was maintained by utilization of additional species and by expansion to new streams. Some of the damage done in this period has not been entirely repaired even now.

Although conservation measures were enacted as early as 1896 , they were generally disregarded and adequate legislative authority for the protection of the salmon fisheries did not become effective until 1924, some time after full exploitation had been realized. By this time a fund of biological information had been accumulated on which to base regulatory con- 
trols. The age at maturity had been determined with certainty, routes of migration through the coastal waters of the Territory had been charted, the time of arrival and duration of the various runs had been determined, and actuarial data had been amassed to indicate the size of runs to be expected from broods of varying size. It was known also that all species of Pacific salmon exhibit a strong tendency to return to the stream in which they were hatched, and invariably die after spawning once.

The salmon resource is very much like an agricultural crop in that we must plant if we are to have a harvest. If too few fish are allowed to escape the commercial fishery to properly seed the spawning grounds, the run of the succeeding cycle will be smaller than it should be. If more fish escape than are required for seeding the spawning grounds, there is an immediate economic waste. All statutory and regulatory controls are directed toward reserving salmon in sufficient numbers so that over the years there will be the greatest return.

Long range forecasts of abundance are made upon the basis of the best information available concerning extent of spawning in the parent year and survival of young. The industry is notified and regulations are adjusted so that the optimum escapement may be achieved. While the runs are on and fishing is in progress, daily records are kept of the catch per unit of effort within the several independent producing areas, and further regulatory adjustments are made to correct for deviations from the predicted runs or to correct for deviations from the anticipated intensity of fishing. When the runs of salmon are larger than expected or when the drain of the commercial fishery is less, it is possible to permit additional fishing time so that all surplus salmon may be taken. The converse also is true; when the runs are smaller than anticipated or when the number of units of gear is greater, fishing is curtailed. Regulatory changes are made in the field simultaneously with the determination of their need.

Total salmon production has been below normal in Alaska for the last six years because of reduced abundance in one or 
more areas, primarily from natural causes. A disproportionately large part of these runs was reserved for spawning purposes to provide for runs of normal volume in the next cycle. There is every reason to be optimistic that this watchful management will maintain this resource at its most productive level.

Not all of the effort in the management of this resource is directed toward regulating commercial salmon fishing. An aggressive program of stream improvement is being carried on by the Fish and Wildlife Service throughout the Territory. A determined effort is being made to provide a maximum amount of readily available spawning area by removal of beaver dams, log jams, and other obstructions to the upstream migration of adult salmon and the downstream migration of young salmon. In 1949 construction was started on three fish ladders over natural barriers, and more than 1 oo $\log$ jams and beaver dams were removed where they blocked the ascent of salmon. Of these barriers, $4^{0}$ were impassable for salmon at all times, and many of the others were complete barricades at certain stages of water.

The development of Alaska in itself presents some problems in the management of the salmon fisheries, if we are to judge by the experience of the Pacific Coast states. Indiscriminate logging operations, with attendant rapid run-off of surface waters, could cause scouring and silting of spawning streams. Unrestricted disposal of pulp-mill and other industrial wastes could do irreparable damage to salmon as well as other fishery resources. Development of hydroelectric power by construction of dams, as already proposed, could wipe out entirely the salmon runs to certain rivers. We are aware of these potential dangers of the future and studies are in progress now to develop the facts needed for management guides.

The razor clam fishery of Central Alaska is anotlier example of marine resource management. This resource supports an industry which is insignificant when compared with salmon, but nevertheless is extremely important locally because it offers an opportunity to the small businessman in one of the ferv virtually nonseasonal occupations. The most important razor 
clam beds in the Territory are those near Cordova. Here, razor clam canning started in 1916, and exploitation of the beds followed the usual pattern. Excessively large packs were produced, first drawing heavily on the older, larger clams, then when the supply was exhausted, an effort was made to maintain production by drawing on immature stocks. The results were disastrous and in 8 years production dropped to 10 percent of its former peak. Research entered the picture at this point, and precise information was obtained concerning the age and size at maturity, rate of growth, and age composition of the clam population. A minimum size-limit was made effective immediately to protect immature clams until they had an opportunity to spawn at least once, thus assuring a limited breeding reserve. Next, an arbitrary limit was placed on the quantity of clams that could be taken, and studies were commenced to show what effect these control measures had on the resource. The age composition of the catch, and the catch per unit of effort were the guides to its condition. The proportion of older clams in the population increased and the average catch per unit of effort increased. Gradually and cautiously the catch limitation or quota was raised. In time this quota exceeded the surplus stock of the resource, and very soon there was a decline in the relative abundance of the older year classes and a falling off of the catch per unit of effort. The quota was lowered when these danger signals appeared, then when they disappeared it was raised again slowly. For about 10 years now the quota or catch limitation has been constant. It appears that the present quotas assure a sustained yield, but the fishery is under constant surveillance for those warning signals that would indicate either need for greater protection or availability of unutilized surplus stocks.

The Pribilof fur-seal herd is often cited as an outstanding example of resource conservation. Let us examine its management.

It was in 1786, 45 years after the discovery of Alaska, that the Pribilofs were discovered and named for the explorer who found them. Ruthless exploitation of the fur-seal herd com- 
menced immediately, and some two million seals were killed for their fur in the next 40 years. A crisis was reached in 1835 , and Russia imposed severe restrictive measures including protection of all females. The herd responded to this protection, and at the time of the Alaska purchase in 1867 it was reported to bave been restored fully.

Exploitation under American ownership was almost as devastating as under the early Russian operations, not because of indiscriminate land killing but because of the highly wasteful and objectionable practice of killing seals at sea irrespective of season, sex, or condition. Pelagic sealing, as this was called, drew heavily on the females which were not killed on land. The sealing fleet followed the seals on their ocean migration from the California coast northward to Bering Sea, taking its toll throughout that 3,000 mile range. Decimation of the herd was inevitable, and by 1910 only 130,000 animals remained. Extermination of this resource was not far away when by international convention signed in 1911, the United States, Great Britain, Japan, and Russia agreed to prevent pelagic sealing in the North Pacific Ocean by their own nationals. This treaty remained in effect until $194^{1}$ and protected the fur seals of Japan's Robben Island and Russia's Commander Islands, as well as those of the Pribilofs. At present a treaty between the United States and Canada protects the Pribilof herd from pelagic sealing.

No mammal in the wild state lends itself more conveniently to rational exploitation than the fur seal. It is a highly polygamous animal with harems numbering $4^{0}$ to 60 cows, yet the sexes are born in equal numbers. There is, therefore, a large surplus of males which can be removed without disturbing the breeding potential of the herd. Conveniently, the immature males not only haul out at the Pribilofs, but they haul out apart from the breeding animals. Killing is restricted to males of only one age-3-year-olds. The fur is prime on these animals and the skins are unscarred by the fighting that occurs among the older animals. The Pribilof fur-seal herd has been cropped in this way, and in recent years the take has fluctuated between 
60,000 and 70,000 animals. The skins are dressed, dyed, and sold at public auction under contract. The net profit to the Government, over and above all expenditures for management of the resource and for administration of the Pribilof Islands, has been $\$ 11,500,000$ since 1910 .

The primary objectives of the Fur-Seal Treaty of 1911 have been splendiclly fulfilled. There has been an enormous increase in the herd in the past 40 years, as even casual observation will testify. There is evidence now that the herd has reached maximum size; the number of animals available for killing has been fairly constant for the past 10 years. Is the herd to be managed now in the same manner as when it was growing or are new methods indicated? To answer these and other related questions, biologists are making an accurate appraisal of the number of animals in the herd, assembling current mortality data, and evaluating the herd's reproductive capacity. We must know at what size it will yield the greatest number of sealskins for commerce, and from what sex and age group these skins should come. This information must be supplied by intensive research to guide future management of the herd.

Through international agreement and sound management policies, this resource has been restored and is in a highly productive state today. Continued international cooperation and scientific management will perpetuate it.

The North Pacific halibut fishery is another example of a marine resource saved by international cooperation. Strictly speaking this is not an Alaskan resource, for the halibut banks are beyond Territorial limits. Nevertheless, the most productive banks are adjacent to Alaska, and contribute in a very material way to the wealth of the Territory. More than half the catch is landed in Alaskan ports and halibut ranks third in importance among Alaska fishery products, being subordinate only to salmon and herring.

The history of the halibut fishery is similar to that of our other modern marine fisheries. Beginning in 1888 , it was concentrated in a relatively small area near the entrance to Puget Sound. As markets expanded and the demand for halibut grew, 
production was increased first by adding more vessels to the fleet, then, when the nearby banks were exhausted, by extending operations to more and more distant banks. By 19 10 this growing and more efficient fleet was operating in the Gulf of Alaska, and a few years later covered the entire range of halibut from Bering Sea to California. The annual catch was maintained during this period of expansion, effectively hiding the successive depletion of bank after bank, but production declined sharply when it was no longer possible to increase the exploited area.

It was evident that the supply of halibut was not inexhaustible, and the need for conservation became more and more apparent. Since this fishery from the very beginning was prosecuted by the nationals of both Canada and the United States, there was increasing insistence on the part of the halibut industry for joint action by the two Governments. It was not until 1923, however, that a treaty for this purpose was signed. An International Commission was established and empowered to investigate and recommend measures for the preservation of the resource. These investigations revealed that the fishery was in a very unsound condition; that landings were being made only by constant increases in fishing intensity. It was shown that where once 3 oo pounds of halibut were taken on a standard unit of gear, the yield on the southern banks had fallen by 1930 to 35 pounds, and on the western banks to 65 pounds. Information was obtained concerning the age at maturity, the migrating habits, and the independence of the various stocks of halibut. Recommendations based on these and other findings led to a revision of the treaty in 1930 to authorize the Commission to regulate the fishery. Regulations issued annually since 1930, have divided the convention waters into areas, limited the catch of halibut to be taken from each, fixed the type of gear to be used, closed grounds found to be populated by small immature fish, and required submission of statistics necessary for administering catch limits and for determining the condition of the fishery.

These regulations, guided by investigations, stopped the 
decline of the fishery and commenced its restoration. The abundance of halibut has increased about $15^{\circ}$ percent under the management of the Commission, and the average annual yield of $5^{6}$ million pounds in recent years is 13 million pounds greater than it was in the unrestricted fishery of 1931. Furthermore, these larger catches are being made with 35 percent less fishing effort.

The Commission's objective is to rebuild the halibut stocks to a level of maximum yield and stabilize them there. Excellent progress has been made toward achieving this objective, and full attainment is in sight.

The resources of the sea are not inexhaustible and the inevitable result of unrestrained exploitation is depletion. The hope of the future, therefore, lies in scientific management which will limit the annual take to such quantities and maintain the resources at such levels that maximum production for all time will be assured.

\section{REFERENCES}

1. Gregory, H. E. and K. Barnes. North Pacific fisheries. American Council, Institute of Pacific Relations. New York. 1939.

2. International Fisheries Commission. Investigations of the International Fisheries Commission to December 1930, and their bearing on regulation of the Pacific halibut fishery. Seattle. 1930.

3. $\longrightarrow$ Report of the International Fisheries Commission No. 1. Seattle. 1931.

4. - Regulation and investigation of the Pacific halibut fishery in 1947. Rept. International Fisheries Comm. No. 13. Seattle. $194^{8}$.

5. - Regulation and investigation of the Pacific halibut fishery in 1948. Rept. International Fisheries Comm. No. 14. Seattle. 1949 .

6. National Resources Committee. Alaska-Its resources and development. House of Representatives Doc. No. $4^{8} 5$ ( $75^{\text {th }}$ Cong. 3rd Session) Washington. 1938.

7. Osgood, W. H., E. A. Preble, and G. H. Parker. The fur seals and other life of the Pribilof Islands, Alaska, in 1914. Bull. Bureau of Fisheries XXXIV. Washington. 1915 . 
8. Rich, W. H. and E. M. BALl. Statistical review of the Alaska salmon fisheries. Part I: Bristol Bay and the Alaska Peninsula. Bull. Bureau of Fisheries, XLIV. Washington. 1918.

9. - Statistical review of the Alaska salmon fisheries. Part II: Chignik to Resurrection Bay. Bull. Bureau of Fisheries, XLIV. Washington. 1931.

10. Statistical review of the Alaska salmon fisheries. Part III: Prince William Sound, Copper River, and Bering River. Bull. Bureau of Fisheries, XLVII. Washington. 1932.

11. Statistical review of the Alaska salmon fisheries. Part IV: Southeastern Alaska. Bull. Bureau of Fisheries, XLVII. Washington. 1933 .

12. Thompson, Seton H. Condition of razor clam fishery in the vicinity of Cordova, Alaska. Investigational Rept. No. 29, Bureau of Fisheries. Washington. 1935.

13. Thompson, W. F. Conservation of the Pacific halibut, an international experiment. Smithsonian Rept. for 1935. Washington. 1936 .

14. Thompson, W. F. and N. L. Freeman. History of the Pacific halibut fishery. Rept. International Fisheries Comm. No. 5. Seattle. 1930.

15. U. S. Fish and Wildlife Service. Annual statistical digest entitled Alaska fishery and fur-seal industries. Washington.

16. Van Hise, C. R. and L. Havemeyer. Conservation of our natural resources. New York. 1931. 


\section{ALASKAN WATERFOWL AND THEIR MANAGEMENT}

Ira N. Gabrielson, President

Wildlife Management Institute

Alaska's waterfowl have excited interest since the first American naturalists visited the territory. Interestingly enough, the earliest ornithological reports were from areas now known to be key waterfowl breeding grounds. These came from a corps of scientists, including W. H. Dall and H. M. Bannister, under the leadership of Robert Kennicott, that accompanied the Russian-American Telegraph Expedition. This venture was financed by a group of San Francisco capitalists who dreamed of constructing a telegraph line to St. Petersburg.

The advance parties entered Alaska in 1865 prior to its acquisition by the United States, and visited among other places St. Michael, the lower Yukon, and the Yukon Flats at Fort Yukon. Their reports provide a story of an abundance of breeding birds that excited the imagination of men accustomed to seeing concentrations of wildlife.

L. M. Turner, a member of the U. S. Signal Corps, the next to visit the great marshes of the Yukon Delta, was stationed at St. Michael from May 1874 until relieved by E. W. Nelson in July 1877. Nelson, who later became chief of the Biological Survey, remained at that station until June $\mathbf{1} 88_{1}$, providing continuous reports for seven years from this important waterfowl area.

Nelson, in addition to local observations, made sled trips each winter and one extensive spring trip by boat. In this way he visited Nelson Island, the lower Kuskokwim, the lower Yukon, Golovin Bay, and Sledge Island on the north side of Norton Sound, and the Yukon as far upstream as the mouth of the Innoko River.

Dall returned to Alaska as a member of the U. S. Coastal 
Survey, working from the Shumagins to Attu. Turner also returned to the Territory and worked at various points from the mouth of the Nushagak to Attu. The reports of these men furnished much information regarding wildlife on these islands and are still of value in analyzing present conditions.

These observers worked some of the key areas that are now known to concern the future of Alaska's waterfowl. These men were impressed with the enormous numbers of breeding waterfowl, especially geese, and subsequent visitors have been equally impressed. However, it is only recently that definite information has commenced to be available. I spent some time at St. Michael and in the Yukon Delta comparing present conditions with those found by Nelson. I had his report with me, and enjoyed the novelty of comparing my daily observations with his narratives referring to the same ponds, streams and willow patches.

When Alaska is viewed from the air, as most travelers see it, the vast number of lakes makes a definite impression. While lakes are sprinkled liberally through much of the Territory, certain areas in the interior and in coastal units on the Bering Sea and the Arctic slope show unusually heavy concentrations of water areas. From the air the landscape at these points appears to be composed almost entirely of water, with only enough land interspersed to give it form and hold it together. These areas of wet and marshy tundra are favored breeding grounds for geese which tend to colonize as well as for other waterfowl which do not.

In addition, there are interior areas which are of importance to other waterfowl. The Yukon Flats have been known ornithologically since Kennicott's first visit in 1865 . Many of the specimens collected by him in this then unknown country are still in the National Museum to substantiate his reports. The Innoko Flats, another intricate complex of marshes and pools, lying at the junction of the Innoko and Iditarod Rivers, is also an important breeding area. Tetlin Lakes which have not been surveyed extensively were reported by early visitors to be the home of numerous waterfowl. The Minto Lakes, between Fair- 
banks and Nenana, are smaller, but have a considerable population of breeding waterfowl.

On the Arctic Slope there are heavy concentrations of waterforl in favorable areas, the most important being, on the basis of present information, one lying on the south and east sides of Kotzebue Sound, and another between Point Barrow and the great delta formed by the Colville River. Other important areas include the Cold Bay district on the Alaska Peninsula, a breeding ground for a substantial number of both ducks and geese, the Copper River Flats near Cordova, and the Stikine River Flats at the mouth of that stream near Wrangell. The last three probably have their greatest value as feeding and resting areas for migrating flocks of waterfowl.

Much of Alaska, while having considerable water area, is thinly populated with waterforvl. It is more heavily populated and probably more productive than similar territory in the Canadian shield (in interior Canada and Labrador) where the underlying rocks furnish relatively little fertility. Many of these more eastern waters are relatively sterile, produce little or no plant or animal life, and waterfowl breeding populations are correspondingly limited. While there are some Alaskan waters which belong in this same class, the majority lie in the tundra and in the great river valleys where better soils and more favorable growing conditions prevail.

Not all tundra ponds are suitable for waterfowl, or at least used by waterforvl. This condition may be due to insufficient breeding populations to occupy all breeding territory, or it may be due to some less favorable condition that exists in these waters. It is, however, difficult to travel anywhere in Alaska during June or July without finding breeding waterfowl wherever water is available. This is true even in the Copper River drainage where lakes are relatively less numerous than in other areas.

On my first visit to the Yukon-Kuskokwim area, Bristol Bay, and the upper part of the Yukon Valley in 1940, I formed the opinion that the importance of Alaskan waterfowl has been underestimated in the prevailing preoccupation with the critical 
conditions that existed in the breeding grounds of the north central states and in the Canadian Prairie Provinces. Only since the end of the war has a sustained effort to secure detailed data of Alaska's breeding waterfowl populations been possible. The work is still too new to provide as complete and accurate information as is available from many other parts of the continent. I may say, however, that each subsequent visit has strengthened my belief in the importance of Alaska to continental waterfowl flights.

Without attempting to catalogue all species of waterforw that breed in Alaska, it is possible to indicate those of major importance. Alaska has breeding populations of the Whistling Swan, Emperor Goose, White-cheeked Goose, Lesser Canada Goose, Cackling Goose, White-fronted Goose, and Black Brant. It also provides suitable nesting habitat for impressive numbers of Pintails, Mallards, Green-rvinged Teals, Baldpates, and Shovelers, among shallow water ducks. It contains one of two principal breeding grounds of the Greater Scaup, and supplies considerable numbers of Barrow's and American Golden-eye and Canvasbacks, among those diving ducks regarded chiefly as game birds. The chief North American breeding grounds of the Spectacled Eider, the Pacific Eider, and Steller's Eider are found within its boundaries. Only in the case of the King Eider, among Alaska's eiders, is more extensive habitat found outside its territorial limits. While these birds are utilized little as game, they are an important part of the native economy in areas in which they are found.

Aside from these birds, there are two other abundant tundra nesting waterfowl-the Old Squaw and the American Scoter, both utilized in furnishing native food and clothing. Alaska produces great numbers of these birds, and there are also extensive breeding grounds in Canada.

The most important single breeding area is the Yukon-Kuskokwim Delta, a great fan-shaped marsh which lies between the mouth of the Kuskokwim around the coast almost to St. Michael and which follows both streams up to the point when they most closely approach each other. This vast area of marshy lowland 
and lakes provides the world's chief breeding ground for Emperor and Cackling Geese.

The Cackling Geese breed entirely in Alaska, being found from the Kuskokwim River to Kotzebue Sound, with much the greater percentage of the birds nesting in this delta. This statement is equally true of the Emperor Geese. They breed from Bristol Bay north to Kotzebue Sound and in small numbers even to Wainwright. Yet, the mass of the known American population breeds in a narrow strip along Bering Sea between Nelson Island and St. Michael. This species winters mainly along the base of the Alaska Peninsula and in the Aleutian Islands while the Cackling Geese furnish an important contribution to the annual waterfowl supply for Oregon, Washington, and California.

White-fronted Geese are also found here in numbers, but they also breed in numbers from Point Barrow to the Colville Delta and in such areas as the Innoko Flats. Whistling Swans breed from the north side of the Alaska Peninsula along the Bering Sea and Arctic Coasts to the Canadian line, although in small numbers, as far as present records indicate, from the Colville River eastward. Again, the greatest Alaskan breeding population is found in the Yukon-Kuskokwim Delta.

The White-cheeked Goose, a huge, dark "honker," nests from Prince William Sound south into British Columbia, with the major part of the population nesting on small lakes and inlets in scattered pairs, and wintering in the salt marshes of southeastern Alaska.

There are thriving colonies of Black Brant from Nelson Island north, and others from Point Barrow east with perhaps the most concentrated Alaskan breeding populations in the Yukon and Colville Deltas. Back from the coast, the Yukon delta furnishes suitable breeding grounds for vast numbers of Pintails and Greater Scaup, and lesser numbers of Shovelers, Baldpates, Green-winged Teals, and Mallards. It is not only the most important breeding area in Alaska, but one of the great waterfowl production units of the continent. The treatment accorded it will decide the fate of Cackling Geese and 
Emperor Geese, and have a major influence upon Whistling Swans, Black Brant, and Greater Scaup populations. It will affect in lesser degree the Green-winged Teals, Pintails, and Baldpates which have much more extensive continental breeding ranges than the other species mentioned.

The Kotzebue Sound waterfowl unit produces largely Pintails, but Lesser Canada Geese, Black Brant, and Greater Scaup are present in important numbers. The Arctic slope from Barrow to the Colville produces more White-fronted Geese and Pintails than other game species, although limited numbers of other birds are also present. It is also of importance to the coastal Eskimo villages as a producer of eiders, old squaws, and scoters which furnish an important part of the vast northbound migration on which many natives rely for food in May and June.

The Innoko Flats are especially important to Pintails, Greater Scaup, and Lesser Canada Geese, with Baldpate, Mallard, White-fronted Geese, and Green-winged Teal also present in worth while numbers.

Little recent work has been done on the Yukon Flats, although the earlier naturalists found practically every species of fresh water duck now found in the Territory breeding there in numbers. In addition such species as Canvasbacks, American Golden-eye, Greater Scaup, and Bufflehead were more numerous than elsewhere. Certainly an area that was as productive as this appeared to be in former years merits attention at a time when wildlife interests are forced to embrace every opportunty to preserve waterfowl breeding, feeding, and wintering grounds.

Present information regarding Tetlin Lakes is even more intangible. I have been in the edge of this area and found most of the common fresh water ducks, and in addition Barrow's Golden-eye, scaups, and Canvasback in some number. I have flown over it and noticed rather heavy concentrations of waterfowl without being able to identify the species. This complex of lakes, lying close to the Canadian boundary on the south side of the Tanana River, needs more study to determine its relative importance. 
Another area which contains a considerable concentration of nesting waterfowl is Minto Lakes between Fairbanks and Nenana. It is smaller than the units previously discussed, but has quite a number of waterfowl, principally scaup and Pintails. It has been chosen as a study area by the Cooperative Wildlife Research Unit at the University of Alaska and more detailed information should become available as this study progresses.

The Copper River Flats is likewise smaller, although large when compared with many waterfowl units in the states. A variety of waterfowl remain through the summer, but no studies have been made of nesting populations. Canada Geese, Mallards, Shovelers, Pintails, Green-winged Teals, Gadwall, and Baldpates are in the area during breeding season, and I have found goose and mallard nests or broods. From their behavior it is almost certain that some of other species also nest in greater or less numbers.

A larger area that has some value as a nesting ground, but which has its greatest value as a fall concentration and feeding area for northern birds, is located at Cold Bay on the outer end of the Alaska Peninsula. Here, Cackling, Snow, and Emperor Geese, and many varieties of ducks gather to rest and feed before undertaking the long migration to the marshes and grain fields of the Pacific states or the shallow bays of the Aleutians that provide winter food for the Emperor Geese and to a less extent for other species. It is an essential key to the future of Alaska's waterfowl resources.

The Stikine Flats, at the mouth of that river near Wrangell is another unit that is probably essential as a feeding and resting area for migratory birds. It is the major concentration area in southeastern Alaska, and is used by Canada Geese, Snow Geese, White-fronted Geese, and a variety of ducks, principally Mallards, Pintails, Green-winged Teals, Baldpates, and Greater Scaup.

Mallards, Pintails, Green-winged Teals, Baldpates, Shovelers, and Greater Scaup are widely scattered outside the major nesting areas, breeding over a wide range wherever suitable 
food and water conditions prevail. The production of these scattered populations added to that of the major units makes Alaska's waterfowl production of increasing importance. It is impossible to evaluate it on a numerical basis, but it is certain that the loss of this contribution would have a definitely adverse effect on the waterfowl resources.

The returns from banding projects also demonstrate its importance to waterfowl production. Lincoln, writing in 1926 of the returns secured from about $25^{\circ}$ Cackling Geese banded in late July of 1924 in the vicinity of Hooper Bay, reported that of the 39 birds recovered, 35 were taken on the coastal areas of Oregon and Washington, at Tule Lake, lying on the Oregon-California boundary, and in the Sacramento Valley. Only one, a bird taken on Moresby Island, was recovered in British Columbia. One bird was killed on Nelson Island the following June not far from the point of banding, and 2 birds killed by a Snowy Owl were recovered in the owl nest soon after banding. These returns indicated a wintering concentration in California and a definite migration route to and from that area.

During the last two seasons, extensive banding has been undertaken in several localities by the use of Pittman-Robertson funds. This followed more limited work in 1948. Six hundred ninety two waterfowl were banded in 1948, 2629 in 1949, and 3573 in 1950. Naturally, returns from the birds banded in the summer of $195^{\circ}$ are not yet available, and past experience indicates that additional bands will be returned from 1949 banded birds. During the 1949 operation, 2634 birds were banded, all but 5 of which were either ducks or geese. Six hundred ninety eight Cackling Geese were banded, and 4 of these were recovered that fall relatively near the banding stations in the Yukon Delta, 1 was returned from Washington, 16 from Oregon, and 17 from California. Three hundred eighty two Black Brant were banded in the Yukon Delta of which 2 were taken near the banding area, 1 in British Columbia, 1 in Washington, and 8 in California. Of the $13^{8}$ White-fronted Geese banded that season, 12 that were banded on the Innoko 
and 1 banded in the Yukon-Kuskokwim Delta were taken by hunters and reported to the Fish and Wildlife Service. The 1 bird from the Yukon Delta was captured in Lake County, Oregon, and of the 12 returns from Innoko birds, I was taken in Mexico, $5^{\circ}$ miles south of Calexico, 1 in California, 1 at Lake Thelma, Alberta, and 9 at various points in Saskatchewan, indicating that White-fronted Geese raised in this area tend to enter the Mississippi or Central Flyway rather than the Pacific.

Fifty recoveries were reported from the 1,032 Pintails banded, of which 30 were taken in California, 3 in Oregon, 3 in Washington, 2 in British Columbia, 2 in Alberta, 1 in Saskatchewan, 2 in Mexico. These birds were produced on the Innoko, Kotzebue Sound, and Arctic slope.

Lesser Canada Geese banded both in 1948 and 1949 in the Innoko-Iditarod area were recovered in Oregon, Washington, and California, British Columbia, and in Alaska. Scattered returns from other species, still too few to be of much significance, indicate that the Pacific Flyway receives most of the puddle ducks and all of the Cackling Geese from these districts. While the returns are too limited to permit definite conclusions, the White-fronted Goose is the only species which has yet shown up in numbers outside the Pacific Flyway. When sufficient birds have been banded, others such as Greater Scaup and Canvasback may be found moving more to the eastern flyways.

This summary of unpublished returns indicate that birds bred in Alaska are important not only to the people in the Territory, but to the entire Pacific Coast. We have in the past witnessed the useless destruction in both the United States and Canada of the marshes on which these birds depend. In some cases important units have been reflooded at public expense. Perhaps it is hoping against hope that this historic lesson will be sufficiently heeded to permit the development and execution of a program designed to prevent a similar sequence of events in Alaska.

The balance between life and death for wildlife in the Arctic is precarious at best. In some areas, the balance which permits these birds to successfully reproduce themselves has already 
been disturbed and destroyed. An outstanding example has occurred in the Aleutians, where all early naturalists indicated that Agattu and Amchitka were important goose and duck breeding grounds. Present evidence points to the introduction of foxes on these islands and the increasing native use of firearms as the factors responsible for this decimation of breeding populations. Recent survey parties have found few or no breeding waterfowl-nothing comparable to the numbers found by Dall and Turner in earlier days or even by Clark in 1906.

Waterfowl populations have decreased within feasible traveling distance of St. Michael, although the village has few if any more inhabitants than in Nelson's day. The increasing use of firearms has reduced breeding waterfowl populations in the territory over which the local inhabitants can conveniently travel.

There are other references to similar conditions, although none have such a broad background of previous information as is available from St. Michael. The introduction of better arms often results in the reduction of the breeding bird populations upon which natives depend. This may or may not be entirely the work of the natives. They unquestionably are at times ably assisted by such white men as live in areas where the birds are exceedingly vulnerable. It is important that definite steps be taken to preserve an important source of native food supply and a substantial part of the continental waterfowl resource.

To accomplish these objectives, some definite recommendations can be formulated. They can be summarized as follows:

1. Set aside immediately as wildlife areas the three now known to be key units in any waterfowl management program. These are the Yukon-Kuskokwim Delta, the Innoko Flats, and Cold Bay. Sufficient surveys have been made to draw boundary lines and draft withdrawal orders, and the Secretary of Interior has the authority to make them effective.

It should be made clear that it is not proposed to create refuges similar to those now operated in continental United 
States under totally different conditions. These breeding grounds should be set aside to protect native food resources and should be administered to permit natives to take waterfowl for their own use. Neither is it necessary to close them to hunting in open hunting seasons prescribed by the annual waterfowl regulations. The one necessity is to withdraw them from entry and prevent the development of hunting lodges and camps, with the concentrated hunting pressures they bring. This is urgent. Areas in Canada that a few years ago were considered safely remote already have been subjected to such development with disastrous results to breeding waterfowl. It is easily possible to destroy such a local population and thereby decrease production of that area for years to come. The penalty of such an error in management will be paid first by the natives in impaired food resources, and secondly by the average waterfowl hunter in the Canadian provinces and in the States through which the birds migrate and in which they winter. Any temporary benefits will accrue to a few resort operators and to a limited number of citizens who are able to gratify their desire to shoot without considering cost.

2. Secure funds and assign personnel to survey such areas as the Selewick Flats and other marsh units on Kotzebue Sound, the Point Barrow-Colville River tundra breeding ground, the Yukon Flats, Tetlin Lakes, Minto Lakes, and perhaps other units of which less is known to determine:

a. The importance of each to the continental waterfowl resource.

b. To outline boundaries (for such as are found to be of major importance) of the areas that should be protected by action similar to that outlined for other key areas.

3. Make similar surveys to determine the importance of the Copper River Flats and Stikine Flats. If they prove to be as vital as present information indicates, to develop a program for protecting and preserving these areas of habitat, and for preserving them for public use perhaps by withdrawal as waterfowl management areas for shooting grounds. 
There are other areas that may be of greater importance than some of these mentioned but little information regarding them is available. It is important to get quick action. The land is almost entirely in public ownership and should remain so. It will be less expensive to protect than it will be to restore, and further, this proposal does not contemplate interference with the present customary uses of such lands.

An important incidental value will accrue in the automatic protection of breeding grounds of some of the uncommon Alaskan shore birds. Such birds as the Pacific Godrvit and the Bristle-thighed Curlew have their chief summer lomes in these areas. Other more abundant species such as Red and Northern Phalaropes, Semipalmated Sandpiper, Western Sandpiper, Bairds Sandpiper, Pectoral Sandpiper, and Long-billed Dowitcher each have their Alaskan breeding centers in one or more of these areas.

4. Expand the present fine program of waterfowl inventories as fast as money and man power will permit to cover the major areas adequately. Only by such work will it be possible to accurately appraise the value of the resource both to Alaska and to the balance of the continent.

5. Expand the present excellent banding program to all major breeding areas. As information accumulates from similar work in other breeding territories, it becomes increasingly evident that birds develop individual or group patterns of migration, and of selecting wintering and breeding habitat that need to be known before intelligent management measures can be taken.

The Cackling Goose, for example, from present rather scant data, breeds in a narrow coastal strip along Bering Sea, winters in an equally restricted area in the Sacramento and San Joaquin Valleys in California, and seems to follow as a group a definite migration path. Much information is at hand indicating similar definitely marked breeding units for some other species, but with no corresponding information yet available as to the route followed on the wintering ground chosen. Extensive large scale banding is needed to furnish such information as a basis for better management. 
6. Build up the Cooperative Wildlife Research Unit recently established at the University of Alaska. This enterprise should help train Alaska boys for better work in territory with which they are familiar and furnish needed information as well. The early interest of the Unit in waterfowl problems is an indication of helpful results for this part of the wildlife resources. It should be encouraged and strengthened at every opportunity. There are almost innumerable waterfowl research and investigative needs that can be better handled in Alaska than elsewhere in American territory. Breeding ground studies of many species can only be developed here, and the Unit can help secure such data.

7. Expand law enforcement staff enough to enable it to protect the wildlife and fisheries resources upon which Alaska is especially dependent. There has been some improvement in recent years, but a comparison of the size of the task with that of any state or province and a like comparison of the men and resources available to handle it indicate that the staff is still inadequate. Waterfowl, as well as other resources, have suffered from this deficiency.

In conclusion, all available information indicates the necessity for outlining and carrying out as rapidly as possible an over-all waterfowl management program to maintain and manage the most important remaining waterfowl breeding grounds under American jurisdiction. It is improbable that with limited information a sufficient program can be completely visualized. A start has been recommended which as it is developed will provide information on which additional details or entirely new major projects can be based.

\section{REFERENCES}

1. Clark, A. H. The birds collected and observed during the cruise of the U. S. Fisheries Steamer Albatross in the North Pacific Ocean and in the Bering, Okhotsk, Japan, and Eastern Seas from April to December, 1906. Proceedings, U. S. National Museum, 38: 25-74. 1910.

2. Dall, W. H., and H. M. Bannister. List of the birds of Alaska with biographical notes. Transactions, Chicago Academy of Science, $I$ (2): 267-310. 1869 .

3. Lincoln, F. C. The migration of the Cackling Goose. Condor, 28: $153^{-157 . ~ J u l y-A u g u s t, ~} 1926$. 
4. Nelson, E. W. Report upon natural history collection made in Alaska between the years 1877 and 1881. No. 3, Arctic Series, Signal Corps, U. S. Army. 337 pp. 1887 (= 1888).

5. Turner, L. M. Contributions to the natural history of Alaska. U. S. Signal Corps. 216 pp. 1886. 



\section{THE ARGTIC INSTITUTE OF NORTH AMERICA}

The Arctic Institute of North America was formed to further the scientific study and exploration of the Arctic. The Institute provides information on the Arctic through its three Offices, awards research grants, and publishes scientific papers and other contributions in its journal Arctic. Those interested in this work are invited to become Associate Members. Associates receive all numbers of the journal. The Libiary and Map Collection at the Montreal Office are principally for their use, and they are welcome there and at the other Institute Offices.

\section{BOARD OF GOVERNORS}

T. H. ManNing, (Chairman), J. T. FLAK.ソE, Washington, D.C.

Ottawa, Ont

E. H. Simth, (Vice-Chaimman), Woods Hole, Mass.

M. J. Dunbar, (Secretary),

Montreal, Que.

WALTER A. WoOD, (Treasurer), New York, N.Y.

Hugh S. Bostock, Ottawa, Ont. John C. Case, New York, N.Y. C. H. D. Clarke, Toronto, Ont. HENRY B. COLlins, LAURENCE M. Gould,

Northfield, Minn. ERNEST GRUENing,

EJNAR MikKelsen, Juneau, Alaska Charlottenlund, Denmark A. E. Porsild, Ottawa, Ont. JoHN C. REED, Washington, D.C. FINN RonNe, Washington, D.C. GRAHAM W. Rowi.eY, Ottawa, Ont. Washington, D.C. Hugh A. Young, Ottawa, Ont. EXECUTIVE DIRECTOR

R. C. WAllace

\section{DIRECTORS OF OFFICES}

Montreal

P. D. BAIRD
Washington

L. O. Colbert
Newl York

WALTER A. WOOD

Editor of the Institute Journai Arctic

Diana Rotvley

OFFICES OF THE INSTITUTE

3485 University Street, Montreal, Que., Canada 1530 P Street N.W., Washington 5, D.C., U.S.A.

v Audubon Terrace, Broadway at 156 th Street,

New York 32, N.Y., U.S.A. 
